\title{
Weld strength of laser-assisted tape-placed thermoplastic composites
}

\section{Wouter Grouve}

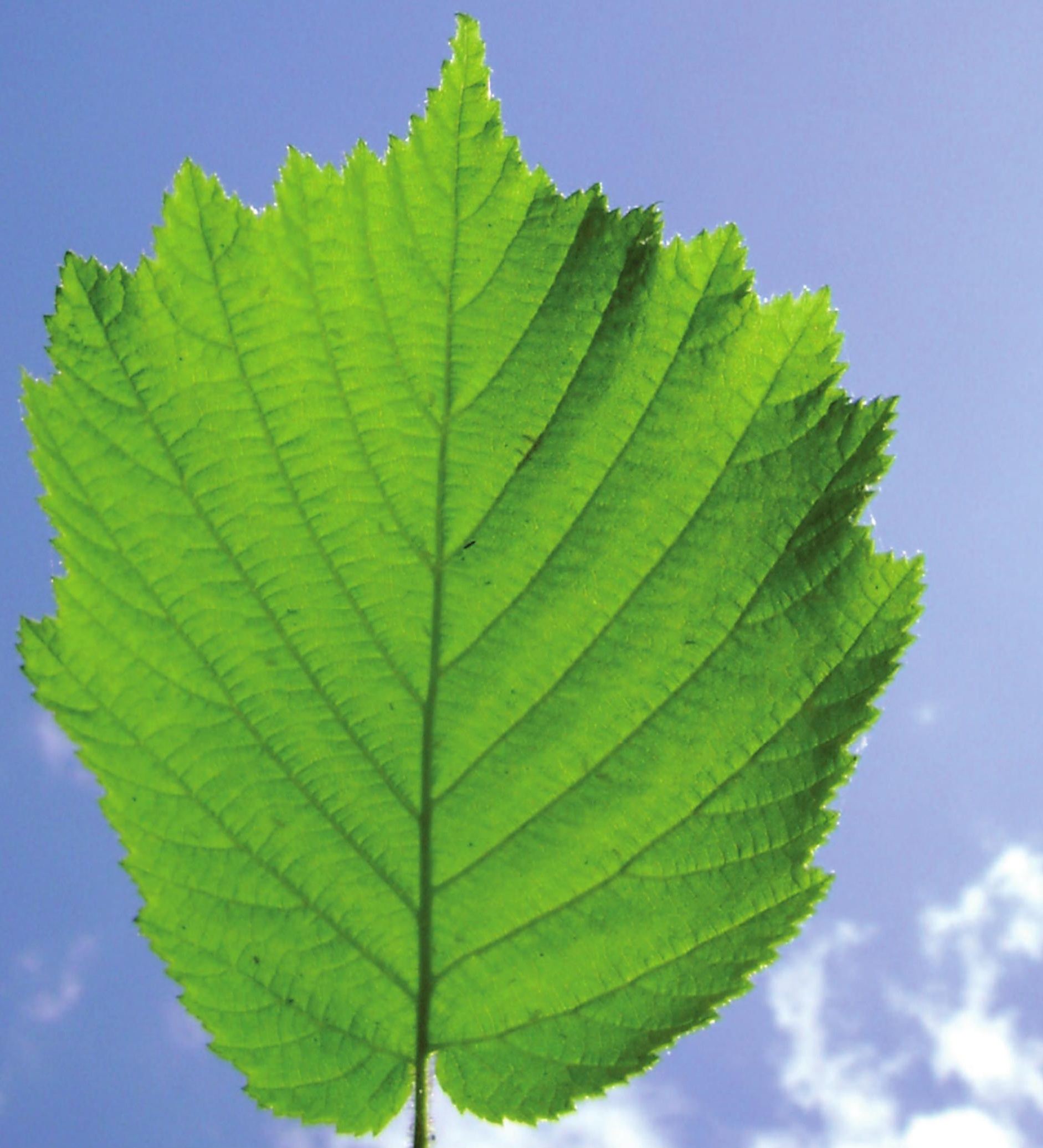




\section{WELD STRENGTH OF LASER-ASSISTED TAPE-PLACED THERMOPLASTIC COMPOSITES}

Wouter Grouve 
De promotiecommissie is als volgt samengesteld:

Voorzitter en secretaris:

prof.dr. F. Eising

Universiteit Twente

Promotor:

prof.dr.ir. R. Akkerman

Universiteit Twente

Leden (in alfabetische volgorde):

prof.dr.ir. A. de Boer

Universiteit Twente

prof.dr.ir. A.J. Huis in 't Veld

Universiteit Twente

prof. A. Poitou

Ecole Centrale de Nantes

dr.ir. L.L. Warnet

Universiteit Twente

prof.dr.ir. S. van der Zwaag

Technische Universiteit Delft

This research project was financially supported by the Eco-Design ITD within the Cleansky framework.

Weld strength of laser-assisted tape-placed thermoplastic composites

Grouve, Wouter Johannes Bernardus

PhD Thesis, University of Twente, Enschede, the Netherlands

August 2012

ISBN 978-90-365-3392-8

DOI 10.3990/1.9789036533928

(C) 2012 by W.J.B. Grouve, Enschede, the Netherlands

Printed by Ipskamp Drukkers B.V., Enschede, the Netherlands

Cover: photograph of a leaf taken in Van Heek Park, Enschede. The veins in the leaf do not only serve to transport water and nutrients, but also support the leaf to give it its structure. 


\title{
WELD STRENGTH OF LASER-ASSISTED TAPE-PLACED THERMOPLASTIC COMPOSITES
}

\section{PROEFSCHRIFT}

\author{
ter verkrijging van \\ de graad van doctor aan de Universiteit Twente, \\ op gezag van de rector magnificus, \\ prof.dr. H. Brinksma, \\ volgens besluit van het College voor Promoties \\ in het openbaar te verdedigen \\ op vrijdag 31 augustus 2012 om 14:45 uur
}

door

Wouter Johannes Bernardus Grouve

geboren op 30 mei 1982

te Hellendoorn 
Dit proefschrift is goedgekeurd door de promotor:

prof.dr.ir. R. Akkerman 


\section{Summary}

Laser-assisted tape placement is an attractive manufacturing technology for the aerospace industry as it combines high productivity with low energy consumption. It comprises the automated deposition of fiber reinforced thermoplastic tapes to incrementally build up a structure. The process can also be used to tailor the properties of conventionally manufactured woven fabric reinforced components by locally reinforcing these with unidirectionally reinforced tapes. This thesis focuses on the weld strength between the tape and the woven fabric reinforced component. The principal objective is to develop an in situ processing strategy, combining high productivity and energy efficiency with high weld strength. For this purpose, the important bonding mechanisms, processing parameters and material properties are identified through a combination of experimental work and physical modeling.

The interlaminar bonding process comprises the development of intimate contact followed by the interdiffusion of polymer chains. Both mechanisms depend strongly on the interface temperature. A thermal process model is, therefore, proposed specifically taking into account the optical aspects of laser heating. The model is validated experimentally. Based on the developed model, the important processing paramaters and material properties are identified.

A mandrel peel test is introduced to quantify the interfacial fracture toughness between the tape and the laminate. The applicability and validity of the method is successfully demonstrated by comparing it to standardized fracture mechanics tests. The interfacial fracture toughness does not only depend on the degree of interlaminar bonding. The crystallinity and structural morphology of the interface also play an important role. This is demonstrated by a comparison between the (fast) tape placement process and a (slow) press-molding process. The tape-placed specimens outperform the press-molded specimens in terms of fracture toughness by almost a factor of two. This is attributed to the high cooling rates and short bonding time during the tape placement process. The former results in a low crystallinity, while the latter prevents the migration of tape fibers into the resin pockets of the laminate and thereby minimizes the fiber-fiber contact. Both the low crystallinity and the presence of resin pockets improve the interfacial fracture toughness.

Finally, a processing strategy is proposed, which maximizes productivity and energy efficiency. The strategy involves the distribution of all laser power to the tape. Although the proposed strategy should be tested in practice, the work in this thesis suggests that an excellent weld strength will be achieved. 



\section{Samenvatting}

Het laser-verwarmd tape-placementproces is een aantrekkelijke productiemethode voor de luchtvaartindustrie, omdat het een hoge productiviteit combineert met een laag energieverbruik. Het proces betreft het geautomatiseerd lassen van vezelversterkte thermoplastische tapes op geconsolideerde laminaten of producten. Tevens kan het worden gebruikt om de eigenschappen van geperste weefselversterkte thermoplastische producten te verbeteren door deze plaatselijk te verstijven met de vezelversterkte tapes. Dit proefschrift richt zich op de lassterkte tussen de tape en het weefselversterkte product. Het doel is een processtrategie te ontwikkelen die productiviteit en energetisch rendement maximaliseert en tegelijkertijd een hoge lassterkte oplevert. Daartoe zijn de belangrijkste lasmechanismen vastgesteld en zijn de relevante procesparameters en materiaaleigenschappen onderzocht.

Een peltest is ontwikkeld om de scheurtaaiheid van het grensvlak tussen de tape en het laminaat te kwantificeren. De testmethode is vergeleken met standaard breukmechanicatesten om de toepasbaarheid en geldigheid aan te tonen. De pelresultaten blijken gevoelig voor een variatie in de procesparameters, zodat deze test een waardevol instrument is voor procesoptimalisatie. Een thermisch procesmodel is ontwikkeld, waarin rekening wordt gehouden met de optische aspecten van laserverwarming. Het model is experimenteel gevalideerd. De belangrijkste procesparameters en relevante materiaaleigenschappen zijn op basis van het model vastgesteld.

De scheurtaaiheid van het grensvlak is niet alleen afhankelijk van de laskwaliteit. Deze wordt ook beïnvloed door de kristalliniteit van de polymere matrix en de structuur van het grensvlak. Dit komt tot uiting bij een vergelijking tussen het snelle tape-placementproces en een (traag) persproces. Het tape-placementsproces resulteert in een significant hogere scheurtaaiheid, hetgeen wordt toegeschreven aan de hoge afkoelsnelheid en korte procestijd. Eerstgenoemde resulteert in een lage kristalliniteit. Door de korte procestijd kunnen de tape-vezels niet migreren in de harsrijke gebieden van het laminaat, waardoor de mate van vezel-vezelcontact in het grensvlak minimaal is. Zowel de lage kristallinteit als de aanwezigheid van harsrijke gebieden op het grensvlak verhogen de scheurtaaiheid.

Tenslotte wordt een processtrategie voorgesteld die de productiviteit en het rendement maximaliseert. Het laservermogen wordt in deze strategie volledig op de tape gericht. Hoewel de strategie nog in de praktijk moet worden getest, wordt op basis van dit proefschrift een uitstekende lassterkte verwacht. 



\section{Contents}

Summary i

$\begin{array}{ll}\text { Samenvatting } & \text { iii }\end{array}$

Nomenclature $\quad$ ix

1 Introduction $\quad 1$

1.1 Background and motivation . . . . . . . . . . . . . 1

1.2 Laser-assisted tape placement . . . . . . . . . . . . . . . . 2

1.3 Interlaminar bonding of thermoplastic composites . . . . . . . . . . 4

1.4 Objective and scope . . . . . . . . . . . . . . 5

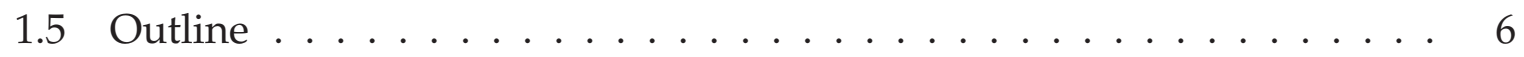

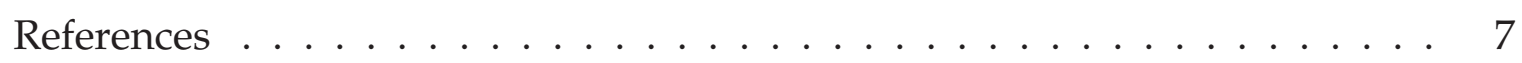

2 Optical model for the LATP process 9

2.1 Introduction . . . . . . . . . . . . . . . . 10

2.2 Optics in laser heating of composites . . . . . . . . . . . . . . . 12

2.3 Material characterization . . . . . . . . . . . . . . . 13

2.3.1 Materials and equipment . . . . . . . . . . . . . 13

2.3.2 Absorption and transmission of laser light . . . . . . . . . . . 13

2.3.3 Reflection of laser light . . . . . . . . . . . . . . . 14

2.3.4 Reflectance of carbon-PPS composites . . . . . . . . . . . . . 17

2.4 Optical process model . . . . . . . . . . . . . . . . . . . . 19

2.4.1 Modeling assumptions . . . . . . . . . . . . . . 20

2.4 .2 Modeling approach .................. 20

2.4 .3 Modeling results . . . . . . . . . . . . . . 22

2.5 Conclusions . . . . . . . . . . . . . . . . . . 23

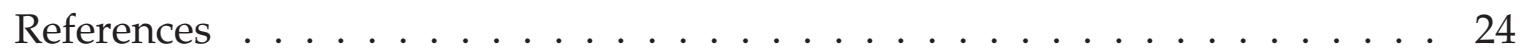


$3 \quad$ Thermal model for the LATP process 27

3.1 Introduction . . . . . . . . . . . . . . . . . . . 28

3.2 Thermal model . . . . . . . . . . . . . . . . . . . . . . . . 29

3.2.1 Modeling assumptions . . . . . . . . . . . . . . . . . 29

3.2.2 Modeling approach . . . . . . . . . . . . 30

3.2.3 Computational implementation . . . . . . . . . . . 33

3.3 Experimental work . . . . . . . . . . . . . . . . 34

3.3.1 Materials and equipment . . . . . . . . . . . 35

3.3.2 Tape placement experiments . . . . . . . . . . . . 35

3.3.3 Experimental results . . . . . . . . . . . . . . . 35

3.4 Model validation . . . . . . . . . . . . . . . . . . . 38

3.4.1 Material properties and boundary conditions . . . . . . . . 38

3.4.2 Modeling results and validation . . . . . . . . . . . . 40

3.5 Discussion . . . . . . . . . . . . . . . . . . 43

3.6 Conclusions and future work . . . . . . . . . . . . . 46

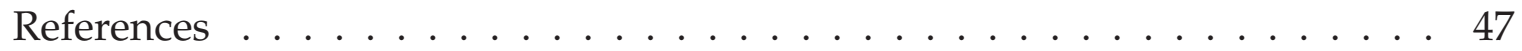

4 Mandrel peel test for thermoplastic composites 49

4.1 Introduction . . . . . . . . . . . . . . . . . . 50

4.1 .1 Background and motivation . . . . . . . . . . . 50

4.1 .2 Mandrel peel test . . . . . . . . . . . . . . . . . . . 51

4.1 .3 Outline .......................... 52

4.2 Energy release rate . . . . . . . . . . . . . . . . 52

4.3 Experimental work . . . . . . . . . . . . . . . . 54

4.3 .1 Materials . . . . . . . . . . . . . . . . . . 54

4.3.2 Specimen preparation . . . . . . . . . . . 55

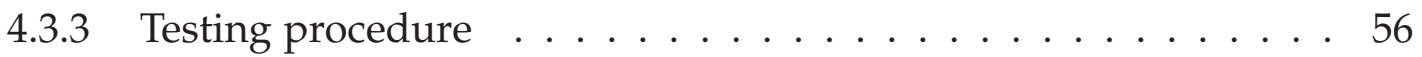

4.4 Experimental results and discussion . . . . . . . . . . . . . 58

4.4.1 Unidirectionally reinforced specimens . . . . . . . . . . . . 59

4.4 .2 Hybrid specimens . . . . . . . . . . . . . . . . 64

4.5 Conclusions . . . . . . . . . . . . . . . . . 67

References ........................... 68 
5 Influence of the LATP process parameters on bond strength 71

5.1 Introduction . . . . . . . . . . . . . . . . . . 72

5.2 Interlaminar bonding of thermoplastic composites . . . . . . . . . . . 73

5.2 .1 Intimate contact . . . . . . . . . . . . . . . . 73

5.2.2 Diffusion process and strength development . . . . . . . . . 75

5.2 .3 Influence of process parameters . . . . . . . . . . . . . 77

5.3 Experimental work . . . . . . . . . . . . . . . . 78

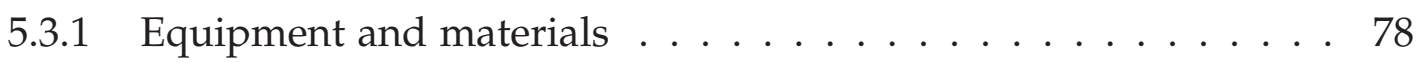

5.3.2 Peel specimen preparation . . . . . . . . . . . . . . 78

5.3.3 Mandrel peel test . . . . . . . . . . . . . . . . . . . 79

5.4 Bonding analysis and experimental results . . . . . . . . . . . . 80

5.4.1 Estimation of characteristic process times . . . . . . . . . . . 80

5.4 .2 Mandrel peel results . . . . . . . . . . . . . . . . . . 84

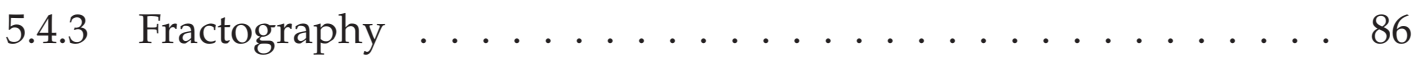

5.5 Discussion . . . . . . . . . . . . . . . . . . . 88

5.6 Conclusions . . . . . . . . . . . . . . . . . . 91

References ........................... 91

6 Fracture toughness of tailored woven fabric reinforced laminates 95

6.1 Introduction . . . . . . . . . . . . . . . 96

6.2 Experimental work . . . . . . . . . . . . . . . . 97

6.2.1 Materials ......................... 97

6.2 .2 Specimen preparation .................... 98

6.2 .3 Mandrel peel test . . . . . . . . . . . . . . . . . . . . 99

6.2 .4 Experimental results . . . . . . . . . . . . . . . . 101

6.3 Discussion . . . . . . . . . . . . . . . . . . . . 101

6.3.1 Influence of crystallinity on fracture toughness . . . . . . . . 102

6.3 .2 Fractography analysis . . . . . . . . . . . . . 106

6.4 Conclusions . . . . . . . . . . . . . . . . . . . . . . . 110

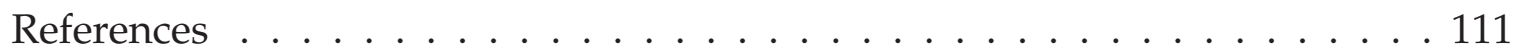

7 Crystallization and fracture toughness of PPS 113

7.1 Introduction . . . . . . . . . . . . . . . . . . . 114

7.1.1 Background and motivation . . . . . . . . . . . . 114

7.1.2 Literature overview . . . . . . . . . . . . . . . . 115

7.1 .3 Objective and outline . . . . . . . . . . . 116

7.2 Experimental work . . . . . . . . . . . . . . 116 
7.2.1 Critical quench rate $\ldots \ldots \ldots . \ldots \ldots 117$

7.2 .2 Tensile properties . . . . . . . . . . . . . . 117

7.2.3 Fracture toughness . . . . . . . . . . . . . . 118

7.3 Experimental results and discussion . . . . . . . . . . . . . 120

7.3.1 Critical quench rate . . . . . . . . . . . . . 120

7.3.2 Tensile properties . . . . . . . . . . . . . . . 121

7.3 .3 Fracture toughness . . . . . . . . . . . . . . . 122

7.4 Discussion . . . . . . . . . . . . . . . . . 123

7.5 Conclusions . . . . . . . . . . . . . . . . . . . 124

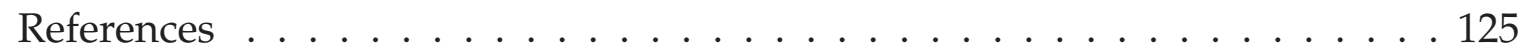

8 Discussion $\quad 129$

8.1 Process overview . . . . . . . . . . . . . . . . . . . . . . 129

8.2 Optimal processing strategy . . . . . . . . . . . . . . . 131

8.2.1 Processing strategy . . . . . . . . . . . . . . . . 131

8.2.2 Energy efficiency . . . . . . . . . . . . . . . . 132

8.2 .3 Productivity . . . . . . . . . . . . . . . . . 134

8.3 The issue of crystallinity . . . . . . . . . . . . . . . . 138

8.3.1 Effect on material properties . . . . . . . . . . . . 138

8.3.2 Improving the degree of crystallinity . . . . . . . . . . . . . 140

8.4 Concluding remarks . . . . . . . . . . . . . . . . . . 141

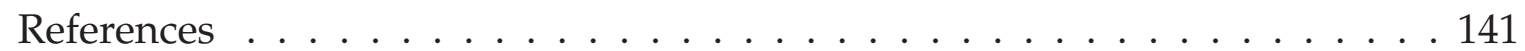

9 Conclusions and recommendations 143

9.1 Conclusions . . . . . . . . . . . . . . . . . . . . . . 143

9.2 Recommendations . . . . . . . . . . . . . . . . . . 145

A Experimental optimization of the LATP process 147

A.1 Experimental work . . . . . . . . . . . . . . . . . . 147

A.1.1 Specimen preparation . . . . . . . . . . . . . . . 147

A.1.2 Testing procedure . . . . . . . . . . . . . . . 148

A.2 Experimental results . . . . . . . . . . . . . . . . . . 148

$\begin{array}{lr}\text { Dankwoord } & 149\end{array}$

$\begin{array}{ll}\text { Publications } & 151\end{array}$ 


\section{Nomenclature}

The symbols used in this thesis are classified into a Greek or a Roman symbol group. Although some symbols can represent multiple quantities, its intended meaning follows from the textual context.

\section{Greek symbols}

$\begin{array}{ll}\alpha & \text { laser angle with respect to the laminate } \\ \beta & \text { curvilinear distance from nip-point } \\ \beta & \text { shape factor for the non-essential work of fracture zone } \\ \Gamma & \text { velocity correction factor } \\ \dot{\gamma} & \text { shear rate } \\ \Delta & \text { correction factor for the DCB and ELS test } \\ \delta_{\mathrm{t}}, \delta_{1} & \text { tape and laminate heated length } \\ \delta & \text { cross-head displacement } \\ \epsilon & \text { emmisivity } \\ \epsilon_{\mathrm{m}}, \epsilon_{\mathrm{r}} & \text { elastic and residual strain } \\ \varepsilon & \text { process energy efficiency } \\ \zeta & \text { 'early regime' skin layer thickness } \\ \eta & \text { viscosity } \\ \eta_{0} & \text { zero-shear-rate viscosity } \\ \theta_{\mathrm{i}}, \theta_{\mathrm{r}}, \theta_{\mathrm{t}} & \text { incident, reflection and transmission angle } \\ \mathcal{\kappa} & \text { thermal diffusivity } \\ \lambda & \text { laser light wavelength } \\ \lambda & \text { relaxation time } \\ \mu & \text { peel setup friction coefficient } \\ \xi & \text { Chebishev-Gauss-Lobatto point location } \\ \rho & \text { density } \\ \sigma & \text { Boltzmann constant } \\ \sigma_{\mathrm{m}}, \sigma_{\mathrm{r}} & \text { mechanical and residual stress } \\ \sigma_{\mathrm{max}} & \text { maximum stress EWF specimen } \\ \tau_{\mathrm{c}} & \text { characteristic time scale for conduction } \\ \varphi & \text { fiber orientation with respect to the laser beam } \\ \chi_{\mathrm{c}} & \text { degree of crystallinity }\end{array}$




\section{Roman symbols}

A

$a, a_{\mathrm{e}}$

$a$

$b$

C

$c_{p}$

$c_{\eta}$

$c_{\lambda}$

$\mathrm{D}^{2}$

$D_{\text {ic }}$

$D_{\mathrm{h}}$

d

$E, E_{\mathrm{f}}$

$E_{\eta}, E_{\lambda}$

$F$

$F_{\mathrm{a}}, F_{\mathrm{p}}$

$\mathcal{G}$

$\mathcal{G}_{\mathrm{c}}$

$\mathcal{G}_{\mathrm{p}}$

$G_{1 c}, G_{2 c}$

$\Delta H_{\mathrm{c}}$

$\Delta H_{\mathrm{f}}$

$\Delta H_{\mathrm{f}}^{0}$

$h$

$h$

$h_{\mathrm{a}}, h_{\mathrm{m}}, h_{\mathrm{r}}$

$I_{0}, I_{\mathrm{a}}, I_{\mathrm{r}}, I_{\mathrm{t}}$

I

K

$k_{x}, k_{z}$

$L$

L

l

$\ell$

N

N

$N_{\mathrm{R}}$

$n_{\mathrm{t}}, n_{1}$

$n$

$P$

$P_{\text {app }}$

$p$ absorptance

crack length and effective crack length

$[-]$

[m]

asperity heigth for the intimate contact model

[m]

width

compliance

specific heat

proportionality coefficient zero-shear viscosity

proportionality coefficient relaxation time

Chebyshev second derivative matrix

degree of intimate contact

degree of healing

asperity width for the intimate contact model

Young's modulus and flexural modulus

activation energy for the viscosity and relaxation time

force

alignment force and peel force

energy release rate

critical energy release rate

specific energy dissipated by plastic deformation

mode I and mode II critical energy release rate

cold crystallization enthalpy

melting enthalpy

reference melting enthalpy

tape thickness

arm thickness DCB and ELS specimens

heat transfer coefficients (air, mold, roller)

incident, absorbed, reflected and transmitted intensity

identity matrix

thermal model system matrix

in-plane and out-of-plane thermal conductivity

Lagrange polynomial

deposition length

[-]

$[\mathrm{m} / \mathrm{N}]$

[J/(kg K)]

[Pa s]

[s]

$[-]$

$[-]$

$[-]$

[m]

[Pa]

[J/mol]

[N]

[N]

$\left[\mathrm{J} / \mathrm{m}^{2}\right]$

$\left[\mathrm{J} / \mathrm{m}^{2}\right]$

$\left[\mathrm{J} / \mathrm{m}^{2}\right]$

$\left[\mathrm{J} / \mathrm{m}^{2}\right]$

[J/g]

[J/g]

[J/g]

[m]

[m]

$\left[\mathrm{W} /\left(\mathrm{m}^{2} \mathrm{~K}\right)\right]$

$\left[\mathrm{W} / \mathrm{m}^{2}\right]$

$[-]$

$[-]$

$[\mathrm{W} /(\mathrm{m} \mathrm{K})]$

$[-]$

[m]

[m]

[m]

ligament length

[-]

[-]

[-]

[-]

[-]

[W]

[Pa] 


$\begin{array}{llr}Q & \text { laser influx } & {\left[\mathrm{W} / \mathrm{m}^{2}\right]} \\ q^{\prime \prime} & \text { heat flux } & {\left[\mathrm{W} / \mathrm{m}^{2}\right]} \\ R & \text { reflectance } & {[-]} \\ R & \text { universial gas constant } & {[\mathrm{J} /(\mathrm{K} \mathrm{mol})]} \\ S, S_{\infty} & \text { interface strength and ultimate interface strength } & {[\mathrm{Pa}]} \\ s & \text { distance from nip-point } & {[\mathrm{m}]} \\ T & \text { temperature } & {[\mathrm{K}]} \\ T_{\mathrm{t}}, T_{1}, T_{\mathrm{i}} & \text { tape, laminate and interface temperature } & {[\mathrm{K}]} \\ T_{\mathrm{s}} & \text { surface temperature of a semi-infinite solid } & {[\mathrm{K}]} \\ T_{\mathrm{g}}, T_{\mathrm{m}} & \text { glass transition and melting temperature } & {[\mathrm{K}]} \\ T_{0}, T_{\infty} & \text { initial and far field temperature } & {[\mathrm{K}]} \\ t & \text { film thickness } & {[\mathrm{m}]} \\ t & \text { time } & {[\mathrm{s}]} \\ t_{\mathrm{c}} & \text { contact time } & {[\mathrm{s}]} \\ t_{\mathrm{r}}, t_{\mathrm{W}} & \text { reptation and weld time } & {[\mathrm{s}]} \\ \bar{t}_{\mathrm{ic}}, \bar{t}_{\mathrm{h}} & \text { time required for intimate contact and healing } & {[\mathrm{s}]} \\ \Delta t & \text { time step size } & {[\mathrm{s}]} \\ t_{\mathrm{o}}, t_{\mathrm{p}} & \text { overhead and total process time } & {[\mathrm{s}]} \\ U_{\mathrm{d}} & \text { dissipated energy } & {[\mathrm{J}]} \\ U_{\mathrm{ext}} & \text { external work } & {[\mathrm{J}]} \\ U_{\mathrm{s}} & \text { strain energy stored in peel arm } & {[\mathrm{J}]} \\ v & \text { placement velocity } & {[\mathrm{m} / \mathrm{s}]} \\ v_{\mathrm{f}} & \text { fiber volume fraction } & {[-]} \\ W_{\mathrm{e}} & \text { essential work of fracture } & {[\mathrm{J} / \mathrm{m}]} \\ W_{\mathrm{f}} f & \text { work of fracture } & {[\mathrm{J} / \mathrm{m}]} \\ W_{\mathrm{p}} & \text { non-essential work of fracture } & {[\mathrm{J}]} \\ w_{\mathrm{e}} & \text { specific essential work of fracture } & {\left[\mathrm{J} /{ }^{2}\right]} \\ w_{\mathrm{f}} & \text { specific work of fracture } & {[\mathrm{J} / 2]} \\ w_{\mathrm{p}} & \text { specific non-essential work of fracture } & {\left[\mathrm{J} /{ }^{2}\right]} \\ w & \text { laser beam width } & {[\mathrm{m}]} \\ w & \text { valley width for the intimate contact model } & {[\mathrm{m}]} \\ w_{\mathrm{m}} & \text { matrix mass fraction } & {[-]} \\ x, z & \text { in-plane and out-of-plane co-ordinate } & {[\mathrm{m}]}\end{array}$

\section{Abbreviations}

CBT

CBTE

CLT

DCB

DSC

ELS

ENF

EWF corrected beam theory

corrected beam theory with effective crack length

classical lamination theory

double cantilever beam

differential scanning calorimetry

end loaded split

end notch flexure

essential work of fracture 
FSC fast scanning calorimetry

LATP laser assisted tape placement

LDPE low density poly(ethylene)

LEFM linear elastic fracture mechanics

PA12 poly(amide) 12

PEEK poly(ether ether ketone)

PET poly(ethylene terephthalate)

PP poly(propylene)

R-curve crack growth resistance curve

SBT

simple beam theory

PPS

poly(phenylene sulfide)

UD

unidirectional

WF woven fabric 


\section{CHAPTER 1}

\section{Introduction}

\subsection{Background and motivation}

Weight reduction is one of the main technology drivers in the aircraft manufacturing industry. This is well illustrated by the increasing application of composite materials in new aircraft; composites show superior specific stiffness and strength compared to their metallic counterparts. For example, composites will account for $50 \%$ of the total aircraft weight in the new Boeing 787 Dreamliner, while this was only $12 \%$ for its predecessor [1]. Cost reduction is another important technology driver and it has led to the automation of manufacturing processes in all fields of industry. Composites form no exception in this respect. Automation reduces labor costs as well as costs associated with scrap and material wastage due to human errors.

The automated tape placement process for fiber reinforced thermoplastics follows naturally from both technology drivers. On the one hand, thermoplastic composites lend themselves pre-eminently to automated and cost-effective manufacturing. The thermoplastic matrix can be repeatedly melted, shaped and solidified, which allows for rapid forming technologies, such as press forming. Moreover, the ability to melt and solidify also enables advanced joining methods, such as induction or ultrasonic welding, which allows for the (automated) assembly of relatively simple parts into complex structures. On the other hand, the tape placement technology itself has a huge potential for automation. The process, which is elaborated in the next section, comprises the automated deposition of fiber reinforced thermoplastic tapes onto a supporting tool to incrementally shape the final component.

A key feature, and frequently used selling point, of the automated tape placement process is its (yet unfulfilled) potential for in situ consolidation [2, 3]. The thermoplastic composite tapes are then consolidated upon deposition, thereby obviating the need for an energy-consuming post-consolidation step in an autoclave [4]. The application of a laser for heating could further increase the energy efficiency of the process. The input energy can be controlled rapidly and accurately and the size and location of the heated area can be controlled to a high degree. Moreover, 
due to its high energy density, laser heating also allows for high productivity. Despite its potential, however, the laser-assisted tape placement process is still in its infancy, lacking large-scale industrial application. This is mainly caused by the complexity of the process. The process window is often characterized as narrow $[5,6]$ and process optimization relies to a large extent on trial and error procedures, involving extensive material inspection.

Much research effort has been spent with the ultimate aim to industrialize the automated (laser-assisted) tape placement process, e.g. $[2,7,8]$. The majority of this research concerns the application of the process as a replacement for conventional manufacturing techniques, such as autoclave processing. Alternatively, however, the process could also be applied as an additional processing step to tailor the properties of conventionally manufactured components. Unidirectionally (UD) fiber reinforced tapes are then locally welded onto fully consolidated structural components, with the aim of enhancing the mechanical properties, while keeping the component weight low. This processing route is especially attractive for reinforcing press-formed woven fabric reinforced components. The high drapeability and impact resistance of these woven fabric reinforced thermoplastics are then combined with the strength and stiffness of the UD reinforced tapes.

The performance of the final tailored structure depends on a number of different factors. For example, the accuracy with which the tapes are deposited determines whether or not overlaps or gaps will exist. Moreover, the void fraction, any developed residual stresses and the degree of crystallinity of the final structure play an important role. Nevertheless, the interlaminar bond strength between the tape and the component is arguably the most important parameter. It determines the ability of the structure to transfer interlaminar stresses. This thesis, therefore, focuses on the interlaminar bond strength development between a UD tape and a woven fabric reinforced laminate during the laser-assisted tape placement process.

The research presented in this thesis was performed within the European research program Clean Sky [9], which focuses on the development of breakthrough technologies to significantly improve the environmental performances of airplanes and air transport. Clean Sky comprises six Integrated Technology Demonstrators (ITDs). The work presented here was part of the Eco-Design ITD, which concentrates on green design and production, withdrawal and recycling of aircraft by optimal use of raw materials and energy.

\subsection{Laser-assisted tape placement}

The terms tape placement, fiber placement and tape laying, generally, all refer to the same, or at least closely related, manufacturing process, where various different definitions are in use. The distinction between laying and placement concerns the 


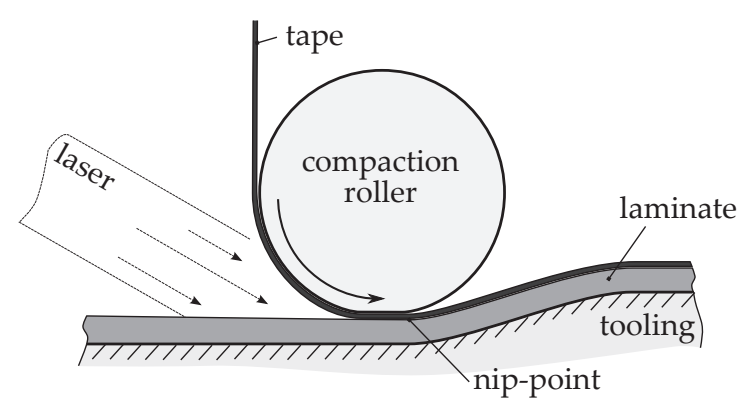

Figure 1.1 Schematic illustration of the laser-assisted tape placement process.

complexity of the lay-up geometry. The former is employed to describe the process of delivering wide prepreg onto a (more or less) flat surface, while the latter concerns the placement of a band of multiple narrow prepreg slices on more complex geometries [10]. The terms fiber and tape are often used interchangeably and can refer to both thermoset and thermoplastic based prepreg. Due to its solid nature and fixed dimensions, however, thermoplastic prepreg is often designated as fiber reinforced tape. Based on these definitions, the term tape placement seems most appropriate for the process at hand and will be used in the rest of this thesis.

Figure 1.1 schematically illustrates the tape placement process. It comprises the automated deposition of fiber reinforced thermoplastic tapes onto a (doubly curved) laminate or tooling. The tapes are bonded under the application of heat and pressure. The pressure can be applied by a compaction roller or a compaction shoe, while the heat is generally supplied using a hot gas torch [11-13] or a laser [14, 15]. A robot is used to deposit the tapes on pre-defined paths, which allows for a high degree of freedom in terms of final product design. Potentially, the tapes can be consolidated directly during depositioning, which would obviate an additional, time and energy consuming, post-consolidation step in an autoclave.

The laser-assisted tape placement (LATP) process relies on a laser to heat the tape and the laminate. The application of laser heating has some advantages over the alternative heat sources, such as a hot gas torch. The two most important advantages are the high energy density and the short response time. The former enables high placement velocities, while the latter allows the lay-up of complicated geometries, involving large variations in placement velocity. The application of a laser, however, also has its disadvantages. The costs for equipment, for example, are high compared to conventional heat sources, while also the laser almost always requires the equipment to be placed in a shielded environment. Additionally, the application of laser heating requires a thorough understanding of the interaction of light with fiber reinforced thermoplastics.

The laser-assisted tape placement process is characterized by the extremely short time available for bonding and consolidation. For example, the available process 
time is less than $25 \mathrm{~ms}$ when considering a placement velocity of $200 \mathrm{~mm} / \mathrm{s}$ and a contact length of $5 \mathrm{~mm}$ between the roller and the laminate. Moreover, the material is subjected to extremely high heating and cooling rates in order to achieve these short process times. In the case of semi-crystalline polymers, these high cooling rates can significantly affect the crystallinity of the final component. Consequently, the final properties may differ compared to conventionally (and slowly) manufactured products, which may well impede the application of established design rules.

\subsection{Interlaminar bonding of thermoplastic composites}

Interlaminar bonding of thermoplastics plays an important role in tape placement processes, but also in a number of other composites manufacturing techniques such as autoclave co-consolidation [16] and various welding methods [17]. The bonding process is schematically shown in Figure 1.2. According to contemporary literature, it comprises two different, but simultaneously occurring, phenomena: $i$. intimate contact has to be achieved between the two adherents and ii. intermolecular diffusion, a process which is also known as healing, takes place between the surfaces in intimate contact.

The development of intimate contact, which is a prerequisite for healing, comprises the flattening of the tape and laminate surface roughness. The initial surface asperities are deformed under the application of heat and pressure. The time required to achieve intimate contact depends on the initial roughness of the surfaces, the applied pressure and the matrix viscosity [18-20]. Due to the temperature dependency of the viscosity, an increase in temperature facilitates intimate contact development.

In the regions where intimate contact has been achieved, interdiffusion of polymer chains occurs due to random thermal motion. The interdiffusion process is generally described using the reptation theory of chain mobility [21, 22]. The matrix material

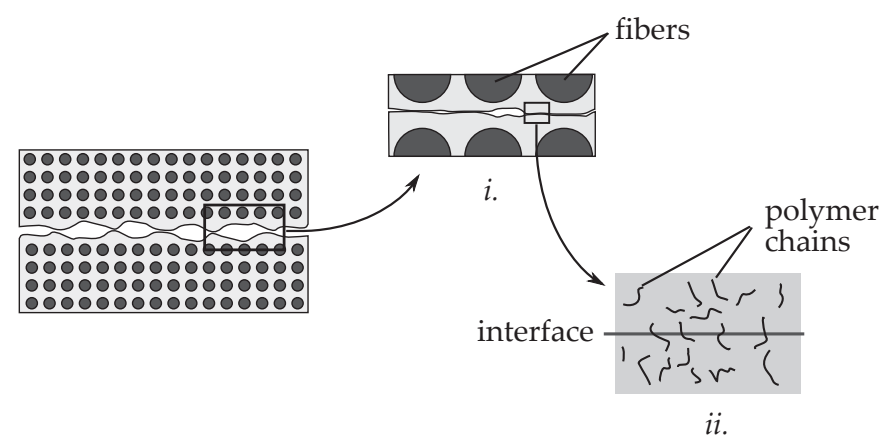

Figure 1.2 Interlaminar bonding of thermoplastic composites: The adherents are brought into contact after which i. intimate contact develops and ii. interdiffusion of polymer chains occurs. 
is considered as an entanglement of polymer chains, in which the movement of the individual chains is restricted. The mobility of the polymer chains and thereby the diffusion rate increases with increasing temperature. In the case of semi-crystalline polymers, the presence of crystallites can severely inhibit the interdiffusion process [23].

Based on the bonding mechanisms described above, the thermal history of the interface is considered to be an important parameter. The thermal aspects of the tape placement process have, therefore, received considerable attention in literature $[6,13,24,25]$. The majority of this research concerned the case in which heat is supplied using a hot gas torch, while only a few considered the specific case of laser heating $[14,15]$.

\subsection{Objective and scope}

The principal objective of this thesis is to develop an efficient processing strategy for the welding of UD reinforced tapes onto woven fabric reinforced laminates using the laser-assisted tape placement process. Ideally, the developed strategy results in a high weld strength, while achieving a high productivity combined with a low energy consumption. In order to achieve this objective, the main mechanisms contributing to the interlaminar bond strength should be identified. The present work concentrates on the weld strength between a single UD tape and a woven fabric reinforced laminate. Based on the identified mechanisms, a thorough understanding needs to be developed of the interrelation between processing parameters, material properties and resulting bond strength. The present work aims to obtain this through a combination of experimental work and physical modeling.

An experimental methodology will be developed to quantify the interfacial fracture toughness as a measure for the degree of bonding between a UD reinforced tape and a woven fabric reinforced laminate. The method will be employed to identify the major bonding mechanisms and to help define a processing window. Furthermore, a combined optical-thermal model will be introduced to determine the effect of processing parameters and material properties on the thermal history in the tape and the laminate. The proposed model will take into account the specific case of laser heating.

The material considered in this thesis comprises unidirectionally carbon reinforced poly(phenylene sulfide) (PPS) tape and carbon woven fabric reinforced PPS laminates. Poly(phenylene sulfide) is a semi-crystalline thermoplastic often used in aerospace applications. It has a glass transition and melting temperature of $85{ }^{\circ} \mathrm{C}$ and $285^{\circ} \mathrm{C}$, respectively. The tape and laminate were provided by Suprem ${ }^{1}$ and Ten Cate

\footnotetext{
${ }^{1}$ Suprem SA (http://www. suprem.ch)
} 
$\mathrm{AC}^{2}$, respectively. The laser-assisted tape placement equipment, used throughout this work, was made available by AFPT $\mathrm{GmbH}^{3}$.

\subsection{Outline}

The core of the thesis is schematically outlined in Figure 1.3. It comprises six chapters (i.e. Chapter 2 to 7 ), which are all reproduced from research papers. As a consequence, some of the essential details are repeated in the different chapters. The author apologizes for any inconvenience caused by the chosen presentation. From a more positive point of view, however, the reader is able to study any individual chapter without having to miss out on any essential details.

The second chapter presents an optical model, based on a ray tracing procedure, for the LATP process. For this purpose, the interaction of the laser light with carbon UD reinforced and carbon woven fabric reinforced PPS was investigated. The model is used to calculate the incident light distribution on the laminate and the tape for various incident laser angles. Subsequently, the incident light distribution is used in a thermal model, presented in chapter three, to calculate the tape and laminate temperature distribution. The combined optical and thermal model is validated experimentally in this third chapter. The relevant processing parameters and material properties are identified for the process and materials at hand.

The fourth chapter introduces the mandrel peel test method, which was used throughout the thesis to quantify the interlaminar fracture toughness as a measure of the bond quality. The applicability and validity of this test for carbon-PPS composites was investigated by comparing the measured fracture toughness to the values obtained by the standardized double cantilever beam and end-loaded-split beam test.

Chapter five concerns the interlaminar bonding process during tape placement. An estimate of the time required for bonding is provided based on the interlaminar bonding models available in the literature. Subsequently, tape placement experiments were performed to study the effect of the laser power, placement velocity and laser angle on the interfacial fracture toughness. The tape and laminate temperature before bonding were measured and used to interpret the experimental results.

Chapter six compares the LATP process to the more conventional press molding process in terms of interfacial fracture toughness. The influence of the degree of crystallinity and process-induced interface morphology is elaborated extensively.

In chapter seven the influence of the PPS matrix crystallinity on the fracture toughness is investigated experimentally. The chapter presents high speed differential calorime-

\footnotetext{
${ }^{2}$ Ten Cate Advanced Composites (http://www.tencate.com)

${ }^{3}$ Advanced Fiber Placement Technology GmbH (http: //www . afpt.de)
} 




Figure 1.3 Outline of the thesis.

try experiments on PPS film specimens. The experiments yield the critical quench rate at which the PPS is unable to crystallize. Subsequently, essential work of fracture experiments were performed on amorphous and annealed PPS films to study the effect of crystallinity on fracture toughness.

The complete work is put into a broader perspective in chapter eight. The process is reviewed and the influence of the processing parameters and material properties is elaborated. A processing strategy is proposed based on the work presented in this thesis. Finally, chapter nine presents the important conclusions and provides the recommendations for further research.

\section{References}

[1] Boeing website: http://www.boeing.com/commercial/787family/programfacts.html, visited on April 13th, 2012.

[2] M. A. Lamontia and M. B. Gruber. Remaining developments required for commercializing in situ thermoplastic ATP. In SAMPE Baltimore, 2007.

[3] R. Schledjewski and A. Schlarb. In-situ consolidation of thermoplastic tape material effects of tape quality on resulting part properties. In SAMPE 2007 Baltimore, 2007.

[4] F. O. Sonmez and M. Akbulut. Process optimization of tape placement for thermoplastic composites. Composites Part A, 38(9):2013-2023, 2007.

[5] V. Agarwal, S. I. Güçeri, R. L. McCullough, and J. M. Schultz. Thermal characterization of the laser-assisted consolidation process. Journal of Thermoplastic Composite Materials, 5(2):115-135, 1992.

[6] R. Schledjewski and M. Latrille. Processing of unidirectional fiber reinforced tapes fundamentals on the way to a process simulation tool (ProSimFRT). Composites Science and Technology, 63(14):2111-2118, 2003. 
[7] M. Steyer, M. Dubratz, A. Schütte, C. Wenzel, and C. Brecher. Laser-assisted thermoplastic tape-laying systems. JEC Composites Magazine, 47:39-41, 2009.

[8] M. A. Khan, P. Mitschang, and R. Schledjewski. Identification of some optimal parameters to achieve higher laminate quality through tape placement process. Advances in Polymer Technology, 29(2):98-111, 2010.

[9] Clean Sky website: http://www.cleansky.eu, visited on January 30th, 2012.

[10] D. H. J. A. Lukaszewicz, C. Ward, and K. D. Potter. The engineering aspects of automated prepreg layup: History, present and future. Composites Part B, Article in press, doi: 10.1016/j.compositesb.2011.12.003, 2012.

[11] J. Tierney and J. W. Gillespie Jr. Modeling of in situ strength development for the thermoplastic composite tow placement process. Journal of Composite Materials, 40(16):1487-1506, 2006.

[12] F. O. Sonmez and H. T. Hahn. Analysis of on-line consolidation process in thermoplastic composite tape placement. Journal of Thermoplastic Composite Materials, 10:543-572, 1997.

[13] Y. M. P. Toso, P. Ermanni, and D. Poulikakos. Thermal phenomena in fiber-reinforced thermoplastic tape winding process: Computational simulations and experimental validations. Journal of Composite Materials, 38(2):107-135, 2004.

[14] S. M. Grove. Thermal modelling of tape laying with continuous carbon fibre-reinforced thermoplastic. Composites, 19(5):367-375, 1988.

[15] M. Nejhad, R. Cope, and S. Güçeri. Thermal analysis of in-situ thermoplastic composite tape laying. Journal of Thermoplastic Composite Materials, 4:20-45, 1991.

[16] P. Nijhuis. Thermoplastic stiffened wing skin made by advanced fiber placement. In International SAMPE Symposium and Exhibition (Proceedings), volume 54, 2009.

[17] C. Ageorges, L. Ye, and M. Hou. Advances in fusion bonding techniques for joining thermoplastic matrix composites: A review. Composites Part A, 32(6):839-857, 2001.

[18] W. I. Lee, M. F. Talbott, G. S. Springer, and L. A. Berglund. Effects of cooling rate on the crystallinity and mechanical properties of thermoplastic composites. Journal of Reinforced Plastics and Composites, 6(1):2-12, 1987.

[19] S. C. Mantell and G. S. Springer. Manufacturing process models for thermoplastic composites. Journal of Composite Materials, 26(16):2348-2377, 1992.

[20] F. Yang and R. Pitchumani. Interlaminar contact development during thermoplastic fusion bonding. Polymer Engineering and Science, 42(2):424-438, 2002.

[21] P. G. De Gennes. Reptation of a polymer chain in the presence of fixed obstacles. Journal of Chemical Physics, 55(2):572-579, 1971.

[22] Y. H. Kim and R. P. Wool. A theory of healing at a polymer-polymer interface. Macromolecules, 16(7):1115-1120, 1983.

[23] J.-F. Lamèthe, P. Beauchêne, and L. Léger. Polymer dynamics applied to PEEK matrix composite welding. Aerospace Science and Technology, 9(3):233-240, 2005.

[24] F. O. Sonmez and H. T. Hahn. Modeling of heat transfer and crystallization in thermoplastic composite tape placement process. Journal of Thermoplastic Composite Materials, 10(3):198-240, 1997.

[25] J. Tierney and J. W. Gillespie Jr. Modeling of heat transfer and void dynamics for the thermoplastic composite tow-placement process. Journal of Composite Materials, 37(19):1745-1768, 2003. 


\title{
CHAPTER 2
}

\section{Optical phenomena and process model for the laser-assisted tape placement process $^{1}$}

\begin{abstract}
The application of laser heating for the tape placement process requires a thorough understanding of the optical phenomena involved. A qualitative experimental analysis is presented to identify the important phenomena during the tape placement of carbon poly(phenylene sulfide) (PPS) tapes onto carbon woven fabric reinforced PPS laminates. These materials are optically non-transparent for the laser wavelength used in this work. A ray-tracing model was implemented to account for the reflection of laser light in the nip-point region. The calculated incident heat flux distribution can subsequently be fed into a thermal model to calculate the tape and laminate temperature distribution.
\end{abstract}

\footnotetext{
${ }^{1}$ Reproduced from: W.J.B. Grouve, L.L. Warnet, B. Rietman, R. Akkerman. An optical-thermal process model for the laser-assisted tape placement process. In preparation for: Composites, Science and Technology.
} 


\subsection{Introduction}

The laser-assisted tape placement (LATP) process is a promising manufacturing technology for thermoplastic composites [1,2], combining high productivity with the ability to manufacture complex geometries. The process comprises the automated lay-up and (in the ideal case) consolidation of pre-impregnated fiber reinforced thermoplastic tapes to incrementally shape a composite structure [3, 4]. Figure 2.1 schematically illustrates the process. A unidirectionally (UD) fiber reinforced thermoplastic tape is guided in between a compaction roller and a laminate. A laser heats both the incoming tape and laminate, which are then consolidated under the applied heat and pressure.

The application of a laser for tape placement has some advantages over the alternative heat sources, such as a hot gas torch [5] or infrared heating. The two most important advantages are the high input energy and the short response time [1]. The former advantage allows high placement velocities, while the latter provides the ability to lay-up complicated geometries, involving large variations in placement velocity. The application of a laser, however, also complicates the process, as the laser wavelength needs to be matched to the optical material properties of the tape and the laminate.

Although tape placement is, generally, used to manufacture complete structures or laminates [6-8], it can also be applied to tailor the properties of conventionally manufactured components. For example, the mechanical properties of press-formed woven fabric reinforced components can be enhanced by locally reinforcing these with UD tapes. The high drapeability and impact resistance of woven fabrics is then combined with the high strength and stiffness of the tapes. The present work is part of a larger framework which focuses on the development of an energy efficient placement strategy for such tailored woven fabric reinforced composite components.

Currently, the (laser-assisted) tape placement process is often followed by an energy consuming, and often expensive, autoclave step to ensure proper consolidation. Potentially, however, the process allows in situ or out-of-autoclave consolidation. The majority of the research aims, therefore, at optimizing the tape placement
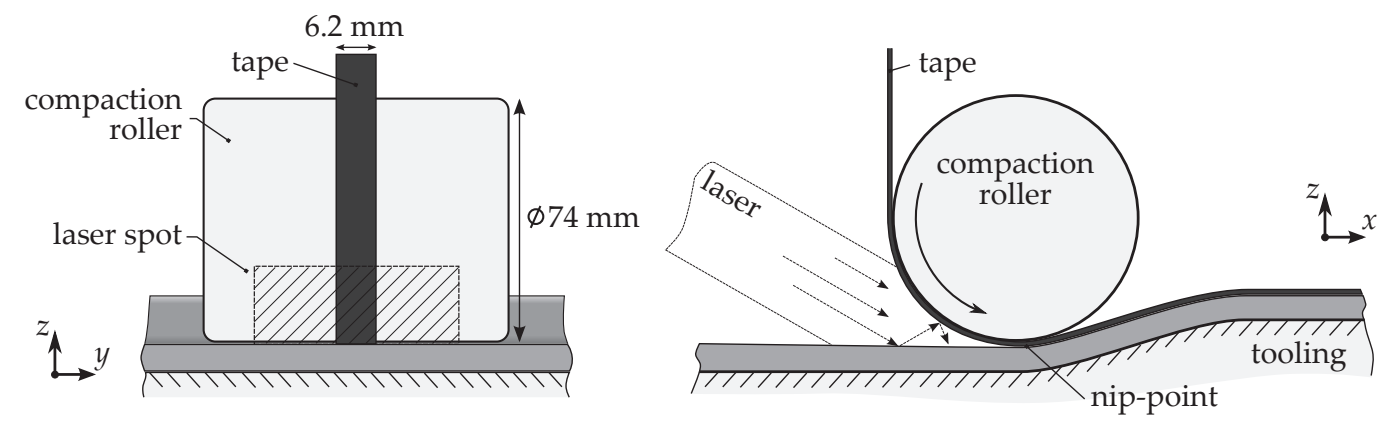

Figure 2.1 Illustration of the laser-assisted tape placement process. Left: Front view. Right: Side view. 
process parameters in order to omit the expensive consolidation step. Several process simulation tools have been developed to aid in this optimization process. Nevertheless, the majority of the developed models concern the tape placement processes in which heat is supplied using a hot gas torch, while only a few are specifically developed for laser heating. Beyeler and Güçeri [9] adopted a twodimensional finite difference method to calculate the temperature distribution during the LATP process. All laser light was assumed to be absorbed completely by the tape and laminate material and any reflection of laser light was neglected. Alternatively, Grove [10] calculated the temperature distribution using a two-dimensional finite element model. The reflection of the laser light was taken into account by assuming a constant reflectance, independent of the angle of incidence, for the tape and laminate surface. Generally, however, the reflectance does depend on the angle of incidence and approaches unity (all light is reflected) for grazing angles. This is especially relevant for the LATP process, as the laser angle with respect to the laminate is often rather small to minimize the shadowing effect of the roller. A proper optical model should take such effects into account.

The present work aims to develop a process tool to optimize the LATP process. Figure 2.2 schematically illustrates the chosen modeling approach. This chapter focuses on the development of the optical model, while the next chapter concerns the thermal model. The development of an optical model requires the understanding of the optical phenomena which govern the LATP process. Therefore, first the interaction of the laser light with the fiber reinforced composites is investigated. An optical model is then proposed to account for the reflection of the light in the nippoint (i.e. where tape and laminate meet) region, based on the Fresnel equations. The optical model predicts the incident heat flux distribution on the tape and laminate,

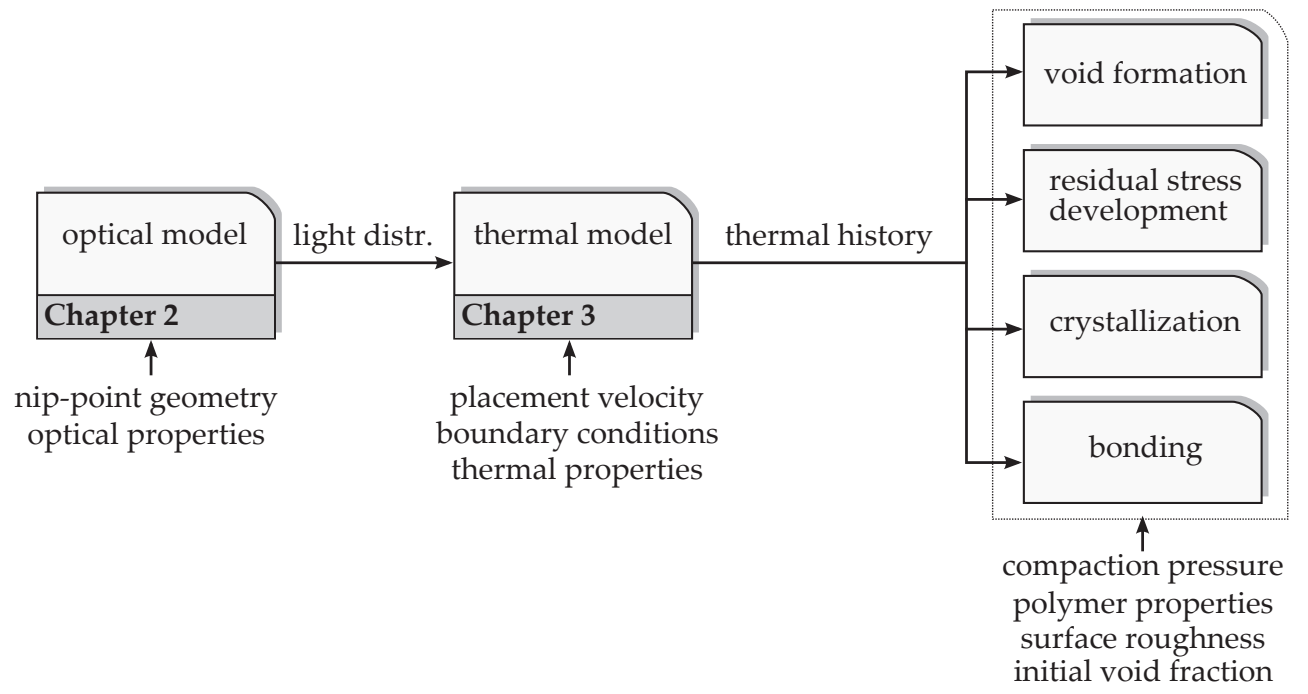

Figure 2.2 Illustration of the modeling approach. The current work focuses on the optical model, while the thermal model is elaborated in Chapter 3. 
which is subsequently used in a thermal model, presented in Chapter 3, to calculate the tape and laminate temperature distribution. Various existing post-processing models could be added to predict, for instance, weld strength [11, 12], residual stresses [13, 14] or degree of crystallinity [6, 15]. The present chapter, however, focuses on the development and implementation of the optical model.

\subsection{Optics in laser heating of composites}

The present section briefly introduces the optical phenomena which govern the laser heating of composites. When laser light strikes a fiber reinforced composite, a part of its initial intensity $\left(I_{0}\right)$ will be reflected $\left(I_{\mathrm{r}}\right)$, some absorbed $\left(I_{\mathrm{a}}\right)$ and some transmitted $\left(I_{\mathrm{t}}\right)$. The amount of light that is reflected, absorbed or transmitted depends on a number of factors, such as material properties (which includes the fibers and matrix), the laser wavelength and the fiber distribution. Figure 2.3 schematically illustrates the optical phenomena which take place when light strikes a composite material. Ideally, the surface of a fiber reinforced tape is covered with a thin, perfectly smooth, layer of thermoplastic matrix material to facilitate bonding. In practice, however, this is rarely the case. The incident laser light, therefore, can reflect from both the thermoplastic matrix as well as the fibers at the tape's surface. The fraction of incident light reflected by a surface, which is known as the reflectance $R$, should be as low as possible for laser heating to be effective.

Any light which is not reflected, is either transmitted or absorbed by the matrix and fibers. It is the absorption of light which actually contributes to the heating of the material, while the transmitted light just passes through. Most thermoplastics are transparent, i.e. they show almost no absorption, for light with a wavelength ranging from 400 to $1600 \mathrm{~nm}$ [16]. Heating these with a laser having such a wavelength, e.g. an Nd:YAG laser has a wavelength of typically $1064 \mathrm{~nm}$, is therefore not effective. In the field of laser (transmission) welding, this is often solved by adding a carbon black filler which absorbs the laser light, independent of its wavelength, causing the optical

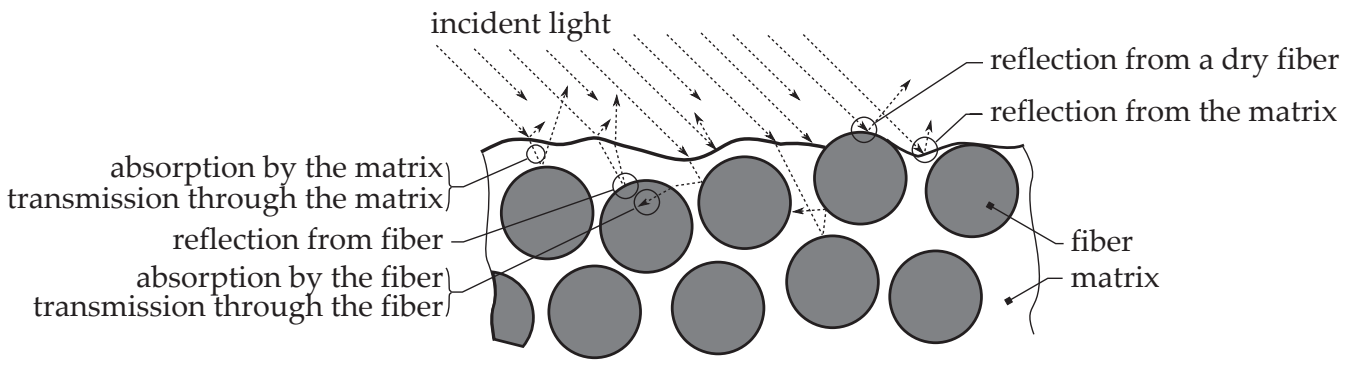

Figure 2.3 Schematic illustration of the optical phenomena which occur when light strikes a fiber reinforced thermoplastic. 
transparency of these plastics to decline to zero [17]. The carbon fibers in composites, discussed here, perform a similar role.

Summarizing, the optical phenomena during the laser heating of composite materials can involve the reflection, absorption and transmission of laser light by the composite. The laser wavelength and materials should be tuned carefully to ensure efficient heating.

\subsection{Material characterization}

The current section presents a qualitative and quantitative optical characterization of the materials used in this work. A qualitative study is presented to identify which of the optical phenomena govern the tape placement process. Subsequently, the experiments are elaborated to obtain the material properties relevant for the optical process model. First, however, the materials and equipment used in this work are introduced.

\subsubsection{Materials and equipment}

The materials considered here are UD carbon reinforced poly(phenylene sulfide) (PPS) tape and carbon woven fabric reinforced PPS laminates. The tape was manufactured by Suprem and has a fiber volume fraction of $55 \pm 3 \%$ and a thickness of $0.15 \mathrm{~mm}$. The laminates were manufactured by Ten Cate and comprised eight plies of quasi-isotropically stacked pre-impregnated 5 harness satin woven fabric carbon (known as CD286) reinforced PPS. The nominal laminate fiber volume fraction and thickness are $50 \%$ and $2.4 \mathrm{~mm}$, respectively. The PPS matrix material is, in both the tape and the laminate, known as Fortron 0214 from Ticona $\mathrm{GmbH}$ and has a glass transition and melt temperature of $85^{\circ} \mathrm{C}$ and $285^{\circ} \mathrm{C}$, respectively.

The tape placement equipment, used throughout this thesis, was provided by AFPT $\mathrm{GmbH}$ and consists of a robot with six degrees of freedom on which a tape placement head is mounted. The laser light has a wavelength of $\lambda=980 \mathrm{~nm}$ and is guided to the tape placement head using an optical fiber. The system uses optics to focus the beam in a rectangular shape with a more or less uniform intensity which decreases rapidly near the edges.

\subsubsection{Absorption and transmission of laser light}

The wavelength of the laser falls within the range of 400 to $1600 \mathrm{~nm}$, making it inefficient for heating thermoplastics. This was validated experimentally for the PPS considered in this work. As the PPS in the as-received tape initially is amorphous 
and the PPS in the laminates is semi-crystalline [18] (see Chapters 6 and 7), the transmittance (i.e. $I_{t} / I_{0}$ ) was determined of amorphous as well as annealed PPS film. The amorphous PPS film was manufactured by Ticona (Fortron 0214) and has a thickness of nominally $160 \mu \mathrm{m}$. Crystallized film was obtained by an annealing procedure in a convection oven for 30 minutes at $130^{\circ} \mathrm{C}$. A DSC analysis confirmed that the film had indeed crystallized.

The experimental setup comprised a laser and a photometer (EG\&G, type 450). A small laser was used with a wavelength and power of $980 \mathrm{~nm}$ and $15 \mathrm{~mW}$, respectively, while the beam diameter was approximately $5 \mathrm{~mm}$. The beam was aimed at the sensor, yielding the initial light intensity $\left(I_{0}\right)$. Subsequently, the PPS film was placed between the laser source and sensor to determine the transmitted intensity $\left(I_{\mathrm{t}}\right)$. The transmittance $\left(I_{\mathrm{t}} / I_{0}\right)$ of the amorphous and annealed PPS film equaled approximately $95 \%$ and $55 \%$, respectively. Hence, the amorphous PPS film (thickness of $160 \mu \mathrm{m}$ ) absorbs virtually no laser light, while the annealed film does absorb some laser light. Jaeschke et al. [17] found similar results for semi-crystalline PPS and a laser wavelength of $940 \mathrm{~nm}$ in a study concerning laser transmission welding.

The distance between the tape surface and fibers is far less than $160 \mu \mathrm{m}$, which means that the amount of light absorbed by the PPS matrix material is negligible. Heating PPS using the laser considered here is therefore not effective. Nevertheless, a similar experiment on the UD carbon reinforced PPS tape and laminates showed that the fibers cause the optical transparency to decline to zero, i.e. no light was transmitted. As discussed earlier, the carbon fibers perform a role similar to carbon black filler material and absorb the laser light irrespective of its wavelength.

\subsubsection{Reflection of laser light}

Although the absorption and transmission of the laser light is dominated by the carbon fibers, the matrix material could affect the reflectance of carbon-PPS composites. The reflection behavior was determined for the UD carbon-PPS tape and carbon woven fabric reinforced PPS laminate. The experimental setup is
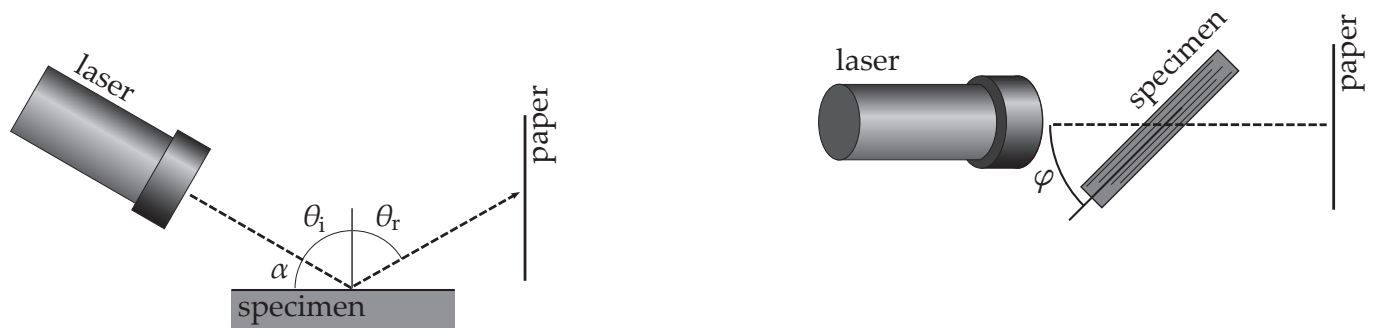

Figure 2.4 Experimental setup to determine the light reflection from carbon-PPS composites. Left: side view. Right: top view. 


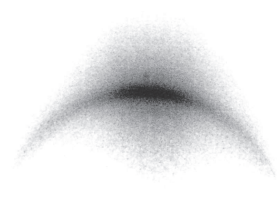

a.

d.

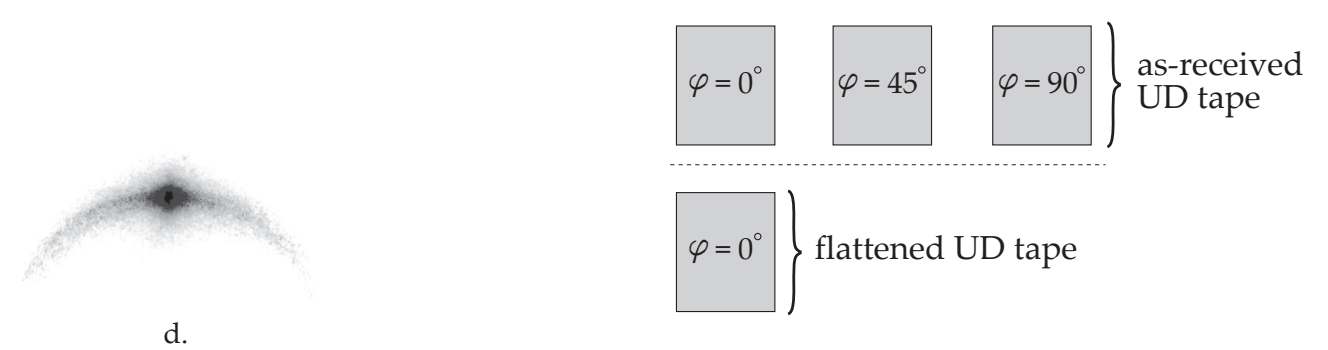

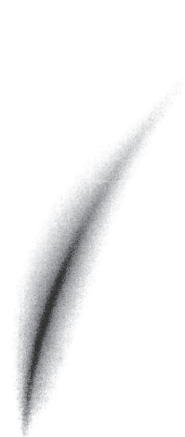

b.

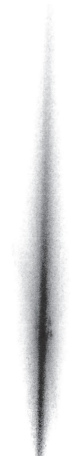

c.

Figure 2.5 Reflection patterns for an as-received and flattened UD reinforced carbon-PPS tape for varying tape orientation angles $\varphi$. The incident angle $\theta_{\mathrm{i}}$ was kept constant at $70^{\circ}$, which corresponds to a laser angle $\alpha=20^{\circ}$.

schematically illustrated in Figure 2.4 and comprised a rotating arm onto which the laser was mounted. The laser was aimed at a specimen which was placed horizontally between the laser and a sheet of paper. The reflected light was projected on the paper and the reflection patterns were recorded using a camera.

The top row in Figure 2.5 shows the reflection patterns for the as-received tape. The fiber orientation angle $\varphi$ with respect to the laser beam was taken as 0,45 and $90^{\circ}$, while the incident angle $\theta_{\mathrm{i}}$ was $70^{\circ}$ for all cases. The pictures show that the light is reflected in multiple directions, depending on the fiber orientation angle. This illustrates an anisotropic reflection behavior for these UD reinforced thermoplastic tapes. A bright spot is shown in the center of the picture in case the orientation angle equals $\varphi=0^{\circ}$, i.e. Figure 2.5a. The reflection angle $\theta_{\mathrm{r}}$ of this bright spot was found to equal the incident angle. The majority of the light, therefore, is reflected specularly, according to the law of reflection, that is the incident angle $\theta_{\mathrm{i}}$ equals the reflection angle $\theta_{\mathrm{r}}$.

The cause for the anisotropic reflection behavior is twofold. Firstly, as the amorphous PPS was found to barely absorb the laser light, any light which has not reflected from the tape surface will reflect from the fibers inside the tape. The cylindrical shape of the fibers causes the different reflection patterns, as is schematically illustrated 

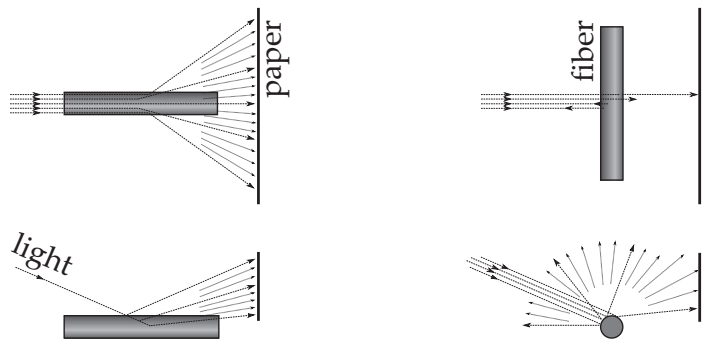

$\varphi=0^{\circ}$

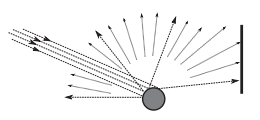

$\varphi=90^{\circ}$

Figure 2.6 Illustration of the influence of fiber orientation angle $\varphi$ on the light reflection pattern.
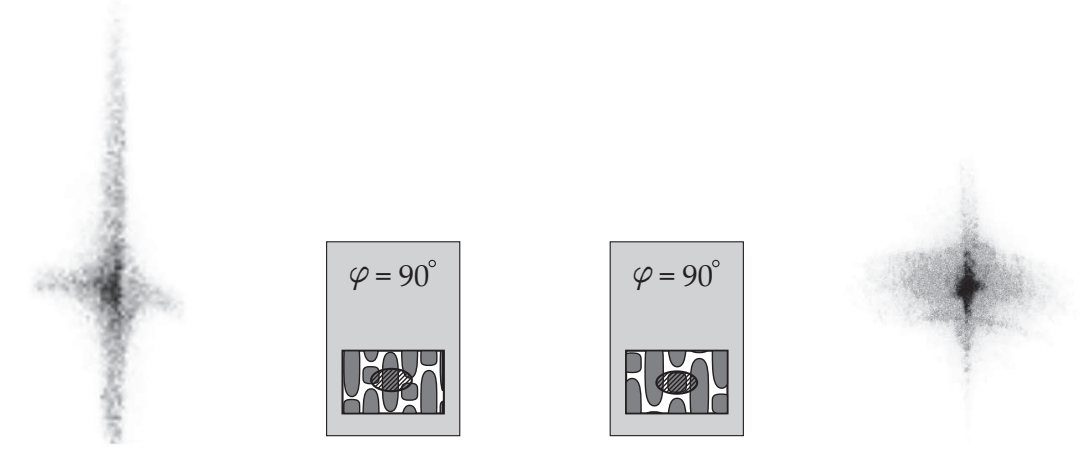

Figure 2.7 Reflection patterns for a woven fabric reinforced PPS laminate with a dominant bundle orientation angle (at the surface) of $\varphi=90^{\circ}$. The incident angle $\theta_{\mathrm{i}}$ was kept constant at $70^{\circ}$, which corresponds to a laser angle $\alpha=20^{\circ}$. Left: Laser spot (hatched ellipse) centered on a weft bundle. Right: Laser spot centered on a resin pool between the bundles.

in Figure 2.6. Secondly, the tape surface roughness results in a more diffuse light reflection from the surface. Moreover, the surface roughness has a slight anisotropic character with small grooves in the direction of the fibers, which enhance the anisotropic reflection behavior of the tape.

The influence of the surface roughness was investigated by performing the same experiment on a flattened tape. It was flattened by tape placing it (welding temperature $T=320{ }^{\circ} \mathrm{C}$, placement velocity $v=50 \mathrm{~mm} / \mathrm{s}$ and applied pressure $\left.P_{\text {app }}=600 \mathrm{kPa}\right)$ onto flat mold covered with a thin $(60 \mu \mathrm{m})$ polyimide film. The tape's surface asperities are then flattened under the application of heat and pressure. Figure $2.5 \mathrm{~d}$ shows that, despite the reduced surface roughness, a circular reflection pattern can still be identified, which indeed demonstrates that a part of the reflection pattern originates from the fibers. The decrease in roughness does, however, seem to increase the intensity of the specularly reflected light. Actually, in both pictures, for a fiber angle $\varphi$ of $0^{\circ}$, the majority of the light is reflected specularly.

Figure 2.7 shows the reflection patterns of the woven fabric reinforced laminate. The dominant bundle orientation at the surface $\varphi$ equaled $90^{\circ}$ for both pictures, as is 
also shown in the small inset in the figure. The surface of the laminate is not only anisotropic, but it is also inhomogeneous, due to the architecture of the woven fabric reinforcement. The left picture in Figure 2.7 shows the reflection pattern when the laser spot is aimed at a weft carbon fiber bundle. The dominant fiber orientation angle in this weft bundle is $\varphi=90^{\circ}$, which corresponds to the Figure 2.6 (right) and explains the reflection pattern. However, as the laser spot size was slightly larger than the bundle itself (see inset in Figure 2.7), the picture also partly shows the circular pattern belonging to an angle $\varphi$ of $0^{\circ}$. Figure 2.7 (right) shows the reflection pattern if the laser is aimed at the space between the weft bundles. The light is reflected in a more specular way and shows less influence of the fibers in the laminate.

\subsubsection{Reflectance of carbon-PPS composites}

The previous sections demonstrated that the carbon-PPS tape and carbon weave reinforced PPS laminate do not transmit the laser light with a wavelength of $\lambda=980 \mathrm{~nm}$. It is therefore valid to write:

$$
A=1-R
$$

with $A$ the absorptance, which is defined as the fraction of incident light absorbed by a specimen, and $R$ the reflectance, which is defined as the fraction of the light reflected $\left(I_{\mathrm{r}} / I_{0}\right)$ from the surface. Equation 2.1 shows that the absorptance follows directly from the reflectance. The latter can be calculated using the Fresnel equations, in the case of specular reflection. The reflectance of s- and p-polarized light yield, respectively [19]:

$$
R_{\mathrm{s}}=\left[\frac{\sin \left(\theta_{\mathrm{i}}-\theta_{\mathrm{t}}\right)}{\sin \left(\theta_{\mathrm{i}}+\theta_{\mathrm{t}}\right)}\right]^{2} \text { and } R_{\mathrm{p}}=\left[\frac{\tan \left(\theta_{\mathrm{i}}-\theta_{\mathrm{t}}\right)}{\tan \left(\theta_{\mathrm{i}}+\theta_{\mathrm{t}}\right)}\right]^{2}
$$

in which the angle of incidence $\theta_{\mathrm{i}}$ is defined as shown in Figure 2.8 (left) and $\theta_{\mathrm{t}}$ follows from Snell's law:

$$
\frac{\sin \theta_{\mathrm{i}}}{\sin \theta_{\mathrm{t}}}=\frac{n_{1}}{n_{2}}
$$

with $n_{i}$ the refractive index of the respective medium. It is assumed that the light is unpolarized, i.e. it contains an equal amount of s- and p-polarized light. The reflectance then yields:

$$
R=\left(R_{\mathrm{p}}+R_{\mathrm{s}}\right) / 2
$$

The reflectance of a surface minimizes when the incident angle approaches zero, 

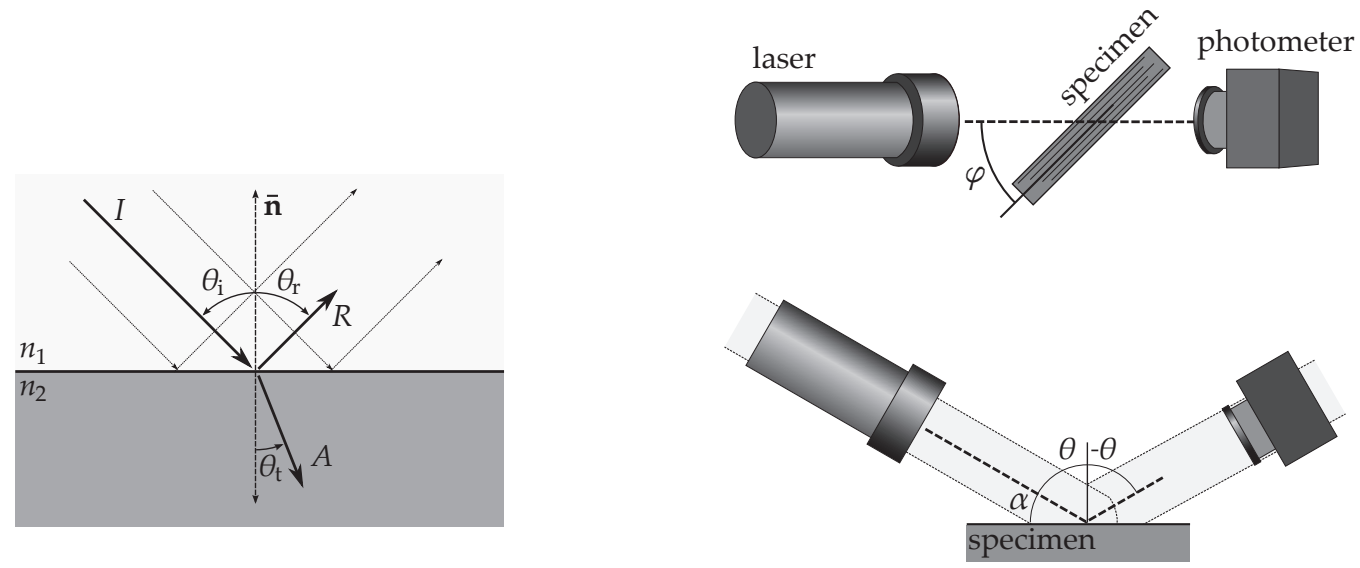

Figure 2.8 Left: Nomenclature for Snell's law and the Fresnel equations. Right: Schematic illustration of the setup to determine the refractive index.

while for grazing incident angles $\left(\theta_{\mathrm{i}} \rightarrow 90^{\circ}\right)$ it approaches unity.

An experimental setup was developed to measure the reflectance, as a function of incident angle $\theta_{\mathrm{i}}$, for the UD carbon PPS tape and the woven fabric carbon reinforced PPS laminate. The setup is schematically shown in Figure 2.8 (right) and comprises two rotating arms with a shared hinge. The laser and the photometer, which were also used earlier, were mounted on the rotating arms. A test specimen was mounted horizontally in the setup ensuring that its surface plane coincided with the arm hinge. The incident angle $\theta_{\mathrm{i}}$ and reflection angle $\theta_{\mathrm{r}}$ were measured using a digital protractor. The intensity of the reflected light $I_{\mathrm{r}}$ was measured using the photometer. The reflectance was obtained for a number of angles $\theta_{\mathrm{i}}$ which varied from $30^{\circ}$ to $85^{\circ}$. The obtained values were fitted to the unpolarized Fresnel equation, which is given in Equations 2.2 to 2.4, to obtain the refractive index $n$ of the specimen.

Figure 2.9 (left) shows the reflectance for the unidirectionally reinforced carbon-PPS tape. The reflectance increases with increasing incident angle $\theta_{\mathrm{i}}$, as is also expected from the Fresnel equations. The fitted refractive index $n_{t}$ is found to overestimate the experimentally obtained reflectance. This is attributed to the fact that, due to the partly circular reflection pattern as shown in Figure 2.5a, not all the light reaches the sensor. The right graph in Figure 2.9 shows the obtained experimental results for the woven fabric reinforced laminate when the laser was aimed at a bundle or a resin pool. Although the differences in the measured reflectance are small, the graph illustrates the inhomogeneous character of the surface of the laminate.

The temperature dependency of the reflectance was investigated experimentally by mounting a small heating element inside the experimental setup. A thin thermocouple was placed on the surface of the specimen. The intensity of the reflected light as well as the specimen surface temperature was monitored, while heating the specimen. Figure 2.10 shows the reflectance of the UD carbon-PPS tape 

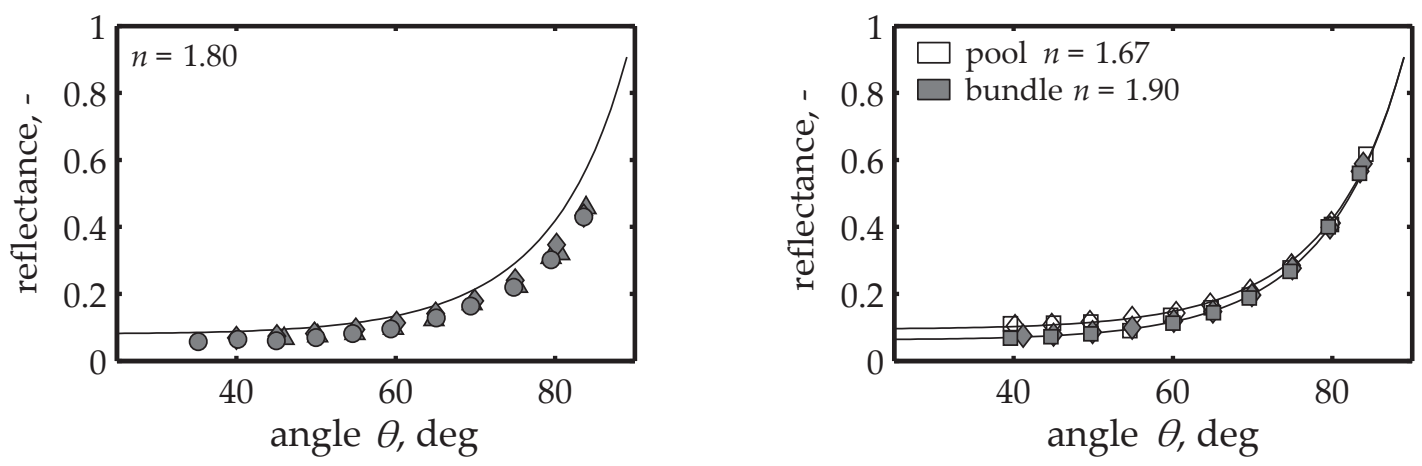

Figure 2.9 Left: Reflectance of a UD reinforced carbon-PPS tape with $\varphi=0^{\circ}$ at room temperature. Right: Reflectance of a woven fabric (CD286) reinforced carbon-PPS laminate with $\varphi=90^{\circ}$ at room temperature. The solid line corresponds to the unpolarized Fresnel equations, while the symbols represent different measurements.

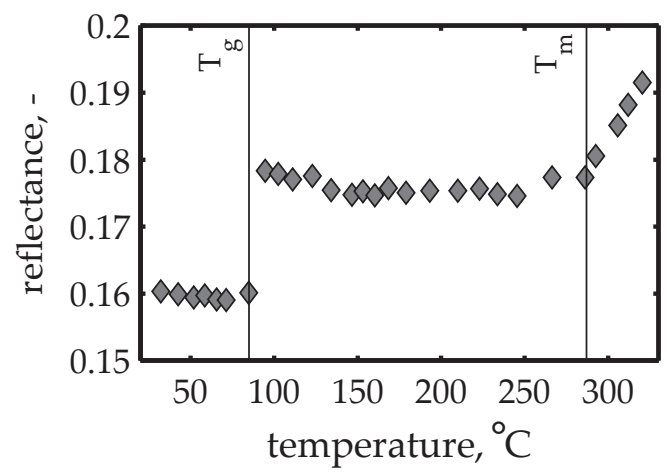

Figure 2.10 Reflectance as a function of temperature for a carbon-PPS tape for a fixed incident angle $\theta_{\mathrm{i}}$ of $66^{\circ}$ and a fiber orientation angle $\varphi=0^{\circ}$.

as a function of the temperature. Although an increase of the reflectance can be seen at the glass transition $T_{\mathrm{g}}$ as well as the melt temperature $T_{\mathrm{m}}$ of the PPS matrix, the effect on the reflectance is negligible. The refractive index $n$ is therefore considered as temperature independent in the current work.

\subsection{Optical process model}

The current section proposes an optical model for the laser-assisted tape placement process. The optical model is part of a larger process tool, which was schematically illustrated in Figure 2.2. It accounts for the reflection of light in the nip-point region and aims to determine the incident laser heat flux distribution on the tape and the laminate surface. Subsequently, the thermal submodel calculates the temperature distribution in the tape and the laminate. The thermal model is elaborated in the next chapter. The combined optical and thermal model will be validated experimentally 
there, by comparing the calculated and the measured tape and laminate surface temperature distribution.

\subsubsection{Modeling assumptions}

The simplifying assumptions for the optical model are formulated based on the observed optical phenomena discussed earlier. The optical transparency of the tape and laminate was found to reduce to zero, due to the reinforcing carbon fibers. As the transmittance of the carbon-PPS composites is negligible, it is assumed that all the incident light will either be reflected or absorbed, that is Equation 2.1 holds.

The reflection patterns in Figure 2.5 and 2.7 demonstrated that the carbon reinforced PPS shows anisotropic and, for the weave reinforced laminate, inhomogeneous laser light reflection. The fiber orientation of the UD reinforced tape with respect to the laser direction equals zero (i.e. $\varphi=0$ ) for the intended application, in which the tapes are welded onto the woven fabric reinforced laminates. A large part of the light is in this case reflected specularly, as shown in Figure 2.5a. This also holds for the woven fabric reinforced laminates. Therefore, it is assumed that all light reflects according to the law of reflection, i.e. the incident angle $\theta_{\mathrm{i}}$ equals the reflection angle $\theta_{\mathrm{r}}$. Consequently, the reflections are assumed to take place in the two-dimensional plane shown in Figure 2.1 (right). Moreover, the reflectance can be described using the Fresnel equations and Snell's law.

\subsubsection{Modeling approach}

Figure 2.11 shows the nip-point geometry under consideration. It consists of a laminate, a tape conforming to the compaction roller and the laser beam. The laser angle $\alpha$ is defined as the angle between the laminate and laser beam. For the LATP equipment used here, the laser is mounted at a fixed point and the angle $\alpha$ governs the light distribution between the tape and the laminate. Although the geometry of

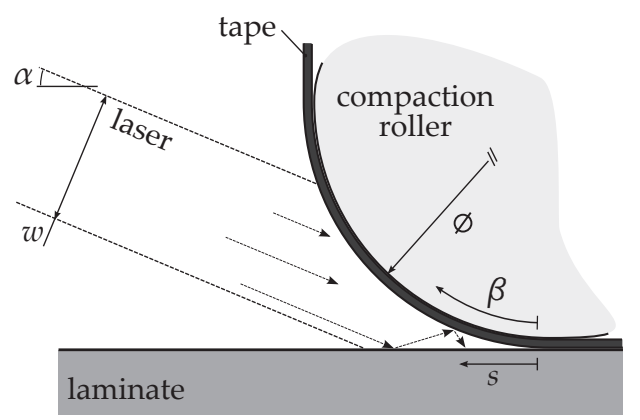

Figure 2.11 Schematic illustration of the nip-point geometry for the optical model. 




$\delta_{\mathrm{t}}=52 \mathrm{~mm}, \delta_{1}=35 \mathrm{~mm}$

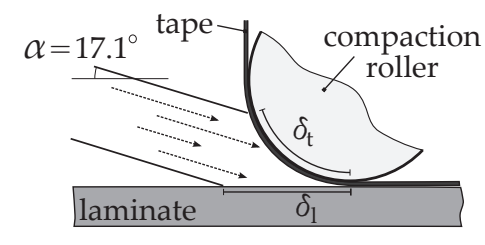

$\delta_{\mathrm{t}}=44 \mathrm{~mm}, \delta_{1}=48 \mathrm{~mm}$

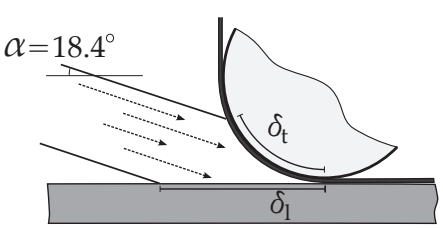

$\delta_{\mathrm{t}}=41 \mathrm{~mm}, \delta_{1}=58 \mathrm{~mm}$

Figure 2.12 Influence of the laser angle $\alpha$ on the light distribution between tape and laminate.

the nip-point seems to ensure the complete absorption of light by the tape and the laminate, a detailed calculation is necessary to predict the actual spatial distribution of the incident heat flux. For this purpose, a ray-tracing procedure is applied to calculate this for a given laser angle and the refractive indexes of the tape and laminate.

The laser system, used in the present work, employs optics to focus the beam into a rectangular shape. The intensity decreases rapidly near the edges of the beam and it was assumed constant over its width in the present analysis. The beam is represented by a large number (typically more than $10^{3}$ ) of rays. The rays are generated over the laser beam width $w$ at the laser source location. Subsequently, each ray is advanced until it encounters either the tape or the laminate. The Fresnel equations, i.e. Equations 2.2 to 2.4, are then applied to calculate the intensity of the reflected light, while the intensity of the absorbed light follows from Equation 2.1. The procedure is then repeated for the reflected ray until it either leaves the optical domain or when its remaining intensity drops below a certain threshold value. The spatial distribution of the incident heat flux is then determined using the intensities and incident angles for each ray. The laminate and tape length are discretized into a number of segments. The contribution of every ray to each segment is then summed to finally yield the incident flux distribution.

A convergence study was performed to determine the minimum amount of rays required to represent the laser source. A total of 5000 rays was found sufficient in the present analysis. The path calculation for a ray was stopped when its intensity dropped below $0.5 \%$ of its initial value.

Table 2.1 Parameters for the optical model.

\begin{tabular}{lccc}
\hline Description & Symbol & Unit & Value \\
\hline Laser beam width & $\mathrm{w}$ & $\mathrm{mm}$ & 28 \\
Roller diameter & $\varnothing$ & $\mathrm{mm}$ & 68 \\
Laminate refractive index & $n_{\mathrm{l}}$ & - & 1.8 \\
Tape refractive index & $n_{\mathrm{t}}$ & - & 1.8 \\
Number of rays & $N_{\mathrm{R}}$ & - & 5000 \\
\hline
\end{tabular}




\subsubsection{Modeling results}

The LATP equipment, briefly introduced in Section 2.3.1, allows variation of the incident laser angle $\alpha$, which governs the distribution of the laser power between the tape and the laminate. Figure 2.12 schematically illustrates this for the three different cases, i.e. $\alpha=15.4,17.1$ and $18.4^{\circ}$, investigated in the present work. These are the angles used in the experimental validation of the combined optical-thermal model, which is presented in the next chapter. The equipment is fitted with a flexible compaction roller which deforms under the applied loading. As the ray-tracing procedure considers the roller as a perfect cylinder, this was incorporated by using a slightly smaller radius obtained from a picture of the deformed roller. Table 2.1 lists the relevant geometrical and material property data. The current chapter focuses on the effect of the laser angle on the incident heat flux on the laminate and the
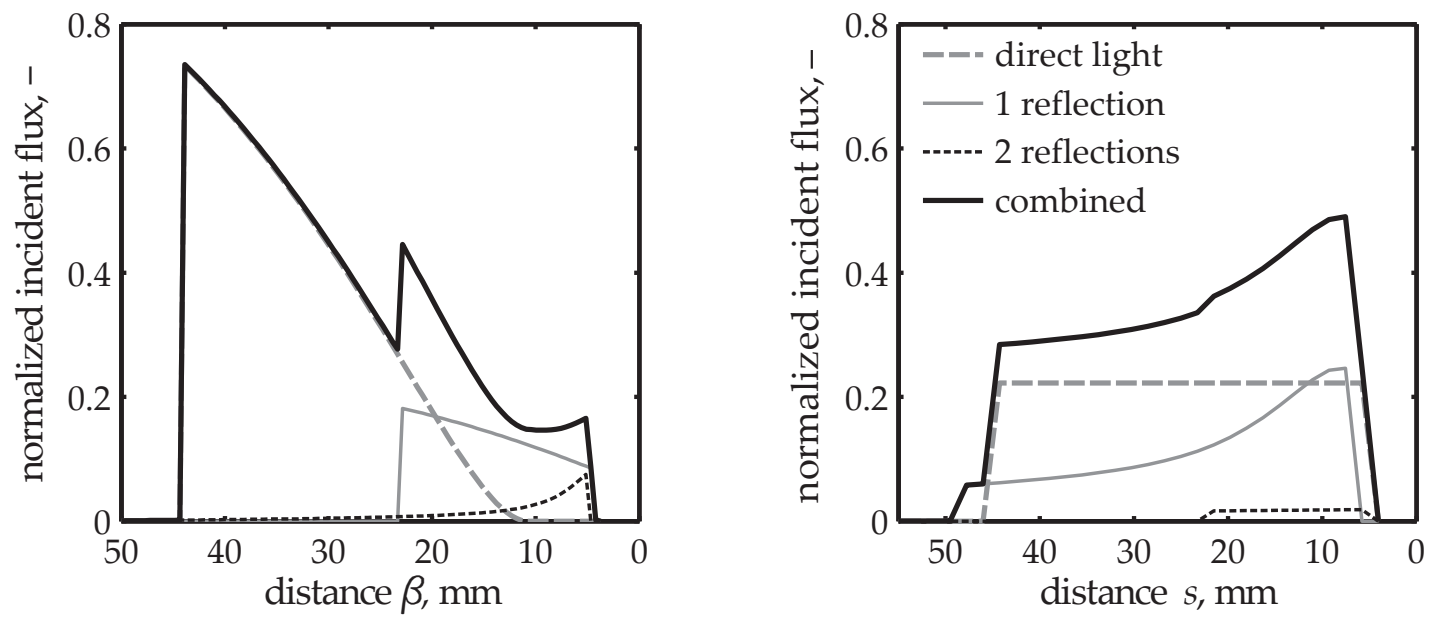

Figure 2.13 Incident heat flux distribution for a laser angle $\alpha=17.1^{\circ}$. Left: Tape surface. Right: Laminate surface. The distance from the nip-point ( $\beta$ and $s$ ) is defined in Figure 2.11.
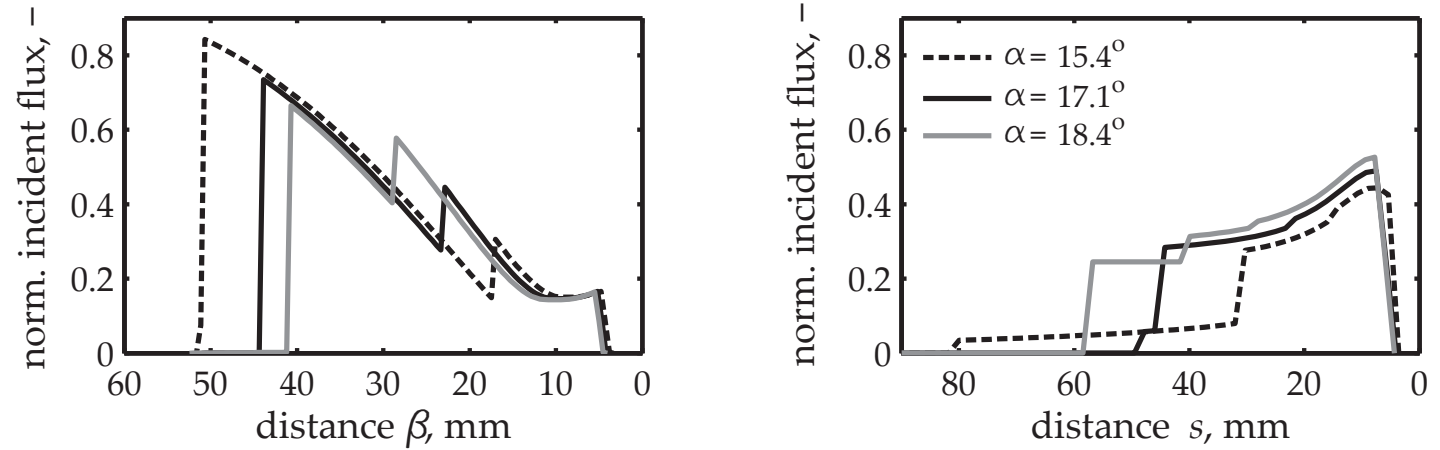

Figure 2.14 Incident heat flux distribution for a varying laser angle $\alpha$. Left: Tape surface. Right: Laminate surface. The distance from the nip-point ( $\beta$ and $s$ ) is defined in Figure 2.11. 
tape, while the next chapter discusses the effect on tape and laminate temperature distribution.

Figure 2.13 shows the incident heat flux distribution on the tape and the laminate surface for an incident angle $\alpha$ of $17.1^{\circ}$ versus the distance ( $\beta$ for the tape, $s$ for the laminate) from the nip-point. The graphs illustrate the contribution of the light that comes directly from the laser source as well as the light which has reflected from the tape or laminate surfaces. The intensity of the light proves to be negligible after just two reflections. Both graphs show that, with the current configuration, no light is able to penetrate deeply into the nip-point. The incident flux distribution on the laminate decreases rapidly near the nip-point due to the shadowing effect of the roller, while the tape influx decreases as the tape bends away from the source, thereby increasing the angle of incidence.

The influence of the laser angle $\alpha$ is shown in Figure 2.14, which depicts the total incident heat flux on the tape and the laminate for the three aforementioned laser angles. As Figure 2.12 demonstrated, the angle $\alpha$ governs the light distribution between tape and laminate. This is also shown in the incident heat flux distribution. Figure 2.14 (left) shows that with the increasing angle the heated tape length $\beta$ decreases, while Figure 2.14 (right) shows that the heated laminate length $s$ increases.

The calculated incident heat flux will be used in a thermal model to predict the tape and laminate temperature distribution. The presented optical model cannot be validated directly. Instead, it will be validated indirectly, in Chapter 3, by comparing the simulated and measured temperature distribution.

\subsection{Conclusions}

Qualitative experiments were performed to determine the optical phenomena governing the laser-assisted tape placement of local reinforcements onto woven fabric reinforced laminates. The materials considered were UD carbon-PPS tapes and 5 harness satin woven fabric reinforced PPS laminates. The tape and laminate were found to be optically non-transparent for the laser, having a wavelength of $980 \mathrm{~nm}$, used in this work. The carbon fibers were responsible for the absorption of the light. The reflection behavior of these composites was found to be anisotropic and, for the laminate, inhomogeneous. Nevertheless, the majority of the incident light was reflected specularly, i.e. the angle of reflection equaled the angle of incidence. The refractive indexes for the tape and the laminate were determined experimentally and can be used to determine the reflectance as a function of incident angle.

A ray-tracing model, based on the Fresnel equations, for the LATP process was implemented. The model accounts for the reflection of laser light in the nip-point region and determines the spatial incident heat flux distribution on the tape and the laminate. Subsequently, this distribution can be used in a thermal model, such as presented in the next chapter, to determine the temperature distribution. 


\section{References}

[1] M. Steyer, M. Dubratz, A. Schütte, C. Wenzel, and C. Brecher. Laser-assisted thermoplastic tape-laying systems. JEC Composites Magazine, 47:39-41, 2009.

[2] R. Schledjewski. Thermoplastic tape placement - in situ consolidation is reachable. Plastics, Rubber and Composites, 38(9-10):379-386, 2009.

[3] W. R. Curry. Flat thermoplastic tape laying. In 2nd ASM Conference on Advanced Composites. Dearborn, Michigan, USA, pages 45-50, 1986.

[4] V. Agarwal, S. I. Güçeri, R. L. McCullough, and J. M. Schultz. Thermal characterization of the laser-assisted consolidation process. Journal of Thermoplastic Composite Materials, 5(2):115-135, 1992.

[5] Y. M. P. Toso, P. Ermanni, and D. Poulikakos. Thermal phenomena in fiber-reinforced thermoplastic tape winding process: Computational simulations and experimental validations. Journal of Composite Materials, 38(2):107-135, 2004.

[6] F. O. Sonmez and H. T. Hahn. Modeling of heat transfer and crystallization in thermoplastic composite tape placement process. Journal of Thermoplastic Composite Materials, 10(3):198-240, 1997.

[7] R. Schledjewski and M. Latrille. Processing of unidirectional fiber reinforced tapes fundamentals on the way to a process simulation tool (ProSimFRT). Composites Science and Technology, 63(14):2111-2118, 2003.

[8] M. A. Lamontia, S. B. Funck, M. B. Gruber, R. D. Cope, B. J. Waibel, and N. M. Gopez. Manufacturing flat and cylindrical laminates and built up structure using automated thermoplastic tape laying, fiber placement, and filament winding. Sampe Journal, 39(2):44-47, 2003.

[9] E. P. Beyeler and S. I. Güçeri. Thermal analysis of laser-assisted thermoplastic-matrix composite tape consolidation. Journal of Heat Transfer, 110(2):424-430, 1988.

[10] S. M. Grove. Thermal modelling of tape laying with continuous carbon fibre-reinforced thermoplastic. Composites, 19(5):367-375, 1988.

[11] L. J. Bastien and J. W. Gillespie Jr. A non-isothermal healing model for strength and toughness of fusion bonded joints of amorphous thermoplastics. Polymer Engineering and Science, 31(24):1720-1730, 1991.

[12] F. Yang and R. Pitchumani. Nonisothermal healing and interlaminar bond strength evolution during thermoplastic matrix composites processing. Polymer Composites, 24(2):263-278, 2003.

[13] F. O. Sonmez and H. T. Hahn. Analysis of process-induced residual stresses in tape placement. Journal of Thermoplastic Composite Materials, 15(6):525-544, 2002.

[14] H. Lü, M. Schlottermüller, N. Himmel, and R. Schledjewski. Effects of tape tension on residual stress in thermoplastic composite filament winding. Journal of Thermoplastic Composite Materials, 18(6):469-487, 2005.

[15] X. Guan and R. Pitchumani. Modeling of spherulitic crystallization in thermoplastic tow-placement process: Heat transfer analysis. Composites Science and Technology, 64(9):1123-1134, 2004.

[16] M. Troughton. Handbook of Plastics Joining. William Andrew Inc., 2008.

[17] P. Jaeschke, D. Herzog, H. Haferkamp, C. Peters, and A. S. Herrmann. Laser 
transmission welding of high-performance polymers and reinforced composites - a fundamental study. Journal of Reinforced Plastics and Composites, 29(20):3083-3094, 2010.

[18] W. J. B. Grouve, L. L. Warnet, B. Rietman, and R. Akkerman. On the weld strength of in situ tape placed reinforcements on weave reinforced structures. Accepted for publication in Composites Part A, 2012.

[19] P. R. Norton. Handbook of Optics, chapter 5. McGraw-Hill, Inc., 1995. 



\title{
CHAPTER 3
}

\section{Thermal model for the laser-assisted tape placement process ${ }^{1}$}

\begin{abstract}
The process window for in situ consolidation is often very narrow for the laser-assisted tape placement process. A process design tool, comprising an optical and a thermal model, was developed to help optimize the processing parameters. The present chapter focuses on the thermal model while the optical model was treated in the previous chapter. A one-dimensional heat transfer model is presented to study the effect of material properties and processing parameters on the temperature distribution. The combined optical and thermal model was validated experimentally. The model overestimates the laminate temperature, while the tape temperature distribution is accurately simulated.
\end{abstract}

\footnotetext{
${ }^{1}$ Reproduced from: W.J.B. Grouve, L.L. Warnet, B. Rietman, R. Akkerman. An optical-thermal process model for the laser-assisted tape placement process. In preparation for: Composites, Science and Technology.
} 


\subsection{Introduction}

The laser-assisted tape placement (LATP) process is a highly automated production process for thermoplastic composite structures. Its high degree of automation and out-of-autoclave potential makes the process attractive for the aerospace and automotive industries [1,2]. The process, shown in Figure 3.1, comprises the automated lay-up and consolidation of pre-impregnated fiber reinforced thermoplastic tapes to incrementally shape a composite structure [3,4]. The major advantages of the application of laser heating for tape placement are the high input energy and the short response time [1]. The former allows high production rates, while the latter provides the ability to shape complicated geometries involving large variations in input power.

The present work is part of a larger framework which aims to utilize the LATP technology as a post-processing step to tailor the mechanical properties of pressformed woven fabric reinforced products. Unidirectionally (UD) reinforced tapes are locally welded onto the woven fabric reinforced component, thereby enhancing its strength and stiffness, while keeping the weight low. This strategy combines the high drapeability and impact resistance of the woven fabric reinforced laminates with the high strength and stiffness of the UD reinforced tapes. Ideally, the tapes should be welded in situ, that is without an expensive consolidation step in an autoclave, to make the process economically attractive. The process window for in situ consolidation, however, is narrow [4] and process optimization often relies on trial-and-error procedures involving extensive material inspection. Within the larger framework, a process design tool is being developed to help accelerate this optimization procedure. The general layout of the process tool was outlined in the previous chapter (see Figure 2.2). The foundation is formed by an optical and a thermal model. The optical model accounts for the reflection of laser light in the nippoint region and determines the incident heat flux distribution. Subsequently, this is used to calculate the temperature distribution in the tape and the laminate during the placement process.
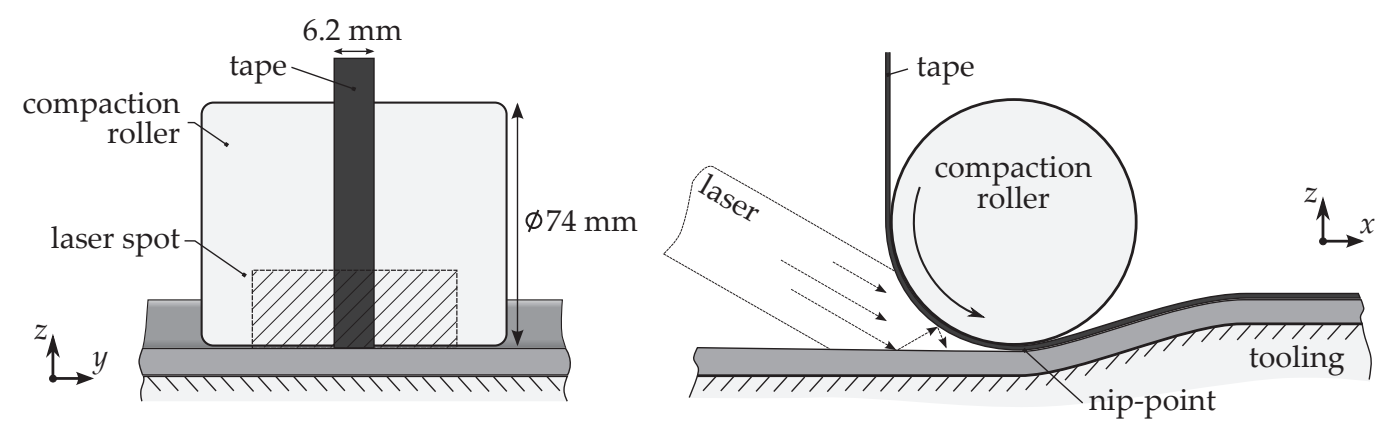

Figure 3.1 Illustration of the laser-assisted tape placement process. Left: Front view. Right: Side view. 
The current chapter focuses on the thermal part and proposes a modeling approach to calculate the temperature distribution in the tape and the laminate. Moreover, tape placement experiments were performed to validate the combined optical and thermal model. For this purpose, unidirectionally carbon reinforced poly(phenylene sulfide) (PPS) tapes were welded onto carbon woven fabric reinforced PPS laminates using an industrial laser-assisted tape placement machine. A thermal camera, mounted on the tape placement head, recorded the tape and laminate temperature distribution before they meet in the nip-point. The calculated and measured temperature distribution are then compared and the validity of the chosen approach is discussed.

The next section introduces the thermal model. First, the simplifying assumptions are discussed, followed by an elaboration of the governing equations and computational implementation. Subsequently, the experimental work and temperature measurements are presented. Section 3.4 compares the measured and simulated temperature distribution to validate the combined optical and thermal model. The last section presents the conclusions and the recommendations for future work.

\subsection{Thermal model}

The tape and laminate are heated by the laser before they meet in the nip-point. The heat is transported under the compaction roller, where the two are bonded under the applied pressure. The interfacial thermal history is important in this context, as it governs the interfacial bonding process $[5,6]$. During the process, heat conduction takes place in the tape and the laminate, while the surfaces are subjected to free convection and radiation. Moreover, the tape is guided along the compaction roller which acts as a heat sink, which is also the case for the tooling supporting the laminate. All these thermal phenomena should be incorporated in a model to accurately calculate the interfacial thermal history.

Several thermal models have been developed for the tape placement process for thermoplastic composites. These range from complex three-dimensional transient finite element models [7, 8] to simpler one-dimensional [9] or two-dimensional $[10,11]$ steady-state approaches. The current work presents a one-dimensional modeling approach, which takes into account all dominant thermal mechanisms. The simplicity of the model allows for a fast solution procedure, which makes the model attractive as an optimization tool.

\subsubsection{Modeling assumptions}

Fiber reinforced composites are inhomogeneous materials by definition. The thermal properties of their constituents, i.e. the fiber and matrix, may differ considerably. Especially the thermal conductivity can differ by two orders of magnitude. The 
present work, however, assumes that this inhomogeneous character is constrained to the microscopic scale and that the materials can be represented as anisotropic but homogeneous. The matrix material in the composites can be semi-crystalline. The heat generation due to crystallization and melting, however, is not included in the model, as it is negligible relative to the external heat input $[12,13]$.

Figure 3.1 showed the layout of the tape placement process as used in the present work. The figure illustrates that the width of the laser spot is large compared to the width of the tape. Therefore, the temperature is assumed uniform over the complete tape width and the laminate under the tape. The thermal problem is reduced to the two-dimensional plane illustrated in Figure 3.1 (right). The time scale $\tau_{\mathrm{c}}$ for conduction (in the placement direction) can be estimated by [14, 15]:

$$
\tau_{\mathrm{c}}=\frac{l^{2}}{\kappa}
$$

in which $l$ is an appropriate length scale and $\kappa$ is the thermal diffusivity which is defined as:

$$
\kappa=\frac{k_{x}}{\rho c_{p}}
$$

with $k_{x}$ the thermal conductivity in fiber direction and $\rho c_{p}$ the volumetric heat capacity. The thermal conductivity in fiber direction of the unidirectionally carbon reinforced PPS is taken as $5 \mathrm{~W} /(\mathrm{m} \mathrm{K})$ [14] to provide an upper-bound estimation. The values for $c_{p}$ and $\rho$ are listed in Table 3.2. The thermal diffusivity equals approximately $\kappa \approx 3 \cdot 10^{-6} \mathrm{~m}^{2} / \mathrm{s}$ using these values. Taking the arbitrary length scale as $l=1 \mathrm{~mm}$, a conduction time scale of $\tau_{\mathrm{c}} \approx 0.3 \mathrm{~s}$ is found. As the placement velocity can exceed $200 \mathrm{~mm} / \mathrm{s}$, as shown in an experimental optimization study [16] (see Appendix A), the laser heat source will have moved $60 \mathrm{~mm}$ within this typical conduction time; this is significantly larger than the arbitrary length scale $l$ for conduction. The heat conduction rate is thus much smaller than the rate at which the laser moves. Consequently, the in-plane conduction is considered negligible, as was also assumed in earlier studies [9, 17]. The through-thickness heat conduction and surface boundary conditions dominate the thermal problem.

\subsubsection{Modeling approach}

Figure 3.2 shows that the tape placement problem is subdivided into four different domains: 1 . incoming tape, 2 . incoming laminate, 3 . consolidated laminate under the compaction roller and 4. consolidated laminate after the compaction roller. Although the tape and laminate are, strictly speaking, not yet completely bonded under the compaction roller, they are treated as such in the present analysis. Alternatively, a 
thermal contact resistance could be applied which evolves as the intimate contact between tape and laminate develops [18].

\section{Energy balance}

A one-dimensional Lagrangian approach was adopted to describe the thermal problem, similar to Tierney and Gillespie [9], in which a through-thickness slice of material (tape, laminate or consolidated laminate) is followed in time. The temperature distribution is described by the one-dimensional energy balance as [15]:

$$
\rho c_{p} \frac{\partial T}{\partial t}=k_{z} \frac{\partial^{2} T}{\partial z^{2}}
$$

in which $\rho$ is the density, $c_{p}$ the specific heat and $k_{z}$ the through-thickness thermal conductivity.

\section{Boundary and initial conditions}

The contact between the domain and the compaction roller or steel tooling is represented by a convective boundary condition using an effective heat transfer coefficient. The boundary condition for all surfaces can then be summarized as follows:

$$
q_{z}^{\prime \prime}(t)=k_{z} \frac{\partial T}{\partial z}=-\overbrace{h\left(T-T_{\infty}\right)}^{\text {convection }}-\overbrace{\epsilon \sigma\left(T^{4}-T_{\infty}^{4}\right)}^{\text {radiation }}+\overbrace{Q(t)}^{\text {laser }},
$$

in which $q_{z}^{\prime \prime}(t)$ is the heat flux, $h$ is an effective convective heat transfer coefficient, $T_{\infty}$ the far field temperature, $\epsilon$ is the emissivity of the surface, $\sigma$ is the Boltzmann

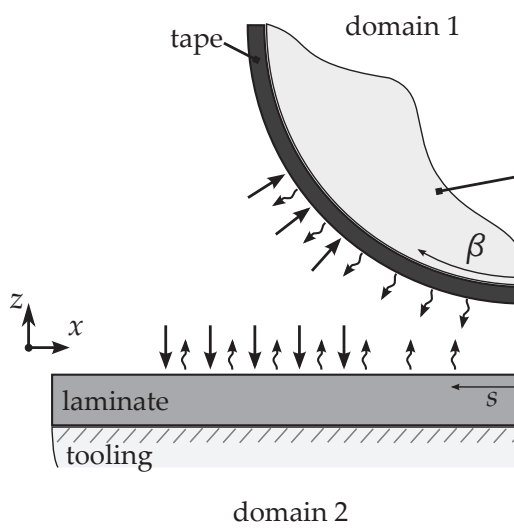

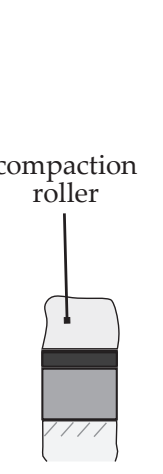

domain 3
$\{$ convection and radiation

$\downarrow$ laser influx $\mathrm{Q}(\mathrm{t})$

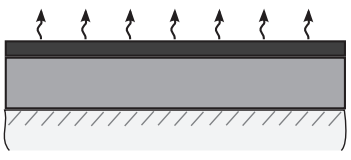

domain 4

Figure 3.2 The thermal model comprises four domains. 
constant and $Q(t)$ the incident heat flux due to the laser light. Table 3.1 summarizes which of the boundary conditions is applied on each domain. The initial conditions and boundary conditions are now briefly introduced:

Domain 1 The bottom surface of the incoming tape is heated by the laser, while the upper side conforms to the compaction roller. The boundary between the tape and the roller is treated as a convection boundary condition employing an effective heat transfer coefficient $h_{\mathrm{r}}$. At the bottom surface, the laser light is incorporated as a heat flux boundary condition with a value $Q_{t}(t)$ which follows from the ray-tracing procedure, outlined in the previous section. The heat loss through convection in air and radiation is also taken into account, using a heat transfer coefficient $h_{\mathrm{a}}$ and an emissivity $\epsilon$. Initially, the tape temperature is constant and uniform at a value $T_{0}$, which is assumed to equal the ambient temperature.

Domain 2 The top surface of the laminate is subjected to the laser heat flux $Q_{1}(t)$. Again, the heat loss through convection is accounted for using an effective heat transfer coefficient $h_{\mathrm{a}}$, while heat loss through radiation is also considered here. The steel mold supporting the laminate is represented by a convection boundary condition with $h_{\mathrm{m}}$ as the effective heat transfer coefficient. The influence of heated tooling can be accounted for by setting $T_{\infty}$ to the tool temperature. The laminate's initial temperature $T_{0}$ is assumed to equal the ambient temperature.

Domain 3 The tape and laminate are coupled, that is $T_{\mathrm{t}}=T_{1}$ and $q_{\mathrm{t}}^{\prime \prime}=q_{1}^{\prime \prime}$ at the interface, after they are brought into contact at the nip-point. The initial temperature distribution follows from the analysis of tape and the laminate, i.e. domain 1 and 2, respectively. The top surface of the consolidated laminate is in contact with the compaction roller while the bottom lies on the steel tooling. The heat loss through these surfaces is again taken into account using the effective heat transfer coefficients $h_{\mathrm{r}}$ and $h_{\mathrm{m}}$ for the roller and tooling, respectively.

Domain 4 The last domain comprises the consolidated laminate downstream of the compaction roller. Upon entering this domain, the contact with the compaction roller is lost, effectively changing the convective heat transfer

Table 3.1 Summary of the thermal boundary conditions on the domains.

\begin{tabular}{lcccccccc}
\hline & \multicolumn{2}{c}{ Domain 1 } & \multicolumn{2}{c}{ Domain 2 } & \multicolumn{2}{c}{ Domain 3 } & \multicolumn{2}{c}{ Domain 4 } \\
& Top & Bottom & Top & Bottom & Top & Bottom & Top & Bottom \\
\hline Convection & $\mathrm{x}$ & $\mathrm{x}$ & $\mathrm{x}$ & $\mathrm{x}$ & $\mathrm{x}$ & $\mathrm{x}$ & $\mathrm{x}$ & $\mathrm{x}$ \\
Radiation & & $\mathrm{x}$ & $\mathrm{x}$ & & & & $\mathrm{x}$ & \\
Laser & & $\mathrm{x}$ & $\mathrm{x}$ & & & & & \\
\hline
\end{tabular}


coefficient. Furthermore, the heat loss through radiation is taken into account. The initial temperature distribution follows from the preceding analysis of the third domain.

\subsubsection{Computational implementation}

The one-dimensional energy balance, Equation 3.3, is discretized in space and time and subsequently solved to obtain the through-thickness temperature distribution. A pseudospectral, or collocation, method was applied to discretize the equation in space. The advantage of this approach is that high temperature gradients can be described with relatively few collocation points. The through-thickness temperature distribution is approximated by an $N^{\text {th }}$ order polynomial:

$$
T(z)=\sum_{i=0}^{N} T_{i} L_{i}(z),
$$

in which $T_{i}$ is the temperature at collocation point $i$ and $L_{i}(z)$ is a Lagrange polynomial defined as:

$$
L_{i}(z)=\prod_{j=0, j \neq i}^{N} \frac{z-z_{j}}{z_{i}-z_{j}} .
$$

The location of the collocation points $z_{i}$ is determined from the Chebyshev-GaussLobatto points, which are defined as follows:

$$
\xi_{i}=\cos \left(\frac{i}{N} \pi\right), \quad i=0 \ldots N
$$

A linear transformation is then applied to obtain the node locations $z_{i}$ on an arbitrary interval $[a, b]$ :

$$
z_{i}=\frac{b-a}{2} \xi_{i}+\frac{a+b}{2}
$$

The second order spatial derivative of the $i^{\text {th }}$ collocation point $T_{i}^{\prime \prime}$ yields:

$$
T_{i}^{\prime \prime}=\sum_{i=0}^{N} L_{i}^{\prime \prime}\left(z_{i}\right) T_{i}
$$

where $L_{i}^{\prime \prime}$ is the second derivative of the Lagrangian polynomial with respect to $z$. 
The second spatial derivative of the temperature $\mathbf{T}^{\prime \prime}$ at the collocation points yields:

$$
\left\{\mathbf{T}^{\prime \prime}\right\}=\left[\mathbf{D}^{2}\right]\{\mathbf{T}\}
$$

in which $\left[\mathbf{D}^{2}\right]$ is the Chebyshev second-derivative matrix and $\{\mathbf{T}\}$ the temperature at the collocation points. The Chebyshev collocation second-derivative matrix can be found in literature concerning spectral methods [19]. A backward Euler method is applied for the temporal discretization:

$$
\frac{\partial T_{i}}{\partial t} \approx \frac{T_{i}^{p}-T_{i}^{p-1}}{\Delta t}
$$

where the superscripts $p$ and $p-1$ denote the temperature at a collocation point at time $t_{p}$ and $t_{p-1}$, respectively. Substitution in the partial differential equation for the energy balance, Equation 3.3, yields:

$$
\frac{\left\{\mathbf{T}^{p}\right\}-\left\{\mathbf{T}^{p-1}\right\}}{\Delta t}=\frac{k_{z}}{\rho c_{p}}\left[\mathbf{D}^{2}\right]\left\{\mathbf{T}^{p}\right\} .
$$

Rearranging finally gives:

$$
\left[\mathbf{I}-\frac{\Delta t k_{z}}{\rho c_{p}}\left[\mathbf{D}^{2}\right]\right]\left\{\mathbf{T}^{p}\right\}=[\mathbf{K}]\left\{\mathbf{T}^{p}\right\}=\left\{\mathbf{T}^{p-1}\right\},
$$

in which I represents the identity matrix. The radiative heat flux at the boundaries is estimated using the temperature distribution of the preceding time step, which simplifies the system of equations considerably. The system matrix $\mathbf{K}$ was then rewritten to incorporate the boundary conditions.

Several numerical simulations were performed to determine the required number of collocation points and the minimum time step size in order to ensure the validity of the solution. The number of collocation points in the tape $N_{t}$ was chosen as 16, while the laminate temperature field was represented by $N_{1}=32$ points. The time step $\Delta t$ size was chosen as $50 \mu \mathrm{s}$, which was found to be sufficiently small for the present analysis. The combined optical and thermal model was implemented in a user-friendly application in Matlab. A complete simulation, which includes the optical and thermal analysis, takes less than 1.5 seconds on a standard laptop $(2.5 \mathrm{GHz}$ quad-core) using the aforementioned settings.

\subsection{Experimental work}

Laser-assisted tape placement experiments were performed to validate the combined optical and thermal model. The present section first introduces the materials and 
equipment used, followed by a description of the experimental procedure. Finally, the experimental results are presented.

\subsubsection{Materials and equipment}

A laser-assisted tape placement machine was used to weld UD carbon reinforced PPS tapes onto carbon woven fabric reinforced PPS laminates. The tape was produced by Suprem and has a fiber volume fraction of $55 \pm 3 \%$ and a thickness of $0.15 \mathrm{~mm}$. The woven fabric reinforced laminates were manufactured by Ten Cate. The laminates comprised eight plies of quasi-isotropically stacked pre-impregnated 5 harness satin woven fabric carbon (known as CD286) reinforced PPS. The nominal laminate fiber volume fraction and thickness are $50 \%$ and $2.4 \mathrm{~mm}$, respectively.

The laser-assisted tape placement equipment was provided by AFPT GmbH and comprises a robot on which a tape placement head is mounted. The head consists of an air-cooled flexible compaction roller, optics for the laser and space for six spools of fiber reinforced thermoplastic tape. The roller is optically transparent for the laser light and has a radius of nominally $37 \mathrm{~mm}$. The laser light has a wavelength of $\lambda=980 \mathrm{~nm}$ and is guided to the tape placement head using an optical fiber. The system uses optics to focus the beam in a rectangular shape with a more or less uniform intensity which decreases rapidly near the edges.

\subsubsection{Tape placement experiments}

The equipment was used to weld the UD reinforced tapes onto the woven fabric reinforced laminates. The tape and laminate surface temperature were recorded using a thermal camera (Xenics, Gobi 384) mounted on the tape placement head. The LATP equipment allowed the variation of three process parameters, i.e. the placement velocity $v$, the laser power $P$ and the incident laser angle $\alpha$. As the laser is mounted at a fixed point on the tape placement heat, the laser angle governs the distribution of the power between the tape and the laminate. The placement velocity was varied between 75, 100 and $125 \mathrm{~mm} / \mathrm{s}$, while the laser power was chosen as 1300, 1500 or $1700 \mathrm{~W}$. The effect of the laser angle was discussed in the previous chapter. At lower angles the majority of energy is supplied to the tape, while at higher angles more energy is supplied to the laminate. The laser angle was varied between 15.4, 17.1 and $18.4^{\circ}$ (see Figure 2.12).

\subsubsection{Experimental results}

Figure 3.3 shows the tape and laminate surface temperature distribution for different placement velocities $v$ and laser angles $\alpha$, while the laser power was kept constant at 


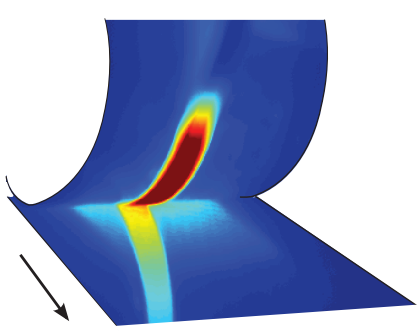

$v=75 \mathrm{~mm} / \mathrm{s}$

$\alpha=15.4^{\circ}$

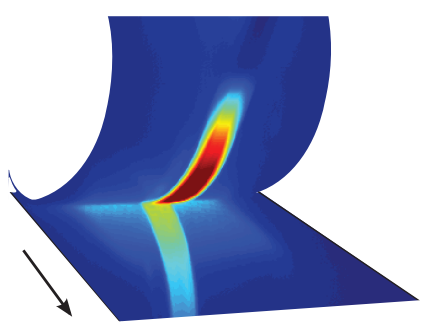

$v=100 \mathrm{~mm} / \mathrm{s}$ $\alpha=15.4^{\circ}$

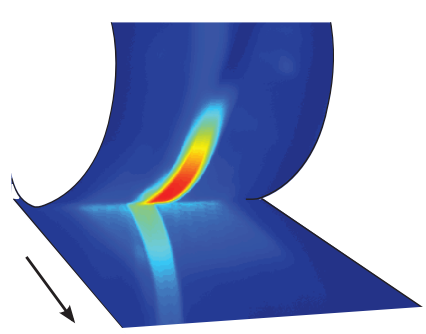

$v=125 \mathrm{~mm} / \mathrm{s}$ $\alpha=15.4^{\circ}$

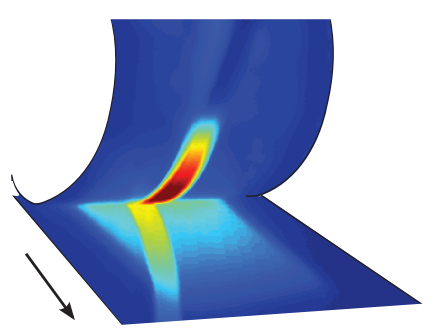

$v=75 \mathrm{~mm} / \mathrm{s}$

$\alpha=17.1^{\circ}$

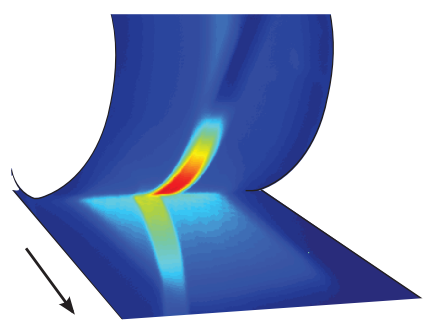

$v=100 \mathrm{~mm} / \mathrm{s}$

$\alpha=17.1^{\circ}$

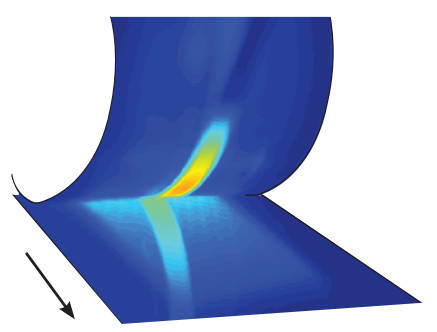

$v=125 \mathrm{~mm} / \mathrm{s}$

$\alpha=17.1^{\circ}$

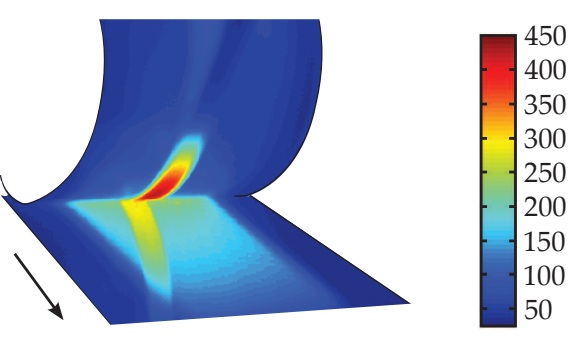

$v=75 \mathrm{~mm} / \mathrm{s}$

$\alpha=18.4^{\circ}$

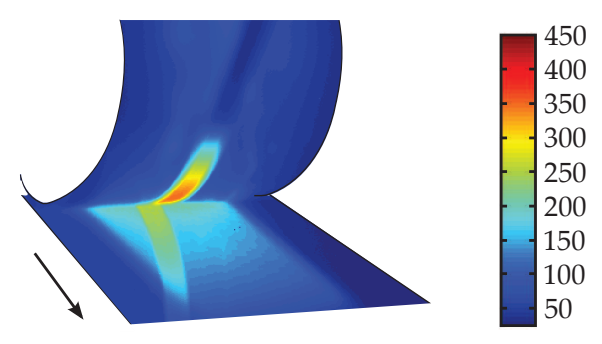

$v=100 \mathrm{~mm} / \mathrm{s}$

$\alpha=18.4^{\circ}$

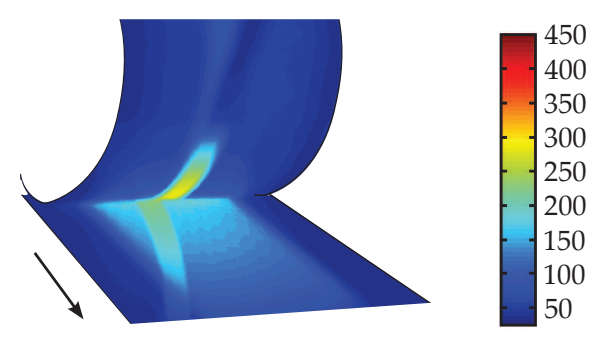

$v=125 \mathrm{~mm} / \mathrm{s}$

$\alpha=18.4^{\circ}$

Figure 3.3 Tape and laminate surface temperature $\left({ }^{\circ} \mathrm{C}\right)$ measured using the thermal camera. The laser power was constant $P=1500 \mathrm{~W}$ for all cases. The arrow indicates the welding direction. 


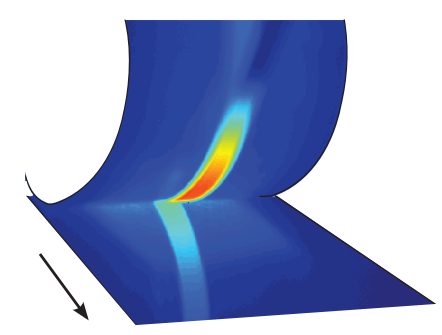

$$
P=1300 \mathrm{~W}
$$

$\alpha=15.4^{\circ}$

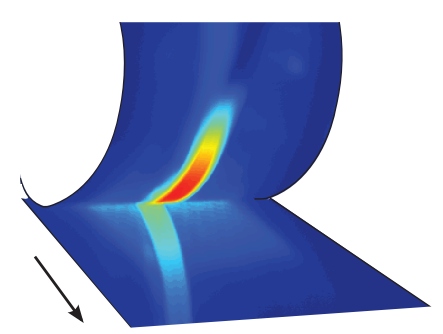

$$
P=1500 \mathrm{~W}
$$$$
\alpha=15.4^{\circ}
$$

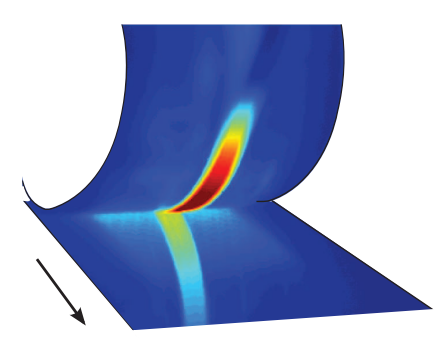

$$
\begin{gathered}
P=1700 \mathrm{~W} \\
\alpha=15.4^{\circ}
\end{gathered}
$$

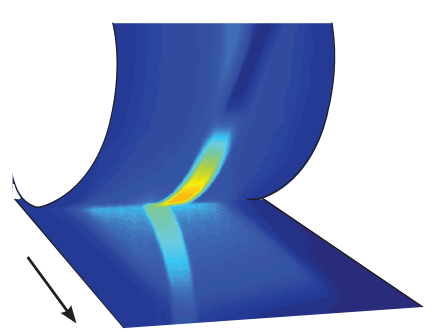

$$
P=1300 \mathrm{~W}
$$$$
\alpha=17.1^{\circ}
$$

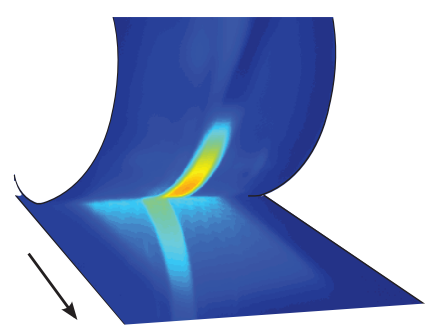

$$
\begin{gathered}
P=1500 \mathrm{~W} \\
\alpha=17.1^{\circ}
\end{gathered}
$$

not tested

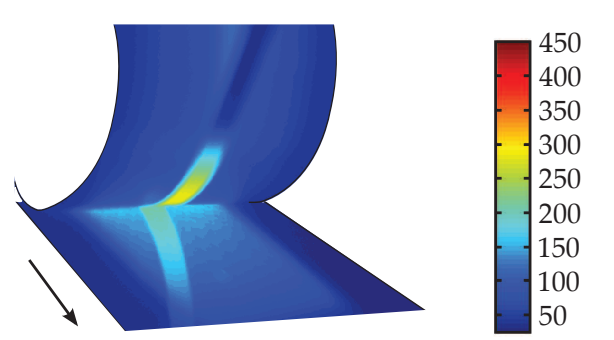

$$
\begin{gathered}
P=1300 \mathrm{~W} \\
\alpha=18.4^{\circ}
\end{gathered}
$$

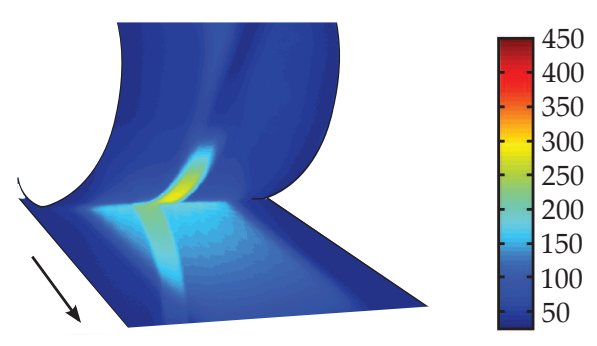

$$
\begin{gathered}
P=1500 \mathrm{~W} \\
\alpha=18.4^{\circ}
\end{gathered}
$$

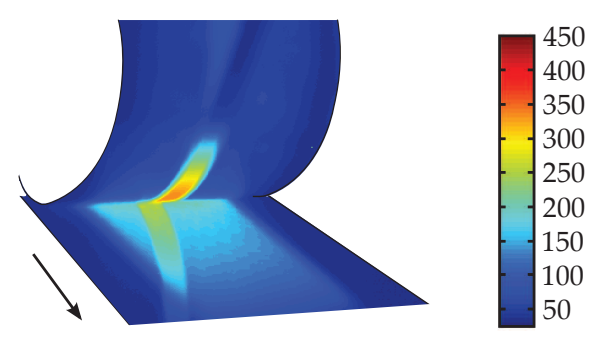

$$
\begin{gathered}
P=1700 \mathrm{~W} \\
\alpha=18.4^{\circ}
\end{gathered}
$$

Figure 3.4 Tape and laminate surface temperature $\left({ }^{\circ} \mathrm{C}\right)$ measured using the thermal camera. The placement velocity was constant $v=125 \mathrm{~mm} / \mathrm{s}$ for all cases. The arrow indicates the welding direction. 
$P=1500 \mathrm{~W}$. The temperature plots show that the tape temperature is significantly higher than the laminate temperature. Due to its smooth surface, the laminate reflects part of the heat radiated from the tape. Both the laminate and tape surface temperature decrease with an increase in placement velocity, because the heating time is inversely proportional to the placement velocity. The influence of the laser power is illustrated in Figure 3.4, which shows the temperature distribution as a function of laser power and angle with a constant placement velocity of $v=125 \mathrm{~mm} / \mathrm{s}$. An increase in laser power, and thereby incident energy, results in an increase of both the tape and laminate surface temperature.

The schematic illustration in Figure 2.12 demonstrated that the angle $\alpha$ controls the distribution of the laser power between the tape and the laminate. This is directly shown in the measured temperature distributions in Figures 3.3 and 3.4. At an angle of $\alpha=15.4^{\circ}$ the majority of the laser power is distributed on the tape, causing high tape and low laminate temperatures. Increasing the angle $\alpha$ reduces the maximum tape temperature and simultaneously increases the maximum laminate temperature. The experiments show that in all cases the maximum tape temperature clearly exceeds the laminate temperature. Moreover, the laminate surface temperature does not exceed the melting temperature of the PPS matrix material. Nevertheless, an excellent interfacial bond strength was obtained using this strategy, as will be discussed in Chapter 5.

\subsection{Model validation}

The thermal camera data will be used to validate the combined optical and thermal model. The incident heat flux distribution on the tape and the laminate was determined in the previous chapter. The thermal model requires the thermal material property data and the values for the boundary conditions. These are obtained from the literature and provided first. Subsequently, the simulated temperature distribution is compared to the experimentally obtained values.

\subsubsection{Material properties and boundary conditions}

\section{Material property data}

Table 3.2 lists the material property data used in the present analysis. There is not much data available on the thermal properties of carbon-PPS composites. The values used here, therefore, are mainly based on unidirectionally reinforced carbonPEEK (APC-2) data [20], which is widely available. As the carbon-PPS tape used in this work has the same fiber volume fraction as the APC-2 tape, the data should provide a good estimate for the tape thermal properties. The laminate, however, 
Table 3.2 Material properties for the thermal analysis.

\begin{tabular}{lcccc}
\hline Description & Symbol & Units & Value & Ref. \\
\hline Tape thermal conductivity & $k_{\mathrm{t}}$ & $\mathrm{W} /(\mathrm{m} \mathrm{K})$ & 0.72 & {$[20]$} \\
Tape heat capacity & $c_{p, \mathrm{t}}$ & $\mathrm{J} /(\mathrm{kg} \mathrm{K})$ & 1425 & {$[20]$} \\
Tape density & $\rho_{\mathrm{t}}$ & $\mathrm{kg} / \mathrm{m}^{3}$ & 1560 & {$[20]$} \\
Tape thickness & $h_{\mathrm{t}}$ & $\mathrm{mm}$ & 0.15 & \\
Tape emissivity & $\epsilon_{\mathrm{t}}$ & - & 0.9 & {$[21]$} \\
Laminate thermal conductivity & $k_{1}$ & $\mathrm{~W} /(\mathrm{m} \mathrm{K})$ & 0.72 & \\
Laminate heat capacity & $c_{p, 1}$ & $\mathrm{~J} /(\mathrm{kg} \mathrm{K})$ & 1425 & \\
Laminate density & $\rho_{1}$ & $\mathrm{~kg} / \mathrm{m}^{3}$ & 1568 & \\
Laminate thickness & $h_{1}$ & $\mathrm{~mm}$ & 2.5 & \\
Laminate emissivity & $\epsilon_{1}$ & - & 0.9 & \\
\hline
\end{tabular}

may have different values. This is especially true for the value used for the thermal conductivity, as this is highly influenced by the architecture of the reinforcement. Therefore, the sensitivity of the model to this value is studied and discussed later.

The emissivity $\epsilon$ of the carbon-PPS tape was chosen as 0.9 , which is based on the value found by Berlin et al. [21] for carbon-PEEK tape. Although the emissivity of the woven fabric reinforced carbon-PPS laminate is probably inhomogeneous, this was neglected and the emissivity was chosen equal to the value for carbon-PEEK.

\section{Boundary conditions}

The tape and laminate are subjected to convective and radiative boundary conditions, as was explained earlier. The convection coefficients are chosen based on the available data in the literature. As there is little data available on carbon-PPS composites, the majority of the values are based on carbon-PEEK (APC-2) data.

A number of studies, e.g. [11, 14, 22, 23], provide effective heat transfer coefficients between carbon thermoplastic composites in contact with steel tooling $h_{\mathrm{m}}$ and air $h_{\mathrm{a}}$. The mentioned values for the composite-steel mold contact $h_{\mathrm{m}}$ vary between 400 and $1000 \mathrm{~W} /\left(\mathrm{m}^{2} \mathrm{~K}\right)$, while the convection coefficient for air $h_{\mathrm{a}}$ is approximately

Table 3.3 Values for the initial conditions and boundary conditions.

\begin{tabular}{lcccc}
\hline Description & Symbol & Units & Value & Ref. \\
\hline Far field temperature & $T_{\infty}$ & $\mathrm{K}$ & 293 & \\
Initial temperature & $T_{0}$ & $\mathrm{~K}$ & 293 & \\
Heat transfer coefficient composite-air & $h_{\mathrm{a}}$ & $\mathrm{W} /\left(\mathrm{m}^{2} \mathrm{~K}\right)$ & 10 & {$[20]$} \\
Heat transfer coefficient tape-roller & $h_{\mathrm{r}}$ & $\mathrm{W} /\left(\mathrm{m}^{2} \mathrm{~K}\right)$ & 100 & \\
Heat transfer coefficient laminate-tool & $h_{\mathrm{m}}$ & $\mathrm{W} /\left(\mathrm{m}^{2} \mathrm{~K}\right)$ & 500 & {$[20]$} \\
\hline
\end{tabular}


$10 \mathrm{~W} /\left(\mathrm{m}^{2} \mathrm{~K}\right)$ in most cases. The boundary between the tape and the air-cooled compaction roller is also represented by a convective boundary condition. The value for the effective heat transfer coefficient $h_{\mathrm{r}}$ is chosen between the values for the steel tooling and the air convection coefficients. The present analysis uses a value of $h_{\mathrm{r}}=100 \mathrm{~W} /\left(\mathrm{m}^{2} \mathrm{~K}\right)$, although later the influence of this parameter will be investigated. Table 3.3 lists the coefficients used in the present analysis.

\subsubsection{Modeling results and validation}

The simulated incident heat flux distributions, as shown in Figure 2.14, served as an input for the thermal model. The refractive indexes for the tape $\left(n_{\mathrm{t}}\right)$ and the laminate $\left(n_{1}\right)$ both equaled 1.8, based on experimental results presented in Chapter 2 . Figures 3.5 and 3.6 show the simulated temperature distribution in the tape and laminate for a laser angle of $17.1^{\circ}$ and a laser power and placement velocity of $1500 \mathrm{~W}$

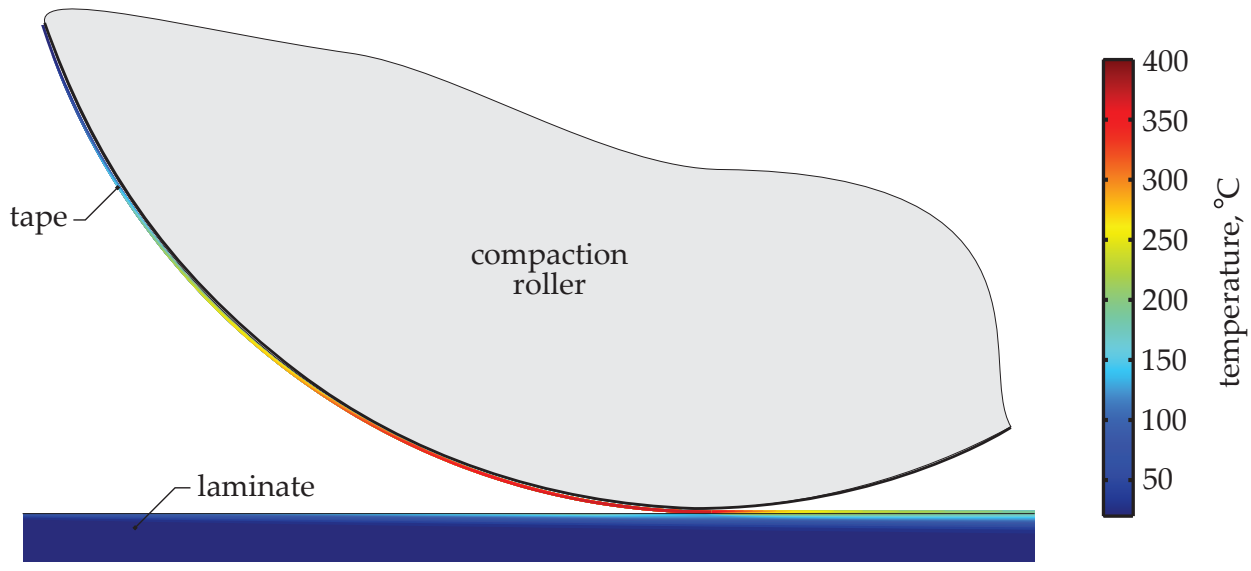

Figure 3.5 Temperature distribution in the tape and the laminate. The laser power and placement velocity equaled $1500 \mathrm{~W}$ and $100 \mathrm{~mm} / \mathrm{s}$, respectively, while the incident laser angle was $17.1^{\circ}$.

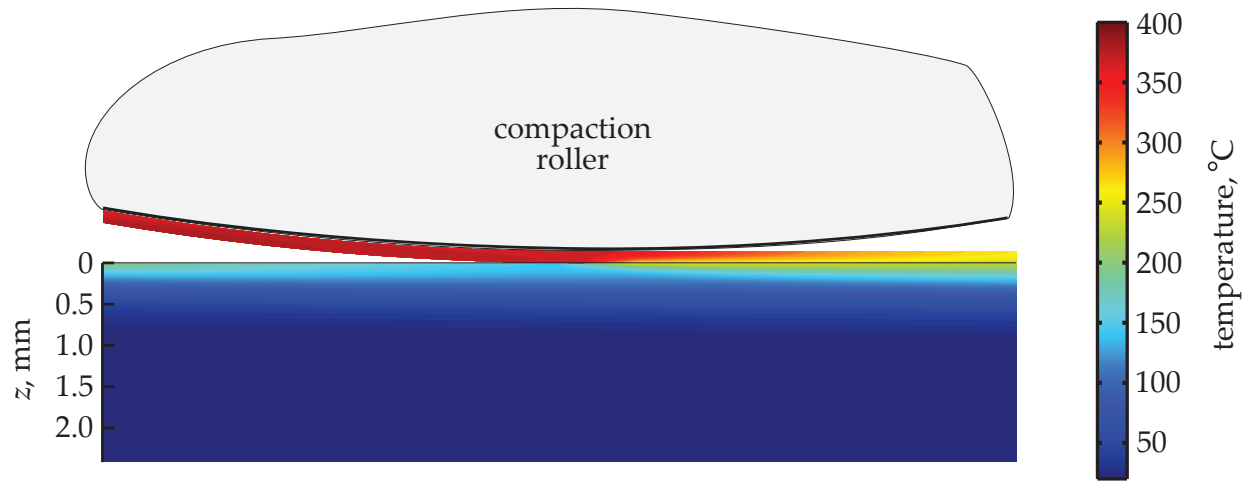

Figure 3.6 Temperature distribution in the nip-point region using the same settings as in Figure 3.5. 
and $100 \mathrm{~mm} / \mathrm{s}$, respectively. The figures show that the tape temperature exceeds the laminate temperature, as was also observed during the experiments. Moreover, the tape is fully heated over its thickness, while this is clearly not the case for the laminate.

The calculated tape and laminate temperature distribution was compared to the data measured with the thermal camera in order to validate the combined optical and thermal model. The recorded images (Figures 3.3 and 3.4) were analyzed to obtain the tape and laminate surface temperature as a function of the distance from the nippoint. In the case of the tape temperature, this distance is defined as the arc-length $\beta$ from the nip-point, as Figure 3.2 illustrates. Figures 3.7 to 3.9 compare the predicted (solid line) and measured temperature distribution (dots) for the varied process settings. The left graphs in these figures show the tape surface temperature. These show that the heat transfer model is able to accurately predict the tape temperature. The influences of the process parameters, i.e. placement velocity, laser power and laser angle, are well captured by the model.

The right graphs in Figures 3.7 to 3.9 show the predicted and measured laminate surface temperature distribution. The solid lines represent the temperature predictions in which the incident heat flux of the direct and the reflected light is taken into account. The thermal modeling results are found to overestimate the actual measured laminate temperature. Two possible explanations were formulated for this discrepancy. Firstly, the laminate transverse thermal conductivity $k_{1}$ was not exactly known and the value used in these calculations corresponds to the tape conductivity. The influence of this parameter is further discussed in the next section. Secondly, the underlying simplification of a two-dimensional ray tracing domain causes an overestimation of the incident heat flux. As is shown in Figure 3.1 the laser beam is rather wide compared to the tape width. The compaction roller itself reflects only a very small fraction of the incident light and is further transparent. Consequently, the light directed at the compaction roller will pass through the roller and heat the laminate under the roller. Therefore, not all light is reflected back onto the laminate in the nip-point region.

So, although the two-dimensional treatment of the problem works fine for the tape, it overestimates the incident heat flux on the laminate. A lower bound solution is, therefore, presented which does not take any reflections into account but instead only the contribution of the light that comes directly from the laser source. The dashed line in the graphs represents the lower bound temperature prediction. As expected, this prediction underestimates the actual measured temperature. The simulated temperature distribution shows that the laminate surface temperature decreases rapidly near the nip-point, while this is not the case for the tape surface temperature. As the laminate is not yet fully heated (see Figure 3.6), a high thermal gradient exists near its surface. When the incident heat flux diminishes due to the shadowing effect of the roller, the heat conduction through the thickness causes 

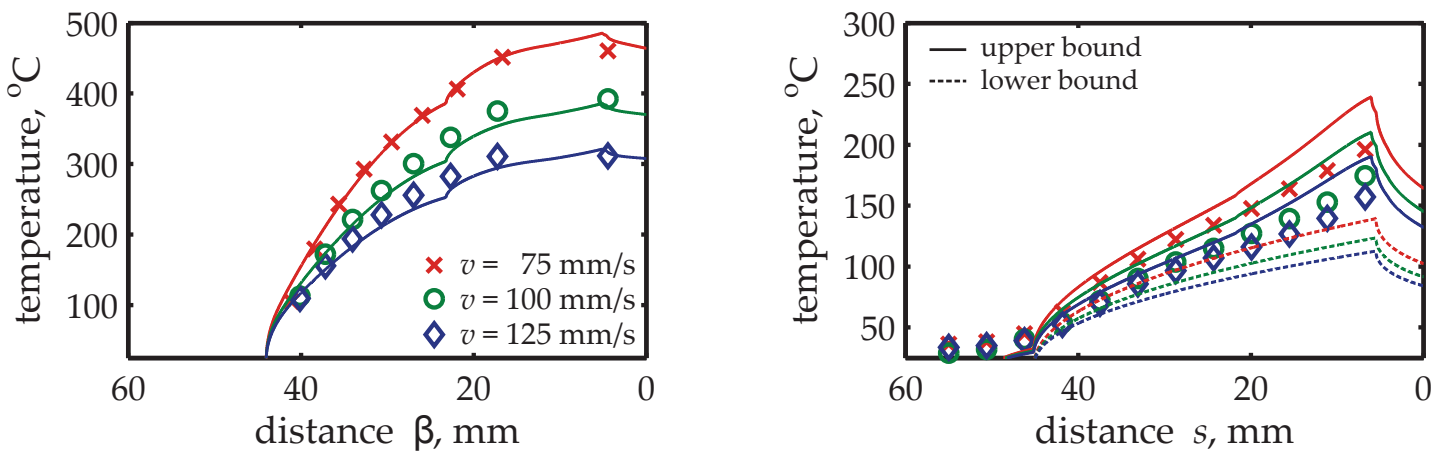

Figure 3.7 Measured (dots) and simulated (solid lines) influence of placement velocity $v$ on surface temperatures for a constant laser angle $\alpha=17.1^{\circ}$ and input power $P=1500 \mathrm{~W}$. Left: Tape surface temperature. Right: Laminate surface temperature. Note the different temperature scales.
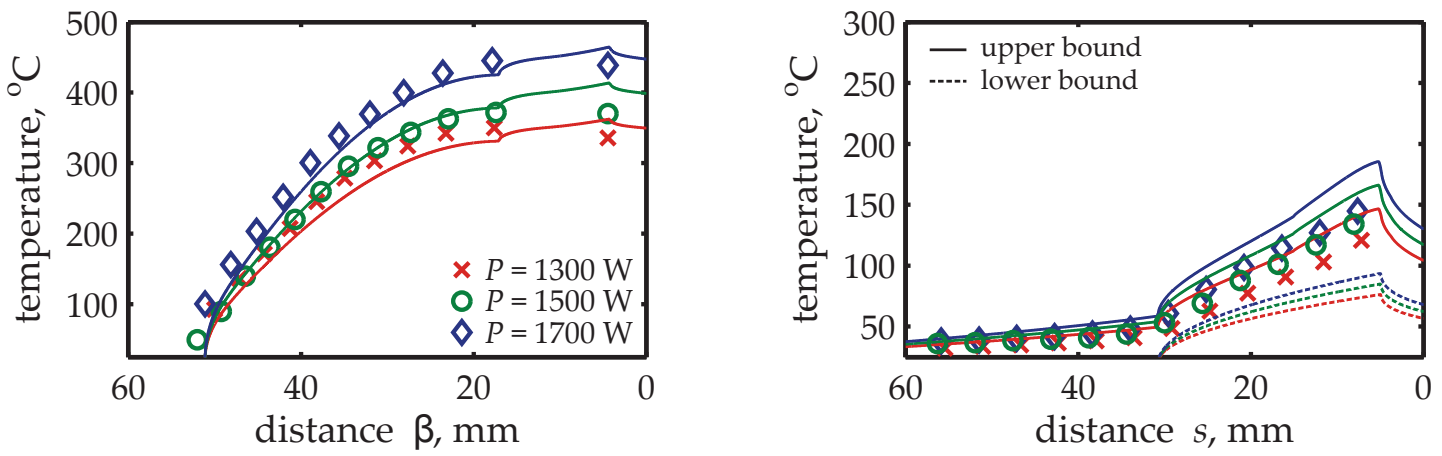

Figure 3.8 Measured (dots) and simulated (solid lines) influence of laser power P on surface temperatures for a constant laser angle $\alpha=15.4^{\circ}$ and placement velocity $v=125 \mathrm{~mm} / \mathrm{s}$. Left: Tape surface temperature. Right: Laminate surface temperature. Note the different temperature scales.
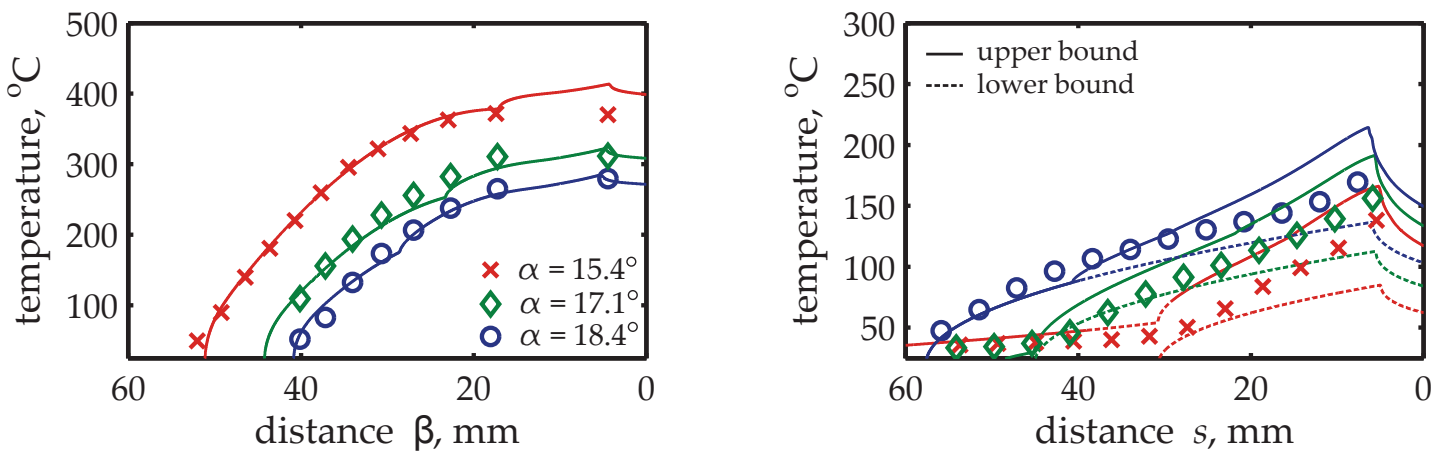

Figure 3.9 Measured (dots) and simulated (solid lines) influence of laser angle $\alpha$ on surface temperatures for a constant laser power $P=1500 \mathrm{~W}$ and placement velocity $v=125 \mathrm{~mm} / \mathrm{s}$. Left: Tape surface temperature. Right: Laminate surface temperature. Note the different temperature scales. 
the surface temperature to drop considerably. On the contrary, the tape is fully heated over its thickness, due to its small thickness and the insulating effect of the compaction roller. Consequently, there is no high temperature gradient near the surface and the temperature only decreases slightly near the nip-point.

\subsection{Discussion}

The present section discusses the obtained modeling and experimental results. The effect of the material property and boundary condition data on the simulation results is investigated by performing a sensitivity study.

Figure 3.10 (left) illustrates the influence of the effective heat transfer between roller and tape coefficient $h_{\mathrm{r}}$ on the tape surface temperature. Increasing this value from 50 to $200 \mathrm{~W} /(\mathrm{m} \mathrm{K})$ results in a decrease of the nip-point temperature of approximately $50{ }^{\circ} \mathrm{C}$, which can significantly influence any bonding analysis. Although difficult to obtain experimentally, the effective heat transfer coefficient $h_{\mathrm{r}}$ is thus an important parameter. As a solution, the experimentally obtained tape temperature distribution, as was shown in Figures 3.7 to 3.9, could be used to fit this parameter. These results also show the influence of the material from which the compaction roller is manufactured. Replacing the polymeric compaction roller with a steel version, thereby increasing the effective heat transfer coefficient, would result in lower tape temperatures and possibly incomplete interlaminar bonding.

Figure 3.10 (right) shows the influence of the transverse thermal conductivity on the laminate temperature distribution. The graph demonstrates that this parameter influences the surface temperature significantly with a decrease of the nip-point temperature of more than $90{ }^{\circ} \mathrm{C}$ if the conductivity is increased from 0.36 to
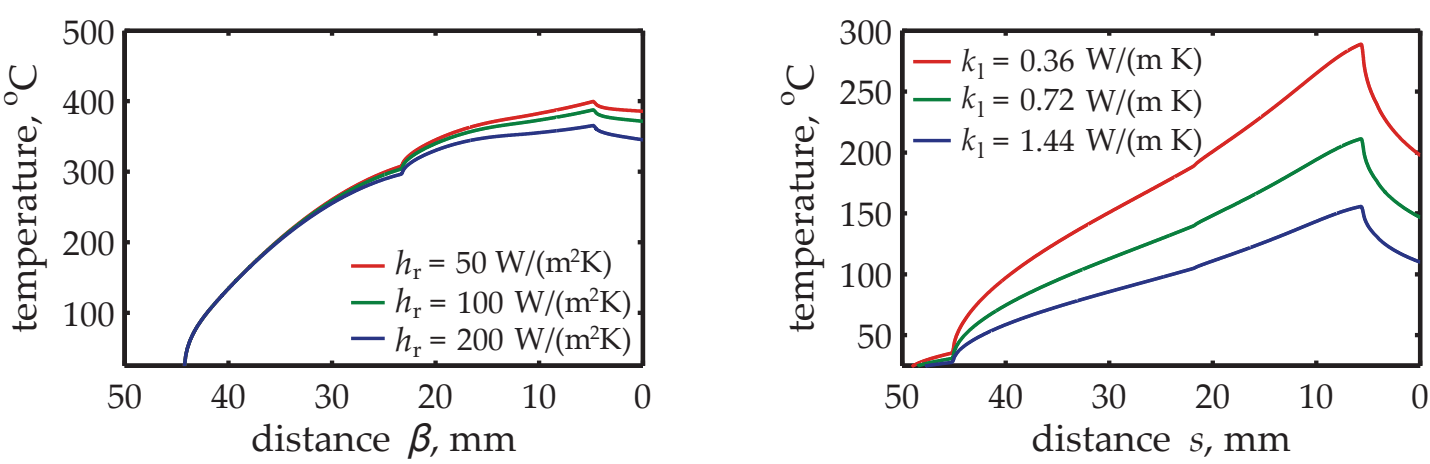

Figure 3.10 Left: Simulated tape surface temperature for different heat transfer coefficients $h_{r}$. Right: Simulated laminate surface temperature for varying thermal conductivity $k_{l}$. The placement velocity and laser power is $v=100 \mathrm{~mm} / \mathrm{s}$ and $P=1500 \mathrm{~W}$, respectively. The laser angle $\alpha$ is $17.1^{\circ}$ for both graphs. The remaining parameters equal the values listed in Table 3.2 and 3.3 . 

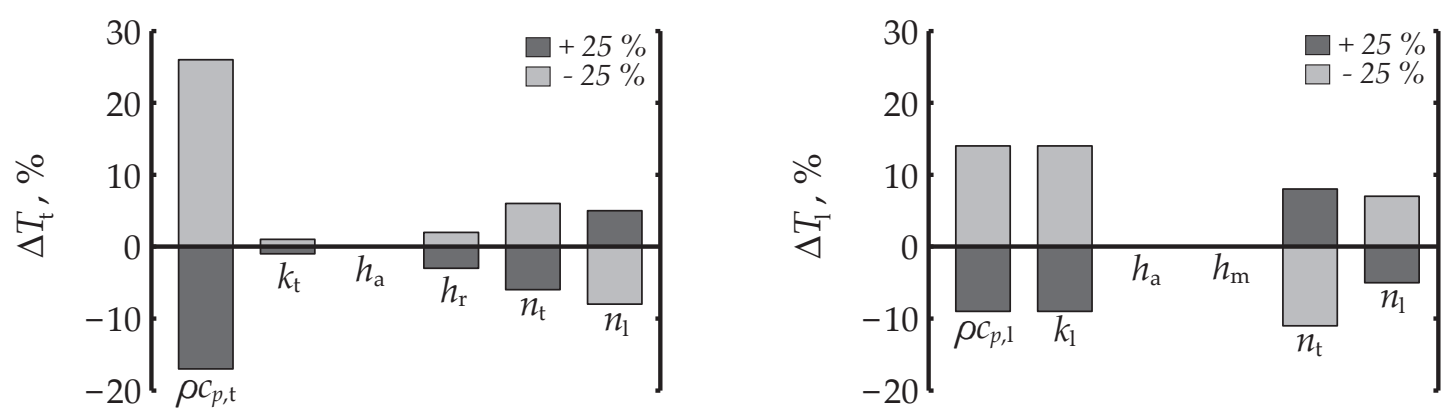

Figure 3.11 Effect of the model parameters on the variation of the maximum temperatures. The input power and placement velocity was $1500 \mathrm{~W}$ and $100 \mathrm{~mm} / \mathrm{s}$, respectively, while the incident laser angle equaled $17.1^{\circ}$. Left: Variation of maximum tape temperature. Right: Variation of maximum laminate (with a thickness of $2.5 \mathrm{~mm}$ ) temperature.
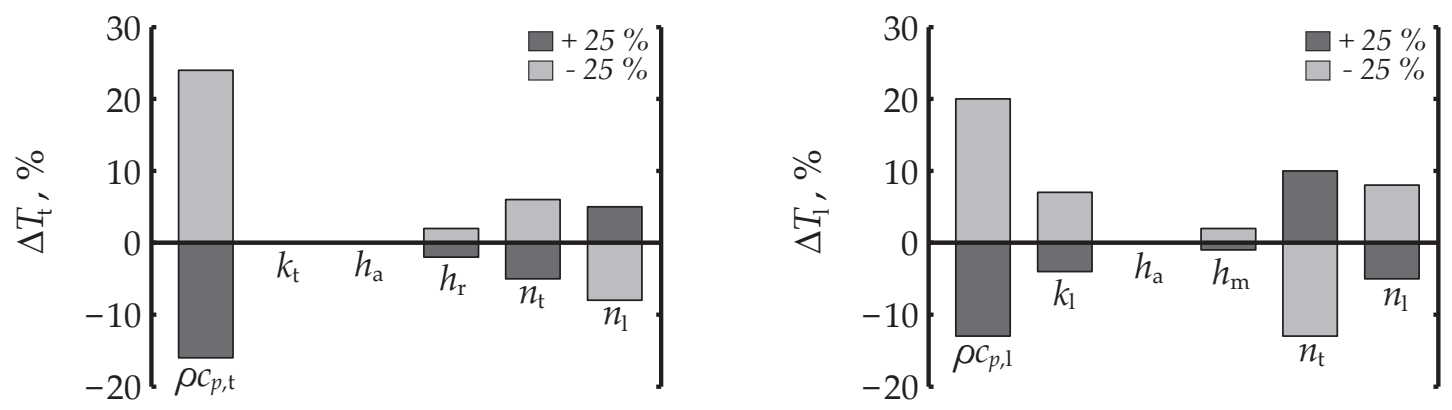

Figure 3.12 Effect of model parameters on variation of maximum temperatures. The input power and placement velocity was $1500 \mathrm{~W}$ and $75 \mathrm{~mm} / \mathrm{s}$, respectively, while the incident laser angle equaled $17.1^{\circ}$. Left: Effect on maximum tape temperature. Right: Effect on maximum laminate (with a thickness of $0.3 \mathrm{~mm}$ ) temperature.

$1.44 \mathrm{~W} /(\mathrm{m} \mathrm{K})$. Accurate material property data is therefore required in order to further improve these simulations.

The effect of the remaining parameters is illustrated in Figures 3.11 and 3.12, which show the effect of an increase or decrease of the different parameters on the maximum tape or laminate temperature. The former figure corresponds to a laminate thickness $t_{1}$ of $2.4 \mathrm{~mm}$, while the latter corresponds to a laminate thickness of $0.3 \mathrm{~mm}$. The graphs demonstrate that a variation in the volumetric heat capacity $\rho c_{p}$ has the most pronounced effect on both the tape and laminate temperature. The laminate thermal conductivity $k_{1}$ has a similar effect as the volumetric heat capacity, when the laminate has a large thickness. This is caused by the fact that the laminate is not yet fully heated, as was also illustrated in Figure 3.6. The laminate can in this case be considered as a semi-infinite solid. For illustration, the surface temperature history 
$T_{\mathrm{S}}(t)$ of a semi-infinite solid subjected to a constant incident heat flux $Q$ yields [15]:

$$
T_{\mathrm{s}}(t)=\frac{2 Q}{\pi \sqrt{k \rho c_{p}}} \sqrt{t},
$$

which directly demonstrates that a change in the volumetric heat capacity $\rho c_{p}$ has a similar effect as a variation in the thermal heat conductivity.

Figure 3.12 shows the sensitivity study for a thinner laminate and a slower placement velocity. The laminate can in this case not be considered as semi-infinite solid anymore. Consequently, a variation in the heat transfer coefficient between laminate and tooling $h_{\mathrm{m}}$ actually influences the surface temperature. Moreover, varying the heat conductivity or volumetric heat capacity does not have a similar effect anymore.

The results of the sensitivity analysis show that the heat transfer coefficients $h_{\mathrm{r}}, h_{\mathrm{a}}$ and $h_{\mathrm{m}}$ have a negligible effect, at least within the tested range, on the maximum temperature. The effect of the emissivity $\epsilon$ was even smaller. The refractive indexes of tape $n_{\mathrm{t}}$ and laminate $n_{1}$ which are used in the optical model, however, do influence the final temperature distribution. These values determine the amount of light which is reflected and absorbed and thereby directly affect the incident heat flux distribution.

Figure 3.13 illustrates the effect of a variation of the processing parameters on the maximum tape and laminate temperature. As expected, an increase in laser power $P$ results in a higher tape and laminate temperature. A decrease of placement velocity causes an increase of the maximum temperature, because the heating time is inversely proportional to this velocity. For the tape, which is fully heated over its thickness, the effect of an increase in power is similar to a comparable decrease in placement velocity. This is, however, not the case for the laminate, which is clearly not yet fully heated over its thickness. As discussed earlier, the laminate can in this case be considered as a semi-infinite solid. Equation 3.14 gives the surface temperature for

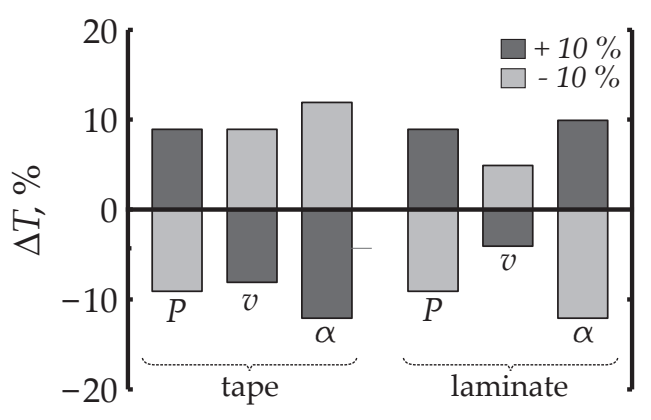

Figure 3.13 Effect of a variation of the processing parameters on the maximum tape and laminate (with a thickness of $2.4 \mathrm{~mm}$ ) temperature. The input power and placement velocity was $1500 \mathrm{~W}$ and $100 \mathrm{~mm} / \mathrm{s}$, respectively, while the laser angle equaled $17.1^{\circ}$. 
a semi-infinite solid subjected to a constant heat flux $Q$. The surface temperature is proportional to the incident heat flux $Q$ and to the square root of the heating time $t$, which explains the velocity dependency for the laminate temperature.

The laser angle $\alpha$ governs the distribution of the laser power between the tape and the laminate. This is also clearly reflected in the bar graph in Figure 3.13. An increase of the laser angle distributes more energy on the laminate, which results in an increase of the maximum laminate temperature and a decrease of the tape temperature. The laser angle is thus an important parameter, which has a pronounced effect on the temperature distribution.

The comparison between the simulated and measured temperature showed that the laminate temperature was overestimated (see right graphs in Figures 3.7 to 3.9), which was attributed to the uncertainty in the used value for the laminate transverse thermal conductivity as well as the two-dimensional representation of the nip-point region. The simplification to represent the nip-point as a two-dimensional domain was already discussed earlier. It causes an overestimation of the amount of light that reflects from the tape onto the laminate. A full three-dimensional optical and heat transfer analysis seems therefore required to accurately predict the laminate spatial temperature distribution.

\subsection{Conclusions and future work}

The process window for in situ laser-assisted tape placement is often narrow and difficult to determine. To aid in this process, a simulation tool is being developed for the laser-assisted tape placement process. The tool comprises an optical and a thermal model. The former model accounts for the reflection of the laser light in the nip-point region and determines the spatial incident heat flux distribution on tape and laminate. The latter uses the heat flux distribution and calculates the temperature distribution in the tape and the laminate. The present chapter focused on the thermal model. A one-dimensional through-the-thickness heat transfer model was implemented to determine the steady-state temperature distribution in the tape and laminate.

Laser-assisted tape placement experiments were performed to validate the combined optical and thermal model. For this purpose, carbon fiber unidirectionally reinforced PPS tapes were welded onto carbon woven fabric reinforced PPS laminates. The incident heat flux distribution on the tape and laminate followed from the analysis presented in Chapter 2. The combined model overestimated the laminate temperature. The simplification of the nip-point region as a two-dimensional plane in the optical analysis is thought to be one of the causes for this discrepancy. Moreover, reliable material property data is required for the carbon woven fabric reinforced laminates. Additional research is required to obtain this data. Although the model 
currently overestimates the laminate temperature, it accurately predicts the tape temperature distribution. This is partly caused by the fact that the two-dimensional simplification does hold for the tape, while there also exists more experimental data on the thermal properties of such fiber reinforced thermoplastic tapes.

A sensitivity study showed that, for the discussed cases, the thermal problem is dominated by the through-thickness heat conduction in the tape and the laminate. The through-thickness thermal conductivity and volumetric heat capacity are the important parameters. The laminate can, if it has a large thickness, be considered as a semi-infinite solid having a high thermal gradient near its surface. Consequently, the surface temperature drops rapidly near the nip-point, where the laser influx diminishes as a result of the shadowing effect of the roller. On the contrary, as the thin tape is fully heated over its thickness, its surface temperature will decrease slowly near the nip-point.

Future work will concentrate on elaborating the current model with additional existing sub-models to predict e.g. bond strength or residual stress levels. Moreover, effort will be spent on characterizing the thermal properties of the carbon weave reinforced laminates used in the present work.

\section{References}

[1] M. Steyer, M. Dubratz, A. Schütte, C. Wenzel, and C. Brecher. Laser-assisted thermoplastic tape-laying systems. JEC Composites Magazine, 47:39-41, 2009.

[2] R. Schledjewski. Thermoplastic tape placement - in situ consolidation is reachable. Plastics, Rubber and Composites, 38(9-10):379-386, 2009.

[3] W. R. Curry. Flat thermoplastic tape laying. In 2nd ASM Conference on Advanced Composites. Dearborn, Michigan, USA, pages 45-50, 1986.

[4] V. Agarwal, S. I. Güçeri, R. L. McCullough, and J. M. Schultz. Thermal characterization of the laser-assisted consolidation process. Journal of Thermoplastic Composite Materials, 5(2):115-135, 1992.

[5] S. C. Mantell and G. S. Springer. Manufacturing process models for thermoplastic composites. Journal of Composite Materials, 26(16):2348-2377, 1992.

[6] L. J. Bastien and J. W. Gillespie Jr. A non-isothermal healing model for strength and toughness of fusion bonded joints of amorphous thermoplastics. Polymer Engineering and Science, 31(24):1720-1730, 1991.

[7] Y. M. P. Toso, P. Ermanni, and D. Poulikakos. Thermal phenomena in fiber-reinforced thermoplastic tape winding process: Computational simulations and experimental validations. Journal of Composite Materials, 38(2):107-135, 2004.

[8] N. Hassan, J. E. Thompson, R. C. Batra, A. B. Hulcher, X. Song, and A. C. Loos. A heat transfer analysis of the fiber placement composite manufacturing process. Journal of Reinforced Plastics and Composites, 24(8):869-888, 2005. 
[9] J. Tierney and J. W. Gillespie Jr. Modeling of in situ strength development for the thermoplastic composite tow placement process. Journal of Composite Materials, 40(16):1487-1506, 2006.

[10] F. O. Sonmez and H. T. Hahn. Modeling of heat transfer and crystallization in thermoplastic composite tape placement process. Journal of Thermoplastic Composite Materials, 10(3):198-240, 1997.

[11] S. C. Dai and L. Ye. Characteristics of CF/PEI tape winding process with on-line consolidation. Composites Part A, 33:1227-1238, 2002.

[12] R. Pitchumani, S. Ranganathan, R. C. Don, J. W. Gillespie Jr., and M. A. Lamontia. Analysis of transport phenomena governing interfacial bonding and void dynamics during thermoplastic tow-placement. International Journal of Heat and Mass Transfer, 39(9):1883-1897, 1996.

[13] J. Tierney and J. W. Gillespie Jr. Modeling of heat transfer and void dynamics for the thermoplastic composite tow-placement process. Journal of Composite Materials, 37(19):1745-1768, 2003.

[14] S. M. Grove. Thermal modelling of tape laying with continuous carbon fibre-reinforced thermoplastic. Composites, 19(5):367-375, 1988.

[15] A. Bejan. Heat Transfer. John Wiley \& Sons, Inc., 1993.

[16] W. J. B. Grouve, L. L. Warnet, R. Akkerman, S. Wijskamp, and J. S. M. Kok. Weld strength assessment for tape placement. International Journal of Material Forming, 3(1):707-710, 2010.

[17] J. Colton and D. Leach. Processing parameters for filament winding thick-section PEEK/carbon fiber composites. Polymer Composites, 13(6):427-434, 1992.

[18] A. Barasinski, A. Leygue, E. Soccard, and A. Poitou. An improvement in thermal modelling of automated tape placement. In International Conference on Advances in Materials and Processing Technologies, 2010.

[19] L. Trefethen. Spectral methods in MATLAB. Society for Industrial and Applied Mathematics, 2001.

[20] F. Cogswell. Thermoplastic Aromatic Polymer Composites. Butterworth Heinemann, 1992.

[21] P. Berlin, O. Dickman, and F. Larsson. Effects of heat radiation on carbon/PEEK, carbon/epoxy and glass/epoxy composites. Composites, 23(4):235 - 243, 1992.

[22] F. Cogswell. The processing science of thermoplastic structural composites. International Polymer Processing, 1(4):157-165, 1987.

[23] E. P. Beyeler and S. I. Güçeri. Thermal analysis of laser-assisted thermoplastic-matrix composite tape consolidation. Journal of Heat Transfer, 110(2):424-430, 1988. 


\title{
CHAPTER 4
}

\section{Critical assessment of the mandrel peel test for fiber reinforced thermoplastic laminates $^{1}$}

\begin{abstract}
The validity of the mandrel peel test for thermoplastic laminates was investigated experimentally by comparing the measured fracture toughness with the values obtained by the double cantilever beam (DCB) and the end-loaded-split (ELS) beam test. Two different laminates were considered: a unidirectionally reinforced carbon-PPS laminate and a carbon-PPS hybrid laminate, in which the interface consisted of a woven fabric and a unidirectionally reinforced ply. The mandrel peel test yielded comparable results as the DCB and ELS tests for the unidirectionally reinforced laminate. Although the fracture toughness of the hybrid interface could not be quantified using the DCB or ELS test, this was possible using the mandrel peel test.
\end{abstract}

\footnotetext{
${ }^{1}$ Reproduced from: W.J.B. Grouve, L.L. Warnet, R. Akkerman. Critical assessment of the mandrel peel test for fiber reinforced thermoplastic laminates. Accepted for publication in: Engineering Fracture Mechanics, 2012.
} 


\subsection{Introduction}

\subsubsection{Background and motivation}

The automated tape placement process for fiber reinforced thermoplastics [1, 2] shows great potential for structural applications in, for example, the aerospace and automotive industries [3]. It combines a high productivity with the ability to manufacture complex structures. Figure 4.1 schematically illustrates the laserassisted tape placement process. A unidirectionally fiber reinforced pre-impregnated thermoplastic tape is welded onto a flat or (double) curved laminate under the application of heat and pressure. Generally, the pressure is applied using a compaction roller, while heat can be applied using, for example, a hot gas torch [4] or a laser [5]. Currently, the tape placement process is often followed by a post-consolidation step in an autoclave in order to obtain the desired mechanical properties. Much effort is spent optimizing the process with the aim of omitting this expensive step and reaching so-called in situ or out-of-autoclave tape placement [6, 7]. One of the possible applications of the technology is the fabrication of tailored fiber reinforced components. The mechanical properties of fully consolidated components can be enhanced by reinforcing these locally with unidirectionally (UD) fiber reinforced tapes. The component stiffness and strength can be improved while keeping its weight low. The strength and stiffness of the UD reinforced tapes combine particularly well with the high drapeability and impact resistance of pressformed woven fabric reinforced components. The interface strength between the UD tape and the component is an important property in these tailored components, as it determines the ability to transfer interlaminar stresses, e.g. during impact events. A reliable and straightforward experimental method is desired to quantify, and subsequently optimize, this interface strength. The present work focuses on the validity of a mandrel peel test to quantify the fracture toughness of these weld interfaces. For this purpose, the mandrel peel test was compared to the standardized double cantilever beam (DCB) and end-loaded-split (ELS) beam tests.

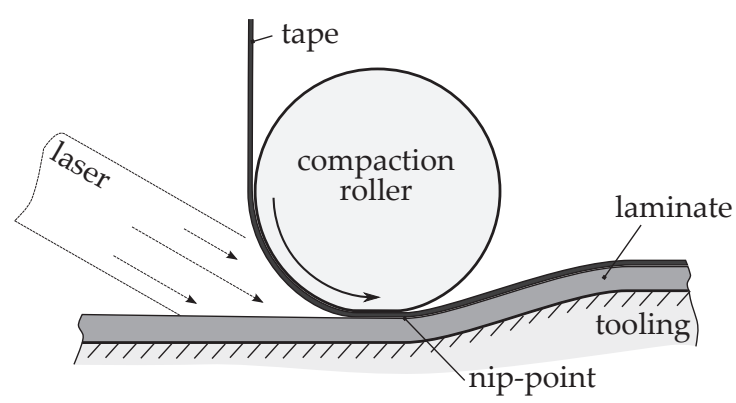

Figure 4.1 Schematic illustration of the laser-assisted tape placement process. The diameter of the compaction roller equals nominally $74 \mathrm{~mm}$. 
All test specimens were obtained using the same processing method to facilitate this comparison. As the DCB and ELS specimens could not be manufactured using a tape placement process, it was chosen to press mold all (i.e. DCB, ELS and mandrel peel) specimens.

\subsubsection{Mandrel peel test}

Figure 4.2 illustrates the configuration of the mandrel peel test setup [8,9]. The peel specimen is fixed, using thin double-sided adhesive tape, to a linear sliding guide, which is mounted in a universal testing machine. The peel arm, which is a fiber reinforced ply or tape in the present context, is bent around a cylindrical mandrel. A tensile force $F_{\mathrm{p}}$ is applied in order to peel the tape from the laminate, while an alignment force $F_{\mathrm{a}}$, acting on the sliding guide, ensures that the peel arm conforms to the mandrel. The alignment force can be applied using a pneumatic cylinder [10] or a dead weight [8]. The fracture toughness $\mathcal{G}_{c}$ of the interface follows from the two forces, as will be explained in the next section.

The test is predominantly used for metal-polymer laminates, e.g. [8, 9], as it allows a direct experimental measurement of the plastic work in the peel arm during debonding [11]. The amount of plastic work in the fiber reinforced tape used in this research, however, was found to be negligible in an earlier study [10]. The choice for the mandrel peel test was motivated by the inapplicability of a standard peel test for these materials. The radius of curvature of the peel arm at the adhesion point becomes too small during such a test, causing the fibers in the tape to fracture before the tape is peeled off. The application of a mandrel ensures a prescribed minimum radius of curvature and thereby prevents the tape from fracturing.

The applicability of a mandrel peel test for these tailored structures was demonstrated earlier in a qualitative comparison study to optimize the laser-assisted tape placement process [10] (see Appendix A). The present work focuses on a more quantitative analysis of the test and aims to analyze how the measured interlaminar fracture toughness compares with values obtained by alternative fracture mechanics experiments. For this purpose, mandrel peel experiments were performed on UD reinforced specimens

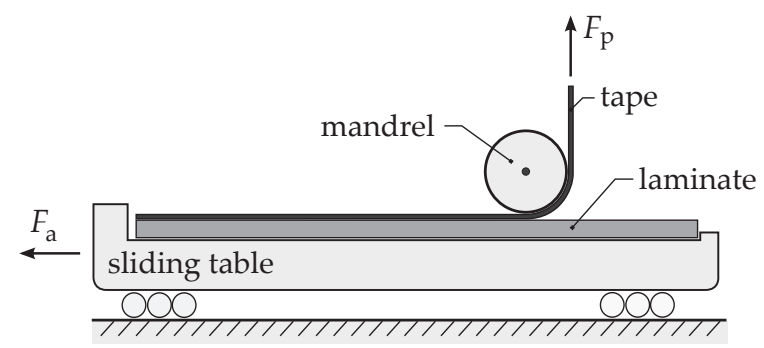

Figure 4.2 Schematic illustration of the mandrel peel setup. 
as well as hybrid specimens, in which woven fabric reinforced plies were combined with UD reinforced plies. As mentioned earlier, all specimens were obtained using a press molding process. The peel test is generally regarded as a mixed (mode I/II) fracture toughness experiment $[12,13]$. The obtained peel fracture toughness was, therefore, compared with values obtained from mode I double cantilever beam (DCB) and mode II end-loaded-split (ELS) beam experiments. The fracture surfaces of the specimens were examined by scanning electron microscopy to determine the major failure mechanisms.

\subsubsection{Outline}

The energy release rate for the mandrel peel test will be presented in the next section. The experimental work is introduced in the third section of this chapter, which includes the specimen preparation and the experimental procedures. Subsequently, the obtained results are presented and discussed. The final section presents the conclusions and recommendations for future work.

\subsection{Energy release rate}

The energy release rate $\mathcal{G}$ during the mandrel peel test follows from the change in elastic strain energy per unit area of crack growth:

$$
\mathcal{G}=\frac{1}{b}\left(\frac{\mathrm{d} U_{\mathrm{ext}}}{\mathrm{d} a}-\frac{\mathrm{d} U_{\mathrm{d}}}{\mathrm{d} a}-\frac{\mathrm{d} U_{\mathrm{s}}}{\mathrm{d} a}\right)
$$

where $U_{\text {ext }}$ is the external work, $U_{\mathrm{d}}$ is the energy dissipated during the test and $U_{\mathrm{s}}$ is the strain energy stored in the peel arm. The crack area change is $b \mathrm{~d} a$ in which $b$ is the width of the peel arm and $\mathrm{d} a$ is a crack length increment.

As the processing of thermoplastic composites is inevitably accompanied by the development of residual stresses [14], these are included in the analysis. The external work performed by the peel force $F_{\mathrm{p}}$ and alignment force $F_{\mathrm{a}}$ yields:

$$
\begin{aligned}
\mathrm{d} U_{\text {ext }} & =-F_{\mathrm{a}} \mathrm{d} a+F_{\mathrm{p}} \mathrm{d} a+F_{\mathrm{p}} \mathrm{d} a\left(\epsilon_{\mathrm{m}}-\epsilon_{\mathrm{r}}\right) \\
& =\left(F_{\mathrm{p}}-F_{\mathrm{a}}\right) \mathrm{d} a+\frac{F_{\mathrm{p}}^{2}}{b h E} \mathrm{~d} a-\frac{F_{\mathrm{p}} \sigma_{\mathrm{r}}}{E} \mathrm{~d} a,
\end{aligned}
$$

in which $E$ and $h$ are the Young's modulus and thickness of the peel arm, respectively. The elastic strain in the peel arm is denoted by $\epsilon_{\mathrm{m}}$, while $\epsilon_{\mathrm{r}}$ is a pre-strain in the peel arm, caused by a residual stress $\sigma_{\mathrm{r}}$ in the bonded state. 
The energy dissipated through plastic work was found to be negligible for the tape under consideration [10]. Energy can still be dissipated, however, through friction in the test setup. This friction is assumed proportional to the applied peel force $F_{\mathrm{p}}$ with $\mu$ the proportionality coefficient. The energy dissipated by friction for an incremental crack growth $\mathrm{d} a$ then yields:

$$
\mathrm{d} U_{\mathrm{d}}=\mu F_{\mathrm{p}} \mathrm{d} a
$$

The strain energy $U_{\mathrm{s}}$ of the global system comprises the tensile strain energy stored in the peel arm and any residual strain energy stored in the bonded part of the peel arm. The strain energy change associated with crack growth yields:

$$
\begin{aligned}
\mathrm{d} U_{\mathrm{s}} & =\frac{1}{2} \sigma_{\mathrm{m}} \epsilon_{\mathrm{m}} b h \mathrm{~d} a-\frac{1}{2} \sigma_{\mathrm{r}} \epsilon_{\mathrm{r}} b h \mathrm{~d} a \\
& =\frac{1}{2} \frac{F_{\mathrm{p}}^{2}}{b h E} \mathrm{~d} a-\frac{1}{2} \frac{b h \sigma_{\mathrm{r}}^{2}}{E} \mathrm{~d} a,
\end{aligned}
$$

with $\sigma_{\mathrm{m}}$ the axial stress in the peel arm. Finally, the energy release rate is then found as:

$$
\mathcal{G}=\frac{1}{b}\left[F_{\mathrm{p}}(1-\mu)-F_{\mathrm{a}}+\frac{1}{2} \frac{F_{\mathrm{p}}^{2}}{b h E}+\frac{1}{2} \frac{b h \sigma_{\mathrm{r}}^{2}}{E}-\frac{F_{\mathrm{p}} \sigma_{\mathrm{r}}}{E}\right] .
$$

The contribution of the change in strain energy and the relaxation of residual stress in the peel arm to the energy release rate $\mathcal{G}$ can be determined from the last three terms in Equation 4.5. The residual stress in the tape is estimated for these tailored structures using the classical lamination theory (CLT). The analysis is performed for a press molding or autoclave process in which the complete laminate is heated and subsequently cooled to room temperature. This yields a worst case value for the residual stress in the tape, compared to the tape placement process $[15,16]$, in which a through-thickness temperature gradient exists in the woven fabric reinforced laminate.

The tailored structure, considered in this analysis, comprises a woven fabric reinforced laminate onto which a UD reinforced tape is welded. This structure was chosen because it resembles the test specimens used in an earlier study, which concerned the experimental optimization of the tape placement process [10]. The laminate consists of eight plies of carbon weave ( 5 harness satin) pre-impregnated with a PPS matrix and has a thickness of $2.4 \mathrm{~mm}$. The UD tape also comprises carbon fibers in a PPS matrix. The tape and laminate material properties are listed in Table 4.1. The tape and laminate matrix material is PPS, which has a glass transition and melt temperature of $85^{\circ} \mathrm{C}$ and $285^{\circ} \mathrm{C}$, respectively. The solidification point, i.e. the point at which the thermal residual stresses start to build up, is chosen 
conservatively at $250{ }^{\circ} \mathrm{C}$ [17]. In this case, the compressive residual stress in the tape equals $90 \mathrm{MPa}$.

In an earlier research on the same material, a fracture toughness $\mathcal{G}_{\mathrm{c}}$ of more than $1 \mathrm{~kJ} / \mathrm{m}^{2}$ was found for a tape having a width $b$ of $7.5 \mathrm{~mm}$, while a peel force $F_{\mathrm{p}}$ of $100 \mathrm{~N}$ was applied. The friction coefficient $\mu$ of the complete setup equaled approximately 0.02 in these experiments [10]. For this specific, but representative, case it can be seen that a compressive residual stress in the tape of $90 \mathrm{MPa}$ contributes less than $1 \%$ to the total energy release rate. Any changes in elastic strain energy stored in the peel arm contribute even less. The residual stress and elastic strain in the peel arm are therefore neglected. The energy release rate thus reduces to the following equation:

$$
\mathcal{G}=\frac{1}{b}\left[F_{\mathrm{p}}(1-\mu)-F_{\mathrm{a}}\right]
$$

\subsection{Experimental work}

The validity of the mandrel peel test was investigated experimentally for fiber reinforced thermoplastic laminates. The mandrel peel fracture toughness was compared with the values obtained using the standardized DCB and ELS beam experiments. Two different laminates were considered. The first was a carbon UD reinforced PPS laminate, while the second was a hybrid carbon-PPS laminate, in which UD reinforced plies were combined with woven fabric reinforced plies. As mentioned earlier, all specimens were obtained using a press molding process. As it was expected that the crack propagates under mixed mode conditions during the mandrel peel test, both mode I DCB as well as mode II ELS tests were performed. The DCB [18] and ELS [19] experiments are well documented for the UD reinforced laminate, which allows a quantitative comparison of the measured toughness values. The experiments on the hybrid laminate mainly aim to demonstrate the applicability of the peel test for tailored woven fabric reinforced structures.

\subsubsection{Materials}

All laminates were supplied by Ten Cate Advanced Composites. The materials used were Cetex Thermo-Lite carbon UD reinforced PPS prepreg and Cetex carbon (5 harness satin) woven fabric reinforced PPS semi-preg. Table 4.1 summarizes the material properties.

The UD reinforced test specimens were acquired from two press-molded laminates, which measured $250 \times 250 \mathrm{~mm}^{2}$ and had a thickness of nominally $2.93 \mathrm{~mm}$. The DCB and ELS specimens were obtained from the first laminate by molding-in a thin 
Table 4.1 Material properties for Cetex Thermo-Lite carbon UD-PPS and Cetex carbon CD286 5HSPPS.

\begin{tabular}{lcccc}
\hline & $\begin{array}{c}\text { modulus } \\
E(\mathrm{GPa})\end{array}$ & $\begin{array}{c}\text { CTE } \\
(\mathrm{ppm} / \mathrm{K})\end{array}$ & $\begin{array}{c}v_{\mathrm{f}}(\%) \\
\text { UD tape }\end{array}$ & $\begin{array}{c}\text { ply thickness } \\
h(\mathrm{~mm})\end{array}$ \\
\hline carbon weave & 56 & 0.17 & $59 \pm 3$ & 0.15 \\
\hline
\end{tabular}

(13 $\mu \mathrm{m})$ release-agent coated polyimide film at the mid-plane to create the pre-crack. Similarly, the peel specimens were obtained from the second laminate by molding-in the polyimide film between the first and second ply of the laminate.

The lay-up for the hybrid laminate is provided in Table 4.2, in which WF stands for the 5 harness satin woven fabric reinforced ply and $\|$ represents the location of the pre-crack film. Although a laminate with a hybrid interface is inherently nonsymmetric, the lay-up was chosen such that the flexural rigidity of both arms was approximately equal and any influence of arm deformation due to residual thermal stresses was minimized [20]. All the hybrid test specimens (DCB, ELS and mandrel peel) were obtained from a single laminate which measured $450 \times 450 \mathrm{~mm}^{2}$ and had a thickness of nominally $3.44 \mathrm{~mm}$. Again, the pre-cracks for the DCB and ELS specimens were introduced at the mid-plane of the laminate, that is between the $0^{\circ} \mathrm{UD}$ ply and a $(90 / 0)$ weave ply. The pre-crack for the mandrel peel specimens was introduced between the first and second ply at the opposite edge of the laminate. The dominant bundle orientation in the fabric with respect to the UD reinforced ply was $90^{\circ}$ at both pre-crack interfaces, as is illustrated in Figures 4.13 and 4.16.

\subsubsection{Specimen preparation}

Six DCB and six ELS specimens, having a width of $20 \mathrm{~mm}$, were cut from the laminates using a diamond-coated saw. The precise thickness and width of each specimen was measured at five points using a micrometer screw gauge. A thin coat of white typewriter correction fluid was applied to the edge of one side of each specimen. Furthermore, the edge of the ELS specimens were marked every $1 \mathrm{~mm}$

Table 4.2 Laminate lay-up and thickness. The unidirectionally reinforced and woven fabric reinforced plies are denoted by 0 and WF, respectively, while $\|$ indicates the pre-crack location.

\begin{tabular}{llc}
\hline & & thickness \\
laminate & lay-up & h $(\mathrm{mm})$ \\
\hline UD (DCB, ELS) & {$\left[0_{10} \| 0_{10}\right]$} & 2.92 \\
UD (peel) & {$\left[0 \| 0_{19}\right]$} & 2.94 \\
hybrid & {$\left[0\left\|\mathrm{WF}_{2 s} / 0 / 0\right\| \mathrm{WF} / 0 / \mathrm{WF}_{2 s} / 0\right]$} & 3.44 \\
\hline
\end{tabular}




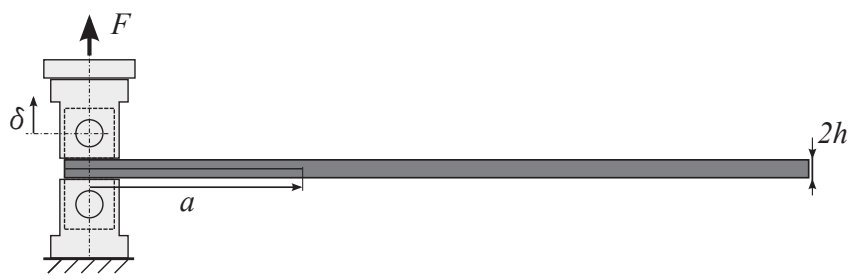

Figure 4.3 Schematic illustration of the double cantilever beam test.

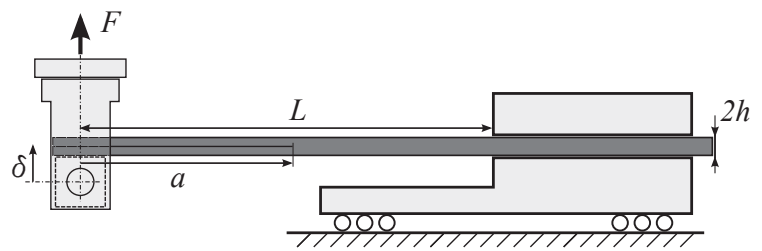

Figure 4.4 Schematic illustration of the end-loaded-split beam test.

using a thin scalpel. These markings helped determine the crack tip position during the ELS experiment. Steel load blocks were bonded onto the specimens using a fast curing adhesive. The load blocks had a width of $20 \mathrm{~mm}$ and the center of the loading hole was $7.5 \mathrm{~mm}$ from the laminate surface.

Twelve mandrel peel specimens, having a width of $8 \mathrm{~mm}$, were also cut from the UD and hybrid laminates. The conformity of the peel arm against the mandrel was monitored during the test using a camera system. For this purpose, a thin coat of white typewriter correction fluid was also applied to one edge of these specimens.

\subsubsection{Testing procedure}

The current section briefly introduces the procedure for the three fracture mechanics experiments. First, the double cantilever beam test will be introduced, followed by the end-loaded-split beam test procedure. Finally, the details of the mandrel peel test are presented.

\section{Double cantilever beam experiments}

The double cantilever beam experiments, schematically illustrated in Figure 4.3, were performed according to the ISO 15024 standard [18]. The specimens were loaded in an Instron universal testing machine equipped with a $1000 \mathrm{~N}$ force cell and a built-in displacement transducer. The crack-tip location was monitored using an automated camera system, mounted on the universal testing machine. The camera was fitted with a lens having a 20x magnification. A software application analyzed the camera pictures taken during the test and adjusted the camera position to determine the crack length [21]. 
The applied force $F$, the displacement $\delta$ as well as the crack length $a$ were measured during the test. The obtained data was reduced using the corrected beam theory (CBT). The critical energy release rate $G_{1 c}$, or fracture toughness, is given by:

$$
G_{1 \mathrm{c}}=\frac{3 F \delta}{2 b(a+\Delta)} \frac{1}{N}
$$

in which $b$ is the specimen width, $N$ is a correction factor for the stiffening of the specimen by the load blocks and $\Delta$ is a correction for crack tip rotation and deflection. No large displacement correction needs to be applied, as the delamination length was measured directly using the horizontal displacement of the traveling camera system. The value of $\Delta$ is determined from a linear regression analysis of $(C / N)^{1 / 3}$ versus $a$ in which $C$ is the measured compliance. The extrapolation of the linear fit through the data yields $\Delta$ as the negative $x$-intercept.

\section{End-loaded-split beam experiments}

The end-loaded-split beam experiments, schematically shown in Figure 4.4 were performed according to the latest ESIS TC4 protocol [19]. The ELS loading fixture comprises a clamping arrangement, which can freely slide in the horizontal direction, with a fixed loading point. The clamped length equaled $60 \mathrm{~mm}$, while the free length $L$ of the specimen was $100 \mathrm{~mm}$. The ratio of the crack length $a$ to the length of the specimen $L$, i.e. $a / L$, was 0.55 or higher for all specimens. Prior to testing, the specimens were pre-cracked in mode I up to 2 to $3 \mathrm{~mm}$.

The fixture was mounted in the Instron universal testing machine. Clamping of the specimen was done using two retaining bolts fastened with a fixed torque of $10 \mathrm{Nm}$. Again, the crack length $a$ was monitored using the camera system. However, in this case the camera position was adjusted manually during the test to center the crack tip in the recorded images. A pencil lead was inserted between the crack faces to minimize friction during testing.

The obtained data was reduced using the corrected beam theory employing the effective crack length (CBTE) [19]. This method does not require the measurement of the actual crack length $a$, but instead calculates it using the known flexural modulus $E_{\mathrm{f}}$ of the specimen. The procedure also requires the value for the clamp correction $\Delta$, which can be determined experimentally [19]. The compliance of the ELS specimen can be written as:

$$
C=\frac{\delta}{F}=\frac{3\left(a_{\mathrm{e}}\right)^{3}+(L+\Delta)^{3}}{2 b h^{3} E_{\mathrm{f}}},
$$


from which the effective crack length $a_{\mathrm{e}}$ can be calculated:

$$
a_{\mathrm{e}}=\left[\frac{1}{3}\left(2 b C h^{3} E_{\mathrm{f}}-(L+\Delta)^{3}\right)\right]^{\frac{1}{3}} .
$$

The effective crack length can now be used to determine the critical energy release rate as follows:

$$
G_{2 \mathrm{c}}=\frac{9 F^{2} a_{\mathrm{e}}^{2}}{4 b^{2} h^{3} E_{\mathrm{f}}}
$$

Alternatively, the data was also analyzed using the simple beam theory (SBT) reduction method [19], which does rely on the measured crack length:

$$
G_{2 \mathrm{c}}^{\mathrm{SBT}}=\frac{9 F^{2} a^{2}}{4 b^{2} h^{3} E_{\mathrm{f}}}
$$

\section{Mandrel peel test}

A mandrel peel setup, as shown in Figure 4.2, was designed following the work of Kawashita et al. [8, 22, 23]. The mandrel used in this work had a radius of $5 \mathrm{~mm}$. The setup was placed in a Zwick universal testing machine which applied the peel force $F_{\mathrm{p}}$, while the alignment force $F_{\mathrm{a}}$ was applied using a pneumatic actuator. Two $1000 \mathrm{~N}$ force transducers were used to measure these forces during the test. The alignment force and peel rate were kept constant at approximately $75 \mathrm{~N}$ and $15 \mathrm{~mm} / \mathrm{min}$, respectively. Nevertheless, a few experiments were performed using an alignment force of $150 \mathrm{~N}$ to investigate its influence on the measured fracture toughness. A camera and mirror were mounted on the setup to monitor whether the peel arm conformed to the mandrel during the test.

The experiment implies two consecutive steps. The tape was peeled from the laminate during the first step. Subsequently, the test was performed again, now with an unbonded tape $\left(\mathcal{G}_{\mathrm{c}}=0\right)$, to determine the friction coefficient $\mu$ in the setup. The critical energy release rate was calculated according to Equation 4.6 as:

$$
\mathcal{G}_{\mathrm{c}}=\frac{1}{b}\left[F_{\mathrm{p}}(1-\mu)-F_{\mathrm{a}}\right] \text {. }
$$

\subsection{Experimental results and discussion}

The current section presents the obtained experimental results. The unidirectionally reinforced reinforced specimens are discussed first, followed by the hybrid speci- 
mens. For each specimen type, the results for the three different experiments (DCB, ELS and mandrel peel) are presented separately, followed by a discussion.

\subsubsection{Unidirectionally reinforced specimens}

\section{Double cantilever beam experiments}

The force versus displacement traces for the UD reinforced DCB specimens were essentially linear upon loading, as is shown in Figure 4.5 (left). The crack initiated after reaching a critical force and subsequently propagated in a stable way, showing a gradual decrease in the measured force signal.

Figure 4.5 (right) shows a typical crack growth resistance curve (R-curve) for a UD DCB specimen. A large number of data points was gathered during the test using the automated camera system, which allowed the construction of a continuous resistance curve. The critical energy release rate $G_{1 c}$ increases gradually after initiation and then levels off to a steady-state or plateau value. The increase in fracture toughness after initiation is attributed to the evolution of a fiber bridging zone across the fracture surfaces [24, 25]. Figure 4.6 shows a micrograph of the edge of a UD reinforced DCB specimen obtained using a stereo-microscope. The figure shows a large fiber bridging zone with a length of approximately $20 \mathrm{~mm}$.
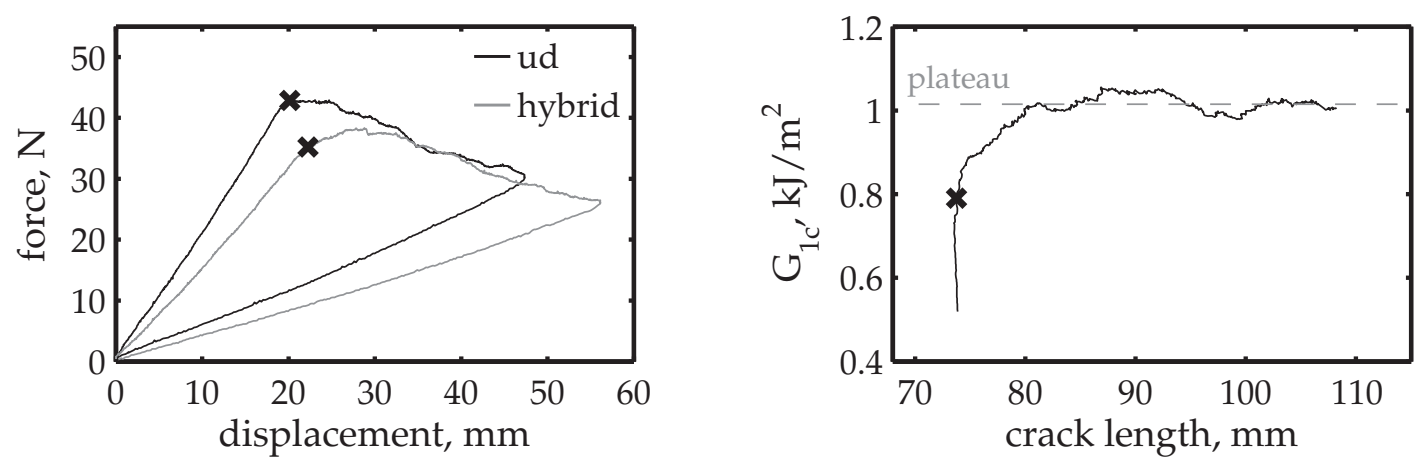

Figure 4.5 Left: Force-displacement trace for a UD reinforced and a hybrid DCB specimen. Right: Resistance curve for a UD reinforced DCB specimen. The cross $\boldsymbol{*}$ denotes the visually observed onset of delamination.

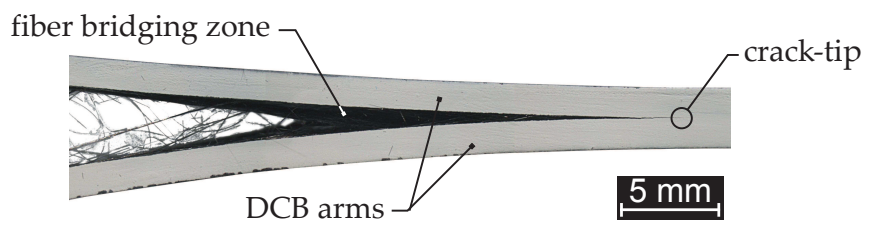

Figure 4.6 Micrograph of the fiber bridging zone in a unidirectionally reinforced DCB specimen. 

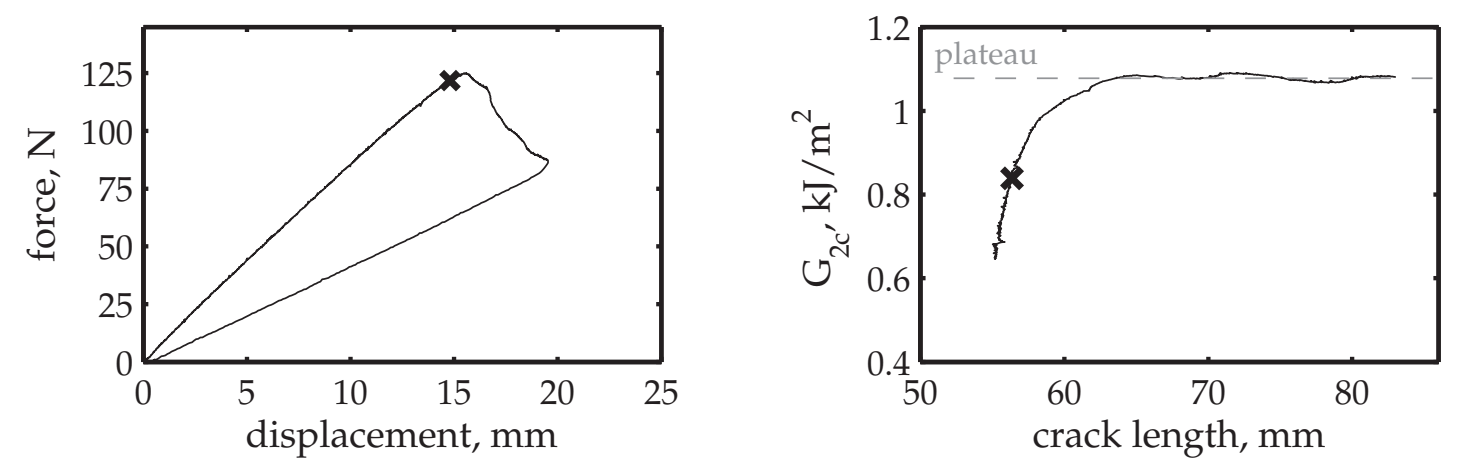

Figure 4.7 Left: Force-displacement trace for a UD reinforced ELS specimen. Right: Resistance curve for a UD reinforced ELS specimen. The cross $\boldsymbol{*}$ denotes the visually observed onset of delamination.

The average initiation and propagation toughness for six UD specimens were $761 \pm 85$ and $1080 \pm 59 \mathrm{~J} / \mathrm{m}^{2}$, respectively. In the current work, the propagation value is taken as the arithmetic mean of the $G_{1 c}$ values recorded over the plateau region.

\section{End-loaded-split beam experiments}

The force-displacement response of the ELS specimens, illustrated in Figure 4.7 (left), exhibited a linear trend until the crack initiated just before the maximum load was reached. Subsequently, the crack propagated stably throughout the specimen. Figure 4.7 (right) shows the resistance curve for a UD ELS specimen. The fracture toughness increases initially, after which it levels off to a plateau propagation value. This behavior is associated with the development of a damage zone in front of the crack tip as the crack propagates [26, 27].

The average initiation and propagation toughness were determined using the CBTE approach and equaled $828 \pm 222$ and $1051 \pm 41 \mathrm{~J} / \mathrm{m}^{2}$, respectively. As a cross-check, the SBT data reduction method yielded an initiation and propagation toughness of $812 \pm 136$ and $1040 \pm 51 \mathrm{~J} / \mathrm{m}^{2}$, respectively. The two data reduction methods resulted in comparable toughness values, although the initiation value showed a lower standard deviation using the crack measurement based method (SBT). The high standard deviation found for the initiation values is associated with the difficulty of visually observing the onset of delamination during these tests.

\section{Mandrel peel experiment}

Figure 4.8 (left) shows the effective peel force, i.e. $F_{\mathrm{p}}-F_{\mathrm{a}}$, as a function of the crack length for a UD reinforced specimen. The black line was obtained during the actual 

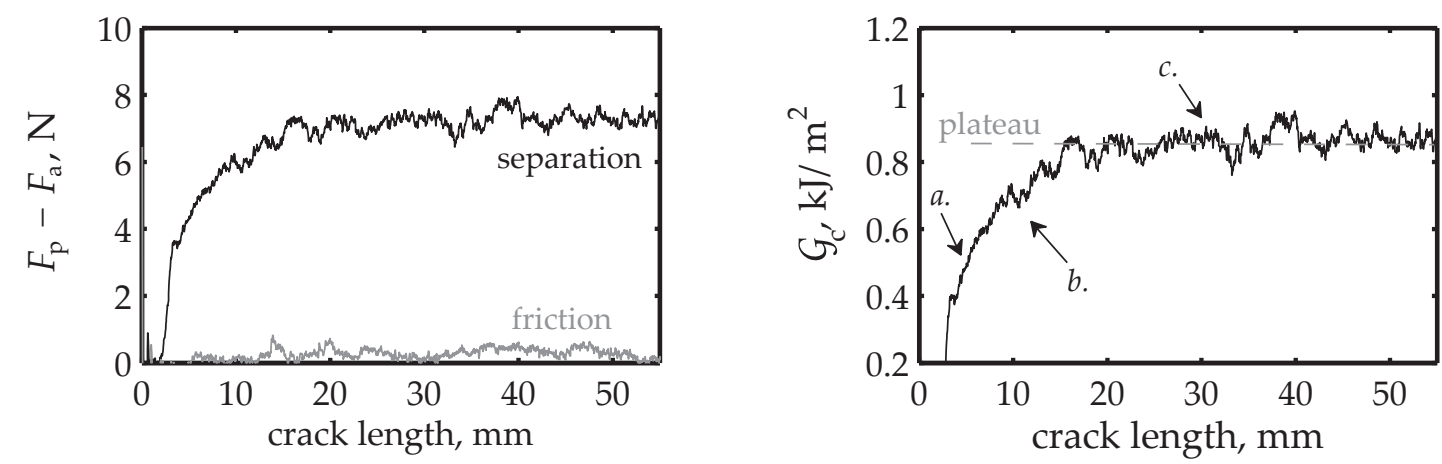

Figure 4.8 Left: Effective force during the peel and friction test for a unidirectionally reinforced peel specimen. Right: Resistance curve for a unidirectionally reinforced mandrel peel specimen. The letters in the graph correspond to the pictures shown in Figure 4.9.
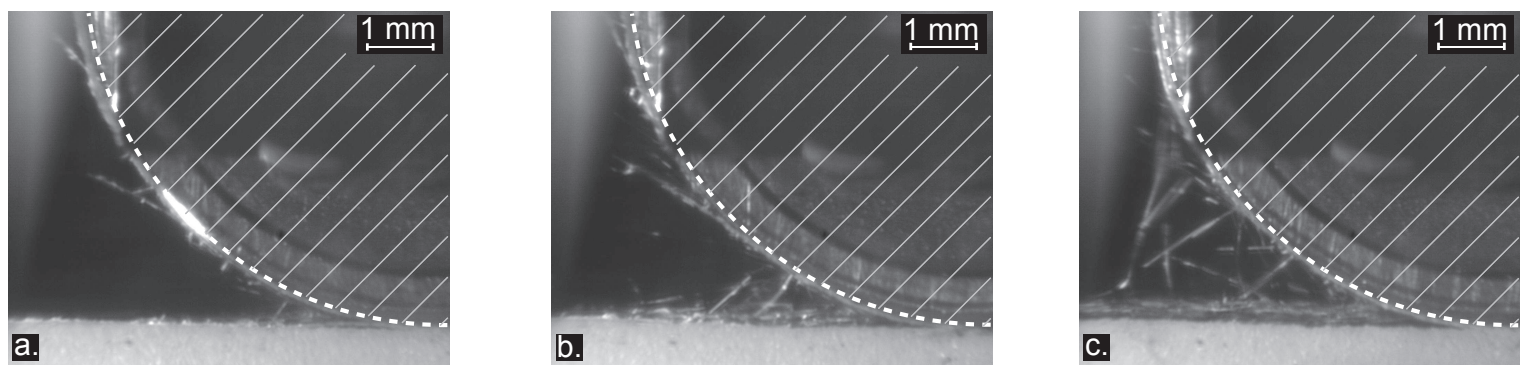

Figure 4.9 Pictures illustrating the size of the fiber bridging zone during the peel experiment on a unidirectional laminate. The hatched region represents the mandrel. The pictures were taken at different stages along the R-curve, shown in Figure 4.8 (right).

peel (separation) experiment, while the gray line corresponds to the subsequent friction correction measurement with the unbonded peel arm. The average friction coefficient $\mu$ equaled approximately $1.5 \%$ for all tested specimens.

Figure 4.8 (right) shows a typical R-curve for these specimens. The fracture toughness increases with crack length until it levels off to a plateau value. The increase in toughness between the initiation and plateau value is partly attributed to the development of a fiber bridging zone directly behind the crack tip. Figure 4.9 shows pictures taken during the peel experiment, which illustrate the increasing size of the bridging zone with increasing crack length. Furthermore, it can be seen that there is no gap between the peel arm and the mandrel during the test.

A total of eight mandrel peel specimens was tested, using an alignment force $F_{\mathrm{a}}$ of $75 \mathrm{~N}$, yielding an averaged propagation fracture toughness of $853 \pm 51 \mathrm{~J} / \mathrm{m}^{2}$. The standard deviation found for these specimens is of the same order of magnitude as for the DCB specimens. Additionally, four specimens were tested using an alignment force of $150 \mathrm{~N}$ to investigate the influence of alignment force. An average fracture toughness of $829 \mathrm{~J} / \mathrm{m}^{2}$ was found for these specimens. The alignment force does not, 
therefore, seem to significantly influence the measured fracture toughness.

\section{Discussion}

Table 4.3 summarizes the experimental results obtained for the UD reinforced carbonPPS specimens. The difference in initiation (init) and plateau propagation (prop) toughness demonstrates the presence of a pronounced R-curve as was observed for the DCB and ELS specimens. The propagation toughness values for these tests are found to be approximately equal, whereas the mandrel peel experiments yielded a lower value. These propagation values, however, include effects such as fiber bridging and damage development at, and in front of, the crack tip. This complicates a direct comparison, because it is not known what the quantitative contributions of these mechanisms are.

There is very little data available in literature concerning the fracture toughness of UD carbon-PPS laminates. Davies et al. [28] reported, in the late eighties, an average DCB propagation value of $799 \mathrm{~J} / \mathrm{m}^{2}$ for specimens with approximately the same thickness. The laminates considered there also comprised UD carbon reinforced PPS, but had a fiber volume fraction of approximately $v_{\mathrm{f}}=56 \%$, which is slightly lower than the laminates used in the current work. Although Davies et al. also observed fiber bridging during propagation, it is not clear how extensive this was compared to the tests performed in the present work.

Davies et al. [28] also performed end-notch-flexure (ENF) experiments and obtained a mode II initiation value of $802 \pm 30 \mathrm{~J} / \mathrm{m}^{2}$. This value agrees quite well with the mode II (ELS) initiation value, $828 \pm 222 \mathrm{~J} / \mathrm{m}^{2}$, found in the present work, though it must be said that the standard deviation reported here is quite high.

The average propagation value for the mandrel peel experiments was $853 \pm 51 \mathrm{~J} / \mathrm{m}^{2}$, which is less than found for the DCB and ELS experiments. Although peel experiments are generally considered as a mixed mode test, this does not include the effects of fiber bridging and extensive damage development in front of the crack tip, making a direct comparison difficult. Comparing the pictures in Figures 4.6 and 4.9 , it is clear that the amount of fiber bridging during the mandrel peel test is rather small compared to the DCB experiment. Not only is the length of the bridging zone smaller, there are also fewer fibers involved in the bridging zone. These effects might be caused by the difference in curvature near the crack-tip. The high curvature of the

Table 4.3 Summary of the averaged fracture toughness (in $\mathrm{J} / \mathrm{m}^{2}$ ) data for the unidirectionally reinforced specimens. The value between parentheses denotes the standard deviation.

\begin{tabular}{|c|c|c|c|c|c|}
\hline \multirow[b]{2}{*}{ sample } & \multicolumn{2}{|c|}{ DCB } & \multicolumn{2}{|c|}{ ELS } & mandrel \\
\hline & init & prop & init & prop & prop \\
\hline UD & $761(85)$ & $1080(59)$ & $828(222)$ & $1051(41)$ & $853(51)$ \\
\hline
\end{tabular}



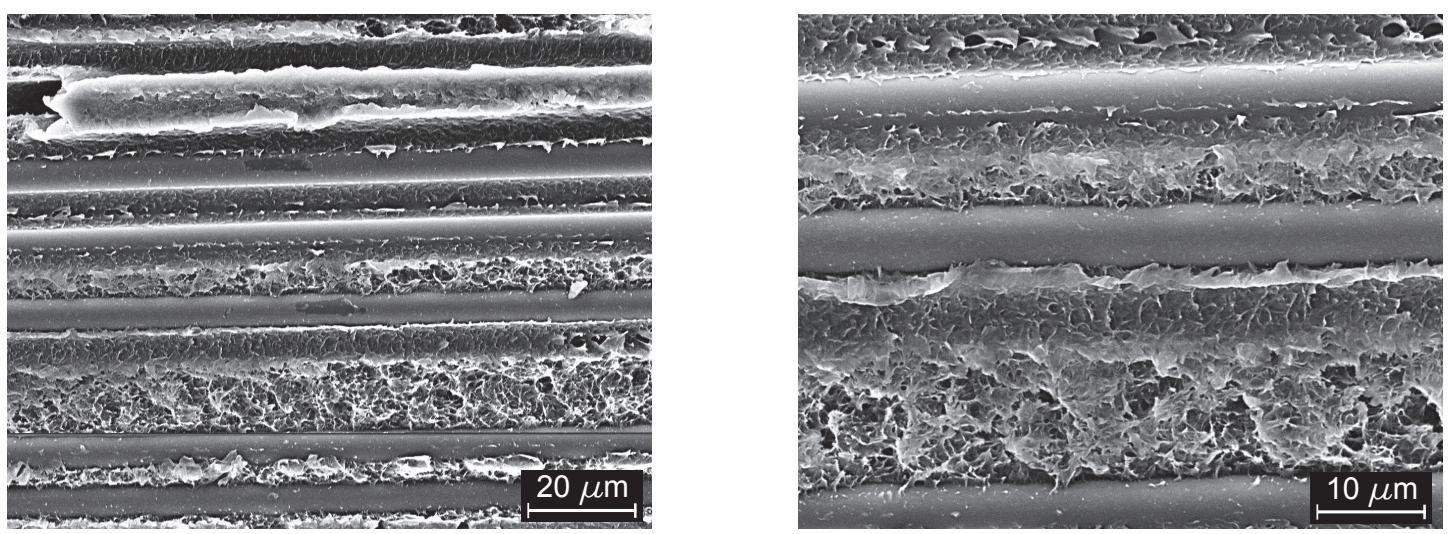

Figure 4.10 Micrographs of the fracture surface of a UD DCB specimen. The crack propagated from left to right.
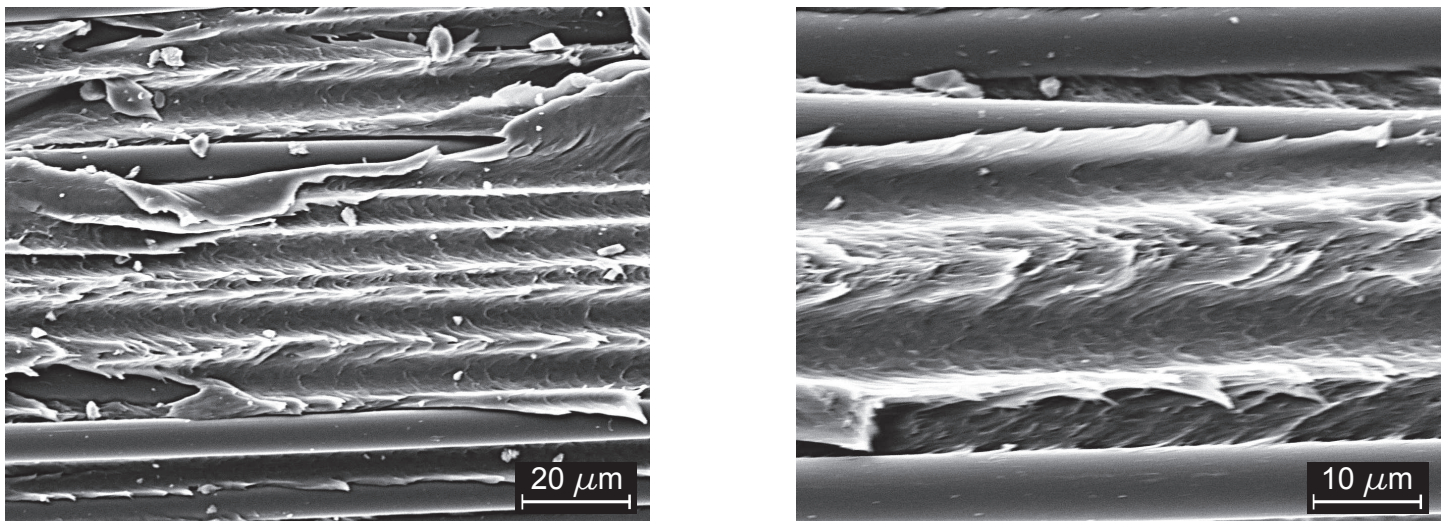

Figure 4.11 Micrographs of the fracture surface of a UD ELS specimen. The crack propagated from left to right.
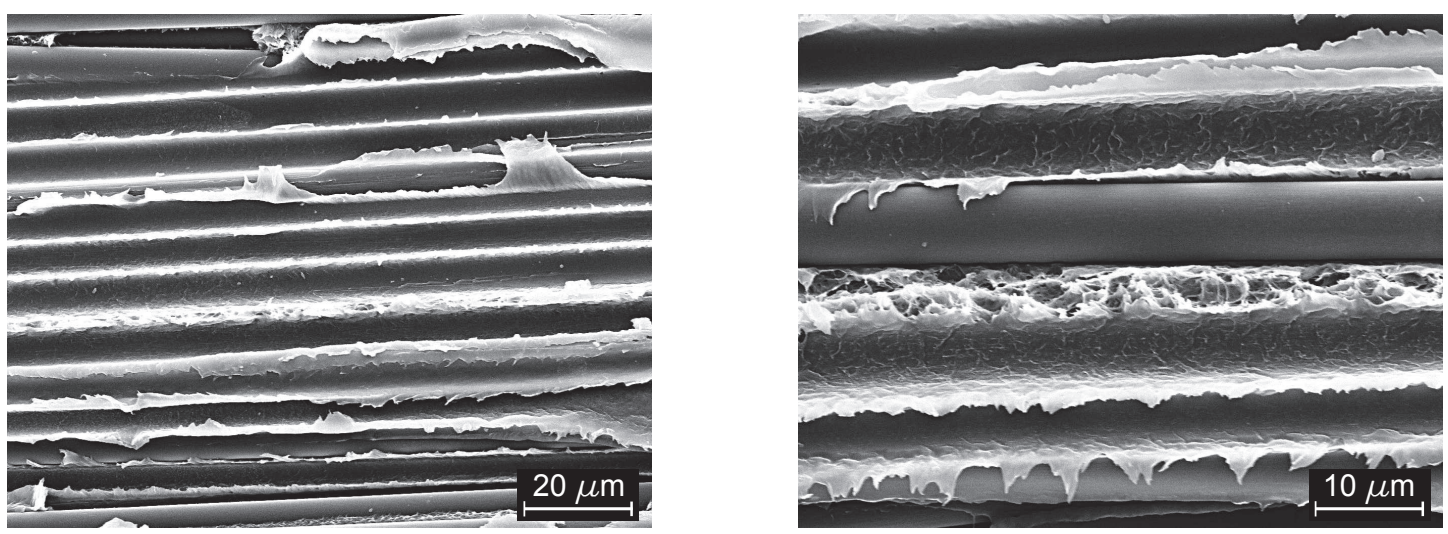

Figure 4.12 Micrographs of the fracture surface of a UD mandrel peel specimen. The crack propagated from left to right. 
peel arm, which is prescribed by the mandrel, prevents the development of a large fiber bridging zone.

The fracture surfaces were examined using a scanning electron microscope (Jeol JCM-500 Neoscope). All specimens showed evidence of fiber-matrix failure, fiber breakage as well as fiber pull-out. The DCB specimens showed a significant amount of loose fibers as evidence of the extensive fiber bridging observed. The ELS specimens showed almost no evidence of fiber bridging as the micrographs showed a lack of broken fibers. The increase in fracture resistance with crack length (R-curve) is therefore not associated with fiber bridging, but with the development of a damage zone ahead of the crack tip [26]. The fracture surfaces of the peel specimens showed only a limited amount of loose fibers in comparison with the DCB specimens. These findings corresponded well with the pictures of the fiber bridging zone in the DCB and peel specimens shown in Figure 4.6 and 4.9, respectively.

Figures 4.10, 4.11 and 4.12 illustrate typical fracture surfaces of a DCB, an ELS and a mandrel peel specimen, respectively. The micrographs all show bare fibers, indicating that failure partly occurred at the fiber-matrix interface. Such failure is generally more prevalent for matrix materials with a high toughness [29, 30]. The fracture surface of the DCB specimen has a less ductile appearance compared to the ELS and peel specimens which show extensive plastic deformation. The distinct morphology of the plastically deformed matrix reflects the loading mode. The fracture surface of the ELS specimen in Figure 4.11 shows traces of significant shear deformation of the matrix material. A more tensile-like matrix failure is observed for the DCB and mandrel peel specimen in Figure 4.10 and 4.12, respectively.

\subsubsection{Hybrid specimens}

\section{Double cantilever beam experiments}

Figure 4.5 (left) shows a representative loading trace for the hybrid DCB specimens. The force versus displacement traces for these specimens were initially linear upon loading. At the onset of crack growth, however, the hybrid specimens showed some nonlinearity. Close inspection of the crack-tip during this stage showed that the crack propagated away from the hybrid, that is the $[0 \| \mathrm{WF}]$ interface, into the adjacent UD reinforced ply. Figure 4.13 shows the fracture surface of such a specimen. The figure illustrates that the crack deflects away from the hybrid interface. As the crack propagates, it becomes increasingly difficult to distinguish the structure of the woven fabric ply at the initial crack interface. The obtained propagation fracture toughness will, therefore, be discarded as it does not belong to the intended hybrid interface.

The averaged initiation toughness for the hybrid DCB specimens was $700 \pm 89 \mathrm{~J} / \mathrm{m}^{2}$. This value, however, should be treated with care, as the specimens were pre-cracked 


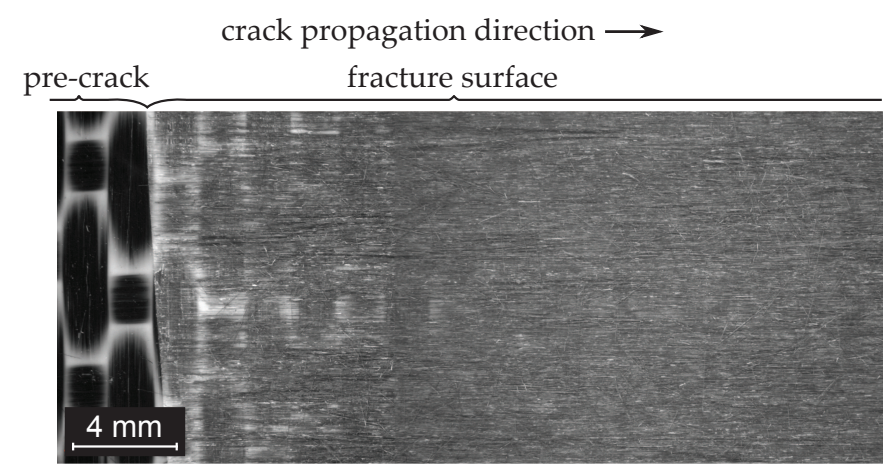

Figure 4.13 Micrograph of the fracture surface of a hybrid DCB specimen.

in mode I for a few millimeters prior to testing. The crack will, therefore, already have propagated slightly away from the hybrid interface.

\section{End-loaded-split beam experiments}

All hybrid ELS specimens showed unstable crack propagation behavior. The crack initiated just before the maximum force was reached and subsequently grew instantaneously throughout the complete specimen. This behavior was observed for all mode I pre-cracked ELS specimens. Increasing the ratio of the initial crack length to the specimen length $(a / L)$ did not result in stable crack propagation. Alternatively, four ELS specimens were tested without any mode I pre-crack. Just one of these showed a few millimeters of stable crack propagation. Post-mortem analysis of the fracture surfaces showed that also here the crack propagated away from the hybrid interface into the adjacent UD ply. As no propagation values could be obtained, only the initiation values are reported. For the sake of consistency, only the precracked results are presented. The averaged initiation toughness for these specimens was $1127 \pm 143 \mathrm{~J} / \mathrm{m}^{2}$. Again, these values should be interpreted with care as the previous section showed that mode I pre-cracking caused the crack to move away from the hybrid interface.

\section{Mandrel peel experiments}

Figure 4.14 shows the fracture toughness as a function of crack length for a hybrid peel specimen. Although the curve shows a rather irregular profile, it is more or less constant with crack length. Compared to the resistance curves obtained for the UD specimens, i.e. Figure 4.5 (right), the hybrid peel specimens show a rather flat curve after initiation, which is attributed to the absence of a fiber bridging zone. Figure 4.16 (left) shows a micrograph of the fracture surface. Almost no UD fibers were found at the fracture surface, demonstrating that the crack propagated between the UD and woven fabric reinforced laminate. 


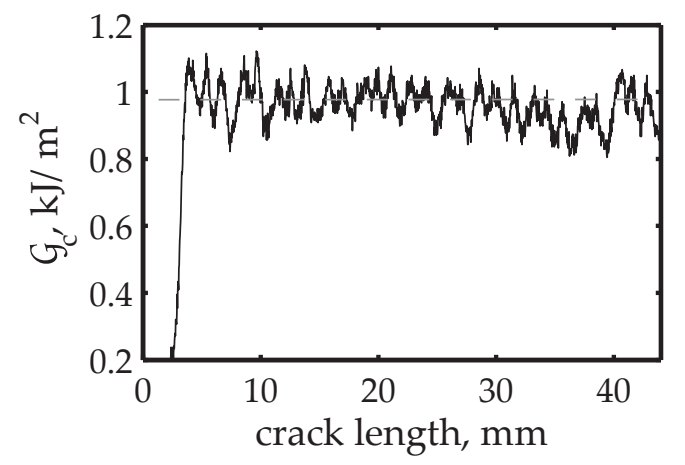

Figure 4.14 Fracture toughness versus crack length for a hybrid mandrel peel specimen.

The irregularity in the peel force originates from the architecture of the 5 harness satin fabric at the interface. The distance between the peaks in the graph corresponds to the distance between the bundles in the woven fabric. A previous study on tapeplaced hybrid specimens [10,31] (see Chapter 6 and Appendix A) yielded similar results. The averaged toughness equals $975 \pm 43 \mathrm{~J} / \mathrm{m}^{2}$ for these specimens.

\section{Discussion}

Table 4.4 summarizes the results obtained for the hybrid specimens. As discussed in the previous sections, the DCB and ELS tests did not yield any propagation data, which was caused by the propagation of the crack into the adjacent UD ply. Moreover, the listed initiation data should be treated with care as these values were obtained after mode I pre-cracking. Contrary to these test methods, the mandrel peel experiment did yield crack propagation data for these hybrid specimens. Moreover, the repeatability of the tested specimens was very satisfactory with a standard deviation of $43 \mathrm{~J} / \mathrm{m}^{2}$.

Figure 4.15 compares the results between the two tested laminate types. It can be seen that the UD specimens show a lower toughness than the hybrid specimens, despite the observed fiber bridging. This corresponds well with the literature concerning delaminations in woven fabric reinforced laminates. Generally, these are found to be more delamination resistant than their UD reinforced counterparts. The nonplanar

Table 4.4 Summary of the averaged fracture toughness (in $\mathrm{J} / \mathrm{m}^{2}$ ) for the hybrid specimens. The value between parentheses denotes the standard deviation.

\begin{tabular}{|c|c|c|c|c|c|}
\hline \multirow[t]{2}{*}{ sample } & \multicolumn{2}{|c|}{ DCB } & \multicolumn{2}{|l|}{ ELS } & mandrel \\
\hline & init & prop & init & prop & prop \\
\hline hybrid & $700(89)^{*}$ & - & $1127(143)^{*}$ & - & $975(43)$ \\
\hline
\end{tabular}

\footnotetext{
* Specimens were pre-cracked in mode I.
} 


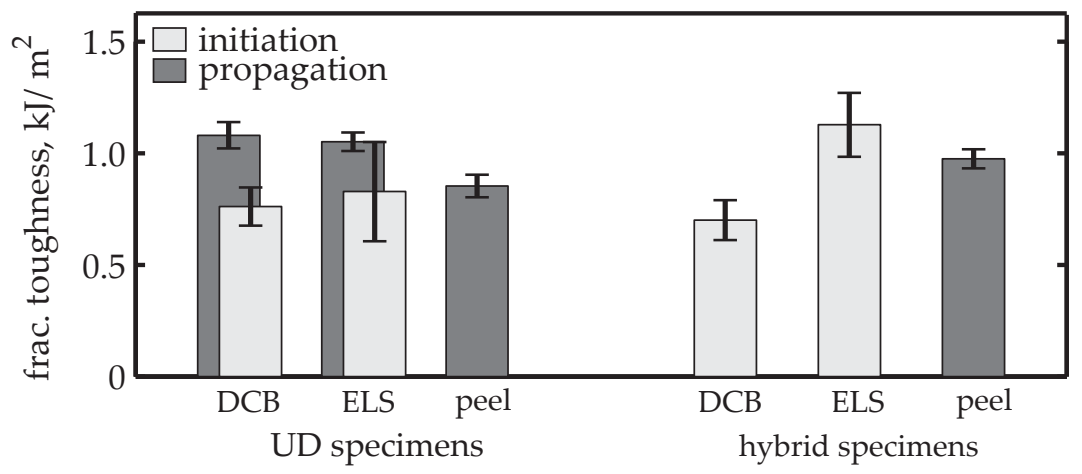

Figure 4.15 Summary of the obtained experimental results.

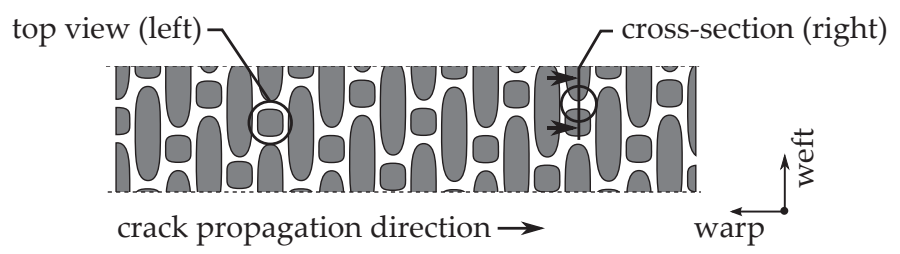

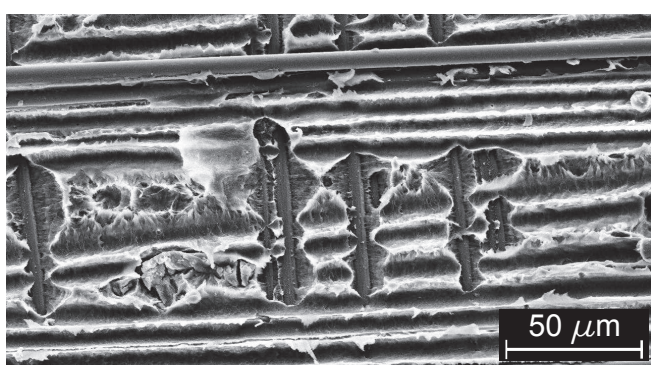

crack propagation direction $\longrightarrow$ weft direction $\uparrow$

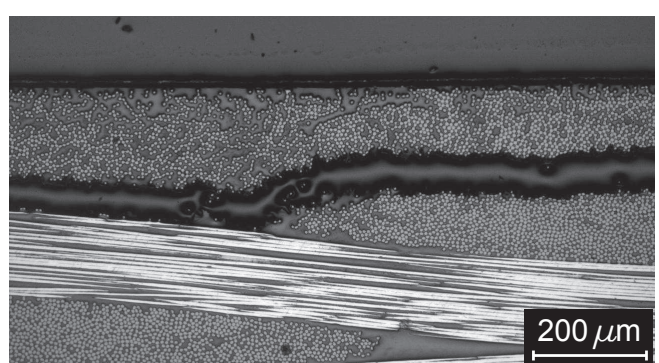

crack propagation direction $\otimes$ weft direction $\longrightarrow$

Figure 4.16 Left: Micrograph of the fracture surface of a hybrid peel specimen. Right: Cross-section of a hybrid mandrel peel specimen near the crack-tip.

structure of woven fabric reinforced composites causes a delamination crack to interact with matrix regions and the weave structure during its propagation, thereby increasing the growth resistance [32,33]. Figure 4.16 (right) shows a cross-section of the hybrid peel specimen. The micrograph illustrates that the tape fibers have locally migrated into the space between the fabric bundles during the press molding process. The resulting nonplanar interface is thought to increase the measured crack growth resistance.

\subsection{Conclusions}

Mandrel peel experiments were successfully performed on press-molded fiber reinforced thermoplastic composites. Two different laminates were tested, namely 
a unidirectionally reinforced laminate and a hybrid laminate, in which the interface comprised a woven fabric reinforced ply combined with a UD reinforced ply. The latter interface is of particular interest for tailored woven fabric reinforced components. The fracture toughness obtained by the mandrel peel tests was compared to values obtained by DCB and ELS experiments.

The mode I (DCB) and mode II (ELS) plateau propagation fracture toughness values were found to be equal, with a value of approximately $1 \mathrm{~kJ} / \mathrm{m}^{2}$, for the UD reinforced specimens. Extensive fiber bridging was observed for the DCB specimens. The fracture toughness obtained for the mandrel peel specimens was $20 \%$ less than that found for the DCB and ELS specimens. The mandrel peel experiments showed little scatter, which was comparable to the DCB and ELS specimens. Pictures of the crack tip during the peel test showed that the amount of fiber bridging was small compared to the DCB experiment, which might explain the lower fracture toughness. Although only one material system was tested, these results demonstrate the potential of the mandrel peel test for UD reinforced thermoplastic laminates.

The fracture toughness experiments were also performed on specimens having a hybrid interface. The DCB and ELS experiments were unsuccessful for these specimens. The crack propagated away from the hybrid interface into the adjacent UD ply during these tests, with the ELS specimens showing highly unstable crack propagation after initiation. The fracture toughness of this interface, however, could be obtained using the mandrel peel test. The repeatability of this test was found to be very satisfactory, with a standard deviation of less than $5 \%$ of the average. Scanning electron microscopy showed that the crack propagated between the fabric reinforced and UD ply with almost no fibers remaining on the fracture surface. The experimental results demonstrate the applicability of the mandrel peel test for these hybrid interfaces.

\section{References}

[1] J. Tierney and J. W. Gillespie Jr. Modeling of in situ strength development for the thermoplastic composite tow placement process. Journal of Composite Materials, 40(16):1487-1506, 2006.

[2] R. Schledjewski. Thermoplastic tape placement - in situ consolidation is reachable. Plastics, Rubber and Composites, 38(9-10):379-386, 2009.

[3] M. A. Lamontia and M. B. Gruber. Remaining developments required for commercializing in situ thermoplastic ATP. In SAMPE Baltimore, 2007.

[4] Y. M. P. Toso, P. Ermanni, and D. Poulikakos. Thermal phenomena in fiber-reinforced thermoplastic tape winding process: Computational simulations and experimental validations. Journal of Composite Materials, 38(2):107-135, 2004.

[5] M. Steyer, M. Dubratz, A. Schütte, C. Wenzel, and C. Brecher. Laser-assisted thermoplastic tape-laying systems. JEC Composites Magazine, 47:39-41, 2009. 
[6] R. Schledjewski and M. Latrille. Processing of unidirectional fiber reinforced tapes fundamentals on the way to a process simulation tool (ProSimFRT). Composites Science and Technology, 63(14):2111-2118, 2003.

[7] F. O. Sonmez and M. Akbulut. Process optimization of tape placement for thermoplastic composites. Composites Part A, 38(9):2013-2023, 2007.

[8] L. F. Kawashita, D. R. Moore, and J. G. Williams. The development of a mandrel peel test for the measurement of adhesive fracture toughness of epoxy-metal laminates. Journal of Adhesion, 80(3):147-167, 2004.

[9] L. F. Kawashita, A. J. Kinloch, D. R. Moore, and J. G. Williams. A critical investigation of the use of a mandrel peel method for the determination of adhesive fracture toughness of metal-polymer laminates. Engineering Fracture Mechanics, 73(16):2304-2323, 2006.

[10] W. J. B. Grouve, L. L. Warnet, R. Akkerman, S. Wijskamp, and J. S. M. Kok. Weld strength assessment for tape placement. International Journal of Material Forming, 3(1):707-710, 2010.

[11] E. Breslauer and T. Troczynski. Determination of the energy dissipated during peel testing. Materials Science and Engineering A, 302(1):168-180, 2001.

[12] M. D. Thouless and H. M. Jensen. Elastic fracture mechanics of the peel-test geometry. The Journal of Adhesion, 38:185-197, 1992.

[13] M. D. Thouless and Q. D. Yang. A parametric study of the peel test. International Journal of Adhesion and Adhesives, 28(4-5):176-184, 2008.

[14] P. P. Parlevliet, H. E. N. Bersee, and A. Beukers. Residual stresses in thermoplastic composites - A study of the literature - part I: Formation of residual stresses. Composites Part A, 37(11):1847-1857, 2006.

[15] M. Cirino and R. B. Pipes. In-situ consolidation for the thermoplastic composite ring residual stress state. Composites Manufacturing, 2(2):105-113, 1991.

[16] G. F. Leon, J. C. Hall, J. J. Kelly, B. S. Coffenberry, and M. Cirino. Affordable thermoplastic processing of marine structures. Composites Manufacturing, 6:193-199, 1995.

[17] S. Wijskamp. Shape distortions in composites forming. Ph.D. thesis, University of Twente, 2005.

[18] ISO 15024: Fibre-reinforced plastic composites - Determination of mode I interlaminar fracture toughness, G1c, for unidirectionally reinforced material, 2001.

[19] B. Blackman. An ESIS TC4 protocol: The determination of the mode II fracture resistance of unidirectional fibre composites using the calibrated end loaded split (C-ELS) test and an effective crack length approach. European Structural Integrity Society - Technical Committee 4 on Polymers, Composites and Adhesives, 2009.

[20] J. A. Nairn. Energy release rate analysis for adhesive and laminate double cantilever beam specimens emphasizing the effect of residual stresses. International Journal of Adhesion and Adhesives, 20:59-70, 2000.

[21] J. Van de Zand. Automated double cantilever beam test system. Master's thesis, University of Twente, 2010.

[22] L. F. Kawashita, D. R. Moore, and J. G. Williams. Comparison of peel tests for metal-polymer laminates for aerospace applications. Journal of Adhesion, 81(6):561-586, 2005. 
[23] L. F. Kawashita, D. R. Moore, and J. G. Williams. Protocols for the measurement of adhesive fracture toughness by peel tests. Journal of Adhesion, 82(10):973-995, 2006.

[24] W. S. Johnson and P. D. Mangalgiri. Investigation of fiber bridging in double cantilever beam specimens. Journal of Composites Technology and Research, 9(1):10-13, 1987.

[25] A. Brunner, B. Blackman, and P. Davies. Fracture Mechanics Testing Methods for Polymers, Adhesives and Composites, chapter Mode I Delamination, pages 277-305. Elsevier, 2001.

[26] S. Hashemi, A. J. Kinloch, and J. G. Williams. The effect of geometry, rate and temperature on the mode I, mode II and mixed-mode I/II interlaminar fracture of carbon-fiber/poly(ether-ether ketone) composites. Journal of Composite Materials, 24:918-956, 1990.

[27] H. Wang and T. Vu-Khanh. Use of end-loaded-split (ELS) test to study stable fracture behaviour of composites under mode II loading. Composite Structures, 36(1-2):71-79, 1996.

[28] P. Davies, M. L. Benzeggagh, and F. X. de Charentenay. Delamination behavior of carbon fiber reinforced PPS. In SAMPE Quarterly, volume 32, pages 134-146, 1987.

[29] G. von Bradsky, R. A. Chivers, R. A. Crick, and R. M. Turner. Interlaminar fracture toughness of a range of continuous fibre PEEK composites. Composites Science and Technology, 47(1):75-81, 1993.

[30] S. Deng and L. Ye. Influence of fiber-matrix adhesion on mechanical properties of graphite/epoxy composites: II. Interlaminar fracture and inplane shear behavior. Journal of Reinforced Plastics and Composites, 18(11):1041-1057, 1999.

[31] W. J. B. Grouve, L. L. Warnet, B. Rietman, and R. Akkerman. On the weld strength of in situ tape placed reinforcements on weave reinforced structures. Accepted for publication in Composites Part A, 2012.

[32] N. Alif, L. A. Carlsson, and J. W. Gillespie Jr. Mode I, mode II and mixed mode interlaminar fracture of woven fabric carbon/epoxy. In Composite Materials: Testing and Design. ASTM STP, 1997.

[33] N. Alif, L. A. Carlsson, and L. Boogh. The effect of weave pattern and crack propagation direction of woven glass and carbon composites. Composites Part B, 29B:603-611, 1998. 


\title{
Influence of the tape placement process parameters on the interlaminar bond strength in carbon-PPS composites ${ }^{1}$
}

\begin{abstract}
The interrelation between process parameters, material properties and interlaminar bond strength is investigated for the laser-assisted tape placement process. For this purpose, unidirectionally carbon reinforced poly(phenylene sulfide) (PPS) tapes were welded onto carbon woven fabric reinforced PPS laminates. The laminate and tape temperature distribution was measured during the welding process. The mandrel peel test method was applied to quantify the bond strength. The experiments demonstrated that an excellent bond quality can be obtained at high velocities and low input power when the laser is primarily pointed at the tape. For these settings, the tape temperature exceeds the laminate temperature, while the latter stays well below the melt temperature of the PPS.
\end{abstract}

\footnotetext{
${ }^{1}$ Reproduced from: W.J.B. Grouve, L.L. Warnet, H.A. Visser, R. Akkerman. Influence of the tape placement process parameters on the interlaminar bond strength in carbon-PPS composites. Submitted to: Composites Part A, 2012.
} 


\subsection{Introduction}

The high degree of automation and out-of-autoclave potential [1,2] make the laserassisted tape placement (LATP) technology attractive for aerospace applications [3]. The process is schematically illustrated in Figure 5.1 and involves the welding of fiber reinforced thermoplastic tapes, under the application of heat and pressure, onto a laminate or onto previously deposited tapes. The final product properties can be tailored to a high degree by incrementally adding tapes in the desired orientation.

The majority of research focuses on the application of the LATP process as a replacement for conventional manufacturing techniques, such as autoclave processing [2, 4, 5]. The technology could, however, also be applied as a postprocessing step to tailor the mechanical properties of conventionally manufactured components. The unidirectionally (UD) fiber reinforced tapes can be welded onto conventionally manufactured components with the aim of locally enhancing the mechanical properties, while keeping the component weight low. Such a process route is especially attractive for tailoring press-formed woven fabric reinforced components. The high drapeability and impact resistance of the woven fabric reinforced thermoplastics is then combined with the high strength and stiffness of the UD reinforced tapes. Ideally, in this processing strategy the tapes should be welded in situ, that is without an expensive post-consolidation step in an autoclave. The current work is performed in a larger framework which aims to develop a placement strategy for such tailored components.

The weld strength between the tape and the woven fabric reinforced component is, especially in the present context, an important parameter as it determines the structure's ability to transfer interlaminar stresses. A complex interrelation exists between the processing parameters, the material properties and the bond strength. The current work explores this interrelation with the aim of developing an energy efficient placement strategy in combination with an excellent bond quality. An experimental program was designed to study the influence of laser power, placement velocity and incident laser angle on the bond strength, which itself was quantified

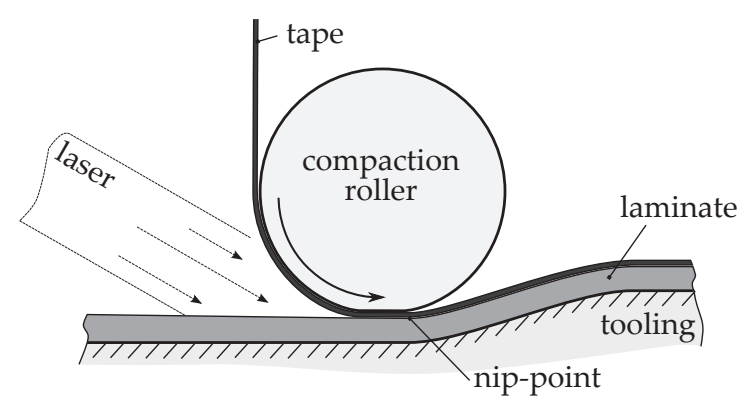

Figure 5.1 Schematic illustration of the tape placement process. The compaction roller has a diameter of nominally $74 \mathrm{~mm}$. 
using a mandrel peel test setup [6, 7] (see Chapter 4). A thermal camera was mounted on the tape placement head to monitor the tape and laminate surface temperature distribution during welding. The relation between these temperatures and the interfacial fracture toughness is discussed in this work. The materials used here, comprise carbon reinforced poly(phenylene sulfide) (PPS) tapes and carbon woven fabric reinforced PPS laminates.

The following section describes the bonding process for thermoplastic composites. The two main contributing phenomena, i.e. the development of intimate contact and the interdiffusion of polymer chains, are briefly discussed. Subsequently, the experimental work is described in Section 5.3, after which the results are discussed. Finally, the conclusions and recommendations for future work are presented.

\subsection{Interlaminar bonding of thermoplastic composites}

The welding of fiber reinforced thermoplastic composites is schematically shown in Figure 5.2 and comprises two different, but simultaneously occurring, phenomena: $i$. intimate contact develops between the two surfaces, and ii. polymer chain interdiffusion, a process also known as healing, takes place between the surfaces in intimate contact. Both phenomena and the influence of the material properties and processing parameters on these phenomena are described in the present section.

\subsubsection{Intimate contact}

Close physical, or intimate, contact between the surfaces is a prerequisite for healing to occur. The degree of intimate contact $D_{\text {ic }}$ is defined as the fraction of the total surface area in contact [8]. Practically, the tape and laminate surfaces are not perfectly smooth, but contain many surface asperities. Complete intimate contact, therefore, cannot be established by simply bringing the two surfaces together. Pressure needs to

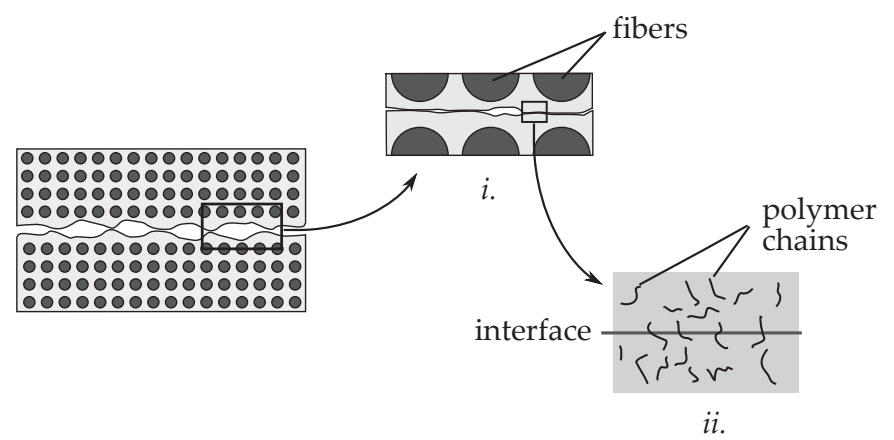

Figure 5.2 Interlaminar bonding: Tape and laminate are brought into contact after which i. intimate contact develops and ii. interdiffusion of polymer chains occurs. 


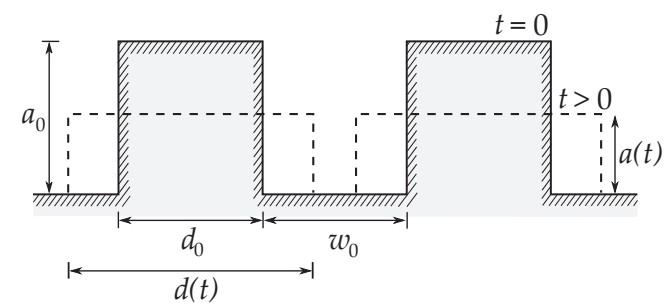

Figure 5.3 Idealized representation of the surface asperities by periodic rectangular elements (reproduced from Lee and Springer [9]).

be applied to deform the asperities, thereby increasing the degree of intimate contact. The actual time required to achieve intimate contact depends on the roughness of the surfaces, the applied pressure and the viscosity of the thermoplastic polymer. An increase in interface temperature facilitates intimate contact development, due to the temperature dependency of the viscosity.

The evolution of intimate contact was originally described mathematically by Dara and Loos [10], who represented the surface roughness as a series of non-uniform rectangles. Lee and Springer [9] simplified the model by considering all rectangles identical with the dimensions shown in Figure 5.3. The applied pressure causes the rectangles to deform, such as indicated by the dashed line in the figure. The degree of intimate contact at time $t_{\mathrm{c}}$ is defined as [9]:

$$
D_{\text {ic }}\left(t_{\mathrm{c}}\right)=\frac{d\left(t_{\mathrm{c}}\right)}{d_{0}+w_{0}}
$$

from which follows that for $D_{\mathrm{ic}}=1$, full intimate contact is achieved. By considering the conservation of mass of a rectangle and assuming laminar flow, the evolution of the degree of intimate contact yields [9]:

$$
D_{\mathrm{ic}}\left(t_{\mathrm{c}}\right)=D_{\mathrm{ic}, 0}\left[1+5\left(1+\frac{w_{0}}{d_{0}}\right)\left(\frac{a_{0}}{d_{0}}\right)^{2} \int_{0}^{t_{\mathrm{c}}} \frac{P_{\mathrm{app}}(t)}{\eta_{0}(T(t))} \mathrm{d} t\right]^{1 / 5},
$$

in which the reference geometric parameters $w_{0}, d_{0}$ and $a_{0}$ for $t=0$ are defined in Figure 5.3. The applied pressure and resin zero-shear-rate viscosity are denoted by $P_{\text {app }}$ and $\eta_{0}$, respectively, while $T$ denotes the temperature. The time $t_{\mathrm{c}}$ is the total time during which pressure is applied, while the amount of area initially in contact is defined as:

$$
D_{\mathrm{ic}, 0}=\frac{d_{0}}{w_{0}+d_{0}}
$$




\subsubsection{Diffusion process and strength development}

The previous section described the evolution of intimate contact between the tape and the laminate. At the areas where this has been achieved, interdiffusion of polymer chains occurs, due to thermal motion. As time passes, a part of the chains will diffuse across the interface and entangle with the polymer chains on the opposite side. The original interface gradually vanishes as the number of crossed chains increases until it cannot be distinguished from the bulk polymer anymore.

The diffusion process for amorphous polymers is generally described using the reptation theory of chain mobility developed by De Gennes [12]. The matrix material is considered as entangled polymer chains, where the movement of an individual chain is restricted by its neighbors [11]. The reptation theory envisions the polymer chain to be confined by a tube, as is shown in Figure 5.4a, in which the chain can only move along the curvilinear length. The chain ends can choose their direction randomly as it moves forward and backward in this virtual tube. With progressing time, the chain ends (head and tail) escape from their original tube and form the so-called minor chains, as shown in Figure $5.4 \mathrm{~b}-\mathrm{d}$. Some of these minor chains will move across the interface, as is illustrated in Figure 5.5, and thereby contribute to the weld strength $[11,13]$. The time required for the chain to exit its original tube is defined as the reptation time $t_{\mathrm{r}}$, which is also considered the characteristic time required to complete healing. The reptation time depends strongly on the molecular weight of the polymer. For high molecular weights, however, the minor chains do not

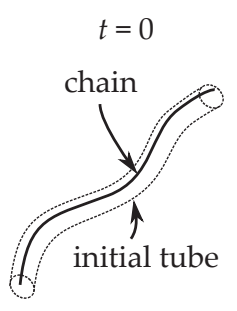

(a)

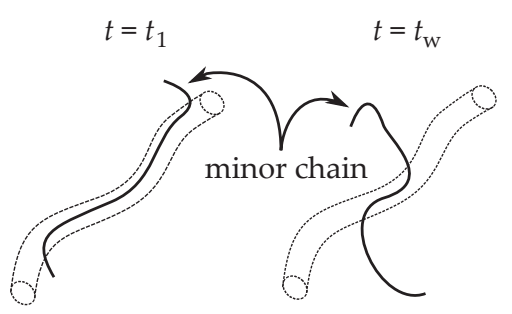

(b)

(c)

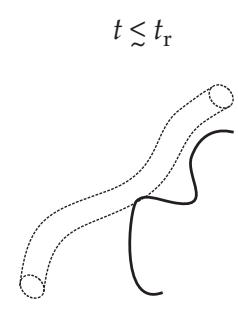

(d)

Figure 5.4 Reptation of a polymer chain $\left(0<t_{1}<t_{\mathrm{w}} \leq t_{\mathrm{r}}\right)$. (Reproduced from Kim and Wool [11]).

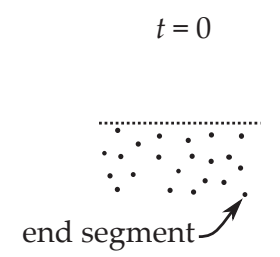

(a)

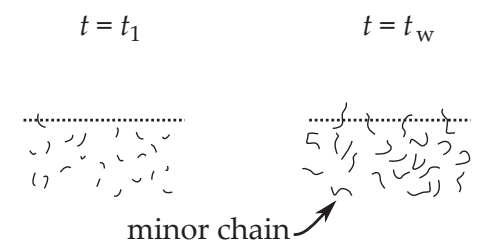

(b) (c)

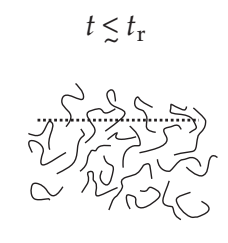

(d)

Figure 5.5 Minor chain motion near an interface contributing to the development of the weld. Only one interface is shown for clarity. (Reproduced from Kim and Wool [11]). 
have to completely escape their virtual tube to attain the maximum weld strength. Instead, healing is completed in a shorter time, designated as the weld time $t_{\mathrm{w}}$ [14].

The degree of healing $D_{\mathrm{h}}(t)$ after a time $t$ is defined as the fraction of the maximum attainable weld strength . The evolution of the non-isothermal degree of healing yields [15]:

$$
D_{\mathrm{h}}(t)=\frac{S(t)}{S_{\infty}}=\left[\int_{0}^{t} \frac{1}{t_{\mathrm{W}}(T(t))} \mathrm{d} t\right]^{1 / 4},
$$

with $S(t)$ and $S_{\infty}$ the bond strength at time $t$ and the ultimate bond strength, respectively. The mobility of the chains increases with increasing temperature, which is reflected by a decrease of the weld time $t_{\mathrm{w}}$. Generally, this temperature dependency is described through an Arrhenius law [16].

Although fusion bonding of amorphous polymers under isothermal conditions has received considerable attention in the literature [13], the same cannot be said for semicrystalline polymers. A direct translation of the theory from amorphous to semicrystalline polymers is not straightforward, as was demonstrated experimentally by Boiko et al. [17]. Moreover, the fusion bonding process takes place under highly non-isothermal conditions in the present application.

Lamèthe et al. [18] studied the fusion bonding of neat and carbon reinforced PEEK around its melting temperature $T_{\mathrm{m}}$ and observed a quick increase of the interfacial fracture toughness when the surfaces were well melted. Comparable results were obtained earlier by Plummer et al. [19], Zanetto et al. [20], and Smith et al. [21] who studied fusion bonding of semi-crystalline PP and PA12 under non-isothermal conditions. The presence of the crystallites obstructs the diffusion process below the melting temperature. A part of the polymer chain is fixed firmly in a crystallite, thereby restricting its maximum interpenetration length [17, 18]. This theory was supported by the work of Boiko et al. [17] who performed experiments on the welding of semi-crystalline and amorphous PET in the vicinity of its glass transition temperature. Although the developed interface strength was rather small at these
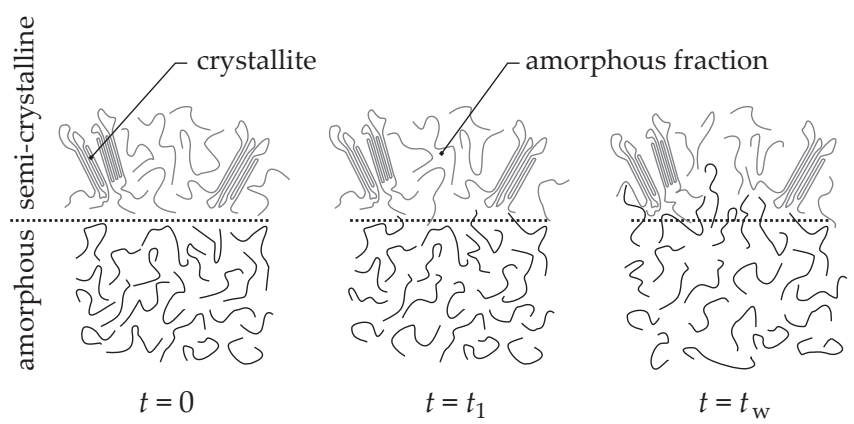

Figure 5.6 Schematic illustration of the fusion bonding process between an amorphous and a semicrystalline polymer. 
temperatures, the experiments helped improve a fundamental understanding of the fusion process itself. The interfacial strength of the crystalline-crystalline interface was found to be one order of magnitude smaller than the strength of the amorphousamorphous and amorphous-crystalline interface. The bond strength in the latter case was assumed to be dominated by the interpenetration of the amorphous chains into the disordered intercrystalline domains of the semi-crystalline polymer, as is schematically illustrated in Figure 5.6. The crystallinity of the semi-crystalline adherent is in this case an important parameter. Boiko et al. showed that an increase of the degree of crystallinity (from 0.27 to 0.40 ), and thereby a decrease in the concentration of chain ends, leads to a decrease of the interfacial strength.

Based on the discussion above, the presence of crystalline regions thus severely complicates the fusion bonding of semi-crystalline polymers. Adequate interdiffusion seems to require at least one of the adherents to be in a molten state. Moreover, the volume fraction of the amorphous phase in the other adherent should be high enough to allow effective entanglement of the amorphous chains.

\subsubsection{Influence of process parameters}

Based on the aforementioned phenomena, the bond strength is governed by the temperature and pressure history at the interface. The laser-assisted tape placement equipment, used in this work, allows the variation of the laser power, compaction pressure, placement velocity and the laser angle. The latter governs the distribution of the laser light between the tape and the laminate. Although a detailed thermal analysis is required to predict the precise thermal history at the interface, the present section summarizes the effect of laser power, pressure and placement velocity on the bond strength. The effect of the laser angle was discussed elaborately in Chapters 2 and 3.

Equation 5.2 shows that the time required for intimate contact decreases with an increase in the applied pressure $P_{\text {app }}$ or a decrease in resin viscosity $\eta_{0}$. Intimate contact can only be developed under the compaction roller, because pressure is required to deform the surface asperities. As the contact time under the roller is inversely proportional to the placement velocity, this poses restrictions on the maximum achievable placement velocity (and thereby productivity). Elevated temperatures will facilitate the development of intimate contact, due to the temperature dependence of the matrix viscosity. The reptation or weld time, and thereby the time required for interdiffusion, also decreases with increasing temperature. The interface temperature will increase either with an increase of laser power or a decrease in velocity. Therefore, an increase of laser power or a decrease in placement velocity is expected to improve the interfacial bond strength.

Although high temperatures facilitate interlaminar bonding, the thermal stability of the thermoplastic poses an upper limit to the process window. Too high processing 
temperatures may lead to polymer degradation or cross-linking [22, 23], which adversely affects the bond strength.

\subsection{Experimental work}

The current section discusses the experimental work. First, the equipment and materials are introduced, followed by a description of the manufacturing process for the test specimens. Subsequently, the mandrel peel test which was used to quantify the interfacial fracture toughness as a measure for the degree of bonding is elaborated.

\subsubsection{Equipment and materials}

The AFPT GmbH company provided the laser-assisted tape placement equipment used in the present work. The machine consists of a welding robot fitted with a tape placement head comprising a compaction roller, optics to focus the laser beam and rigs to mount spools of fiber reinforced tape. A thermal imaging camera (Xenics, Gobi 384) was mounted on the tape placement head to measure the tape and laminate temperature before these were bonded in the nip-point.

The equipment was used to weld UD carbon-PPS tapes onto carbon woven fabric reinforced PPS laminates. The tape was manufactured by Suprem and has a fiber volume fraction of $55 \pm 3 \%$, while the width and thickness equaled $6.25 \mathrm{~mm}$ and $0.15 \mathrm{~mm}$, respectively. The tape had a low degree of crystallinity of approximately $7 \%$, as was shown in an earlier study [7] (Chapter 6). The laminates, measuring $0.5 \times 0.5 \mathrm{~m}^{2}$, were provided by Ten Cate and consisted of eight plies of quasi-isotropically stacked 5 harness satin carbon-PPS semi-preg. The fiber volume fraction and thickness of the laminates were $50 \%$ and $2.4 \mathrm{~mm}$, respectively. The laminates were manufactured using a press molding process between two caul sheets. The slow cooling rate during production allowed the PPS in these laminates to crystallize and a degree of crystallinity of $28 \%$ was obtained.

The PPS matrix material, in both the tape and laminate, is known as Fortron 0214 and was manufactured by Ticona $\mathrm{GmbH}$. Rheological experiments were performed on the neat PPS material to obtain the viscosity $\eta$ and estimate the weld time $t_{\mathrm{w}}$ at typical processing temperatures.

\subsubsection{Peel specimen preparation}

The mandrel peel specimens were manufactured by welding the carbon-PPS tapes onto the laminates with an in-between distance of approximately $25 \mathrm{~mm}$. This distance ensured that the weld strength of the already deposited tapes is not 


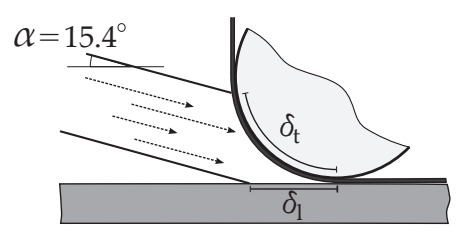

$\delta_{\mathrm{t}}=52 \mathrm{~mm}, \delta_{1}=35 \mathrm{~mm}$

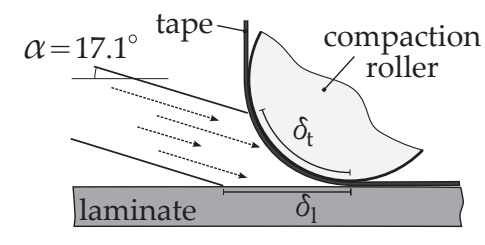

$\delta_{\mathrm{t}}=44 \mathrm{~mm}, \delta_{1}=48 \mathrm{~mm}$

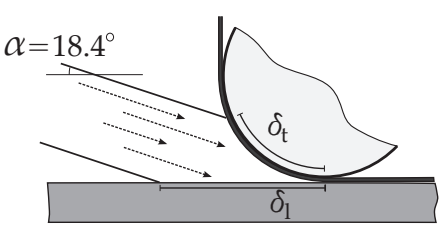

$\delta_{\mathrm{t}}=41 \mathrm{~mm}, \delta_{1}=58 \mathrm{~mm}$

Figure 5.7 Influence of the laser angle $\alpha$ on the light distribution between tape and laminate. (The diameter of the compaction roller equals $74 \mathrm{~mm}$ ).

influenced by the placement of the next tape. A thin $(25 \mu \mathrm{m})$ polyimide film having a length of $100 \mathrm{~mm}$, placed at the edges of the laminate, served as a crack initiator for the peel specimens. Moreover, the film also prevented any start-up effects that may influence the measured toughness. Finally, the specimens were cut from the laminate using a diamond-coated saw after tape placement. A total of four specimens was tested for each combination of process parameters.

The tape placement equipment used in this work allowed the variation of three different process parameters, i.e. the laser power $P$, the placement velocity $v$, and the incident laser angle $\alpha$. The latter controls the distribution of the laser light between the tape and the laminate, as the laser source is mounted at a fixed point on the tape placement head. The laser power was varied between 1300, 1500 and $1700 \mathrm{~W}$, while the placement velocity was chosen between 75, 100 and $125 \mathrm{~mm} / \mathrm{s}$. Also three different laser angles were chosen, that is $15.4,17.1$ and $18.4^{\circ}$. Figure 5.7 illustrates the effect of the laser angle on the power distribution between tape and laminate. The compaction pressure was kept constant for all specimens in this work, in order to keep the number of experiments to a reasonable level. A maximum pressure of approximately $600 \mathrm{kPa}$ was applied, as measured using a pressure-sensitive film.

\subsubsection{Mandrel peel test}

The mandrel peel test was used in the present work to quantify the interfacial fracture toughness as a measure for the degree of bonding. The method, schematically represented in Figure 5.8, was successfully used in earlier studies on the same material combination [7, 24] (see Chapters 4 and 6). The tape is peeled from the laminate with the aid of a cylindrical mandrel having a diameter of $10 \mathrm{~mm}$. An alignment force $F_{\mathrm{a}}$ is applied with a pneumatic actuator to ensure that the tape conforms to the mandrel, thereby preventing the tape from fracturing at the adhesion point. The peel force $F_{\mathrm{p}}$ and the alignment force $F_{\mathrm{a}}$ were measured during the test using two Zwick $1000 \mathrm{~N}$ force transducers. The interfacial fracture toughness yields [7]:

$$
\mathcal{G}_{\mathrm{c}}=\frac{1}{b}\left[F_{\mathrm{p}}(1-\mu)-F_{\mathrm{a}}\right] \text {, }
$$




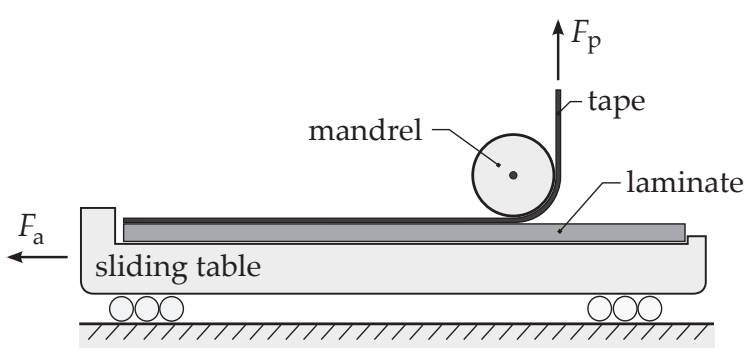

Figure 5.8 Schematic illustration of the mandrel peel test. The mandrel has a diameter of $10 \mathrm{~mm}$.

in which $b$ is the width of the tape. Any friction in the setup is assumed to be proportional to the peel force with $\mu$ the proportionality coefficient. A peel experiment was performed on a non-bonded specimen (thus $\mathcal{G}_{\mathrm{c}}=0$ ) to determine the proportionality coefficient $\mu$, which equaled approximately 0.01 in the used setup. The alignment force $F_{\mathrm{a}}$ and peel rate were kept constant at $100 \mathrm{~N}$ and $15 \mathrm{~mm} / \mathrm{min}$, respectively, for all experiments. Scanning electron microscopy images were obtained from the fracture surfaces to determine dominant failure mechanisms.

\subsection{Bonding analysis and experimental results}

The current section discusses the obtained experimental results. First, an estimate of the times required for intimate contact and healing is presented based on the basic models discussed in Section 5.2. Second, the mandrel peel results are presented, followed by the microscopy analysis on the failed specimens. Finally, the obtained results are discussed.

\subsubsection{Estimation of characteristic process times}

The presented models for intimate contact development and healing are applied to determine which of these mechanisms dominates the interlaminar bonding of carbon-PPS composites under tape placement conditions. For this purpose, rheological experiments on the PPS matrix were performed, as well as profilometry to characterize the tape surface roughness.

\section{Intimate contact}

The time required to achieve full intimate contact $\left(D_{\text {ic }}=1\right)$ is estimated from Equation 5.2. For this purpose, it is assumed that the pressure and the temperature 
Table 5.1 Representative geometric parameters, as defined in Figure 5.3, for the carbon-PPS tape surface.

\begin{tabular}{lccc}
\hline Parameter & Symbol & Units & Value \\
\hline Asperity height & $a_{0}$ & $\mu \mathrm{m}$ & $2.45 \pm 0.86$ \\
Asperity width & $d_{0}$ & $\mu \mathrm{m}$ & $19.96 \pm 8.99$ \\
Valley width & $w_{0}$ & $\mu \mathrm{m}$ & $13.35 \pm 5.73$ \\
\hline
\end{tabular}

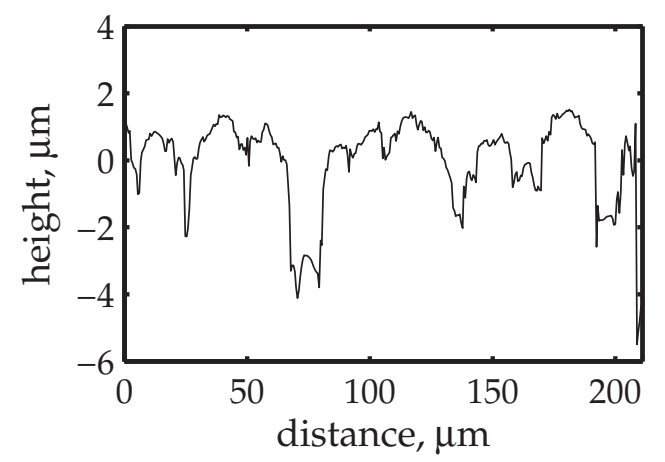

Figure 5.9 Typical surface roughness profile (perpendicular to the fiber direction) for the UD carbon-PPS tape.

are constant under the compaction roller. Rewriting Equation 5.2 then yields:

$$
\bar{t}_{\mathrm{ic}}=\left(D_{\mathrm{ic}, 0}^{-5}-1\right)\left(\frac{1}{5} \frac{d_{0}^{2}}{\left(1+w_{0} / d_{0}\right) a_{0}^{2}}\right) \frac{\eta_{0}(T)}{P_{\mathrm{app}}},
$$

with $a_{0}, d_{0}$ and $w_{0}$ the geometric parameters, as defined in Figure 5.3, which characterize the surface roughness. The laminate surface was very smooth compared to the tape surface, as the former was manufactured using a flat platen molding process between two polished caul sheets. The flattening of the tape surface is, therefore, considered as the limiting factor for intimate contact development. The surface roughness of the tape was characterized using confocal microscopy (Keyence). Figure 5.9 shows a typical surface height profile for the carbon-PPS tape. The obtained roughness surface profiles were fitted with a series of similar rectangles, leading to the values provided in Table 5.1.

The viscosity of the PPS was obtained from capillary rheometry experiments on the neat matrix material of the same type as used in the tape and the laminates. Figure 5.10 (left) shows the apparent viscosity as a function of the shear rate at different temperatures. The experimental data was fitted to a Cross-Arrhenius relation [25]:

$$
\eta(T, \dot{\gamma})=\eta_{0}(T)\left[\frac{1}{1+(\lambda(T) \dot{\gamma})^{1-n}}\right],
$$


Table 5.2 Cross-Arrhenius viscosity parameters for PPS.

\begin{tabular}{lccc}
\hline Parameter & Symbol & Units & Value \\
\hline Power law index & $n$ & - & 0.28 \\
Universal gas constant & $R$ & $\mathrm{~J} /(\mathrm{mol} \mathrm{K})$ & 8.31 \\
Activation energy & $E_{\eta}$ & $\mathrm{J} / \mathrm{mol}$ & $6.86 \cdot 10^{4}$ \\
Proportionality constant & $c_{\eta}$ & Pa s & $1.25 \cdot 10^{-4}$ \\
Activation energy & $E_{\lambda}$ & $\mathrm{J} / \mathrm{mol}$ & $4.50 \cdot 10^{4}$ \\
Proportionality constant & $c_{\lambda}$ & $\mathrm{s}$ & $2.21 \cdot 10^{-8}$ \\
\hline
\end{tabular}

with $T$ the temperature, $\dot{\gamma}$ the shear rate and $n$ the power law exponent. The temperature dependency of the relaxation time $\lambda(T)$ is further elaborated in the next section (Equation 5.9). The temperature dependency of the zero-shear-rate viscosity $\eta_{0}$ is described using an Arrhenius equation:

$$
\eta_{0}(T)=c_{\eta} \exp \left(\frac{E_{\eta}}{R T}\right)
$$

in which $E_{\eta}$ is the activation energy, $R$ the universal gas constant and $c_{\eta}$ a fitting constant, which are all listed in Table 5.2. The lowest advised processing temperature of PPS is approximately $300{ }^{\circ} \mathrm{C}$, which corresponds to a viscosity $\eta_{0}$ of approximately $200 \mathrm{~Pa} \cdot \mathrm{s}$.

As discussed earlier, the maximum applied pressure during placement was $600 \mathrm{kPa}$ as measured using the pressure-sensitive film. Based on the size of the contact area under the roller and the applied force, the average pressure $P_{\text {app }}$ equals nominally $400 \mathrm{kPa}$. Using this pressure, a viscosity of $200 \mathrm{~Pa} \cdot \mathrm{s}$ and the geometric parameters listed in Table 5.1, a characteristic time for intimate contact $\bar{t}_{\mathrm{ic}}$ of approximately $50 \mathrm{~ms}$ is found.
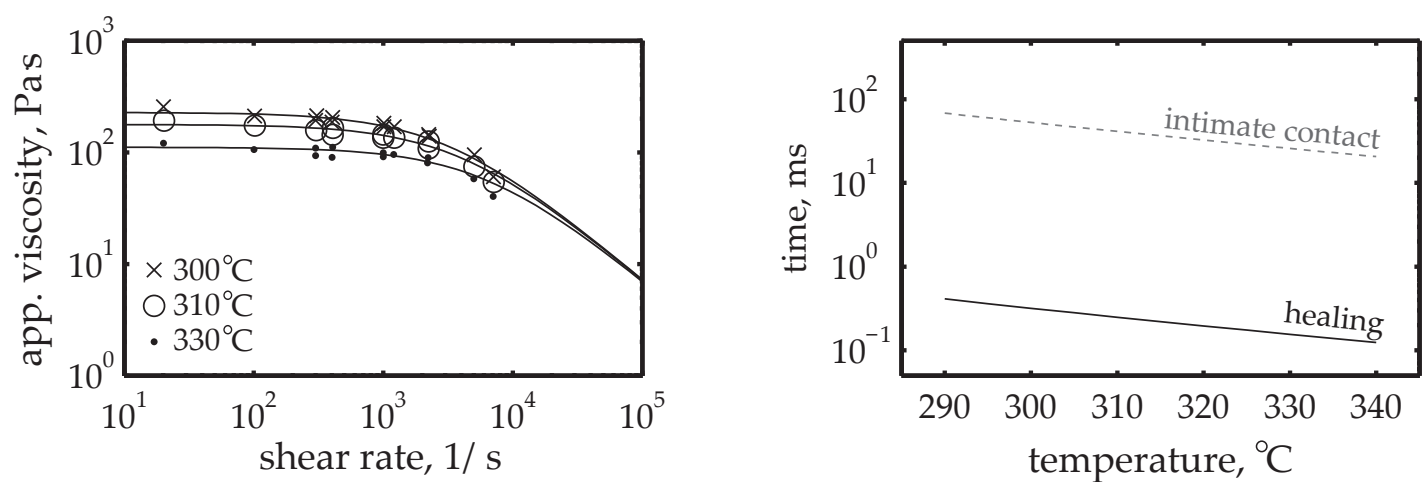

Figure 5.10 Left: Apparent viscosity of PPS as a function of shear rate for different temperatures. Right: Temperature dependency of the characteristic time required for intimate contact and healing. 


\section{Healing}

The time required to complete the healing process can be estimated from Equation 5.4, which requires the temperature-dependent weld time. Much knowledge concerning the healing process has been gained in the past by performing welding experiments on flattened amorphous polymer specimens at different temperatures. The use of amorphous polymers allowed the welding to take place at temperatures near the glass transition temperature. Consequently, the reptation time becomes so large that healing becomes the rate-controlling step for bonding. For semi-crystalline thermoplastics, however, the presence of the crystallites obstructs the interdiffusion process $[17,18]$. Therefore, bonding seems to require at least one of the adherents to be above its melt temperature. Consequently, the reptation time becomes so small that healing is not the (only) rate-controlling step, making it difficult to obtain reptation times by performing actual welding experiments.

Alternatively, the reptation time (and its temperature dependency) may be estimated from rheological experiments [22, 23]. According to Gedde [26], the terminal relaxation time $\lambda$ may be considered as the time needed to complete the renewal of the molecular tube, i.e. $\lambda=t_{\mathrm{r}}$. The terminal relaxation time $\lambda$ can be obtained from rheological experiments and corresponds to the inverse of the shear rate at the transition between the Newtonian plateau and the shear thinning regime. The temperature dependence of the relaxation time obeys Arrhenius law [27]:

$$
t_{\mathrm{r}}(T) \approx \lambda(T)=c_{\lambda} \exp \left(\frac{E_{\lambda}}{R T}\right)
$$

with $E_{\lambda}$ and $c_{\lambda}$ the activation energy and proportionality constant, respectively. Table 5.2 lists the values found by fitting the experimentally obtained viscosity data. The terminal relaxation time is plotted against the temperature in Figure 5.10 (right), from which can be seen that the time required for tube renewal and thus full healing $\bar{t}_{\mathrm{h}}$ equals approximately $0.5 \mathrm{~ms}$ at a typical processing temperature of $300{ }^{\circ} \mathrm{C}$.

\section{Interlaminar bonding}

The simplified analysis demonstrates that, for the materials considered in the present work, the development of intimate contact is the rate controlling step. Moreover, the upper limit bond time is with a value of approximately $50 \mathrm{~ms}$ very short, suggesting that high placement velocities should be achievable. This is confirmed by earlier welding experiments, in which placement velocities of $250 \mathrm{~mm} / \mathrm{s}$ resulted in an excellent bond strength (see Appendix A). The velocity was actually limited by the size of the lay-up tooling and the maximum attainable robot acceleration in that study. 


\subsubsection{Mandrel peel results}

Figure 5.11 (left) depicts a typical example of the effective forces, i.e. the difference between the peel $F_{\mathrm{p}}$ and alignment force $F_{\mathrm{a}}$, during a peel (actual separation) test and during an experiment to determine the friction coefficient $\mu$ for the complete setup. The right graph in the figure shows the fracture toughness for two different specimens. The black line, which corresponds to the forces presented in the left graph, shows that the fracture toughness progresses irregularly. Previous work [24], presented in Chapter 6, demonstrated that such crack propagation behavior is caused by the architecture of the woven fabric reinforcement in the laminate. The distance between the peaks in the graph corresponds with the distance between the resin pockets (nominally $1.5 \mathrm{~mm}$ ) between the carbon fiber bundles at the surface of the laminate. The gray line corresponds to a specimen, manufactured under different conditions, showing a lower fracture toughness in which the crack also seems to propagate more steadily.

The steady-state values are averaged over four specimens for all samples. Figures 5.12 and 5.13 summarize the obtained fracture toughnesses for varying laser power, placement velocity and laser angle. The former graph illustrates the results for a constant laser power of $1500 \mathrm{~W}$, while in the latter the placement velocity was constant at a value of $125 \mathrm{~mm} / \mathrm{s}$. The mandrel peel test results are shown to be sensitive to the variation of the LATP processing parameters. The graphs also show the tape and laminate temperatures measured before the nip-point using the thermal camera. As the camera was calibrated between 0 and $500{ }^{\circ} \mathrm{C}$, temperatures outside this range could not be measured. The dashed line corresponds to the melt temperature of the PPS as provided by the manufacturer [28]. The processing settings strongly affect the tape temperature, which varied at least $200{ }^{\circ} \mathrm{C}$ for the chosen parameters. The laminate temperature varies less, with a difference of maximally
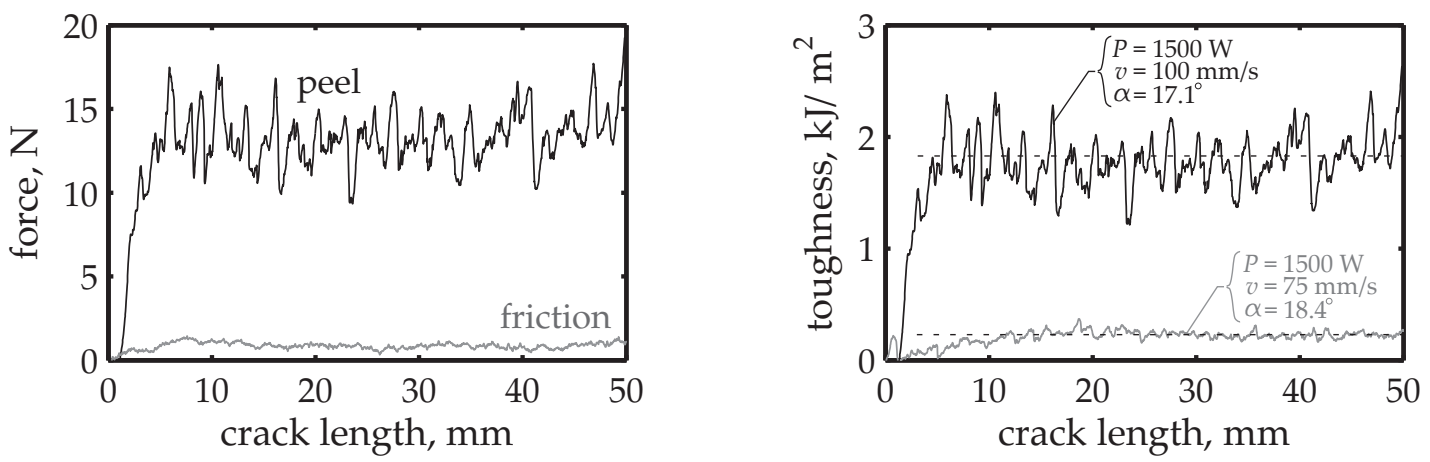

Figure 5.11 Left: Typical peel (separation) and friction force versus crack length graph for a peel specimen. The placement velocity and laser power was $v=100 \mathrm{~mm} / \mathrm{s}$ and $P=1500 \mathrm{~W}$, respectively, while a laser angle $\alpha$ of $17.1^{\circ}$ was used. Right: Fracture toughness as a function of crack length for two specimens processed under different conditions. 


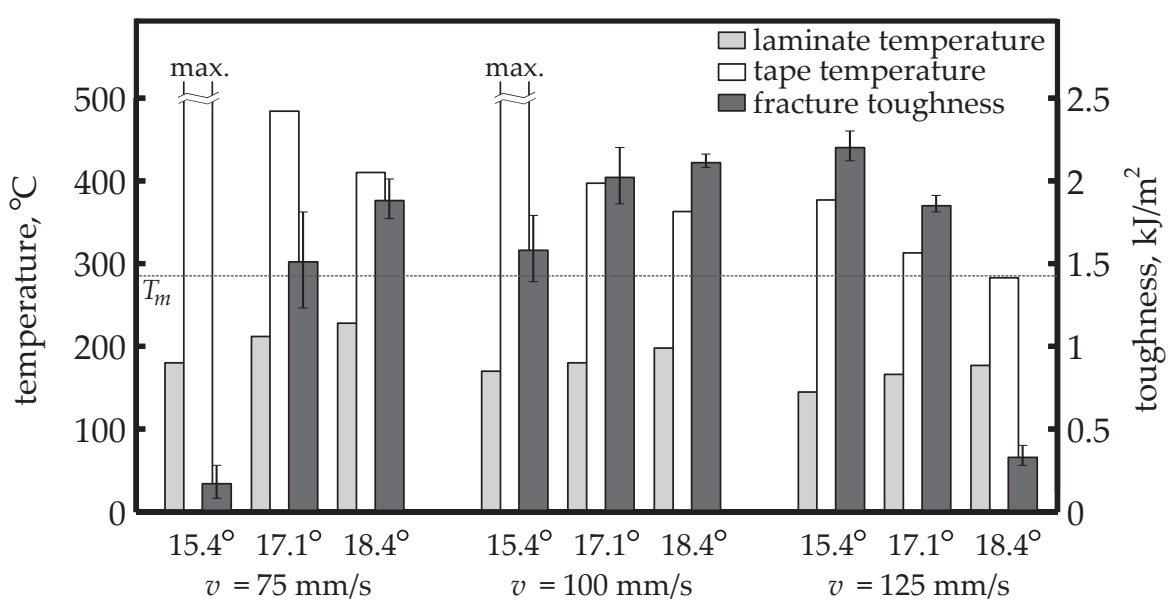

Figure 5.12 Measured tape and laminate temperature (just before the nip-point) and peel fracture toughness as a function of placement velocity and incident laser angle for a fixed power of $P=1500 \mathrm{~W}$. The error bars indicate the standard deviation from the average fracture toughness.

$100{ }^{\circ} \mathrm{C}$. Moreover, the graphs show that the tape temperature $T_{\mathrm{t}}$ exceeds the laminate temperature $T_{1}$ for all depicted cases with an average difference of approximately $200{ }^{\circ} \mathrm{C}$.

Figure 5.12 shows that for the lowest incident laser angle (i.e. $\alpha=15.4^{\circ}$ ) and a placement velocity of 75 or $100 \mathrm{~mm} / \mathrm{s}$ the tape temperature exceeded the $500{ }^{\circ} \mathrm{C}$ upper-bound value. The tape was observed to burn, involving flashes and smoke, during the welding experiment at a velocity of $75 \mathrm{~mm} / \mathrm{s}$. Moreover, traces of carbon black were left on the compaction roller. The accompanying interfacial fracture toughness was very low. This can be attributed to the thermal degradation of the tape matrix material, which for PPS includes crosslinking and chain scission $[22,23,29,30]$. Crosslinking of the PPS would hinder the healing process as the mobility of the chains is severely reduced, while chain scission decreases the strength of the polymer. Increasing the laser angle $\alpha$ at this velocity resulted in a decrease of the tape temperature and an increase of the laminate temperature, which is accompanied by an improvement of the fracture toughness. At a higher velocity of $125 \mathrm{~mm} / \mathrm{s}$, however, increasing the laser angle had the opposite effect and resulted in a strong reduction of the toughness. Possibly, the tape and laminate temperatures were too low to enable healing. The maximum fracture toughness, using a laser power of $1500 \mathrm{~W}$, equaled approximately $2.2 \mathrm{~kJ} / \mathrm{m}^{2}$ and was obtained for a placement velocity of $125 \mathrm{~mm} / \mathrm{s}$ and a laser angle of $15.4^{\circ}$.

The influence of laser power on the interfacial fracture toughness and temperature before the nip-point is shown in Figure 5.13 for a constant placement velocity of $v=125 \mathrm{~mm} / \mathrm{s}$. As expected, the interfacial fracture toughness improves with increasing laser input power. The maximum measured tape temperature equals 


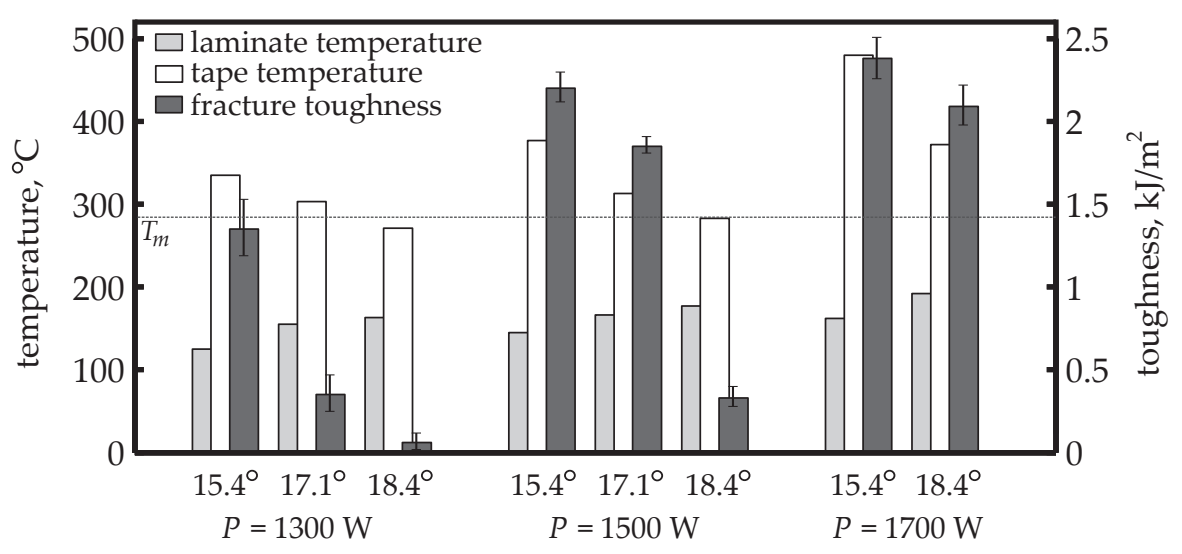

Figure 5.13 Measured tape and laminate temperature (just before the nip-point) and peel fracture toughness as a function of laser power and incident laser angle for a fixed placement velocity of $v=125 \mathrm{~mm} / \mathrm{s}$. The error bars indicate the standard deviation from the average fracture toughness.

approximately $480{ }^{\circ} \mathrm{C}$ at an input power and an incident angle of $1700 \mathrm{~W}$ and $15.4^{\circ}$, respectively. These process settings resulted in the highest measured interfacial fracture toughness. Moreover, for these settings, varying the laser angle has no pronounced effect on toughness, whereas this is the case for a lower laser power. At the lowest input power of $1300 \mathrm{~W}$ a moderately high interfacial fracture toughness is found still when the laser is primarily focused on the tape.

\subsubsection{Fractography}

Scanning electron microscopy images were obtained from the fracture surfaces of the peel specimens with the aim of determining the dominant failure mechanisms. A combination of interlaminar and intralaminar failure occurred in all specimens. In the case of intralaminar fracture, the crack can propagate in the tape or the laminate. Tape failure is observed for all specimens, while laminate failure is only seen for the specimens exhibiting a high fracture toughness.

Figure 5.14 shows the laminate fracture surface of a peel specimen welded with a laser power of $1500 \mathrm{~W}$, a placement velocity of $75 \mathrm{~mm} / \mathrm{s}$ and a laser angle of $15.4^{\circ}$. According to the bar graph in Figure 5.12 this specimen showed a very low interfacial fracture toughness, which was attributed to an extremely high tape temperature during the placement process. The left micrograph shows that some matrix material and a few fibers from the tape can be found on the laminate surface after fracture. Moreover, the micrographs also reveal the existence of bubbles or pores in the tape matrix material. Despite the high tape temperature, apparently some degree of interlaminar bonding was still achieved. A mixed (interlaminar and intralaminar) fracture behavior is observed with the crack propagating alternatingly at the weld interface and through the tape. The right micrograph shows a magnification of the 

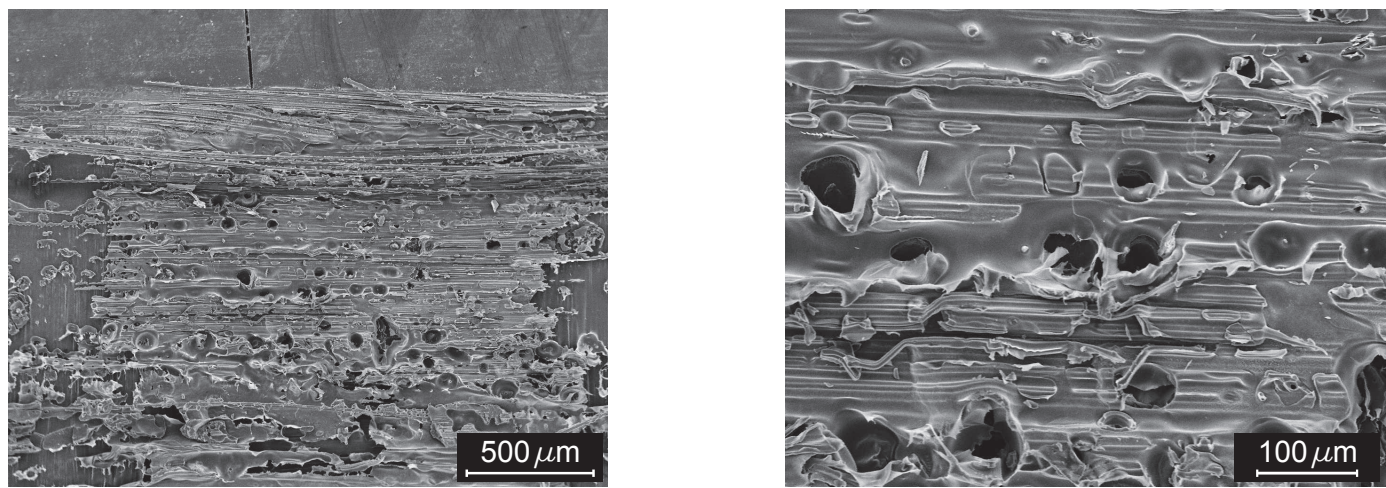

Figure 5.14 SEM micrographs of a peel specimen (laminate) welded using a laser power $P=1500 \mathrm{~W}$, a placement velocity $v=75 \mathrm{~mm} / \mathrm{s}$ and a laser angle $\alpha=15.4^{\circ}$. The crack propagated from left to right. $\left(\mathcal{G}_{\mathrm{c}}=0.17 \mathrm{~kJ} / \mathrm{m}^{2}, T_{\mathrm{t}}>500^{\circ} \mathrm{C}, \mathrm{T}_{1}=180^{\circ} \mathrm{C}\right)$.
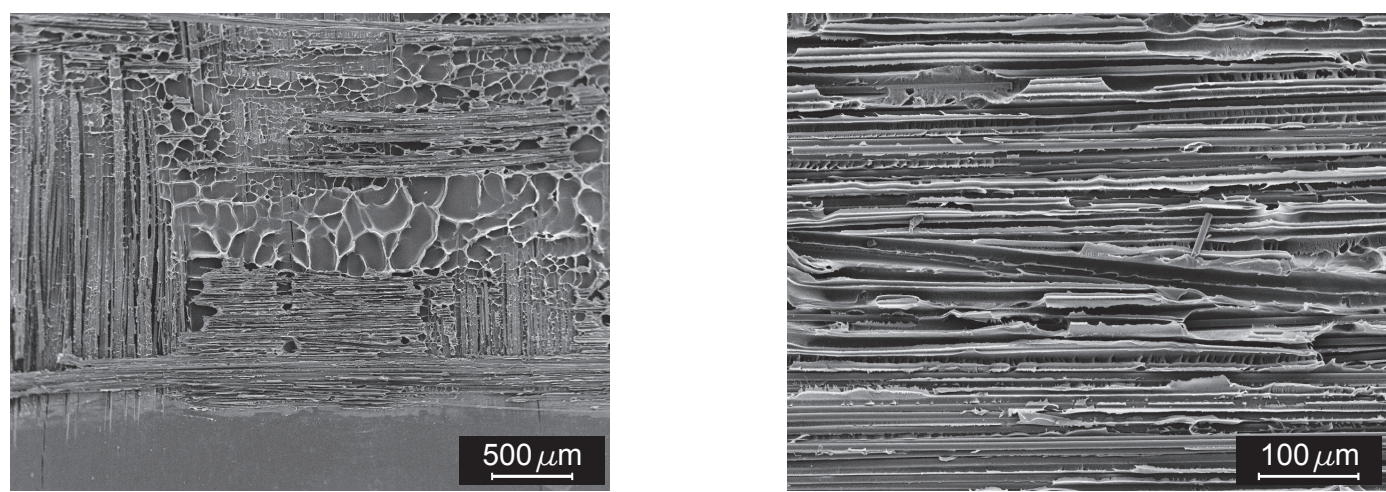

Figure 5.15 SEM micrographs of a peel specimen (laminate) welded using a laser power $P=1500 \mathrm{~W}, \mathrm{a}$ placement velocity $v=100 \mathrm{~mm} / \mathrm{s}$ and a laser angle $\alpha=17.1^{\circ}$. The crack propagated from left to right. $\left(\mathcal{G}_{\mathrm{c}}=2.02 \mathrm{~kJ} / \mathrm{m}^{2}, T_{\mathrm{t}}=397^{\circ} \mathrm{C}, \mathrm{T}_{1}=181^{\circ} \mathrm{C}\right)$.


Figure 5.16 SEM micrographs of a peel specimen (laminate) welded using a laser power $P=1500 \mathrm{~W}, \mathrm{a}$ placement velocity $v=125 \mathrm{~mm} / \mathrm{s}$ and a laser angle $\alpha=18.4^{\circ}$. The crack propagated from left to right. $\left(\mathcal{G}_{\mathrm{c}}=0.33 \mathrm{~kJ} / \mathrm{m}^{2}, T_{\mathrm{t}}=283^{\circ} \mathrm{C}, \mathrm{T}_{1}=177^{\circ} \mathrm{C}\right)$. 
remaining tape matrix material on the laminate. The fracture surface has a brittle appearance, especially compared with the right micrograph in Figure 5.15 which corresponds to a specimen having a high fracture toughness. The high temperature possibly resulted in the thermal degradation of the PPS in the tape which can involve crosslinking and chain scission. Nevertheless, as little information is available on the thermal degradation of PPS subjected to extremely high $\left(>500{ }^{\circ} \mathrm{C}\right)$ temperatures for short times $(<1 \mathrm{~s})$, additional research into this subject is required.

The exact source of the bubbles and pores shown in Figure 5.14 is unknown. Amanat et al. [31] observed similar bubbles and pores during the laser transmission welding of PEEK films. Although the precise origin of the bubbles and pores was not completely clear, these authors offered two possible explanations. The first involves the boiling of the matrix material causing gaseous bubbles to get trapped, while the second involves the evaporation of absorbed water in the matrix.

Figure 5.15 shows the micrograph of a specimen welded using a laser power of $1500 \mathrm{~W}$, velocity of $100 \mathrm{~mm} / \mathrm{s}$ and an angle of $17.1^{\circ}$. The previous section discussed that these specimens exhibited an excellent interfacial fracture toughness. The fracture process was mainly intralaminar with the crack propagating alternatingly in the tape and the laminate. This particular fracture behavior was observed in an earlier research and is extensively described in Chapter 6. The right micrograph shows that the intra-tape failure is accompanied with extensive plastic deformation of the PPS matrix material, thereby significantly contributing to the interfacial fracture toughness.

Figure 5.16 depicts the micrographs obtained for the peel specimen welded using a laser power of $1500 \mathrm{~W}$, a placement velocity of $125 \mathrm{~mm} / \mathrm{s}$ and a laser angle of $18.4^{\circ}$. According to Figure 5.12, these peel specimens showed a negligible interfacial fracture toughness combined with a low tape and laminate temperature. As expected, the micrographs show that almost no bond was developed between the tape and the laminate. The left micrograph shows a largely clean laminate surface with small traces of matrix material from the tape.

\subsection{Discussion}

Figure 5.12 shows that, for a laser power of $1500 \mathrm{~W}$, the highest toughness was obtained for the highest placement velocity. The fractography images of these specimens showed a predominantly intralaminar fracture behavior, with the crack propagating alternatingly in the tape and the laminate. This demonstrated that good interlaminar bonding between the tape and the laminate was achieved and suggests that the process is not limited by the time available for bonding. The simplified analysis, presented in Section 5.4.1, showed that the interlaminar bonding process was limited by the time required to achieve intimate contact. Nevertheless, for the 
simplified case given there, the time required for bonding is still very short, with a value of approximately $50 \mathrm{~ms}$. A placement velocity of $300 \mathrm{~mm} / \mathrm{s}$ should be possible, when considering a contact length between roller and laminate of $15 \mathrm{~mm}$. An earlier study (Appendix A) confirmed this and showed that specimens welded at a velocity of $250 \mathrm{~mm} / \mathrm{s}$ exhibited an excellent interfacial fracture toughness. Additional research is, however, desired to investigate the maximum attainable placement velocity for these materials.

Figure 5.17 (left) shows the interfacial fracture toughness versus the measured laminate (diamonds) and tape temperature (crosses). Clearly, there exists no unambiguous relation between these temperatures and the interfacial fracture toughness. As discussed earlier, the laminate temperature does not exceed the PPS melt temperature. Therefore, melting of the crystallites can only be achieved if the interface temperature is raised sufficiently upon contact with the hot tape. An estimation of the interface temperature $T_{\mathrm{i}}$ can be obtained by averaging the tape and laminate temperature before the nip-point, under the assumption that the heat capacities of the tape and laminate are comparable:

$$
T_{\mathrm{i}}=\left(T_{\mathrm{t}}+T_{1}\right) / 2
$$

This estimation provides an upper-bound value, as the tape and laminate temperature will decrease due to the shadowing effect of the compaction roller, which limits the laser influx near the nip-point. Especially the laminate surface temperature can drop considerably $\left(>50{ }^{\circ} \mathrm{C}\right)$ due to the fact that the laminate is not yet fully heated over its thickness, as was demonstrated in Chapter 3.

The right graph in Figure 5.17 shows the fracture toughness as a function of this interface temperature. The data represented by the squares should be interpreted with care as these represent the specimens in which the tape temperature exceeded $500{ }^{\circ} \mathrm{C}$. As the thermal camera was calibrated up to this temperature, the exact tape temperature is unknown. The graphs show that the interface temperature stayed well below the melting temperature for a number of samples. Consequently, the crystallites in the PPS matrix of the laminate might not have been molten. Despite this, these specimens showed a high interfacial fracture toughness. As the tape itself has an amorphous morphology, it seems that the interdiffusion is dominated by the interdiffusion of amorphous chains into the inter-crystalline regions in the laminate. Actually, the present experiments show some resemblance to the work of Boiko et al. [17]. These authors showed that healing of a semi-crystalline-amorphous interface resulted in an interface strength comparable to an amorphous-amorphous interface.

Nevertheless, such conclusions should be treated with some reservation. Two contributing factors should be kept in mind. Firstly, the interface temperature was defined as the average of the tape and laminate temperature before the nip-point. Such an averaging assumes the tape and laminate volumetric heat capacity to have a 

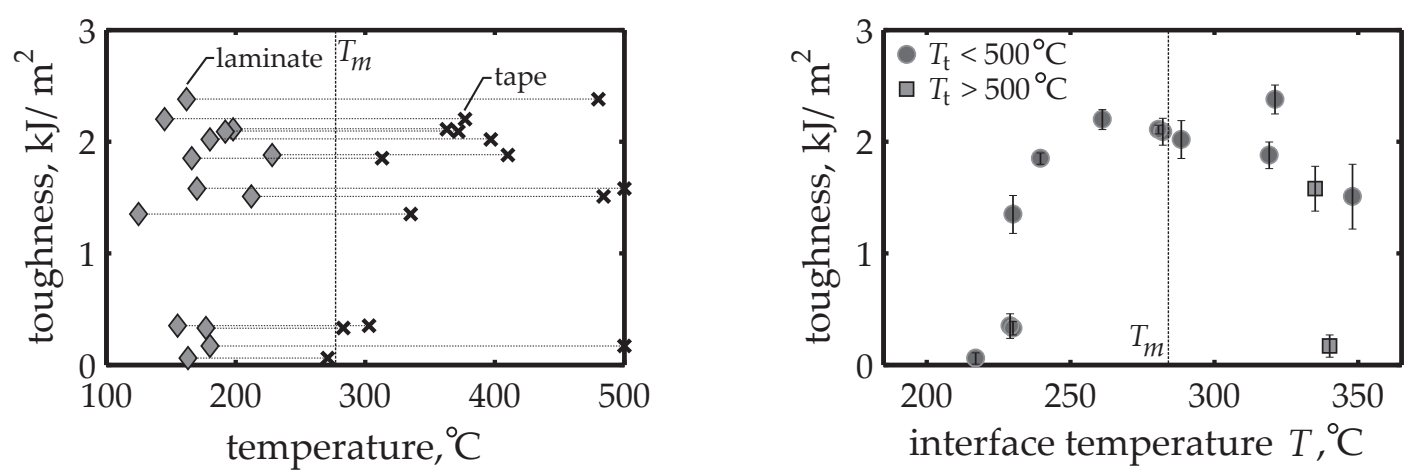

Figure 5.17 Left: Fracture toughness versus the measured laminate (diamonds) and tape (crosses) temperature. Right: Fracture toughness as function of the interface temperature $T_{\mathrm{i}}$ as defined in Equation 5.10 (error bars represent the standard deviation).

comparable value. Although on a macroscopic scale this assumption seems feasible, it might not hold on a meso- or microscopic scale. The heat capacity of the tape and laminate is not only governed by the constituent material properties, but also strongly affected by the fiber distribution. Due to the architecture of the woven fabric reinforcement, the local heat capacity will therefore vary within the laminate. The heat capacity of the resin pockets (in between the bundles) should approach the value for the neat PPS, while the value for the bundles (and tape) can be estimated from a rule of mixtures approach. As the volumetric heat capacity of the carbon fibers exceeds the value for the PPS, it is anticipated that the interfacial temperature at the resin pockets is underestimated using the Equation 5.10. Secondly, by defining the melting temperature of the PPS by the peak in the melting endotherm in a DSC analysis, it is ignored that the local melting point can vary within the semi-crystalline polymer [21]. Moreover, the degree of crystallinity and crystalline morphology at the surface of the laminate might not compare well with the data based on neat PPS.

The presented experimental results and discussion demonstrate the complexity of the tape placement process for these fiber reinforced thermoplastic tapes. Additional research is required to develop a more fundamental understanding of the interdiffusion process for semi-crystalline polymers. From an engineering point of view, however, the results demonstrated that, with the chosen placement strategy, involving a hot tape and a cooler laminate, favorable interfacial fracture toughness can be achieved. Such a strategy may prove valuable especially when adding ply after ply to incrementally build up a component. The already deposited tapes are not repeatedly subjected to high temperatures, thereby reducing the detrimental effects of thermal degradation. 


\subsection{Conclusions}

The present work addressed the welding of UD carbon-PPS thermoplastic tapes onto carbon woven fabric (5 harness satin) reinforced PPS laminates using the tape placement process. The industrial tape placement machine was equipped with a thermal camera which allowed the measurement of the laminate and tape temperature before they meet in the nip-point. The effect of the processing parameters on the bond strength was investigated experimentally using a mandrel peel test. The tape placement equipment allowed the variation of three process parameters, i.e. the laser power, the placement velocity and the incident laser angle. The latter governs the distribution of the laser power between tape and laminate. The mandrel peel test results were found to be sensitive to a variation of these parameters.

Low interfacial fracture toughness was found for either extremely high tape temperatures, of more than $500{ }^{\circ} \mathrm{C}$, or for low interface temperatures. In the former case, the high temperature possibly results in thermal degradation of the PPS, which could have a detrimental effect on the toughness. In the latter case, due to the low thermal energy, no interdiffusion of polymer chains can take place. The tape temperature exceeded the laminate temperature for all manufactured specimens, with an average difference of approximately $200{ }^{\circ} \mathrm{C}$. Moreover, the laminate temperature did not exceed the PPS melt temperature. Effectively, a very hot tape was thus welded on a rather cool (below $T_{m}$ ) laminate. An estimation of the interface temperature $T_{\mathrm{i}}$ suggests that welding is possible at interface temperatures below the melt temperature. Nevertheless, additional research into this particular topic is required.

The experimental results showed that an excellent interfacial fracture toughness can be obtained at high placement velocities and low input power when the laser is primarily focused on the tape. An advantage of such a strategy is that the underlying laminate is not repeatedly subjected to high temperatures in the case of multiple adjacently welded tapes, which minimizes the detrimental effects of thermal degradation. The obtained results, moreover, demonstrate the applicability of the mandrel peel test for process optimization purposes.

\section{References}

[1] S. M. Grove. Thermal modelling of tape laying with continuous carbon fibre-reinforced thermoplastic. Composites, 19(5):367-375, 1988.

[2] F. O. Sonmez and H. T. Hahn. Analysis of on-line consolidation process in thermoplastic composite tape placement. Journal of Thermoplastic Composite Materials, 10:543-572, 1997.

[3] M. A. Lamontia and M. B. Gruber. Remaining developments required for commercializing in situ thermoplastic ATP. In SAMPE Baltimore, 2007. 
[4] R. Schledjewski and M. Latrille. Processing of unidirectional fiber reinforced tapes fundamentals on the way to a process simulation tool (ProSimFRT). Composites Science and Technology, 63(14):2111-2118, 2003.

[5] J. Tierney and J. W. Gillespie Jr. Modeling of in situ strength development for the thermoplastic composite tow placement process. Journal of Composite Materials, 40(16):1487-1506, 2006.

[6] L. F. Kawashita, A. J. Kinloch, D. R. Moore, and J. G. Williams. A critical investigation of the use of a mandrel peel method for the determination of adhesive fracture toughness of metal-polymer laminates. Engineering Fracture Mechanics, 73(16):2304-2323, 2006.

[7] W. J. B. Grouve, L. L. Warnet, and R. Akkerman. Critical assessment of the mandrel peel test for fiber reinforced thermoplastic laminates. Submitted to Engineering Fracture Mechanics., 2011.

[8] C. A. Butler, R. L. McCullough, R. Pitchumani, and J. W. Gillespie Jr. An analysis of mechanisms governing fusion bonding of thermoplastic composites. Journal of Thermoplastic Composite Materials, 11:338-363, 1998.

[9] W. I. Lee and G. S. Springer. A model of the manufacturing process of thermoplastic matrix composites. Journal of Composite Materials, 21(11):1017-1055, 1987.

[10] P. H. Dara and A. C. Loos. Thermoplastic matrix composite processing model. Technical Report 24061, Virginia Polytechnic Institute and State University, Blacksburg, Virginia, 1985.

[11] Y. H. Kim and R. P. Wool. A theory of healing at a polymer-polymer interface. Macromolecules, 16(7):1115-1120, 1983.

[12] P. G. De Gennes. Reptation of a polymer chain in the presence of fixed obstacles. Journal of Chemical Physics, 55(2):572-579, 1971.

[13] R. P. Wool. Polymer Interfaces. Carl Hanser Verlag, 1995.

[14] F. Yang and R. Pitchumani. Nonisothermal healing and interlaminar bond strength evolution during thermoplastic matrix composites processing. Polymer Composites, 24(2):263-278, 2003.

[15] F. Yang and R. Pitchumani. Healing of thermoplastic polymers at an interface under nonisothermal conditions. Macromolecules, 35(8):3213-3224, 2002.

[16] L. J. Bastien and J. W. Gillespie Jr. A non-isothermal healing model for strength and toughness of fusion bonded joints of amorphous thermoplastics. Polymer Engineering and Science, 31(24):1720-1730, 1991.

[17] Y. M. Boiko, G. Guérin, V. A. Marikhin, and R. E. Prud'homme. Healing of interfaces of amorphous and semi-cristalline poly(ethylene terephthalate) in the vicinity of the glass transition temperature. Polymer, 42:8695-8702, 2001.

[18] J.-F. Lamèthe, P. Beauchêne, and L. Léger. Polymer dynamics applied to PEEK matrix composite welding. Aerospace Science and Technology, 9(3):233-240, 2005.

[19] C. J. G. Plummer, P. E. Bourban, J. E. Zanetto, G. D. Smith, and J. A. E. Månson. Nonisothermal fusion bonding in semicrystalline thermoplastics. Journal of Applied Polymer Science, 87(8):1267-1276, 2003.

[20] J. E. Zanetto, C. J. G. Plummer, P. E. Bourban, and J. A. E. Månson. Fusion bonding of polyamide 12. Polymer Engineering and Science, 41(5):890-897, 2001.

[21] G. D. Smith, C. J. G. Plummer, P. E. Bourban, and J. A. E. Månson. Non-isothermal 
fusion bonding of polypropylene. Polymer, 42:6247-6257, 2001.

[22] G. Regnier, C. Nicodeau, J. Verdu, J. Cinquin, and F. Chinesta. A multi-physic and multi-scale approach to model the continuous welding of thermoplastic matrix composites. In ICCM International Conferences on Composite Materials, 2007.

[23] M. A. Khan, P. Mitschang, and R. Schledjewski. Identification of some optimal parameters to achieve higher laminate quality through tape placement process. Advances in Polymer Technology, 29(2):98-111, 2010.

[24] W. J. B. Grouve, L. L. Warnet, B. Rietman, and R. Akkerman. On the weld strength of in situ tape placed reinforcements on weave reinforced structures. Accepted for publication in Composites Part A, 2012.

[25] D. A. Siginer and R. P. Chabra. Advances in the Flow and Rheology of Non-Newtonian Fluids. Elsevier, 1999.

[26] U. W. Gedde. Polymer Physics. Chapman and Hall, 1995.

[27] C. Ageorges and L. Ye. Fusion Bonding of Polymer Composites. Springer, 2002.

[28] Ticona GmbH website: http://www.ticona.com, visited on March 6th, 2012.

[29] M. Dai and D. R. Budgell. Kinetics of thermal degradation of poly(phenylene sulfide). Thermochimica Acta, 203:465-474, 1992.

[30] C. Gros, J. Tarrieu, V. Nassiet, and E. Dutarde. A study of mechanisms of poly(phenylene sulfide) thermal degradation in air. Advanced Materials Research, 112:9-17, 2010.

[31] N. Amanat, C. Chaminade, J. Grace, D. R. McKenzie, and N. L. James. Transmission laser welding of amorphous and semi-crystalline poly-ether-ether-ketone for applications in the medical device industry. Materials and Design, 31:4823-2830, 2010. 



\title{
CHAPter 6
}

\section{Fracture toughness of tailored woven fabric reinforced laminates ${ }^{1}$}

\begin{abstract}
Unidirectionally reinforced thermoplastic tapes were welded onto woven fabric reinforced laminates using a laser-assisted tape placement process. A mandrel peel setup was used to quantify the interfacial fracture toughness between the tape and the laminate as a measure for weld strength. The tape placement process was compared to a conventional press molding process in terms of interfacial fracture toughness. The tape-placed specimens were found to outperform the press-molded specimens. Additional experiments were performed to investigate the influence of the degree of crystallinity and the process-induced weld interface on the measured fracture toughness.
\end{abstract}

\footnotetext{
${ }^{1}$ Reproduced from: W.J.B. Grouve, L.L. Warnet, B. Rietman, R. Akkerman. On the weld strength of in situ tape placed reinforcements on woven fabric reinforced structures. Composites Part A 43:15301536, 2012.
} 


\subsection{Introduction}

The potential for automation and out-of-autoclave production make the tape placement process for thermoplastic composites attractive for the aerospace manufacturing industry [1]. The process is schematically shown in Figure 6.1. Thermoplastic composite components are manufactured by welding pre-impregnated unidirectionally (UD) fiber reinforced tapes onto previously placed and consolidated laminates under the application of heat and pressure. Heat can be applied using, for example, a hot gas torch [2] or a laser [3], while pressure is generally applied with a compaction roller. The actual bonding process is characterized by extremely high heating and cooling rates, often exceeding $400{ }^{\circ} \mathrm{C} / \mathrm{s}$, and a very short bonding time, typically in the order of 0.1 seconds.

The majority of research concentrates on the application of the tape placement process as an alternative for conventional manufacturing techniques, such as autoclave processing [4-6]. The tape placement process, however, may also be applied as an additional processing step. Unidirectionally fiber reinforced tapes are then welded onto fully consolidated structural components with the aim of locally enhancing the mechanical properties, while keeping the component weight low. This processing route is especially attractive for reinforcing press-formed woven fabric reinforced components. The high drapeability and impact resistance of these woven fabric reinforced thermoplastics is then combined with the strength and stiffness of the UD reinforced tapes. Ideally, the tapes should be welded in situ, i.e. without the need for an additional autoclave step, to make the proposed processing route economically more attractive.

The present work focuses on the interfacial weld strength between the UD tape and the woven fabric reinforced laminate. This is an important property as it determines to a large degree the load-carrying capacity of such tailored components. The tape placement process should achieve a weld strength comparable to a conventional manufacturing technique, in order to fulfill the in situ requirement. The present research considers carbon fiber unidirectionally reinforced poly(phenylene sulfide)

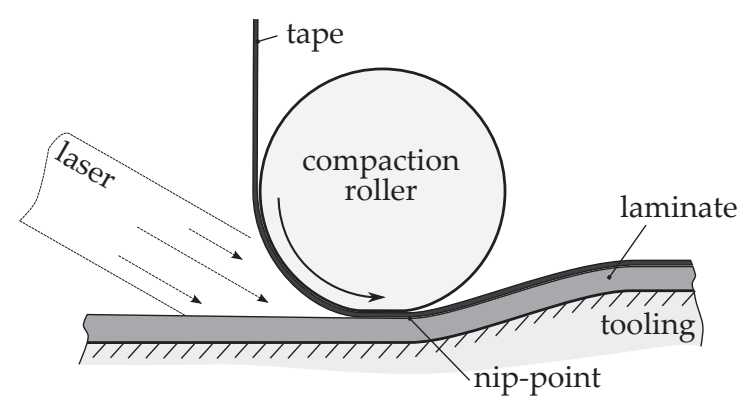

Figure 6.1 Schematic illustration of the laser-assisted tape placement process. The diameter of the compaction roller equals nominally $74 \mathrm{~mm}$. 
(PPS) tapes welded onto a carbon woven fabric reinforced PPS laminate. The test specimens were produced by welding the UD tapes onto pre-consolidated flat laminates using a laser-assisted tape placement (LATP) process. The process parameters for the tape placement process were optimized for weld strength in an earlier study in [7] (see Appendix A of this thesis). As a reference, specimens were also produced using a flat platen hot press.

A mandrel peel test [8-10] was used to quantify the interfacial fracture toughness between the tape and the laminate as a measure for the weld strength. The proposed experimental method provides a straightforward procedure to quantify the interfacial fracture toughness for these tailored components. The specimens are easily produced and, as opposed to the interlaminar shear strength test (ILSS) or wedge peel test [11] for example, closely resemble the intended practical application. Furthermore, the test allows post-mortem analysis of the fracture surface, which provides valuable information about the mechanisms governing the weld strength. The applicability of the method, for the same material combination, was already demonstrated in an earlier study [7].

The test procedure is introduced in the next section, which concerns the experimental work. The third section discusses the experimental results and briefly reviews the mechanisms associated with weld strength development. The two processes under consideration, i.e. LATP and press molding, differ significantly in terms of cooling rate and total process time. The former is expected to influence the matrix crystallinity, while the latter might cause variations in the fiber distribution at the interface. Therefore, the discussion includes these effects. The conclusions are presented in the last section.

\subsection{Experimental work}

\subsubsection{Materials}

The current research focuses on the weld strength between UD carbon reinforced PPS tape and a carbon woven fabric reinforced PPS flat laminate. The pre-impregnated tape was produced by Suprem and consists of unidirectional carbon fibers (AS4) and a PPS matrix (Fortron 0214, from Ticona $\mathrm{GmbH}$ ). The PPS has a glass transition and melting temperature of $85^{\circ} \mathrm{C}$ and $285^{\circ} \mathrm{C}$, respectively. The thickness of the tape is $0.15 \mathrm{~mm}$, while its width equals $6 \mathrm{~mm}$. The tape has a fiber volume fraction of $v_{\mathrm{f}}=55 \pm 3 \%$, according to the specifications of the manufacturer.

The carbon woven fabric reinforced PPS laminates were kindly provided by Ten Cate Advanced Composites. The laminates consist of eight plies of CD286 carbon (T300) 5 harness satin fabric stacked in a quasi isotropic lay-up impregnated with a PPS matrix, which was of the same type as used in the UD tape. A flat platen press 
was used to consolidate the laminates at a temperature of $320^{\circ} \mathrm{C}$ and a pressure of 1.0 MPa. The press was cooled down with a cooling rate of less than $5^{\circ} \mathrm{C} / \mathrm{min}$ after consolidation. The laminates measure $500 \times 500 \mathrm{~mm}^{2}$ and have a thickness of $2.6 \mathrm{~mm}$, while the final fiber volume fraction equals $v_{\mathrm{f}}=50 \%$.

\subsubsection{Specimen preparation}

\section{Tape-placed peel specimens}

The tape-placed specimens were manufactured using a laser-assisted tape placement machine, which was provided by Advanced Fiber Placement Technology (AFPT). The setup consisted of a robot with six degrees of freedom on which a tape placement head was mounted. The head itself comprises a flexible compaction roller, a heatsensitive camera and rigs to place up to six spools with fiber reinforced tape. A diode laser heated the tape and substrate, while the temperature at the nip-point, i.e. where tape and laminate meet, was measured using the heat-sensitive camera. The diode laser has a wavelength and maximum power of $980 \mathrm{~nm}$ and $2 \mathrm{~kW}$, respectively. Optics are used to focus the beam in a square-shaped spot measuring $42 \times 42 \mathrm{~mm}^{2}$. The power was distributed equally between the tape and the laminate. The machine was equipped with a feedback controller to adjust the laser power during welding in order to keep the nip-point temperature constant.

Multiple carbon reinforced PPS tapes were welded on the laminates with a $30 \mathrm{~mm}$ spacing. This distance was chosen such that the subsequent welding of the tapes did not influence the tapes deposited previously. The tape orientation was chosen perpendicular to the dominant bundle orientation in the top ply of the laminate, as Figure 6.2 illustrates. The start edge of the laminate was covered with a thin $(13 \mu \mathrm{m})$ polyimide film with a width of $150 \mathrm{~mm}$, which served as a crack initiator and also prevented any machine start-up effects to influence the measured fracture toughness. Finally, the peel specimens with a length of approximately $250 \mathrm{~mm}$ were cut from the tape-placed laminate using a diamond-coated saw.

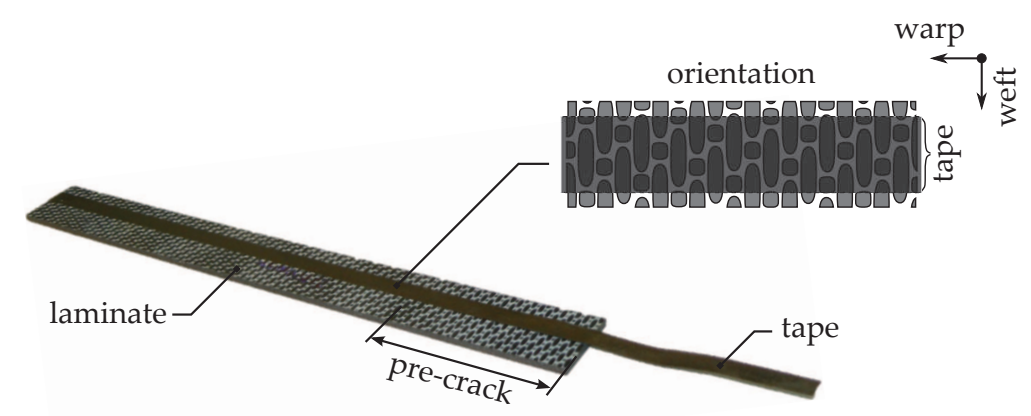

Figure 6.2 Photograph of a tape-placed peel specimen and a schematic illustration of the orientation of the UD tape with respect to the dominant bundle orientation of the top ply in the laminate. 
The processing parameters for the current material and equipment were optimized for weld strength in an earlier study, which is summarized in Appendix A. The placement velocity was kept constant at $150 \mathrm{~mm} / \mathrm{s}$ for both peel samples, while the nip-point temperature equaled 275 and $300{ }^{\circ} \mathrm{C}$. The average compaction pressure was approximately $450 \mathrm{kPa}$, as determined from the measured compaction force and the measured size of the contact area between the flexible roller and the laminate. The maximum compaction pressure exerted on the tape was also measured using a pressure-sensitive film (FujiFilm Prescale). For this purpose, a tape was deposited on the film at room temperature with a placement velocity of $150 \mathrm{~mm} / \mathrm{s}$. The measured maximum pressure was approximately $600 \mathrm{kPa}$.

Six specimens were produced for each temperature setting. The temperature recorded with the heat-sensitive camera was found to underestimate the actual temperature under the compaction roller as measured with thin thermocouples placed on the tape path. In practice, the maximum temperature was found to be slightly higher, approximately $15^{\circ} \mathrm{C}$, than the nip-point temperature recorded by the camera.

\section{Press-molded peel specimens}

The press-molded specimens were manufactured in a purpose-built laboratory press mounted in a universal testing machine. The press provided space for two specimens with a length and width of $200 \mathrm{~mm}$ and $20 \mathrm{~mm}$, respectively. The carbon-PPS laminates were placed in the press and the top ply was completely covered with adjacently placed unidirectional carbon-PPS tapes. The orientation of the tapes with respect to the bundle orientation in the top ply of the laminate was chosen equal to the tape-placed samples. A thin polyimide film was inserted as a crack initiator.

The press was heated to a processing temperature of $310^{\circ} \mathrm{C}$, while applying a pressure of $100 \mathrm{kPa}$ to facilitate heating of the specimens. Subsequently, the pressure was increased to $600 \mathrm{kPa}$, which equals the approximated maximum pressure used for the tape-placed specimens. Moreover, this pressure is in the typical range used for these materials. The temperature was kept constant for 10 minutes, after which the press was water cooled to room temperature with a cooling rate of approximately $10^{\circ} \mathrm{C} / \mathrm{min}$. The peel specimens with a width of $8 \mathrm{~mm}$ were cut from the pressmolded laminates. A total of six peel specimens was produced.

\subsubsection{Mandrel peel test}

The mandrel peel test method, based on the work of Breslauer and Troczynski [8] and Kawashita et al. [9, 10], was employed to measure the interfacial fracture toughness between the tape and the laminate. Figure 6.3 illustrates the setup schematically. The 


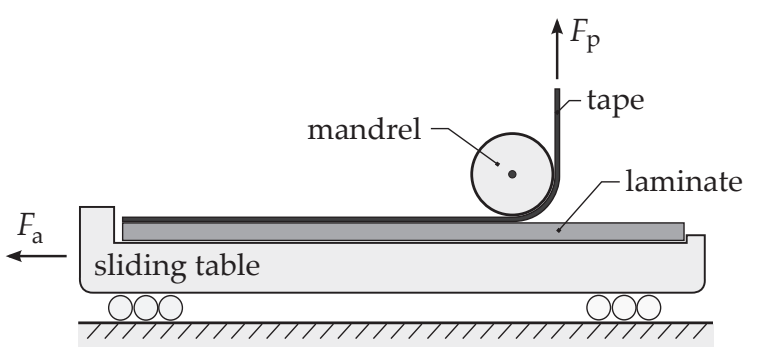

Figure 6.3 Schematic representation of the mandrel peel setup.

peel specimen, comprising a single tape welded on a flat laminate, is mounted on a linear bearing system using thin double-sided adhesive tape. The UD reinforced thermoplastic tape is peeled from the laminate with the aid of a cylindrical mandrel, which in the present work had a radius of $5 \mathrm{~mm}$. An alignment force $F_{\mathrm{a}}$ ensures that the tape conforms to the mandrel during debonding, which in turn prevents the tape from breaking at the crack-tip. The peel force $F_{\mathrm{p}}$ is applied using a universal testing machine, while a pneumatic actuator applied the alignment force.

Breslauer and Troczynski [8] presented the relation between alignment force $F_{\mathrm{a}}$ and peel force $F_{\mathrm{p}}$ if the elastic energy stored in the peel arm (which in the present context is the UD tape) is negligible:

$$
F_{\mathrm{p}}(1-\mu)=F_{\mathrm{a}}+b\left(\mathcal{G}_{\mathrm{c}}+\mathcal{G}_{\mathrm{p}}\right)
$$

in which $\mathcal{G}_{\mathrm{c}}$ is the fracture toughness, $\mathcal{G}_{\mathrm{p}}$ the specific energy associated with plastic deformation of the peel arm and $b$ the width of the peel arm. The specific energy $\mathcal{G}_{\mathrm{p}}$ was found to be negligible for this material combination [7]. The friction force in the setup is assumed to be proportional to the peel force with $\mu$ the proportionality coefficient, which can be interpreted as an average coefficient of friction for the complete setup. The experiment consists of two steps. Firstly, the tape is partly peeled from the laminate to obtain the sum of the forces required to separate the tape from the laminate and the force to overcome friction:

$$
F_{\mathrm{p}}-F_{\mathrm{a}}=b \mathcal{G}_{\mathrm{c}}+\mu F_{\mathrm{p}}
$$

Secondly, the same specimen, now with a debonded tape (thus $\mathcal{G}_{\mathrm{c}}=0$ ), is tested again to determine the friction coefficient $\mu$ of the setup for the tested specimen. The two steps finally yield the fracture toughness $\mathcal{G}_{\mathrm{c}}$ of the interface between the tape and laminate. The average friction coefficient $\mu$ was found to be less than $2 \%$ for the current setup. The alignment force $F_{\mathrm{a}}$ and the peel rate were kept constant for all specimens at approximately $100 \mathrm{~N}$ and $15 \mathrm{~mm} / \mathrm{min}$, respectively. The peel force $F_{\mathrm{p}}$ and the applied alignment force $F_{\mathrm{a}}$, as well as the peeled length, were recorded during the experiments. It should be mentioned here that only half of the full weld 
length was initially quantified for each specimen. The remaining interface length was tested later, as will be explained in the discussion in Section 6.3.

\subsubsection{Experimental results}

Figure 6.4 (left) shows the measured fracture toughness for a tape-placed and a pressmolded specimen. The fracture toughness is normalized by dividing by the average fracture toughness for the press-molded specimens, which equaled $1.05 \mathrm{~kJ} / \mathrm{m}^{2}$. The experimental reproducibility for the press-molded specimens was very satisfactory with a standard deviation of less than $4 \%$. The fracture toughness for the peel specimens progresses irregularly. The origin of this behavior will be discussed in the following section. The left graph in Figure 6.4 shows that the average fracture toughness of the press-molded specimens is less than half the value found for the tape-placed specimens.

The normalized fracture toughness for each specimen was averaged over the peeled length. Figure 6.4 (right) shows the averaged fracture toughness for the press-molded and tape-placed specimens. The chart shows that the tape-placed specimens, for both nip-point temperatures, clearly outperform the press-molded specimens.

\subsection{Discussion}

According to contemporary literature, the development of weld strength comprises two different, but simultaneously occurring mechanisms: $i$. Intimate contact develops between the two surfaces and ii. Intermolecular diffusion, a process which is also known as healing, takes place between the surfaces in intimate contact [12-14].
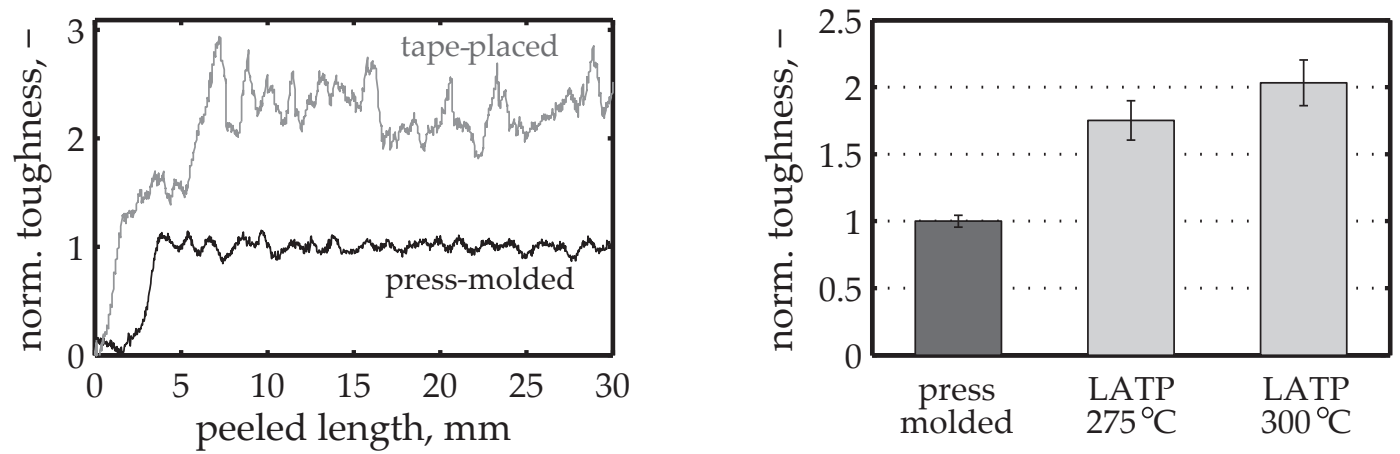

Figure 6.4 Left: Normalized fracture toughness for a tape-placed specimen $\left(T_{\text {nip }}=300^{\circ} \mathrm{C}\right.$, $v=150 \mathrm{~mm} / \mathrm{s}$ ) and a press-molded specimen. Right: Normalized average fracture toughness for the press-molded and tape-placed specimens. The error bars represent the standard deviation. 
Although the weld strength development during tape placement for UD laminates is discussed extensively in the literature, e.g. $[5,15,16]$, UD tape placement on woven fabric reinforced laminates has not yet received much attention.

The first mechanism, that is the development of intimate contact, comprises the flattening of the surface asperities on the tape and laminate. The time required to achieve full intimate contact depends on the roughness of the tape and laminate, the applied pressure and the temperature, through the viscosity, at the weld interface $[12,17-19]$. The second mechanism, that is the interdiffusion of polymer chains, occurs in the regions where intimate contact has been established. Polymer chains migrate across the weld interface during this diffusion process. The process is generally described using the reptation theory [20, 21]. The matrix material is considered as an entanglement of polymer chains, in which the movement of the individual chains is restricted. The mobility of the polymer chains and thereby the diffusion rate increases with temperature, which then again decreases the time required to complete healing $[6,13,14]$.

Based on the mechanisms described above, the large difference in weld time between the LATP and the press molding process suggests that the maximum weld strength should be achieved using the slower press molding process. Nevertheless, as already stated in the previous section, the tape-placed specimens showed a higher interfacial fracture toughness than the press-molded specimens. Apparently, the short weld time during tape placement is sufficient to complete intimate contact and diffusion. Other mechanisms should, therefore, be taken into account to explain the difference in fracture toughness for the press-molded and tape-placed specimens. The next section focuses on the influence of crystallinity on the fracture toughness, while the section thereafter considers the process induced structural morphology of the weld interface.

\subsubsection{Influence of crystallinity on fracture toughness}

The degree of crystallinity of the weld interface is mainly determined by the cooling rate from the melt. The high cooling rate for the LATP process, typically above $400{ }^{\circ} \mathrm{C} / \mathrm{s}$, suggests that the tape-placed weld interface will exhibit a low degree of crystallinity. Essentially, the weld interface is quenched from the melt and consequently a purely amorphous morphology is expected [22]. The press-molded specimens, on the contrary, are allowed to cool down slowly $\left(10^{\circ} \mathrm{C} / \mathrm{min}\right)$ and will obtain a high degree of crystallinity [23, 24].

The relation between crystallinity and the fracture toughness of PPS based composites has been investigated by Davies et al. [25] and Nishihata et al. [26]. Davies et al. performed both mode I double cantilever beam (DCB) and mode II end-notch flexure (ENF) tests on UD carbon reinforced PPS specimens. These authors performed the tests both on quenched specimens (low level of crystallinity of approximately 5\%) 
and on specimens which were annealed after quenching (high level of crystallinity of approximately 30\%). The mode I as well as the mode II energy release rates were found to decrease (approximately 12\%) upon annealing. Nishihata et al. [26] performed fracture toughness experiments on neat PPS and found that the plane strain fracture toughness $\mathrm{K}_{1 \mathrm{c}}$ decreased with increasing crystallinity.

As mentioned above, the difference in degree of crystallinity for the two processes is expected to be quite large. Based on the work of Davies et al. [25] and Nishihata et al. [26], the fracture toughness is anticipated to decrease with increasing crystallinity. The current work investigates the influence of crystallinity on the weld strength between tape and laminate. For this purpose, three different experiments were performed:

- Differential scanning calorimetry (DSC) measurements were performed to determine the degree of crystallinity of the tape prior to and after placement.

- The influence of crystallinity on the tensile properties of the matrix material was obtained by performing tensile tests on as-received (low degree of crystallinity) and annealed dumbbell-shaped PPS film specimens.

- The peel specimens, which were tested in the previous section, were subjected to an annealing step after which the remainder of the tape was peeled from the laminate.

The results of these experiments are discussed in the next three paragraphs.

\section{DSC measurements}

The degree of crystallinity of the carbon reinforced PPS tape was measured using a differential scanning calorimeter from Mettler-Toledo (DSC 822). The crystallinity of the as-received tape and the welded tape (before and after an annealing step) was determined by heating samples from room temperature to $320^{\circ} \mathrm{C}$ with a heating rate of $10{ }^{\circ} \mathrm{C} / \mathrm{min}$. The mass of the samples was approximately $13 \mathrm{mg}$ and the tests were carried out under $\mathrm{N}_{2}$ atmosphere. The mass fraction of the crystalline region yields:

$$
\chi_{\mathrm{c}}=\frac{\Delta H_{\mathrm{f}}+\Delta H_{\mathrm{c}}}{w_{\mathrm{m}} \Delta H_{\mathrm{f}}^{0}},
$$

in which $\Delta H_{\mathrm{f}}$ and $\Delta H_{\mathrm{c}}$ are the measured value of the melting enthalpy and the cold crystallization enthalpy, respectively. By convention, $\Delta H_{\mathrm{f}}$ is positive and $\Delta H_{\mathrm{c}}$ is negative. The value for $\Delta H_{\mathrm{f}}^{0}$ represents the melting enthalpy of PPS with $100 \%$ crystallinity and a value of $150.4 \mathrm{~J} / \mathrm{g}$ [27] was used in the present work. The matrix weight fraction $w_{\mathrm{m}}$ is provided by the data sheets from the manufacturers and equals 0.38 and 0.43 for the tape and laminate, respectively. 
Figure 6.5 (left) shows the DSC heating traces of the UD carbon-PPS tape. The asreceived tape showed a cold crystallization peak at $125{ }^{\circ} \mathrm{C}$ and a melt peak at $280{ }^{\circ} \mathrm{C}$. The area under the crystallization peak approximately equals the area under the melt peak, which indicates that the as-received tape has a low degree of crystallinity, which equaled $\chi_{c}=6.6 \%$. A similar cold crystallization peak is observed for the tapes which were welded onto the laminate using the laser-assisted tape placement equipment. The crystallization peak demonstrates that the cooling rates during tape placement were too high for the PPS to crystallize. A degree of crystallinity of $7.1 \%$ was found for these tapes. The peel specimens were annealed at $130{ }^{\circ} \mathrm{C}$ for 30 minutes. The DSC traces of these specimens do not show the exothermal cold crystallization peak. With a degree of crystallinity of $26.6 \%$, these specimens were fully crystallized during the annealing step. A DSC analysis also confirmed that the tape for the press-molded specimens reached maximum crystallinity with a value of $\chi_{\mathrm{c}}=27.5 \%$.

The woven fabric reinforced laminates were produced by Ten Cate AC using a flat platen molding process. A DSC analysis showed that these laminates had a degree of crystallinity of $28.1 \%$. The amorphous tapes were thus welded onto semi-crystalline laminates. Due to the high heating rate and short process time, it is unclear whether the crystalline regions in the laminate were able to melt during the tape placement process. As only a very thin layer of thermoplastic is involved in the interdiffusion process, it is difficult to assess the exact morphology of the weld interface using a DSC analysis. The morphology of the weld interface is, therefore, not known at this stage. Nevertheless, if the fracture process is accompanied with intra-tape failure, the low crystallinity of the PPS in the tape could have a beneficial effect on the measured fracture toughness.

\section{Tensile properties of PPS film}

The influence of the degree of crystallinity on the tensile properties of PPS was investigated by performing tensile tests on as-received and annealed PPS films. The film, also Fortron 0214 from Ticona, was kindly provided by Ten Cate AC and had a thickness of approximately $160 \mu \mathrm{m}$. A manual die cutting machine was used to obtain dumbbell-shaped specimens. The specimens were all oriented with their length parallel to the roll direction. The gauge length and gauge width of the specimens equaled $35 \mathrm{~mm}$ and $6 \mathrm{~mm}$, respectively. A part of the prepared specimens was annealed in a convection oven at $130{ }^{\circ} \mathrm{C}$ for 30 minutes. The degree of crystallinity of the as-received and annealed film was $5.1 \%$ and $23.8 \%$, respectively.

The tensile properties of the as-received and annealed dumbbell-shaped PPS film specimens were obtained using a Zwick universal testing machine. The machine was fitted with a sensor arm extensometer to measure the strain, while the applied force was recorded using a $100 \mathrm{~N}$ force transducer. The tests were performed with a cross- 

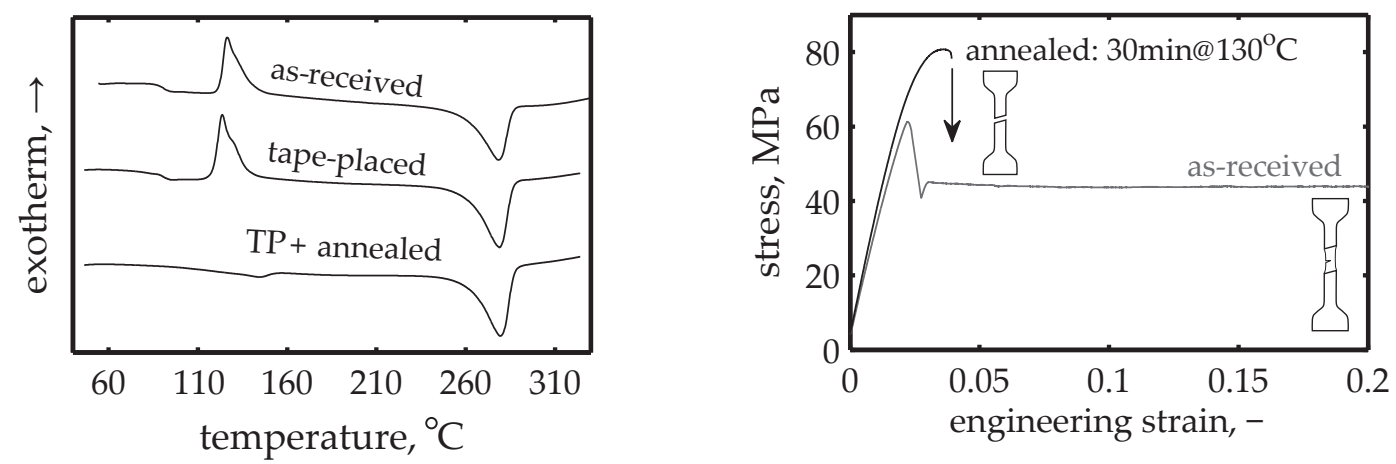

Figure 6.5 Left: DSC heating traces $\left(10^{\circ} \mathrm{C} / \mathrm{min}\right)$ of c-PPS tape for different processing conditions. Right: Stress-strain curves and a schematic representation of the associated failure mode of as-received and annealed PPS film.

head speed of $0.5 \mathrm{~mm} / \mathrm{min}$. A total of twelve specimens, of which six were annealed, was tested.

Figure 6.5 (right) shows the stress-strain curves for an as-received and an annealed PPS dumbbell film specimen. The two curves demonstrate that both the plane stress elastic modulus as well as the yield stress increase upon annealing. The elastic modulus and yield stress for the six as-received dumbbell specimens equaled $2.91 \pm 0.04 \mathrm{GPa}$ and $61.67 \pm 1.10 \mathrm{MPa}$, respectively, versus $3.32 \pm 0.06 \mathrm{GPa}$ and $81.86 \pm 1.22 \mathrm{MPa}$ for the annealed specimens.

Nevertheless, more relevant is the change in failure mode, which is also shown in Figure 6.5 (right). The as-received dumbbell specimens showed necking and an extensive period of cold drawing before fracture. The final global strain equaled $40 \%$ for the depicted as-received specimen. Locally, however, the strain could exceed $250 \%$, as determined by measuring the length change between markings on the specimen. The as-received specimens failed before the full gauge length yielded, which was attributed to local impurities or thickness variations in the tested film. The annealed specimens, adversely, show no cold drawing before fracture and showed a more brittle failure. Although it is difficult to directly link these results to the fracture behavior of the tailored composites, the results clearly show the embrittlement of the PPS upon crystallization. The following section presents the influence of annealing, and thereby the degree of crystallinity, on the interfacial fracture toughness of the peel specimens.

\section{Fracture toughness: annealing experiments}

The tape-placed specimens tested in Section 6.2 were annealed in a convection oven at $130{ }^{\circ} \mathrm{C}$. The specimens were allowed to crystallize for 30 minutes, after which the remainder of the tape was peeled from the laminate. The effect of annealing 

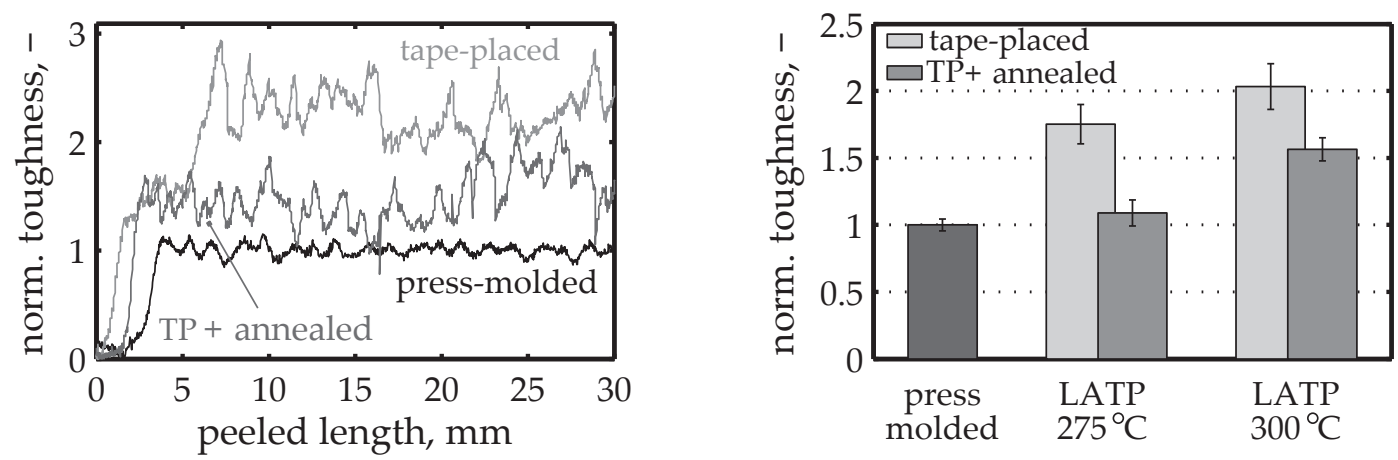

Figure 6.6 Left: Normalized fracture toughness for a tape-placed specimen $\left(T_{\text {nip }}=300^{\circ} \mathrm{C}\right.$, $v=150 \mathrm{~mm} / \mathrm{s}$ ) before and after annealing, and a press-molded specimen. Right: Normalized average fracture toughness for the press-molded and tape-placed specimens. The error bars represent the standard deviation.

on interfacial fracture toughness is illustrated in Figure 6.6. The graphs show that annealing significantly deteriorates the measured fracture toughness. Davies et al. [25] and Nishihata et al. [26] also observed a decrease in fracture toughness upon annealing for carbon-PPS composites, although they reported only a slight decrease. Despite the significant decrease in fracture toughness, the tape-placed specimens still outperform the press-molded specimens. The next section presents a fractography analysis of the peel samples to explain the observed differences in fracture toughness.

\subsubsection{Fractography analysis}

After peel testing, the laminate and tape fracture surfaces were examined using a scanning electron microscope (Jeol Neoscope JCM-5000) to determine the dominant failure mechanisms. The tape-placed specimens, both before and after annealing, showed two major modes of failure which could be related to the architecture of the woven reinforcement in the laminate. Figure 6.7 schematically illustrates the top view of the woven fabric reinforced laminate and the orientation of the tape. Two distinct regions can be identified from the figure. The first corresponds to the resin pockets found between the bundles, while the second region corresponds with a weft bundle at the surface of the laminate.

Figure 6.8 shows the fracture modes associated with these regions. In the first region the interfacial strength of the weld exceeds the transverse tensile strength of the tape. The tape's fibers are extracted from the tape matrix material which itself remains on the laminate, proving an excellent weld quality. The SEM image in Figure 6.9 shows that this failure mode is accompanied by severe plastic deformation of the remaining tape matrix material. Figure $6.10 \mathrm{~b}$ depicts the fracture surface 
of an annealed (tape-placed) specimen. Compared to the fracture surface before annealing (Figure 6.10a), there is far less plastic deformation. This corresponds well with the tensile tests results on the dumbbell-shaped PPS film specimens. These tests demonstrated that the as-received (low degree of crystallinity) PPS showed significant plastic deformation before fracture, whereas the annealed PPS specimens showed almost no plastic deformation before fracture.

In the second failure region the crack propagates between the fibers in the weft bundle, just below the surface, and the laminate matrix material. The interfacial weld strength in this case exceeds the fiber-matrix adhesion in the laminate. Figure 6.10a shows a SEM image of the transition between the two regions. The left side shows the tape matrix which remains on the laminate with the imprints of the tape fibers. The right side shows the stripped fibers of the weft bundle in the laminate.

The failure mode for these tape-placed specimens is thus predominantly intralaminar with the crack propagating alternatingly in the tape and laminate. Almost no

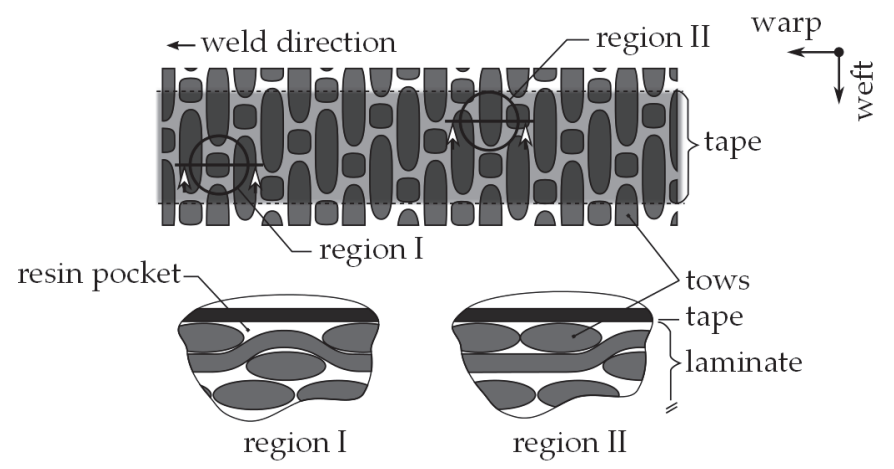

Figure 6.7 Top view of the laminate fracture surface indicating the two major failure regions.
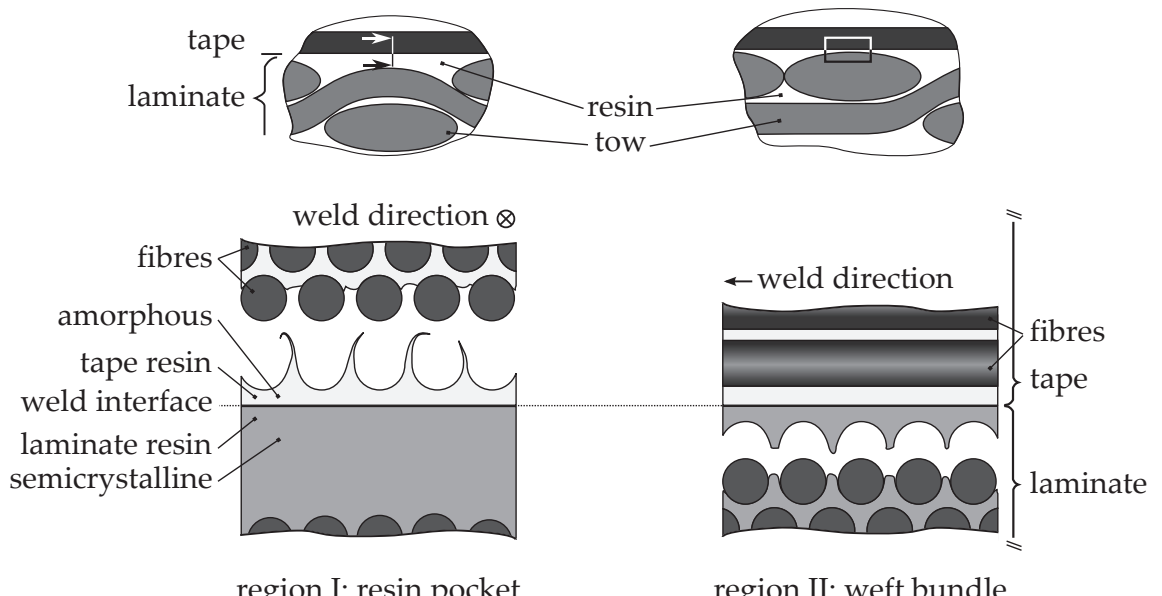

Figure 6.8 Schematic representation of the two fracture modes for the tape-placed specimens. 


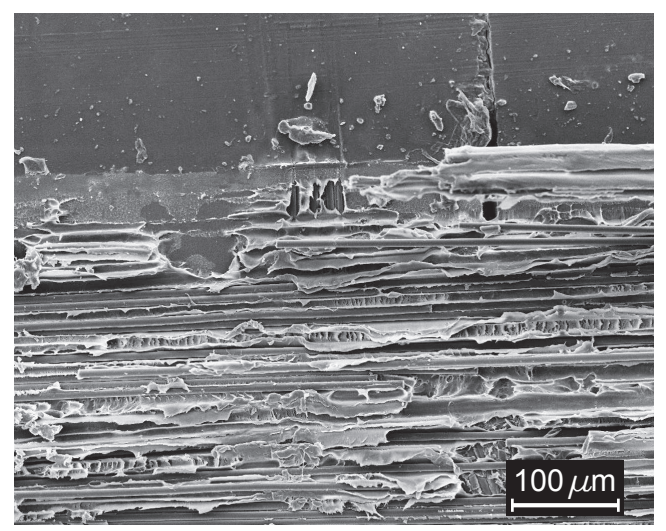

Figure 6.9 Laminate fracture surface for a tape-placed specimen.

interlaminar failure was observed, which demonstrates that the short welding time is sufficient for the interfacial weld strength to develop. The alternating crack propagation behavior also manifests itself in the measured fracture toughness. Figure 6.6 (left) showed that the fracture toughness progresses irregularly for the tape-placed specimen. Closer examination showed that the distance between the peaks in the graph corresponds to the position of the resin pockets in the laminate. The large plastic deformation associated with the fracture mode in region I causes the local increase in fracture toughness.

Figure 6.6 (left) shows that the fracture toughness for the press-molded specimen progresses more smoothly, which suggests a more constant fracture behavior. Scanning electron microscopy images, as in Figure 6.10c, confirm this and show a far more uniform fracture surface. The cause of this uniform fracture surface was investigated by obtaining micrographs of the cross-section near the crack-tip. Figure 6.11 shows the cross-section, obtained by a light microscope (Leica DM2500), for a tape-placed and a press-molded specimen. The micrographs show the tape and laminate just behind the slightly opened crack-tip. Figure 6.11 (right) shows that the fibers in the tape redistributed themselves during the slow press molding process and locally migrated into the resin pockets of the laminate. Effectively, this results in an increase of fiber-fiber contact, which in turn reduces the effect of the resin pockets and lowers the fracture toughness. Figure 6.11 (left) shows that no fiber migration occurs during tape placement. The short weld time inhibits any fiber migration, which in the present context is advantageous because it limits the amount of fiber-fiber contact. 

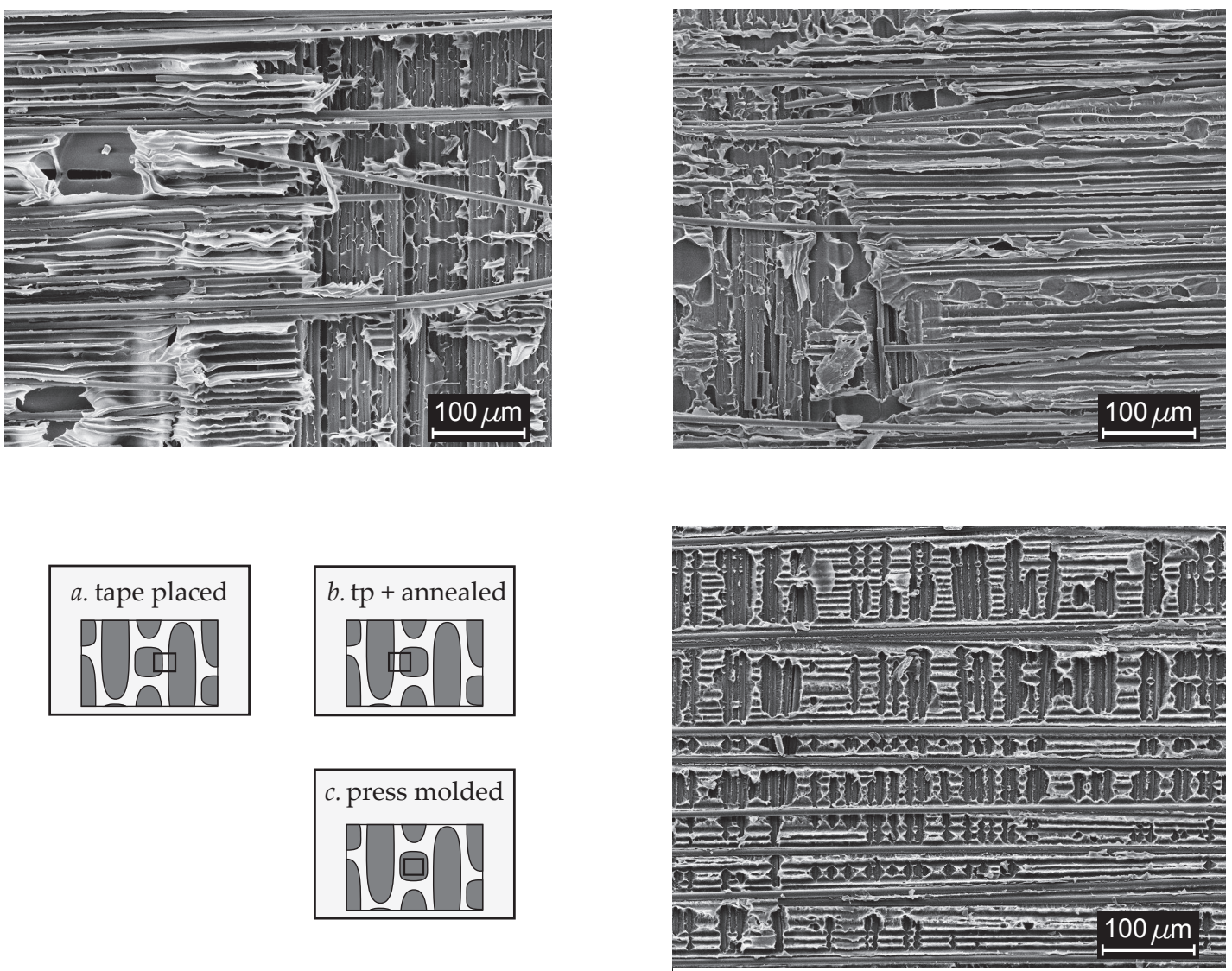

Figure 6.10 a. Laminate fracture surface for a tape-placed specimen showing the transition from fracture region I (left side) to fracture region II (right side). $\boldsymbol{b}$. Laminate fracture surface for a tape-placed and subsequently annealed specimen. c. Fracture surface for a press-molded specimen.

$\otimes$ weld direction $\rightarrow$ weft direction

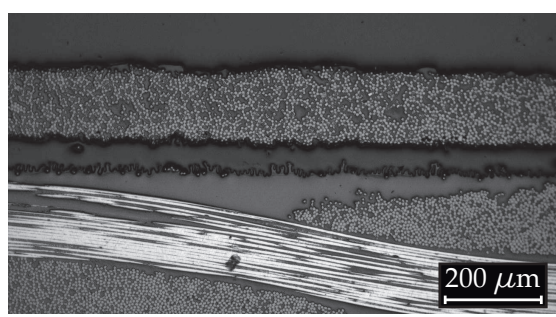

tape placed specimen

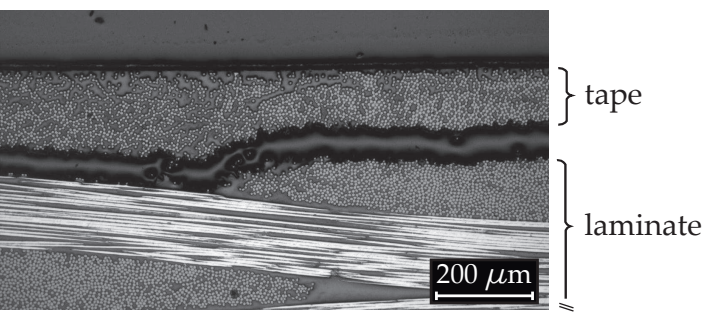

press molded specimen

Figure 6.11 Left: Cross-section of a tape-placed peel specimen just in front of the crack-tip. Right: Cross-section of a press-molded peel specimen just in front of the crack-tip. 


\subsection{Conclusions}

A laser-assisted tape placement machine was used to weld unidirectionally reinforced PPS tapes onto pre-consolidated woven fabric reinforced PPS laminates. The resulting tailored structure potentially combines the strength and stiffness of UD reinforced tapes with the drapeability and impact resistance of woven fabric reinforced thermoplastics. The welding itself comprises the development of intimate contact followed by the interdiffusion of polymer chains.

A mandrel peel test was used to quantify the fracture toughness of the weld interface between tape and laminate. The fracture toughness achieved by tape placement was compared to a conventional press molding process. Due to the large difference in characteristic weld time, an upper-bound fracture toughness was expected to be found for the press-molded specimens. However, the experimental results showed the opposite with the tape-placed specimens outperforming the press-molded specimens with almost a factor two. These results demonstrated that the short weld time during tape placement was sufficient to achieve complete bonding. Moreover, two additional mechanisms which influence weld strength were considered:

Degree of crystallinity: The high cooling rate during tape placement caused the carbon-PPS tape to remain amorphous during welding, an effect which can also be expected for other semi-crystalline thermoplastic tapes. The influence of the degree of crystallinity on the fracture toughness was investigated experimentally. The experimental results showed that the fracture toughness of the weld interface deteriorates after annealing. The annealed tape-placed specimens, however, still outperformed the press-molded specimens.

Process-induced weld interface: Fractography showed that the tape's fibers migrated into the resin pockets between the bundles of the laminate during the press molding process. The long process time during press molding actually facilitates the fiber migration. The resulting increase in fiber-fiber contact further deteriorated the fracture toughness for these press-molded specimens. The tape-placed specimens did not show any fiber migration, which is attributed to the short process time during tape placement.

Altogether, the results demonstrate the in situ potential of the laser-assisted tape placement process for tailoring press-formed woven fabric reinforced thermoplastic structures. 


\section{References}

[1] M. A. Lamontia and M. B. Gruber. Remaining developments required for commercializing in situ thermoplastic ATP. In SAMPE Baltimore, 2007.

[2] Y. M. P. Toso, P. Ermanni, and D. Poulikakos. Thermal phenomena in fiber-reinforced thermoplastic tape winding process: Computational simulations and experimental validations. Journal of Composite Materials, 38(2):107-135, 2004.

[3] M. Steyer, M. Dubratz, A. Schütte, C. Wenzel, and C. Brecher. Laser-assisted thermoplastic tape-laying systems. JEC Composites Magazine, 47:39-41, 2009.

[4] R. Schledjewski and M. Latrille. Processing of unidirectional fiber reinforced tapes fundamentals on the way to a process simulation tool (ProSimFRT). Composites Science and Technology, 63(14):2111-2118, 2003.

[5] J. Tierney and J. W. Gillespie Jr. Modeling of in situ strength development for the thermoplastic composite tow placement process. Journal of Composite Materials, 40(16):1487-1506, 2006.

[6] F. O. Sonmez and H. T. Hahn. Analysis of on-line consolidation process in thermoplastic composite tape placement. Journal of Thermoplastic Composite Materials, 10:543-572, 1997.

[7] W. J. B. Grouve, L. L. Warnet, R. Akkerman, S. Wijskamp, and J. S. M. Kok. Weld strength assessment for tape placement. International Journal of Material Forming, 3(1):707-710, 2010.

[8] E. Breslauer and T. Troczynski. Determination of the energy dissipated during peel testing. Materials Science and Engineering A, 302(1):168-180, 2001.

[9] L. F. Kawashita, D. R. Moore, and J. G. Williams. The development of a mandrel peel test for the measurement of adhesive fracture toughness of epoxy-metal laminates. Journal of Adhesion, 80(3):147-167, 2004.

[10] L. F. Kawashita, A. J. Kinloch, D. R. Moore, and J. G. Williams. A critical investigation of the use of a mandrel peel method for the determination of adhesive fracture toughness of metal-polymer laminates. Engineering Fracture Mechanics, 73(16):2304-2323, 2006.

[11] A. B. Hulsher, M. Marchello, and J. A. Hinkley. Wedge peel testing for automated fiber placement. Journal of Advanced Materials, 31:37-43, 1999.

[12] W. I. Lee and G. S. Springer. A model of the manufacturing process of thermoplastic matrix composites. Journal of Composite Materials, 21(11):1017-1055, 1987.

[13] L. J. Bastien and J. W. Gillespie Jr. A non-isothermal healing model for strength and toughness of fusion bonded joints of amorphous thermoplastics. Polymer Engineering and Science, 31(24):1720-1730, 1991.

[14] F. Yang and R. Pitchumani. Nonisothermal healing and interlaminar bond strength evolution during thermoplastic matrix composites processing. Polymer Composites, 24(2):263-278, 2003.

[15] R. Pitchumani, S. Ranganathan, R. C. Don, J. W. Gillespie Jr., and M. A. Lamontia. Analysis of transport phenomena governing interfacial bonding and void dynamics during thermoplastic tow-placement. International Journal of Heat and Mass Transfer, 39(9):1883-1897, 1996.

[16] R. Pitchumani, J. W. Gillespie Jr., and M. A. Lamontia. Design and optimization of a 
thermoplastic tow-placement process. Journal of Thermoplastic Composite Materials, 31(3):244-275, 1997.

[17] P. H. Dara and A. C. Loos. Thermoplastic matrix composite processing model. Technical Report 24061, Virginia Polytechnic Institute and State University, Blacksburg, Virginia, 1985.

[18] C. A. Butler, R. L. McCullough, R. Pitchumani, and J. W. Gillespie Jr. An analysis of mechanisms governing fusion bonding of thermoplastic composites. Journal of Thermoplastic Composite Materials, 11:338-363, 1998.

[19] F. Yang and R. Pitchumani. A fractal Cantor set based description of interlaminar contact evolution during thermoplastic composites processing. Journal of Materials Science, 36(19):4661-4671, 2001.

[20] P. G. De Gennes. Reptation of a polymer chain in the presence of fixed obstacles. Journal of Chemical Physics, 55(2):572-579, 1971.

[21] R. P. Wool and K. M. O'Connor. A theory of crack healing in polymers. Journal of Applied Physics, 52(10):5953-5963, 1981.

[22] D. Brady. The crystallinity of poly(phenylene sulfide) and its effect on polymer properties. Journal of Applied Polymer Science, 20:2541-2551, 1976.

[23] L. C. Lopez and G. L. Wilkes. Crystallization kinetics of poly(p-phenylene sulfide): effect of molecular weight. Journal of Macromolecular Science - Reviews in Macromolecular Chemistry and Physics, C29:83-151, 1989.

[24] C. Auer, G. Kalinka, T. Krause, and G. Hinrichsen. Crystallization kinetics of pure and fiber-reinforced poly(phenylene sulfide). Journal of Applied Polymer Science, 51(3):407-413, 1994.

[25] P. Davies, M. L. Benzeggagh, and F. X. de Charentenay. Delamination behavior of carbon fiber reinforced PPS. In SAMPE Quarterly, volume 32, pages 134-146, 1987.

[26] N. Nishihata, T. Koizumi, Y. Ichikawa, and T. Katto. Plane strain fracture toughness of polyphenylene sulfide. Polymer Engineering and Science, 38(3):403-408, 1998.

[27] J. E. Spruiell and C. J. Janke. A review of the measurement and development of crystallinity and its relation to properties in neat poly(phenylene sulfide) and its fiber reinforced composites. Technical report, Oak Ridge National Laboratory, 2004. 


\title{
On the crystallization and fracture toughness of poly(phenylene sulfide) under tape placement conditions ${ }^{1}$
}

\begin{abstract}
Fiber reinforced thermoplastic tapes are subjected to high heating and cooling rates during the tape placement process. Such high cooling rates can significantly inhibit the crystallization of the thermoplastic polymer and thereby affect its mechanical properties, such as strength or toughness. In the present work, the crystallization of poly(phenylene sulfide) (PPS) subjected to high cooling rates was investigated using a fast scanning calorimeter. The PPS was found to be unable to crystallize when subjected to cooling rates higher than $20^{\circ} \mathrm{C} / \mathrm{s}$. The influence of the degree of crystallinity on fracture toughness was investigated using an essential work of fracture approach. The amount of plastic work during the fracture process was found to decrease after moderate annealing.
\end{abstract}

\footnotetext{
${ }^{1}$ Reproduced from: W.J.B. Grouve, G. Vanden Poel, L.L. Warnet, R. Akkerman. On the crystallisation and fracture toughness of poly(phenylene sulphide) under tape placement conditions. Submitted to: Plastic, Rubber and Composites, 2012.
} 


\subsection{Introduction}

\subsubsection{Background and motivation}

The laser-assisted tape placement process, schematically illustrated in Figure 7.1, is a promising manufacturing technique for thermoplastic composites, combining in situ consolidation with high productivity [1]. Unidirectionally (UD) fiber reinforced thermoplastic tapes can be deposited at high rates onto a pre-consolidated (in some cases double-curved) laminate. This laminate can be produced by either the tape placement process itself or by an alternative, more conventional, manufacturing technique. The mechanical properties of the final component can be tailored to a high degree by incrementally placing the tapes in the desired orientation. The process shows great potential for automation which makes it attractive for the aerospace or automotive industry. Moreover, the tapes can potentially be welded in situ, that is without an energy-consuming post-consolidation step in an autoclave. Currently, however, such a post-consolidation step is still required in order to obtain the desired mechanical properties [1]. Much effort is spent optimizing the process in order to omit this expensive step and reach truly in situ tape placement. Such an optimization procedure requires a thorough understanding of the interrelation between processing parameters, constituent material properties and final component performance.

The characteristic process time, i.e. the time available for interlaminar bonding and consolidation, is extremely short for the tape placement process. For example, a process time of approximately $0.1 \mathrm{~s}$ is found for a placement velocity of $150 \mathrm{~mm} / \mathrm{s}$ and a contact length of $15 \mathrm{~mm}$ between the (flexible) compaction roller and the tape. Such short process times can only be achieved when the material is subjected to extremely high heating and cooling rates $[2,3]$ which can easily exceed $400{ }^{\circ} \mathrm{C} / \mathrm{s}$. In the case of semi-crystalline polymers, these high rates can significantly influence the resulting degree of crystallinity of the matrix material, and thereby the final product properties. The emergence of such fast manufacturing processes, therefore,

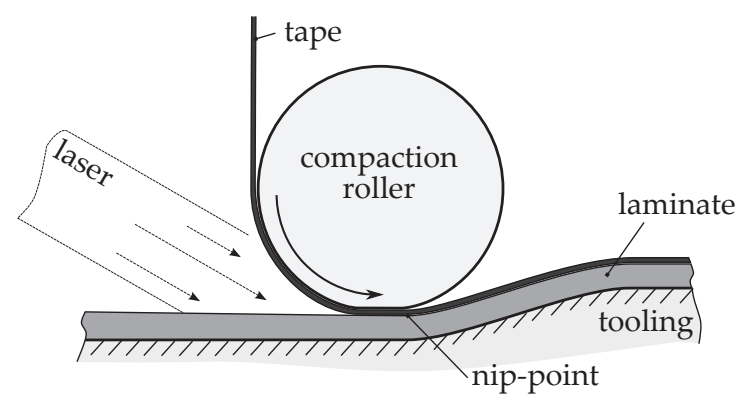

Figure 7.1 Illustration of the laser-assisted tape placement process for thermoplastic composites. The diameter of the compaction roller equals nominally $74 \mathrm{~mm}$. 
calls for an improved understanding of the crystallization kinetics under highly nonisothermal conditions. Moreover, the influence of the degree of crystallinity on the material properties also becomes of increased interest.

The present work focuses on poly(phenylene sulfide) (PPS), which is a thermoplastic used in composite structures for aerospace applications. Earlier work, presented in Chapter 5 and 6, focused on the tape placement of UD carbon reinforced PPS tapes onto woven fabric reinforced PPS laminates. It was shown that the UD carbon-PPS tapes exhibited a very low degree of crystallinity after tape placement. Apparently, the high cooling rates prevented the PPS in the tape from crystallizing. Mandrel peel experiments demonstrated that these tape-placed specimens exhibited a very high interfacial fracture toughness compared to press-molded (and slowly cooled) specimens. This difference was partly attributed to the low degree of crystallinity of the PPS in the tape, making it more susceptible to dissipate energy through plastic deformation during the fracture process. The present work aims to support these observations and investigates the crystallization and fracture behavior of neat PPS under tape placement conditions.

\subsubsection{Literature overview}

The isothermal [4-6] and non-isothermal [7, 8] crystallization kinetics of PPS have been investigated thoroughly in the literature. The literature reviews of Lopez and Wilkes [9] and Cebe [10] provide a comprehensive overview of the earlier work. Despite the abundance of literature on this topic, little work has been performed on the crystallization behavior of PPS under highly non-isothermal conditions. The present work employs fast scanning calorimetry to investigate at which rate the PPS in unable to crystallize. The experimental results aim to support the earlier experimental observations (Chapter 6) that the carbon-PPS tapes cannot crystallize during the tape placement process.

Spruiell and Janke [11] provide a comprehensive overview of the research on the effect of crystallinity and morphology on the mechanical properties of neat and fiber reinforced PPS. The tensile modulus and strength are, for the high molecular weight PPS used in composites, found to increase with an increasing degree of crystallinity. The fracture toughness of PPS and its composites, however, has not been researched extensively. Davies et al. [12] investigated the influence of crystallinity on fracture toughness of PPS-based composites and showed that the mode I and mode II fracture toughness of carbon PPS composites slightly decreases with increasing crystallinity. A similar observation was made by Nishihata et al. [13]. Nevertheless, there is, to the best of the authors' knowledge, not much literature available on the influence of the degree of crystallinity on the fracture toughness of neat PPS. The present work therefore investigates the fracture toughness of as-received (low degree of crystallinity) and annealed PPS film using the essential work of fracture approach. 


\subsubsection{Objective and outline}

The present work investigates the crystallinity and fracture behavior of PPS that has been subjected to high cooling rates. For this purpose, the work is broadly divided into three coherent parts. Firstly, the critical cooling rate is determined at which PPS is still able to crystallize. The experiments are performed using a, recently introduced, fast scanning calorimeter from Mettler-Toledo: the Flash DSC1. The aim is to confirm whether the PPS in the tape is indeed unable to crystallize under typical tape placement conditions. Secondly, tensile tests are performed on as-received (low degree of crystallinity) and annealed PPS film to study the effect of crystallinity on the tensile properties. These tests provide qualitative information concerning the amount of plastic deformation during failure. Finally, the effect of crystallinity on the fracture properties is investigated quantitatively using a fracture mechanics approach. The present work employs the essential work of fracture (EWF) approach on PPS films. The EWF method can be used to quantify the fracture toughness for materials which show significant crack-tip plasticity, when the linear elastic fracture mechanics (LEFM) approach becomes invalid.

The next section introduces the experimental work, which comprises fast scanning calorimetry and mechanical testing. Subsequently, the experimental results are presented, followed by a discussion. Finally, the conclusions are presented.

\subsection{Experimental work}

The material under consideration is poly(phenylene sulfide) film known as Fortron 0214 from Ticona. The PPS has a glass transition temperature and melting temperature of $85^{\circ} \mathrm{C}$ and $285^{\circ} \mathrm{C}$, respectively, according to the data from the manufacturer. The Flash DSC 1 experiments and tensile tests were performed on film with a thickness of $160 \mu \mathrm{m}$, while the essential work of fracture experiments were performed on film having a thickness of $60 \mu \mathrm{m}$. The mechanical tests were performed on both as-received and annealed film specimens. The degree of crystallinity $\chi_{\mathrm{c}}$ of the samples was measured using a standard differential scanning calorimeter from Mettler Toledo (DSC 822). These specimens were heated with a rate of $10^{\circ} \mathrm{C} / \mathrm{min}$ to a temperature of $330^{\circ} \mathrm{C}$. The mass fraction of the crystalline region is then given by:

$$
\chi_{\mathrm{c}}=\frac{\Delta H_{\mathrm{f}}+\Delta H_{\mathrm{c}}}{\Delta H_{\mathrm{f}}^{0}},
$$

in which $\Delta H_{\mathrm{f}}$ and $\Delta H_{\mathrm{c}}$ are the measured values of the melting enthalpy and the heat associated with the cold crystallization exotherm, respectively. By convention, $\Delta H_{\mathrm{f}}$ is positive and $\Delta H_{\mathrm{c}}$ is negative. The value for $\Delta H_{\mathrm{f}}^{0}$ represents the melting enthalpy 
of PPS with $100 \%$ crystallinity for which a value of $150.4 \mathrm{~J} / \mathrm{g}$ [11] was used in the present work.

\subsubsection{Critical quench rate}

The investigation of the crystallization of PPS under tape placement conditions requires fast scanning calorimetry (FSC). In the present work, an FSC based on micro-electro-mechanical system technology is applied: the Flash DSC 1 from Mettler-Toledo, which was released by the end of 2010 [14-17]. Recently, it has been elaborately investigated for its performance and for finding and defining the calibration protocols required for reliable results and adequate interpretation of the data generated [18]. The equipment was kindly made available at DSM Resolve laboratory.

The Flash DSC 1 does not measure samples in a crucible, because the heat capacity and thermal conductivity of the pan would have a significant influence on the end results. Instead, the sample is placed directly onto a chip, which allows measurements under extremely high heating and cooling rates of more than $20 \mathrm{k}^{\circ} \mathrm{C} / \mathrm{s}$. A small specimen, in the order of $1 \mu \mathrm{g}$, was cut from the as-received PPS film. The specimen was loaded in the Flash DSC 1, melted down in order to stick on the sensor and cooled from $350{ }^{\circ} \mathrm{C}$ to $-50{ }^{\circ} \mathrm{C}$ with a cooling rate varying from $1{ }^{\circ} \mathrm{C} / \mathrm{s}$ to $5000{ }^{\circ} \mathrm{C} / \mathrm{s}$. Subsequently, the specimen was heated with a scan rate of $100{ }^{\circ} \mathrm{C} / \mathrm{s}$, which was high enough to prevent cold crystallization. The data was evaluated with the StarE software v. 10 of Mettler-Toledo. The heating curves are monitored to observe whether or not a melting peak can be identified. If a melting peak is present this would indicate that the PPS was able to crystallize on the preceding cooling run.

\subsubsection{Tensile properties}

Tensile tests were performed on dumbbell-shaped PPS film specimens having a thickness of $160 \pm 2 \mu \mathrm{m}$. The gauge width and length, as shown in Figure 7.2 (right), were $6 \mathrm{~mm}$ and $35 \mathrm{~mm}$, respectively. All specimens were cut using a manual die cutting machine with their length oriented parallel to the roll direction. A total of twelve specimens were produced of which six were annealed in an oven at $130{ }^{\circ} \mathrm{C}$ for 30 minutes. The DSC showed that the as-received film had a crystallinity $\chi_{\mathrm{c}}$ of $5.5 \%$, while for the annealed specimens a degree of crystallinity of approximately $24 \%$ was found. The specimens were loaded in a universal testing machine fitted with a $1 \mathrm{kN}$ force cell and Zwick sensor arm extensometer. Furthermore, the specimens were marked every $5 \mathrm{~mm}$ to provide an estimate of the local strain in the necking area after testing. The crosshead displacement rate equaled $0.5 \mathrm{~mm} / \mathrm{min}$ for all specimens. 

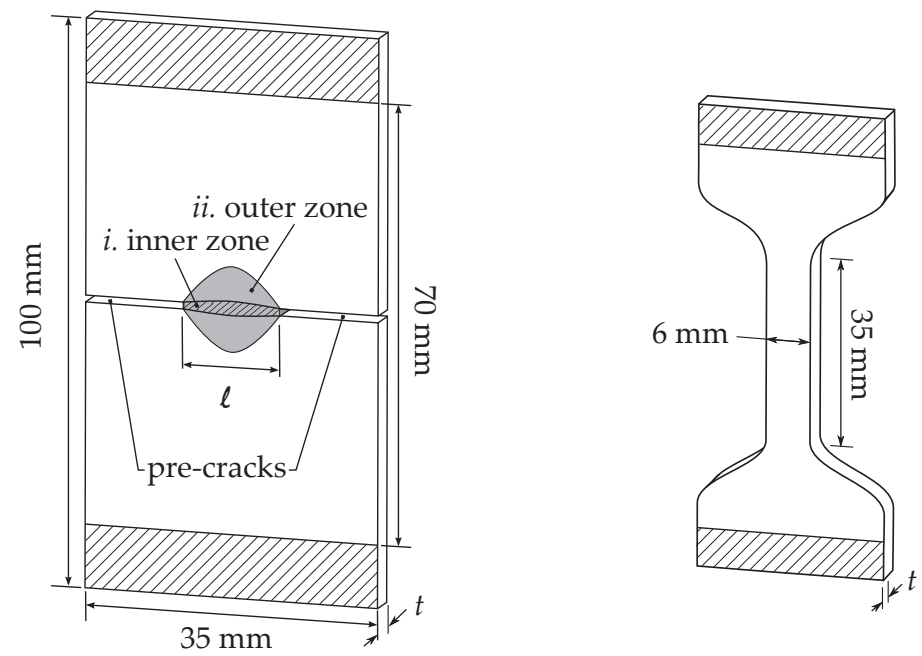

Figure 7.2 Film test specimen dimensions (hatching represents the clamped part). Left: Notched specimen for the EWF experiment showing the fracture zones (i. inner fracture process zone and ii. outer plastic deformation zone). Right: Dumbbell specimen for tensile tests.

\subsubsection{Fracture toughness}

\section{Background}

The essential work of fracture method allows the toughness characterization of ductile polymers for which the LEFM approach is invalid. The foundation of the EWF approach was laid down by Broberg [19] who proposed that the region near the crack tip may be divided into two zones: $i$. an inner fracture process zone and ii. an outer plastic deformation zone. Figure 7.2 (left) shows the specimen size and illustrates these process zones. The work in the inner fracture process zone comprises the energy required to create new surfaces and includes the necking and subsequent tearing of the ligament. The work in the outer plastic deformation process zone comprises various deformation mechanisms such as shear yielding or microvoiding [20]. The total work of fracture $W_{\mathrm{f}}$, calculated from the area under a force-displacement curve, can now be partitioned into two terms:

$$
W_{\mathrm{f}}=W_{\mathrm{e}}+W_{\mathrm{p}}
$$

The essential work of fracture $W_{\mathrm{e}}$ represents the work expended in the inner fracture process zone and is assumed to be proportional to the ligament length $\ell$. The non-essential work of fracture $W_{\mathrm{p}}$ represents the work spent in the outer plastic deformation zone and is assumed to be proportional to the squared ligament length:

$$
W_{\mathrm{f}}=w_{\mathrm{e}} t \ell+w_{\mathrm{p}} \beta t \ell^{2}
$$

in which $t$ represents the film thickness and $\beta$ represents a shape factor. Normalizing 
Equation 7.3 with respect to $t \ell$ yields the specific total work of fracture:

$$
w_{\mathrm{f}}=\frac{W_{\mathrm{f}}}{t \ell}=w_{\mathrm{e}}+w_{\mathrm{p}} \beta \ell
$$

The specific essential work of fracture $w_{\mathrm{e}}$ is now determined as the y-intercept of a linear least square fit of $w_{\mathrm{f}}$ versus $\ell$ data, while the slope of the fit gives the value for $\beta w_{\mathrm{p}}$, which is known as the specific non-essential work of fracture. The essential specific work of fracture $w_{\mathrm{e}}$ is considered a material parameter for a given thickness $[21,22]$. The non-essential work of fracture $\beta w_{\mathrm{p}}$ is not regarded as a material property, but measures the amount of plastic deformation around the crack tip.

The experimental procedure reduces to obtaining the total work of fracture $W_{\mathrm{f}}$ from the area under the force-displacement curves of film specimens with different ligament lengths $[23,24]$. The simplicity of this procedure is one of the major reasons for the increasing popularity of the EWF method. The method has been applied to a great number of different polymers of which the recent review work by Bárány et al. [24] gives a broad overview. The influence of crystallinity (or rather an annealing procedure) on the specific essential $w_{\mathrm{e}}$ and specific non-essential $\beta w_{\mathrm{p}}$ work of fracture has been investigated for a few thermoplastics, such as LDPE [25] and PP [26]. Generally, it can be said that an increase in crystallinity results in an increase of $w_{\mathrm{e}}$, but reduces $\beta w_{\mathrm{p}}$ [24]. However, to the best of the authors' knowledge, no results have been published on EWF experiments on PPS.

\section{Experimental procedure}

The procedure followed for the EWF experiments was based on the latest ESIS TC4 protocol [27]. The specimens were cut from the PPS film using a sharp scalpel. The specimens had a thickness of approximately $60 \pm 2 \mu \mathrm{m}$ and width and length of $35 \mathrm{~mm}$ and $100 \mathrm{~mm}$, respectively. The length between the clamps equaled $70 \mathrm{~mm}$, as is also shown in Figure 7.2. The notches were applied by sliding a sharp razor blade through the notches of a steel template. A total of four templates was used, having ligament lengths of nominally $3,4,6$ and $8 \mathrm{~mm}$. A new razor blade was used for every specimen. The final ligament length $\ell$ was measured using a traveling microscope and the thickness of the film at the ligament was measured using a film thickness gauge with a resolution of $0.5 \mu \mathrm{m}$. At least five specimens were tested for each steel template.

The tests were performed on as-received film and on annealed film. A few specimens were subjected to the annealing procedure followed for the tensile specimens, i.e. these were annealed at $130{ }^{\circ} \mathrm{C}$ for 30 minutes. The majority of the specimens, however, was annealed at a lower temperature of $120^{\circ} \mathrm{C}$ and for a shorter time period of 15 minutes. A DSC measurement showed that these annealed $\left(120^{\circ} \mathrm{C}\right)$ specimens had a degree of crystallinity $\chi_{c}$ of approximately $17 \%$, compared to $24 \%$ for the 
specimens annealed for 30 minutes at $130{ }^{\circ} \mathrm{C}$. The EWF specimens were loaded in a universal testing machine fitted with a Zwick $100 \mathrm{~N}$ force cell. The crosshead displacement was measured using a displacement transducer with a resolution of $1 \mu \mathrm{m}$. The crosshead displacement rate equaled $0.5 \mathrm{~mm} / \mathrm{min}$ for all specimens.

\subsection{Experimental results and discussion}

The current section presents the experimental results. The Flash DSC results are presented first, followed by the tensile and EWF experiments.

\subsubsection{Critical quench rate}

The critical quench rate was determined by subjecting PPS to various cooling rates (from 1 up to $5000{ }^{\circ} \mathrm{C} / \mathrm{s}$ ) and one particular heating rate, which presents melting only (so no cold crystallization). Figure 7.3 shows the Flash DSC 1 heating curves of the PPS specimen after cooling at various rates. The PPS sample was heated in all cases from $-50{ }^{\circ} \mathrm{C}$ to $350{ }^{\circ} \mathrm{C}$ with a scan rate of $100{ }^{\circ} \mathrm{C} / \mathrm{s}$. The trace corresponding to a cooling rate of $1{ }^{\circ} \mathrm{C} / \mathrm{s}$ clearly shows an endothermic peak near $275^{\circ} \mathrm{C}$, which represents the melting of the crystalline structure. The peak demonstrates that the PPS specimen was able to crystallize during the preceding cooling run at $1{ }^{\circ} \mathrm{C} / \mathrm{s}$. Similar, though smaller, peaks are observed when the PPS was cooled with rates of $5{ }^{\circ} \mathrm{C} / \mathrm{s}$ and $10{ }^{\circ} \mathrm{C} / \mathrm{s}$. Nevertheless, when cooled at a rate of $20^{\circ} \mathrm{C} / \mathrm{s}$, the subsequent heating trace does not show any endothermic peak signal, from which can be

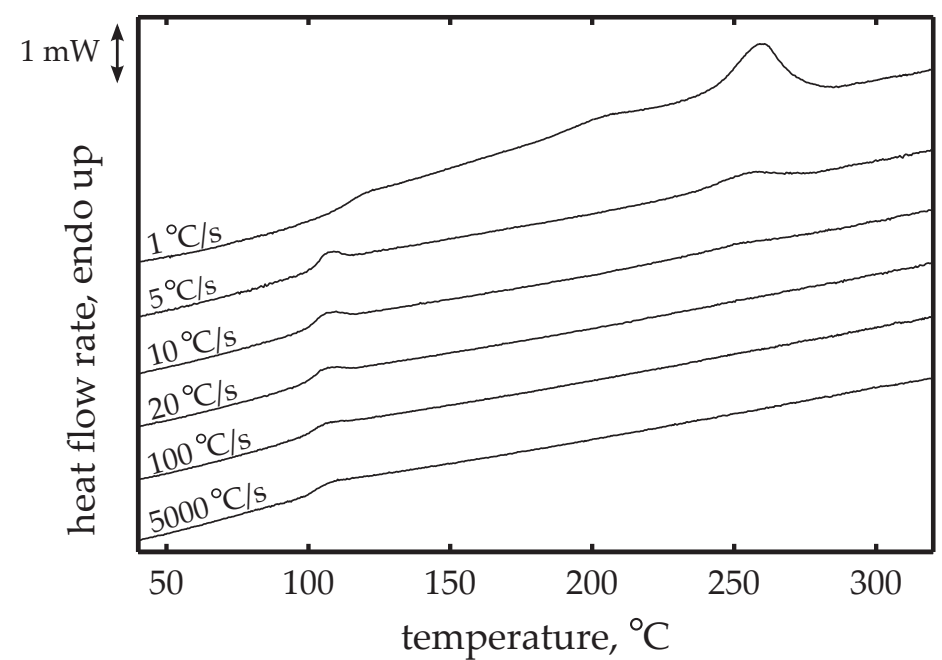

Figure 7.3 Subsequent Flash DSC heating curves of PPS (scan rate equals $100{ }^{\circ} \mathrm{C} / \mathrm{s}$ ) after cooling at rates from 1 to $5000^{\circ} \mathrm{C} / \mathrm{s}$. 
interpreted that no melting occurs. Apparently, the PPS is unable to crystallize at cooling rates of $20^{\circ} \mathrm{C} / \mathrm{s}$ or higher. The subsequent heating curves after respectively 100 and even $5000{ }^{\circ} \mathrm{C} / \mathrm{s}$ of cooling are similar if not equal to the one for cooling at $20{ }^{\circ} \mathrm{C} / \mathrm{s}$.

Firmly, one can state that this type of PPS is fully quenched, and hence is completely amorphous, at cooling rates above $20^{\circ} \mathrm{C} / \mathrm{s}$. Typically, a fiber reinforced thermoplastic tape can be subjected to cooling rates in excess of $400^{\circ} \mathrm{C} / \mathrm{s}$ during the tape placement process. This means that during the processing of PPS tapes the polymer is unable to crystallize. As a result, the properties, such as chemical resistance or fracture toughness, of the resulting structure might differ from structures manufactured using more conventional, and slower, production processes.

\subsubsection{Tensile properties}

The left graph in Figure 7.4 shows a typical stress-strain curve for an as-received and an annealed PPS dumbbell specimen. The graph shows a significant change in tensile behavior upon crystallization. The as-received specimens showed necking followed by an extensive period of cold drawing before failure, while the annealed specimens failed in a more brittle manner.

Table 7.1 Averaged data from the tensile tests on as-received and annealed (30min@130 C) PPS dumbbell specimens. The data between brackets represents the standard deviation (6 specimens for each sample).

\begin{tabular}{lcccc}
\hline & $\begin{array}{c}\text { crystallinity } \\
\chi_{\mathrm{c}}\end{array}$ & $\begin{array}{c}\text { tensile modulus } \\
\mathrm{GPa}\end{array}$ & $\begin{array}{c}\text { max. stress } \\
\mathrm{MPa}\end{array}$ & $\begin{array}{c}\text { max strain } \\
\%\end{array}$ \\
\hline sample & 5 & $2.91(0.04)$ & $61.67(1.10)$ & $19(12)$ \\
an-received & 5 & $3.32(0.06)$ & $81.86(1.22)$ & $4(0.09)$ \\
\hline
\end{tabular}
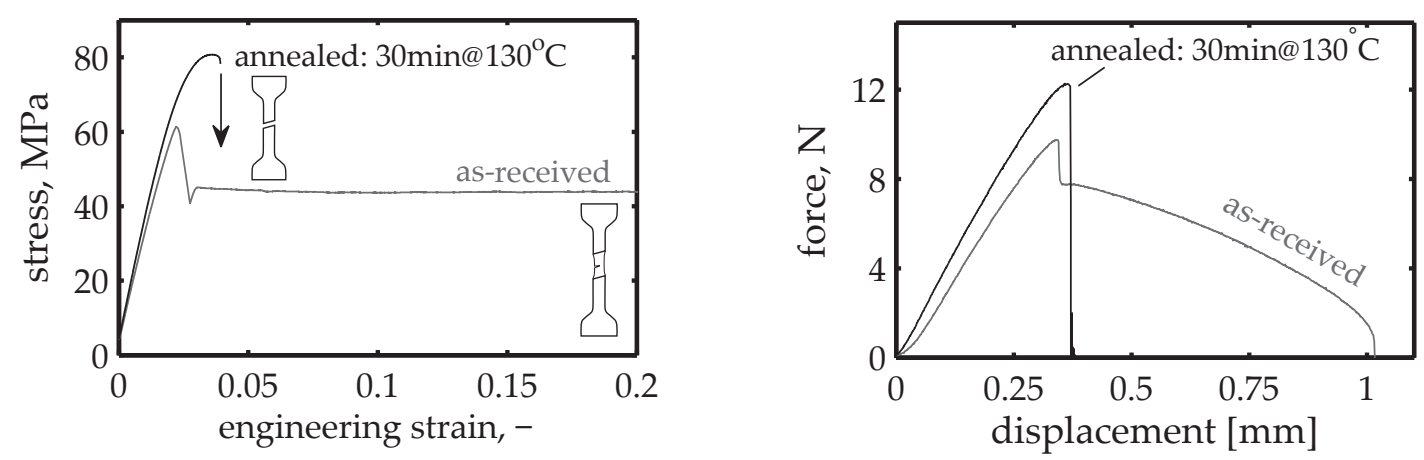

Figure 7.4 Left: Stress-strain for the as-received and annealed PPS film. Right: Force-displacement curve for an as-received EWF specimen $(\ell=2.64 \mathrm{~mm})$ and annealed, at $130{ }^{\circ} \mathrm{C}$ for 30 minutes, EWF specimen $(\ell=2.63 \mathrm{~mm})$. 
Table 7.1 summarizes the obtained experimental results. The tensile modulus and the maximum stress increased after annealing, while the maximum strain at failure decreased significantly as was also shown in Figure 7.4. The maximum strain listed in Table 7.1 concerns the global strain as measured by the extensometer. Locally, the strain could exceed $250 \%$ as determined by measuring the length change between the markings on the specimens. All as-received specimens failed before the full ligament length yielded, which was attributed to impurities and local thickness variations in the film.

\subsubsection{Fracture toughness}

The right graph in Figure 7.4 shows the force-displacement curve for an as-received and an annealed specimen. The specimen shown here was annealed for 30 minutes at $130{ }^{\circ} \mathrm{C}$. The graph clearly shows that this specimen failed in a more brittle manner and showed no yielding and tearing prior to failure, thereby rendering the EWF approach inapplicable. The specimens annealed at $120^{\circ} \mathrm{C}$ for 15 minutes, however, did show full ligament yielding prior to failure. The EWF analysis is, therefore, applied on these as well as the as-received specimens. Figure 7.5 shows typical force-displacement curves for the as-received and annealed $\left(120^{\circ} \mathrm{C}\right)$ specimens. All specimens, except the annealed specimens with a ligament length $\ell$ larger than $6 \mathrm{~mm}$, underwent full ligament yielding prior to final fracture. A basic requirement for applying the EWF approach is a geometrical similarity of the curves for varying ligament lengths. The graphs show that this is clearly the case for the tested PPS specimens. Furthermore, it can be seen that annealing reduces the extension at failure, but increases the maximum force. The tensile tests, presented earlier, showed a similar trend.

The left graph in Figure 7.6 shows the calculated maximum stress for all tested specimens. The gray areas represent the stress criterion given in the ESIS TC4
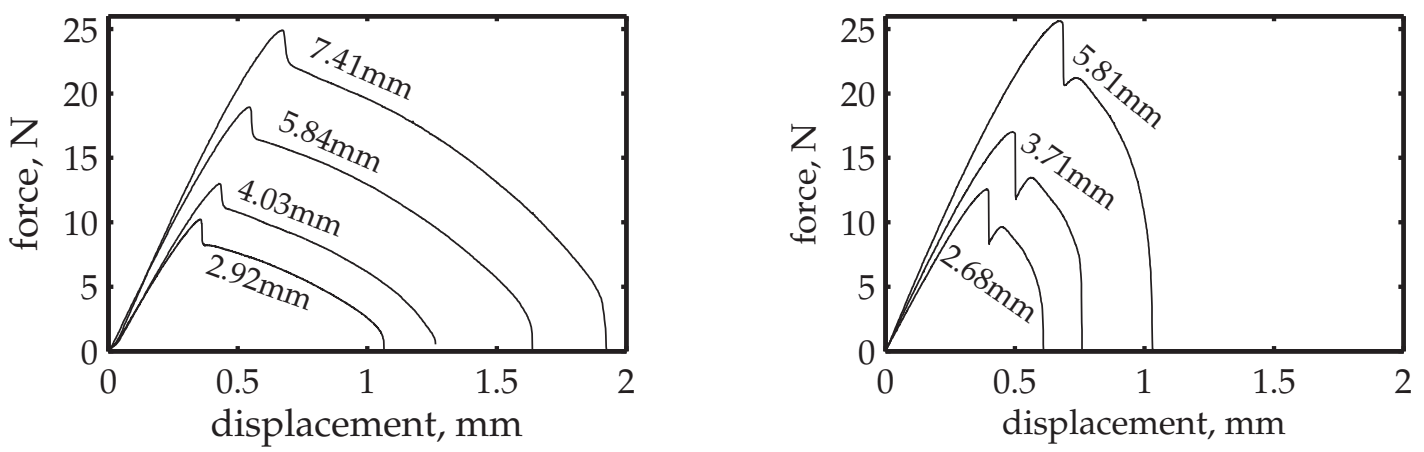

Figure 7.5 Typical force-displacement graphs for different ligament lengths. Left: As-received specimens. Right: Annealed (15min@120 C) specimens. 

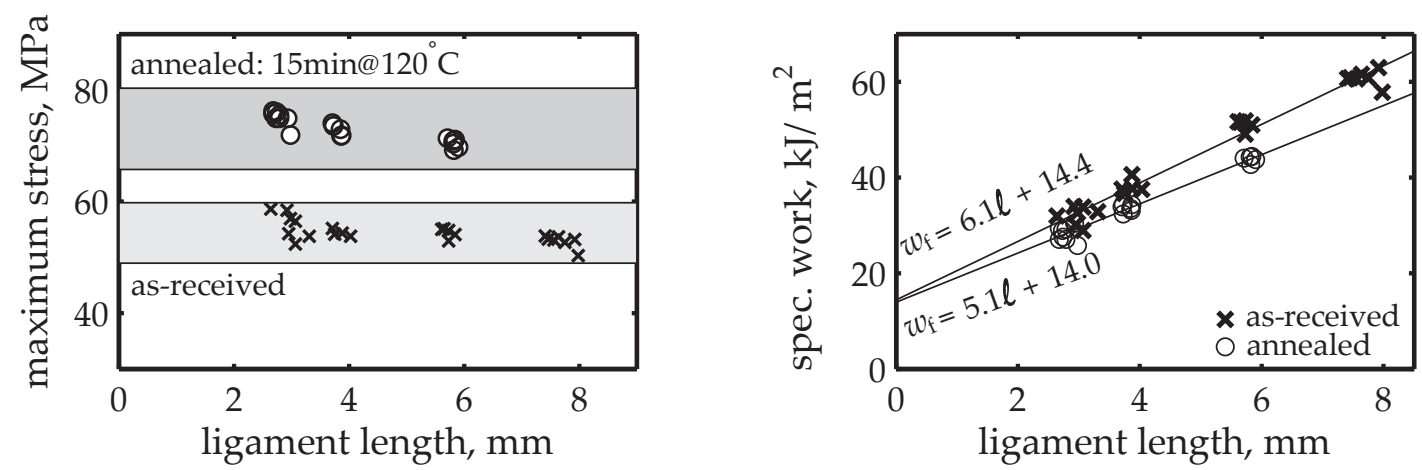

Figure 7.6 Left: Maximum stress for the as-received and annealed (15min@120 $\left.{ }^{\circ} \mathrm{C}\right)$ EWF specimens. Right: Specific work of fracture for the as-received and annealed (15min@120 C) PPS film specimens.

protocol [27]. This criterion states that any essential work data for which the maximum stress is greater than $1.1 \sigma_{\max }$ or less than $0.9 \sigma_{\max }$ should be rejected, in which $\sigma_{\max }$ represents the average value of the maximum stress:

$$
\sigma_{\max }=\frac{F_{\max }}{\ell t}
$$

with $F_{\max }$ the maximum measured force. The graph shows that all data used in the present work fulfills this criterion.

The right graph in Figure 7.6 shows the specific work of fracture $w_{\mathrm{f}}$ as a function of ligament length $\ell$ for the as-received and annealed specimens. The figure shows a linear relation between $w_{\mathrm{f}}$ and $\ell$ for both samples, although it must be pointed out that only three distinct ligament lengths were used for the annealed sample. A linear fit of the data demonstrates that the essential work of fracture $w_{\mathrm{e}}$ is not affected by the annealing procedure. According to the literature, however, annealing often results in an increase of $w_{\mathrm{e}}$. The chosen annealing procedure $\left(15 \mathrm{~min} @ 120^{\circ} \mathrm{C}\right)$ might not have any distinctive effect on the essential work of fracture. The change in slope of the linear fit $\beta w_{\mathrm{p}}$, however, does indicate that annealing decreases the amount of plastic work during failure.

\subsection{Discussion}

The previous experiments focused on the crystallization and fracture behavior of PPS under tape placement conditions. The DSC experiments showed that the PPS, considered in this work, is unable to crystallize when subjected to cooling rates larger than $20^{\circ} \mathrm{C} / \mathrm{s}$, which is significantly lower than the rate typically observed during tape placement. Consequently, tape-placed PPS composites will exhibit a low degree of 
crystallinity, as was also demonstrated in an earlier study [28] (see Chapter 6). It must be pointed out here, however, that the crystallization was investigated under quiescent condition. The shear-induced crystallization of PPS has received very little attention in the literature, e.g. [29]. Nevertheless, based on the observation that the shear rates during tape placement are small compared to the values mentioned in literature, the effect of shear-induced crystallization is anticipated to be negligible.

The effect of the degree of crystallinity on the toughness was investigated using the EWF approach. Although the as-received (low crystallinity) specimens showed a higher specific work of fracture $w_{\mathrm{f}}$ than the annealed specimens, the specific essential work of fracture $w_{\mathrm{e}}$ was approximately equal for both samples. Apparently, the short annealing time at a relatively low temperature did not result in a distinctive change in the amount of energy required to create new surfaces. The amount of specific non-essential work of fracture $w_{\mathrm{p}} \beta$, however, decreases upon annealing, indicating a reduction of the energy dissipated by plastic deformation. The tensile tests on the as-received and annealed specimens yielded comparable results.

Although the EWF results show a clear trend and can be used in a qualitative manner, a direct quantitative translation of the EWF results to the toughness of composites is difficult. The toughness of composites not only depends on the polymer properties, but also on for example the fiber-matrix adhesion and fiber distribution near the crack interface. Moreover, the properties of the polymer depend strongly on its thermal history. The tested annealed PPS film cannot be readily compared to the PPS in tape-placed composites in terms of crystalline morphology and degree of crystallinity. Nevertheless, the results support the earlier experimental work concerning the fracture toughness of UD reinforced carbon-PPS tapes welded (using laser-assisted tape placement equipment) on carbon woven fabric PPS reinforced laminates. There, the fracture toughness of the weld interface was found to decrease significantly upon annealing, which was mainly attributed to a decrease in the amount of plastic work during fracture.

\subsection{Conclusions}

The present work investigated the crystallization and fracture toughness of PPS under tape placement conditions. A new fast scanning calorimeter from Mettler-Toledo (the Flash DSC 1) was successfully applied to investigate the critical (quench) rate. The PPS was found to be unable to crystallize when subjected to cooling rates in excess of $20^{\circ} \mathrm{C} / \mathrm{s}$. As the cooling rates observed during in situ tape placement can be significantly higher, the PPS in such composites is anticipated to have an amorphous morphology. Consequently, the final product properties, such as stiffness, chemical resistance or thermal stability, can differ from conventionally manufactured components. Clearly, the introduction of these new manufacturing methods, 
involving high heating and cooling rates, calls for an improved understanding of polymer crystallization and its resulting properties.

The effect of crystallinity on the tensile behavior and fracture toughness, through an essential work of fracture (EWF) approach, was investigated experimentally for PPS film. The tests were performed on as-received (low crystallinity) as well as annealed film specimens. The as-received tensile specimens showed extensive plastic deformation prior to fracture, while the annealed specimens showed a more brittle fracture behavior. Similarly, the EWF experiments demonstrated that the amount of plastic work spent during fracture decreases after an annealing procedure. The experimental results show that the tape placement of PPS-based composites results in favorable fracture properties. Nevertheless, for practical applications other properties, such as chemical resistance or strength and stiffness, should also be taken into account. Additional research is therefore required to understand the effect of high heating and cooling rates on the properties of PPS and its composites.

\section{References}

[1] R. Schledjewski. Thermoplastic tape placement - in situ consolidation is reachable. Plastics, Rubber and Composites, 38(9-10):379-386, 2009.

[2] E. P. Beyeler and S. I. Güçeri. Thermal analysis of laser-assisted thermoplastic-matrix composite tape consolidation. Journal of Heat Transfer, 110(2):424-430, 1988.

[3] F. O. Sonmez and H. T. Hahn. Modeling of heat transfer and crystallization in thermoplastic composite tape placement process. Journal of Thermoplastic Composite Materials, 10(3):198-240, 1997.

[4] K. Ravindranath and J. P. Jog. Polymer crystallization kinetics: poly(ethylene terephthalate) and poly(phenylene sulfide). Journal of Applied Polymer Science, 49(8):1395-1403, 1993.

[5] C. Auer, G. Kalinka, T. Krause, and G. Hinrichsen. Crystallization kinetics of pure and fiber-reinforced poly(phenylene sulfide). Journal of Applied Polymer Science, 51(3):407-413, 1994.

[6] C. Silvestre, E. Di Pace, R. Napolitano, B. Pirozzi, and G. Cesario. Crystallization, morphology, and thermal behavior of poly(p-phenylene sulfide). Journal of Polymer Science, Part B: Polymer Physics, 39(4):415-424, 2001.

[7] L. C. Lopez and G. L. Wilkes. Non-isothermal crystallization kinetics of poly(p-phenylene sulphide). Polymer, 30(5):882-887, 1989.

[8] L. I. Minkova and P. L. Magagnini. Non-isothermal crystallization kinetics of poly(phenylene sulfide)/vectra-B blends. Polymer, 36(10):2059-2063, 1995.

[9] L. C. Lopez and G. L. Wilkes. Crystallization kinetics of poly(p-phenylene sulfide): effect of molecular weight. Journal of Macromolecular Science - Reviews in Macromolecular Chemistry and Physics, C29:83-151, 1989.

[10] P. Cebe. Review of recent developments in poly(phenylene sulphide). Polymers and Polymer Composites, 3(4):239-266, 1995. 
[11] J. E. Spruiell and C. J. Janke. A review of the measurement and development of crystallinity and its relation to properties in neat poly(phenylene sulfide) and its fiber reinforced composites. Technical report, Oak Ridge National Laboratory, 2004.

[12] P. Davies, M. L. Benzeggagh, and F. X. de Charentenay. Delamination behavior of carbon fiber reinforced PPS. In SAMPE Quarterly, volume 32, pages 134-146, 1987.

[13] N. Nishihata, T. Koizumi, Y. Ichikawa, and T. Katto. Plane strain fracture toughness of polyphenylene sulfide. Polymer Engineering and Science, 38(3):403-408, 1998.

[14] Mettler-Toledo website: http://www.mt.com, visited on February 23th, 2012.

[15] V. Mathot, M. Pyda, T. Pijpers, G. Vanden Poel, E. Van de Kerkhof, S. Van Herwaarden, F. Van Herwaarden, and A. Leenaers. The Flash DSC 1, a power compensation twin-type, chip-based fast scanning calorimeter (FSC): First findings on polymers. Thermochimica Acta, 522(1-2):36-45, 2011.

[16] S. Van Herwaarden, E. Iervolino, F. Van Herwaarden, T. Wijffels, A. Leenaers, and V. Mathot. Design, performance and analysis of thermal lag of the UFS1 twin-calorimeter chip for fast scanning calorimetry using the Mettler-Toledo Flash DSC 1. Thermochimica Acta, 522(1-2):46-52, 2011.

[17] E. Iervolino, A. W. Van Herwaarden, F. G. Van Herwaarden, E. Van de Kerkhof, P. P. W. Van Grinsven, A. C. H. I. Leenaers, V. B. F. Mathot, and P. M. Sarro. Temperature calibration and electrical characterization of the differential scanning calorimeter chip UFS1 for the Mettler-Toledo Flash DSC 1. Thermochimica Acta, 522(1-2):53-59, 2011.

[18] G. Vanden Poel. Performance and calibration of the Flash DSC 1, a new, MEMS-based fast scanning calorimeter. In press. Thermochimica Acta, 2011.

[19] K. B. Broberg. On stable crack growth. Journal of the Mechanics and Physics of Solids, 23(3):215-237, 1975.

[20] S. Hashemi. Effect of temperature on fracture toughness on an amorphous poly(ether-ether ketone) film using essential work of fracture analysis. Polymer Testing, 22:589-599, 2003.

[21] B. Cotterell and J. K. Reddel. The essential work of plane stress ductile fracture. International Journal of Fracture, 13(3):267-277, 1977.

[22] Y. W. Mai and B. Cotterell. On the essential work of ductile fracture in polymers. International Journal of Fracture, 32(2):105-125, 1986.

[23] Y. W. Mai, S. C. Wong, and X. H. Chen. Application of fracture mechanics for characterization of toughness of polymer blends. Polymer Blends, 2:17-58, 2000.

[24] T. Bárány, T. Czigány, and J. Karger-Kocsis. Application of the essential work of fracture (EWF) concept for polymers, related blends and composites: A review. Progress in Polymer Science (Oxford), 35(10):1257-1287, 2010.

[25] J. J. Casellas, P. M. Frontini, and J. M. Carella. Fracture characterization of low-density polyethylenes by the essential work of fracture: Changes induced by thermal treatments and testing temperature. Journal of Applied Polymer Science, 74(4):781-796, 1999.

[26] R. Lv, W. Xu, B. Na, and J. Yan. Correlation of mechanical behaviors with crystalline phase and related cavitation in isotactic polypropylene. Journal of Applied Polymer Science, 108(5):3185-3190, 2008.

[27] E. Clutton. Essential work of fracture. In Fracture Mechanics Testing Methods for Polymers, Adhesives and Composites, volume 28 of European Structural Integrity Society, pages 
177-195. Elsevier, 2001.

[28] W. J. B. Grouve, L. L. Warnet, B. Rietman, and R. Akkerman. On the weld strength of in situ tape placed reinforcements on weave reinforced structures. Accepted for publication in Composites Part A, 2012.

[29] R. C. Zhang, Y. Xu, K. Cheng, and Z. M. Li. Shear-induced crystallization of poly(phenylene sulfide). Polymer, 45:2606-2616, 2008. 



\section{CHAPTER 8}

\section{Discussion}

The present chapter consolidates the work presented in the previous chapters and discusses a processing strategy for the laser-assisted tape placement of tailored structures. Firstly, the effect of the processing parameters and material properties on the interfacial fracture toughness between a tape and a laminate is discussed. Secondly, a placement strategy is proposed based on the modeling and experimental results presented in this thesis. The energy efficiency and productivity of the proposed strategy is investigated. The last section concerns the degree of crystallinity of the tape-placed structures. The effect of crystallinity on the material properties is discussed, as well as possible strategies to increase the crystallinity.

\subsection{Process overview}

The work presented in the previous chapters concerned the interlaminar bonding of UD carbon-PPS tapes onto carbon woven fabric reinforced PPS laminates, employing the laser-assisted tape placement process. Several topics were addressed, ranging from the optical aspects of laser heating to the interrelation between crystallinity and fracture toughness. Figure 8.1 schematically illustrates the connection between these topics (and chapters). This section summarizes the process and discusses the effect of the processing parameters and relevant material properties on the final interfacial fracture toughness.

The laminate and tape are heated by a laser before they meet in the nip-point. Chapter 2 studied the optical aspects of laser heating for carbon reinforced PPS composites. The laser light $(\lambda=980 \mathrm{~nm})$ was found to be either reflected or absorbed, while virtually no light was transmitted. The refractive indexes of the tape $n_{\mathrm{t}}$ and the laminate $n_{1}$ determine, together with the angle of incidence, the fraction of light which is reflected (and thus also the fraction of the light which is absorbed). Hence, in terms of processing, the laser angle $\alpha$ is an important parameter which controls the distribution of laser power between the tape and the laminate. Combined with the refractive indexes, this angle governs the incident heat flux distribution $Q$ on the 


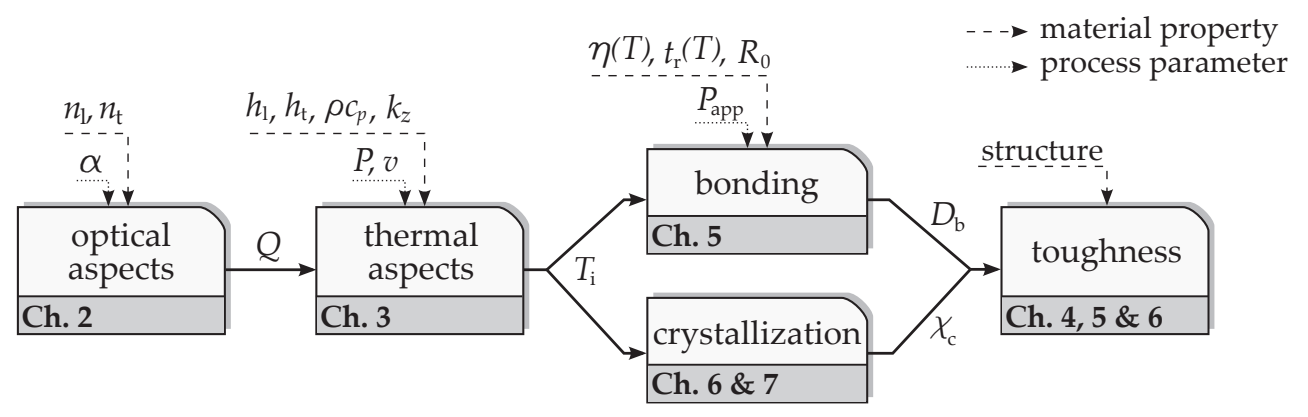

Figure 8.1 Interlaminar bond development during the laser-assisted tape placement process.

tape and the laminate. The heat flux distribution, subsequently, determines to a large extent the temperature distribution in the tape and the laminate.

Chapter 3 considered the thermal aspects of the process. The thermal problem is dominated by through-thickness heat conduction, with the thermal conductivity $k_{z}$ and volumetric heat capacity $\rho c_{p}$ of the tape and the laminate as the important material properties. Heat loss through convection or radiation at the surfaces is negligible. In terms of processing parameters, the combination of laser angle $\alpha$, input power $P$ and placement velocity $v$ governs the temperature distribution in the tape and laminate. Due to its small thickness and the insulating effect of the compaction roller, the tape heats up considerably faster than the laminate. The thermal gradients in the tape decay quickly and, in the limit, its through-thickness temperature can be approximated by a single value. The laminate, adversely, can be considered as a semiinfinite solid exhibiting a high temperature gradient near its surface. Consequently, the laminate's surface temperature drops quickly near the nip-point, as the incident heat flux diminishes, due to the shadowing effect of the roller.

The actual interlaminar bonding process, which was discussed in Chapter 5, consists of two different, but simultaneously occurring, mechanisms. First, intimate contact needs to be developed between the tape and the laminate surface; this comprises the flattening of the surface asperities on the tape and laminate under the application of heat and pressure. The time required to achieve full intimate contact depends on the initial surface roughness $R_{0}$, the matrix viscosity $\eta(T)$ and the pressure $P_{\text {app }}$ applied by the compaction roller. Subsequently, interdiffusion of polymer chains (also known as healing) occurs at the places where intimate contact has been achieved. This involves the diffusion of polymer chains across the interface and is often described using the reptation theory. The time required to complete interdiffusion equals the reptation time $t_{\mathrm{r}}$. The final degree of bonding $D_{\mathrm{b}}$ strongly depends on the thermal history at the interface $T_{\mathrm{i}}(t)$, due to the temperature dependency of both the viscosity and reptation time.

A mandrel peel test was introduced in Chapter 4 to quantify the interfacial fracture 
toughness $\mathcal{G}_{\mathrm{c}}$ as a measure of the degree of bonding. It must be pointed out here, however, that the fracture toughness not only depends on the degree of interlaminar bonding. As was shown in Chapter 6, also the structural morphology and the crystallinity $\chi_{\mathrm{c}}$ of the interface play an important role. The effect of the former was discussed in Chapter 6 . The presence of resin pockets at the weld interface was found to improve the toughness of the interface. The effect of the latter was investigated in Chapter 7. The high cooling rates observed during the LATP process inhibit crystallization. Consequently, the resulting low degree of crystallinity contributes to a high interfacial fracture toughness.

\subsection{Optimal processing strategy}

The work presented in the previous chapters provides a good foundation for the definition of a process strategy for the welding of UD carbon-PPS tapes onto woven fabric reinforced laminates. The first part of this section proposes such a strategy, while subsequently the energy efficiency and the productivity of this strategy are discussed. The former concerns the amount of material which can be deposited per unit energy, while the latter relates to the amount of material deposited per unit time. Ideally, the process strategy combines high productivity with high energy efficiency.

\subsubsection{Processing strategy}

The interlaminar bonding process comprises the development of intimate contact and the interdiffusion of polymer chains. The analysis in Chapter 5 demonstrated that, for the materials considered in this thesis, the bonding process was limited by the time required to achieve intimate contact. A characteristic time for intimate contact of approximately $50 \mathrm{~ms}$ was found, assuming a constant temperature and pressure under the compaction roller of $300{ }^{\circ} \mathrm{C}$ and $400 \mathrm{kPa}$, respectively. The time required for interdiffusion at the same temperature was, with a value of $0.5 \mathrm{~ms}$, significantly smaller. Therefore, an increase in placement velocity (and thereby productivity) requires a reduction of the time required for intimate contact development. According to Equation 5.2, this can be achieved, for a given material, by increasing the compaction pressure or by decreasing the resin viscosity, through an increase of the interface temperature. The feasibility of an increase in pressure is discussed first, followed by an analysis on the possibilities to raise the interface temperature. Finally, a processing strategy is formulated for the tape placement of carbon-PPS tapes onto carbon woven fabric reinforced PPS laminates.

The compaction pressure can be varied independently of the chosen placement velocity, input power or laser angle. Its effect is very direct and clear: according to Equation 5.2, the time required for intimate contact is inversely proportional to the 
applied pressure. The maximum pressure, however, is limited by the specifications of the equipment. A typical tape placement robot can handle a payload of $1500 \mathrm{~N}$. For comparison, a compaction force of nominally $800 \mathrm{~N}$ was employed during all LATP experiments presented in this thesis. The actual pressure history depends strongly on the deformability of the compaction roller. On the one hand, a metallic (stiff) roller barely deforms under the applied force. The contact area will in this case be very small, which leads to high pressures. Due to the small contact area, however, the contact time will also be quite small. On the other hand, the application of an elastomeric (compliant) compaction roller, as used in this work, results in lower pressures, but longer contact times.

The time required for intimate contact development can also be reduced through an increase of the interface temperature. The mandrel peel experiments presented in Chapter 5 suggest that an interface temperature $T_{\mathrm{i}}$ of more than $240{ }^{\circ} \mathrm{C}$ provides an excellent interfacial fracture toughness. The temperature $T_{i}$ was defined as the average of the tape and laminate temperature just before they meet in the nip-point (i.e. Equation 5.10). Although no unambiguous interrelation was found between the interfacial toughness and the tape or laminate temperature, it seems that the maximum temperature should not exceed $500{ }^{\circ} \mathrm{C}$ to prevent thermal degradation. The laser angle $\alpha$ controls the distribution of laser power between the tape and the laminate. Due to its small thickness and the insulating effect of the compaction roller, the tape is heated faster and more efficiently than the laminate. It seems, therefore, beneficial to supply the majority of the laser power to the tape.

A processing strategy is now proposed, based on the observations above. The strategy involves the distribution of all laser power to the tape, while providing no energy to the laminate. The tape should be heated to a maximum temperature of approximately $500{ }^{\circ} \mathrm{C}$ to prevent degradation. The interface temperature $T_{\mathrm{i}}$ would in this case still exceed $240^{\circ} \mathrm{C}$ and, based on the work in Chapter 5, an excellent interfacial toughness is expected. The subsequent sections discuss the energy efficiency and productivity of this strategy.

\subsubsection{Energy efficiency}

As introduced above, the efficiency of a process concerns the amount of material deposited per unit energy. It is defined as:

$$
\varepsilon=\frac{\rho h_{\mathrm{t}} b v}{P}
$$

in which $h_{\mathrm{t}}$ is the thickness and $b$ the width of the tape, while $\rho$ denotes its density. The parameters $v$ and $P$ represent the placement velocity and input power, respectively. An optimization problem in terms of energy efficiency can, in its most 


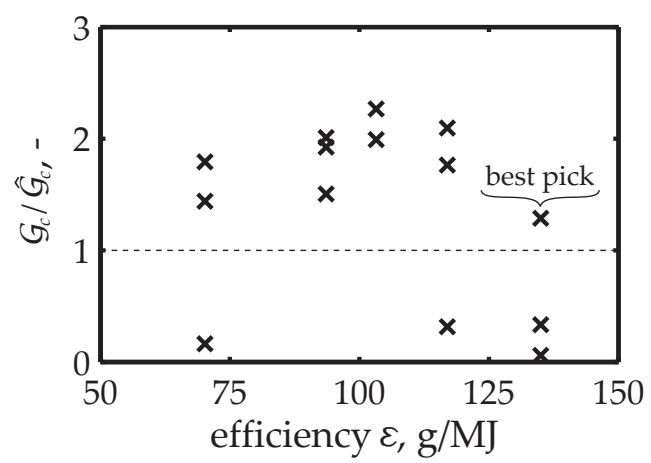

Figure 8.2 Process efficiency versus normalized fracture toughness for the processing parameters reported in Chapter 5.

simplified form, be formulated as:

$$
\max (\varepsilon), \quad \text { subject to: } \mathcal{G}_{\mathrm{c}} \geq \hat{\mathcal{G}}_{\mathrm{c}}
$$

where $\hat{\mathcal{G}}_{\mathrm{c}}$ is the minimum desired interfacial fracture toughness, which would typically equal the value obtained for autoclave processing or press molding. Table 8.1 lists the efficiency and normalized fracture toughness for a few of the processing parameter combinations used in this work, while Figure 8.2 shows the efficiency versus normalized fracture toughness for all experiments presented in Chapter 5. The reference value $\hat{\mathcal{G}}_{\mathrm{c}}$ equals the value found for press molding $\left(\hat{\mathcal{G}}_{\mathrm{c}}=1.05 \mathrm{~kJ} / \mathrm{m}^{2}\right)$, as was discussed in Chapter 6 . The obtained efficiency $\varepsilon$ equals approximately $100 \mathrm{~g} / \mathrm{MJ}$, with a maximum efficiency of $135 \mathrm{~g} / \mathrm{MJ}$ found for (not surprisingly) the lowest input power and highest velocity. The laser angle equaled $15.4^{\circ}$ for this specific case, which means that the majority of the laser power was distributed to the tape. For comparison, an efficiency of 1 to $50 \mathrm{~g} / \mathrm{MJ}$ is reported in the literature for autoclave processing [1, 2].

The theoretical efficiency of the proposed strategy can be estimated from the power required to heat the tape to a temperature of $500{ }^{\circ} \mathrm{C}$. It is assumed that all input

Table 8.1 Placement efficiency and normalized fracture toughness for some typical process parameters used in this work (see Chapter 5).

\begin{tabular}{ccccc}
\hline $\begin{array}{c}\text { laser power } \\
P, \mathrm{~W}\end{array}$ & $\begin{array}{c}\text { placement velocity } \\
v, \mathrm{~mm} / \mathrm{s}\end{array}$ & $\begin{array}{c}\text { laser angle } \\
\alpha^{\circ}\end{array}$ & $\begin{array}{c}\text { norm. toughness } \\
\mathcal{G}_{\mathrm{c}} / \hat{\mathcal{G}}_{\mathrm{c}},\end{array}$ & $\begin{array}{c}\text { efficiency } \\
\varepsilon, \mathrm{g} / \mathrm{MJ}\end{array}$ \\
\hline 1300 & 125 & 15.4 & 1.29 & 135 \\
1500 & 75 & 18.4 & 1.79 & 70 \\
1500 & 100 & 17.1 & 1.92 & 94 \\
1500 & 125 & 15.4 & 2.09 & 117 \\
1700 & 125 & 18.4 & 1.99 & 103 \\
\hline
\end{tabular}


energy is absorbed by the tape, which means that no incident light is reflected or transmitted. Moreover, heat losses due to convection or radiation are considered negligible. The power required to increase the tape temperature with $\Delta T$ at a placement velocity $v$ then yields:

$$
P=\rho c_{p} b h_{\mathrm{t}} v \Delta T
$$

from which the efficiency, according to Equation 8.1, follows:

$$
\varepsilon=\frac{1}{c_{p} \Delta T}
$$

A process efficiency of approximately $1.40 \mathrm{~kg} / \mathrm{MJ}$ is obtained by considering the tape's specific heat (listed in Table 3.2) and a temperature increase of $500{ }^{\circ} \mathrm{C}$. Clearly, the efficiency exceeds the values shown in Figure 8.2. This is partly caused by the fact that the laser power was divided between the tape and the laminate during the experiments. Heating the latter, however, is less efficient than heating the tape. Moreover, as the tape width was small compared to the laser spot width, not all laser power contributed to the heating of the tape. It seems, therefore, that the efficiency of the process can be increased considerably by adjusting the laser angle and spot size. The actual efficiency of this strategy should, however, be tested in a practical application.

From a material point of view, the energy efficiency (as formulated in Equation 8.1) of the chosen strategy seems to depend only on the specific heat capacity of the tape. The effect of surface roughness and matrix material properties is, however, indirectly incorporated in the required temperature increase $\Delta T$. The time required for intimate contact decreases for flatter tapes or for a lower matrix viscosity and reptation time; possibly this allows welding to take place at a lower interface temperature. Also, in the preceding thermal analysis it was assumed that all laser power is absorbed by the tape. This imposes restrictions on the optical material properties for the used materials. The optical performance of the composite materials requires additional research in order to improve the energy efficiency of the process.

\subsubsection{Productivity}

Apart from energy efficiency, the productivity of the placement strategy is also an important aspect. The previous section already discussed that the tape is heated more efficiently than the laminate. Moreover, the tape is also heated faster than the laminate, due to its small thickness. Hence, also in terms of productivity it is beneficial to distribute all laser power to the tape. The present section investigates the maximum achievable placement velocity using this strategy. 
An important underlying assumption in the efficiency analysis above is that the tape is fully heated over its thickness, i.e. the initial thermal gradients have decayed and its temperature can be approximated by a single value. At high placement velocities, however, this assumption will not hold. Instead, there will be a distinct skin layer with a high temperature gradient towards the heated surface and a colder back side. Similarly to the laminate, the tape's surface temperature would in this case decrease rapidly near the nip-point, where no energy is supplied anymore, due to the shadowing effect of the roller. The maximum placement velocity is thus limited by the time required for the temperature gradients to decay (i.e. the time required to fully heat the tape over its thickness). The thickness of the skin layer $\zeta$, as depicted in Figure 8.3, evolves with the square root of time [3]. Rewriting in terms of placement velocity yields:

$$
\zeta \approx \sqrt{\frac{k_{z}}{\rho c_{p}} \frac{\delta_{\mathrm{t}}}{v}},
$$

in which $\delta_{\mathrm{t}}$ is the heated tape length. The velocity can be now be determined at which the skin layer thickness equals the tape thickness, i.e. $\zeta=h_{\mathrm{t}}$. The actual decay of the thermal gradients near the surface, however, will take more time and thus requires a lower placement velocity. Rewriting Equation 8.5 and taking a velocity correction factor $\Gamma$ into account yields the maximum allowable placement velocity:

$$
\bar{v} \approx \frac{1}{\Gamma} \frac{k_{z}}{\rho c_{p}} \frac{\delta_{\mathrm{t}}}{h_{\mathrm{t}}^{2}} .
$$

As this velocity $\bar{v}$ is proportional to the heated tape length $\delta_{\mathrm{t}}$, it is advantageous to increase the laser spot size. Equation 8.6 also demonstrates that the maximum placement velocity strongly depends on the tape thickness. A large tape thickness

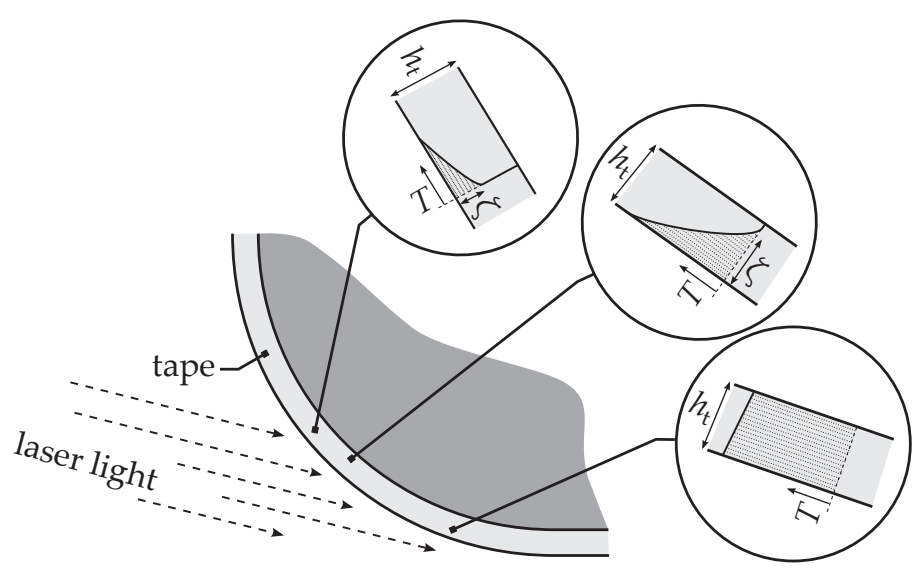

Figure 8.3 Schematic illustration of the temperature profile development in the tape. 
limits the maximum placement velocity, as it takes more time for the thermal gradients to decay and completely heat the tape over its thickness. It seems, therefore, beneficial to use thin tapes, which allow high placement velocities. Nevertheless, the application of thin tapes would then require multiple deposition runs to achieve the desired final thickness. The overhead time associated with the repositioning of the tape placement head should in this case be taken into account. For example, the total process time for a simple unidirectionally reinforced laminate, measuring $L_{x}$ by $L_{y}$ and having a thickness of $h_{1}$, yields by approximation:

$$
t_{\mathrm{p}} \approx \frac{L_{y}}{b}\left(\frac{L_{x}}{v} \frac{h_{1}}{h_{\mathrm{t}}}+t_{\mathrm{o}} \frac{h_{1}}{h_{\mathrm{t}}}\right),
$$

where $t_{\mathrm{o}}$ represents the overhead time per deposition run. As introduced earlier, this time is associated with the time lost due to transferring the tape placement head to the new position. Moreover, it also includes the time lost due to the acceleration and deceleration during tape placement. The term $h_{1} / h_{\mathrm{t}}$ is the minimum number of plies required to achieve the desired total thickness. Substitution of the maximum achievable velocity (Equation 8.6) into Equation 8.7 yields the total process time as:

$$
t_{\mathrm{p}}=\frac{L_{y} h_{1}}{w}(\overbrace{\Gamma \frac{\rho c_{p}}{k_{z}} \frac{L_{x}}{\delta_{\mathrm{t}}} h_{\mathrm{t}}}^{\text {placement }}+\overbrace{t_{0} \frac{1}{h_{\mathrm{t}}}}^{\text {overhead }}),
$$

in which the first term within the brackets represents the time associated with the actual lay-up of material (at a constant velocity $v$ ), while the second term represents the total overhead time. The former term is proportional to the tape thickness, while the latter is inversely proportional to this thickness. For given material properties and equipment specifications, the optimum tape thickness depends on the lay-up length. The first term between brackets dominates the process time if $L_{x}$ is large, which means that short process times can be achieved when using thin tapes. Adversely, thick tapes should be used when the lay-up length is short and the overhead time governs the problem.

Figure 8.4 illustrates the breakdown of the total process time as a function of the tape thickness for two different lay-up lengths. The left figure corresponds to a length $L_{x}$ of $2 \mathrm{~m}$, while the right corresponds to a length of $10 \mathrm{~m}$. In the former case, the optimum (in terms of productivity) tape thickness is approximately $0.2 \mathrm{~mm}$, while this equals $0.05 \mathrm{~mm}$ in the latter case. Clearly, small products desire a tape with a large thickness, while for the limiting case of tape winding (in which $L_{x} \rightarrow \infty$ ) the application of thin tapes would maximize productivity.

The analysis above is based on the thermal aspects of the tape placement process. 

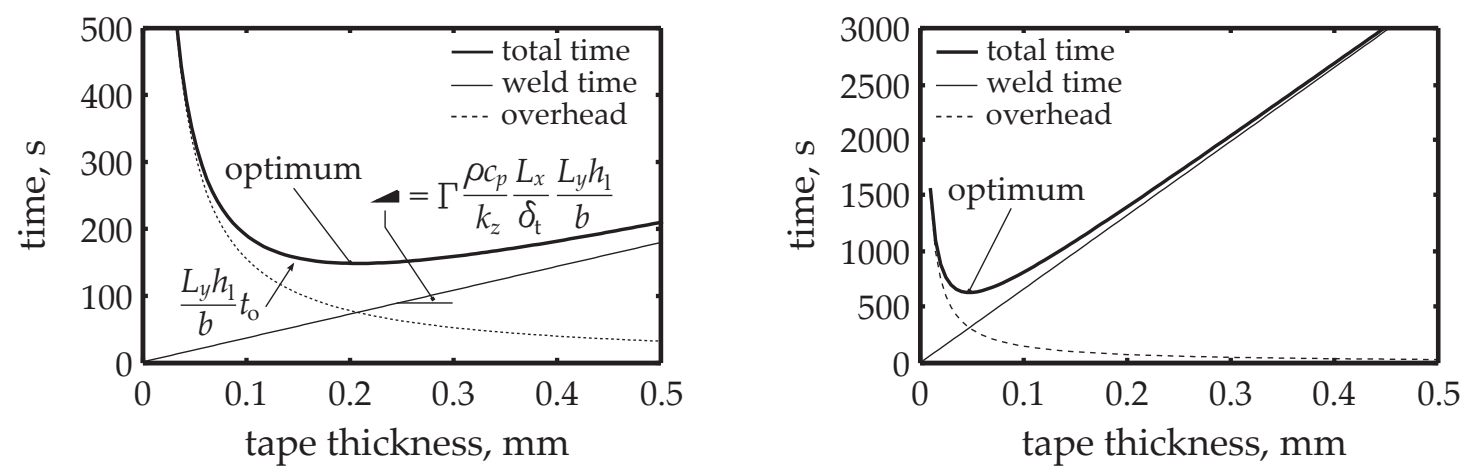

Figure 8.4 Breakdown of the total processing time as a function of the carbon-PPS tape thickness for two different lay-up lengths. Tape material properties are listed in Table 3.2. The heated tape length $\delta_{\mathrm{t}}$ equals $52 \mathrm{~mm}$, while $L_{y} h_{1} / \mathrm{b}$ is $0.6 \mathrm{~mm}$. The overhead time $t_{\mathrm{o}}$ and velocity correction factor $\Gamma$ are $25 \mathrm{~s}$ and 5, respectively. Left: Lay-up length $L_{x}$ of $2 \mathrm{~m}$. Right: Lay-up length $L_{x}$ of $10 \mathrm{~m}$.

The maximum achievable placement velocity is, of course, also limited by the time required for interlaminar bonding. The previous section already discussed the effect of the interface temperature and compaction pressure on the bonding process. From a material point of view, the productivity can be increased by decreasing the surface roughness of the tape or by reducing the viscosity and reptation time of the matrix. The feasibility of altering the latter, however, is limited. As the process was limited by the time required to develop intimate contact, a reduction of the tape surface roughness can immediately improve the productivity. According to Equation 5.6, the intimate contact time is inversely proportional to the squared asperity height. Ultimately, in the limiting case of perfectly flat tapes, the bonding time reduces to the time required for healing.

The analysis provided above is also largely valid when the process is limited by the time required for healing instead of intimate contact development. Although in this case the productivity and energy efficiency of the process cannot be improved by an increase in pressure, an increase of the interface temperature has a comparable effect. As discussed in Chapter 5, the time required for healing decreases with increasing temperature, due to the temperature dependency of the reptation time. Again, the maximum tape temperature should not exceed the degradation temperature of the thermoplastic.

The process strategy analysis, provided in this and the previous section, focused on the interlaminar bond development between the tape and laminate. Nevertheless, the efficiency and productivity could be limited by additional mechanisms, such as intralaminar void reduction or residual stress development. Additional research regarding these topics seems desired in order to further optimize the process in a general sense. 


\subsection{The issue of crystallinity}

The DSC experiments presented in Chapters 6 and 7 showed that the high cooling rate during tape placement inhibits the crystallization of the PPS in the tape. Consequently, the final properties of the structure differ from conventionally (slowly) manufactured components. The present section elaborates on the interrelation of processing parameters, degree of crystallinity and final product properties. First, the interrelation between the crystallinity and material properties is elaborated. Subsequently, the feasibility of obtaining a high degree of crystallinity using the LATP process is discussed.

\subsubsection{Effect on material properties}

The fracture toughness experiments demonstrated that the low degree of crystallinity of the PPS in the tape actually improved the interfacial fracture toughness for the tape-placed specimens. Although important, the interfacial fracture toughness is not the only property that determines the final structure performance. Crystallinity also affects the static and dynamic properties, as well as the thermal and environmental stability of PPS-based composites.

\section{Mechanical properties}

The tensile tests on PPS film, presented in Chapter 7, already showed that the stiffness and strength of PPS increase with crystallinity. These results correspond with the findings in the literature. Generally, an increase in the degree of crystallinity is accompanied by an improvement in stiffness and strength of a thermoplastic polymer $[4,5]$. The tensile properties in the fiber direction of thermoplastic composites, however, are anticipated to be fairly insensitive to the matrix crystallinity. Data available in the literature concerning carbon-PPS, e.g. [6-8], confirm this, but do mention an increase in tensile properties in the transverse direction upon annealing.

The effect of crystallinity on the impact resistance of PPS and its composites has received little attention in the literature. Lu et al. [9] performed Izod impact tests on unreinforced PPS specimens and showed that the impact toughness decreased with an increasing degree of crystallinity. Comparable results were obtained for UD carbon-PEEK composites by Davies et al. [10] and Gao and Kim [11]. Generally, an increase of crystallinity decreases the impact resistance of thermoplastic polymers [12], although it depends to a large extent on the size and distribution of the crystallites.

The long term properties, such as creep or fatigue resistance, of thermoplastics are also affected by the degree of crystallinity. Creep is defined as the tendency of a 
solid to deform slowly (and permanently) under the application of stress. Physically, it involves the slippage of polymer chains past each other. The chain mobility in amorphous polymers increases significantly above the glass transition temperature, thereby decreasing the creep resistance. The presence of crystallites inhibits the slippage of polymer chains by acting as physical crosslinks. Consequently, the amorphous morphology of the PPS in the welded tapes is expected to decrease the creep resistance of the structure.

There is very little information available on the fatigue properties of PPS and its composites. Carbon reinforced PEEK has received a bit more attention. Harris [13] summarized the available experimental work. The fatigue performance of carbonPEEK was found to depend on the degree of crystallinity as well as the crystalline morphology. The available experimental work suggests that the fatigue performance improves with an increase in the degree of crystallinity. Nevertheless, additional work is required into this specific subject.

\section{Thermal and environmental stability}

Neat and fiber reinforced PPS show excellent retention of mechanical properties above its glass transition temperature, which can be attributed to its semicrystalline morphology. The continuous service temperature of (semicrystalline) PPS is reported to be $240{ }^{\circ} \mathrm{C}$ [14]. Amorphous polymers soften at the glass transition temperature $T_{\mathrm{g}}$, leading to reduction of stiffness and strength. Although the amorphous regions between the crystallites also soften at $T_{\mathrm{g}}$, the strength and stiffness is retained due to the presence of the rigid crystallites. Crystallinity, therefore, enhances the high temperature performance of the polymer [15].

Poly(phenylene sulfide) shows very limited water absorption of nominally $0.02 \%$, according to the manufacturer data sheet [14]. Fiber reinforced PPS absorbs less water than PEEK-based composites and an order of magnitude less than epoxy composites [16]. Nevertheless, these data are based on PPS with a high degree of crystallinity. The effect of crystallinity on the water absorption in carbon woven fabric reinforced PPS laminates was investigated by Ma and Yur [6]. These authors found that an annealing procedure, thereby increasing the degree of crystallinity, results in a decrease of the water absorption values. The maximum moisture content for the non-annealed and annealed specimens was $0.13 \mathrm{wt} \%$ and $0.09 \mathrm{wt} \%$, respectively. Although the exact degree of crystallinity is not known for these specimens, the results show that an increase in crystallinity seems to reduce the water absorption. $\mathrm{Ma}$ and Yur [6] also investigated the effect of water absorption on the flexural strength. Although water absorption had a slight detrimental effect on the flexural strength, the retention of strength was still very high, having a value of $95 \%$, after long term exposure (> 1400 hours) at $80{ }^{\circ} \mathrm{C}$ and $85 \%$ relative humidity. 
Chemicals can have detrimental effects on the properties of thermoplastic composites. They may either dissolve the polymer or may be absorbed and cause swelling, crazing or solvent-induced crystallization [16]. Poly(phenylene sulfide) is renowned for its chemical resistance to many aircraft fluids, such as kerosene and aviation hydraulic fluids $[17,18]$. The effect of crystallinity on this resistance, however, has not been investigated for PPS. From a more general viewpoint, semicrystalline polymers have better chemical resistance than their amorphous counterparts. The crystallites act as physical crosslinks and prevent the dissolution of the molecular network [15]. An increase in the degree of crystallinity, therefore, increases the chemical resistance $[4,19]$.

\subsubsection{Improving the degree of crystallinity}

The discussion above showed that the degree of crystallinity can have a pronounced effect on the material properties. The desired level of crystallinity mainly depends on the intended application of the final structure. The crystallinity is predominantly governed by the cooling rate from the melt; too high cooling rates will inhibit crystallization. Compared to conventionally manufacturing techniques, the LATP process is inseparably connected to high heating and cooling rates. It seems therefore difficult to combine high productivity (high deposition speed) with a high degree of crystallinity. Three different approaches can be suggested to increase crystallinity nevertheless. The first comprises the extension of the tape placement head with an additional heater, in order to reduce the maximum cooling rate of the tape. The second approach concerns the application of heated tooling to increase the laminate temperature and thereby ensure crystallization. The last option is an additional annealing step in an oven or autoclave.

The crystallization of PPS occurs approximately between 250 and $120{ }^{\circ} \mathrm{C}$ [16], while the maximum cooling rate should not exceed $5{ }^{\circ} \mathrm{C} / \mathrm{s}$, according to the flash DSC experiments presented in Chapter 7. Using these figures, additional heat should be applied for a period of approximately 30 seconds to slowly cool down from $250{ }^{\circ} \mathrm{C}$ to $120^{\circ} \mathrm{C}$. Such long post-heating time, however, requires a heater length of more than $7 \mathrm{~m}$ for a placement velocity of $250 \mathrm{~mm} / \mathrm{s}$. Adding an additional heater to the tape placement head to ensure proper crystallization seems, therefore, infeasible for rapid composite processing envisaged here.

A mold temperature higher than $140{ }^{\circ} \mathrm{C}$ guarantees well crystallized products, according to the manufacturer of the PPS [14]. Heating the supporting tooling and the laminate to this temperature and maintaining this during the complete process time, however, requires costly molds and a large amount of energy. Alternatively, the manufactured components could also be post-crystallized in an oven or autoclave. Lee et al. [20] investigated the effect of annealing temperature and time on the final degree of crystallinity of glass reinforced PPS specimens having a thickness of 
$1.8 \mathrm{~mm}$. Complete crystallinity was obtained after 30 and 15 minutes at an annealing temperature of 160 and $204{ }^{\circ} \mathrm{C}$, respectively. It should be kept in mind, however, that this depends on the dimensions (mainly the thickness) of the actual component.

\subsection{Concluding remarks}

The work presented in this thesis demonstrated that in situ tape placement (at least in terms of interlaminar bonding) is feasible for carbon-PPS composites. The applied compaction pressure and laser angle are the important parameters, which govern the efficiency and productivity of the process. An increase in applied pressure would decrease the time required for intimate contact and directly increase the maximum achievable velocity. Moreover, the optimization study demonstrated that both the efficiency and productivity can also be maximized by distributing all laser power to the tape. Due to its low thickness, the tape is heated more efficiently and quickly than the laminate. Theoretically, a process efficiency $\varepsilon$ of more than $1.40 \mathrm{~kg} / \mathrm{MJ}$ should be feasible, which is significantly higher than the values reported for autoclave processing. Nevertheless, the proposed processing strategy needs to be tested in practice before definitive conclusions can be drawn.

The laser-assisted tape placement process is characterized by high heating and cooling rates. The latter can severely inhibit the crystallization of the PPS in the tape and laminate. Practically, it can be difficult to combine a high productivity with a high degree of crystallinity. As a solution the supporting tooling could be heated or, alternatively, the final component could be post-annealed in an oven or autoclave.

\section{References}

[1] T. Suzuki and J. Takahashi. Prediction of energy intensity of carbon fiber reinforced plastics for mass-produced passenger cars. In The Ninth Japan International SAMPE Symposium, 2005.

[2] Y. S. Song, J. R. Youn, and T. G. Gutowski. Life cycle energy analysis of fiber-reinforced composites. Composites Part A, 40:1257-1265, 2009.

[3] A. Bejan. Heat Transfer. John Wiley \& Sons, Inc., 1993.

[4] S. Béland. High Performance Thermoplastic Resins and their Composites. William Andrew Publishing, 1990.

[5] F. C. Campbell. Structural Composite Materials. ASM International, 2010.

[6] C. C. M. Ma and S. W. Yur. Environmental effects on the water absorption and mechanical properties of carbon fiber reinforced PPS and PEEK composites. Part II. Polymer Engineering \& Science, 31(1):34-39, 1991.

[7] J. Deporter and D. G. Baird. Effects of thermal history on the structure/property relationship in polyphenylenesulfide/carbon fiber composites. Polymer Composites, 14(3):201-213, 1993. 
[8] N. Nishihata, T. Koizumi, Y. Ichikawa, and T. Katto. Plane strain fracture toughness of polyphenylene sulfide. Polymer Engineering and Science, 38(3):403-408, 1998.

[9] D. Lu, Y. Yang, G. Zhuang, Y. Zhang, and B. Li. A study of high-impact poly(phenylene sulfide), 1 . The effect of its crystallinity on its impact properties. Macromolecular Chemistry and Physics, 202(5):734-738, 2001.

[10] P. Davies, W. J. Cantwell, P. Y. Jar, H. Richard, D. J. Neville, and H. H. Kausch. Cooling rate effects in carbon fiber/PEEK composites, pages 70-88. ASTM, Philadelphia, 1991.

[11] S. L. Gao and J. K. Kim. Cooling rate influences in carbon fibre/PEEK composites. Part III: impact damage performance. Composites Part A, 32:775-785, 2001.

[12] A. B. Mathur and I. S. Bhardway. Testing and Evaluation of Plastics. Allied Publishers, 2003.

[13] B. Harris. Fatigue in Composites: Science and Technology of the Fatigue Response of Fibre-Reinforced Plastics. Woodhead Publishing, 2003.

[14] Ticona GmbH website: http://www.ticona.com, visited on March 6th, 2012.

[15] F. Cogswell. Thermoplastic Aromatic Polymer Composites. Butterworth Heinemann, 1992.

[16] J. E. Spruiell and C. J. Janke. A review of the measurement and development of crystallinity and its relation to properties in neat poly(phenylene sulfide) and its fiber reinforced composites. Technical report, Oak Ridge National Laboratory, 2004.

[17] C. C. M. Ma, C. L. Lee, and N. H. Tai. Chemical resistance of carbon fiber-reinforced poly(ether ether ketone) and poly(phenylene sulfide) composites. Polymer Composites, 13(6):435-440, 1992.

[18] J. Mark, editor. Polymer Data Handbook. Oxford University Press, 1999.

[19] G. Lubin. Handbook of Composites. Van Nostrand Reinhold, 1982.

[20] T. H. Lee, F. Y. C. Boey, and K. A. Khor. On the determination of polymer crystallinity for a thermoplastic PPS composite by thermal analysis. Composites Science and Technology, 53:259-274, 1995. 


\section{CHAPTER 9}

\section{Conclusions and recommendations}

\subsection{Conclusions}

This thesis focuses on the welding of unidirectionally fiber reinforced thermoplastic tapes onto woven fabric reinforced thermoplastic laminates, employing the laserassisted tape placement process. The ultimate aim was to develop a placement strategy resulting in a high weld strength, while achieving a high energy efficiency and productivity. Several topics were addressed, of which the present section summarizes the main conclusions.

\section{Processing}

The interlaminar bonding process strongly depends on the thermal history at the interface. A process model was developed to determine which processing parameters and material properties govern the temperature distribution in the tape and the laminate. The model comprises two parts, that is an optical part and a thermal part. The former accounts for the reflection of laser light in the nip-point region and calculates the incident heat flux distribution on the tape and the laminate. The latter accounts for the relevant thermal phenomena and predicts the temperature distribution in the tape and the laminate.

The laser-assisted tape placement process was, for the materials and equipment considered in this thesis, dominated by the through-thickness heat conduction in the tape and the laminate, while heat losses through convection and radiation were found to be negligible. Due to its small thickness and the insulating effect of the compaction roller, the tape is heated faster and more efficiently than the laminate. Consequently, the laser angle is an important process parameter in terms of energy efficiency and productivity, as it governs the distribution of laser power between the tape and the laminate.

An interlaminar bonding analysis showed that the maximum placement velocity was limited by the time required to achieve intimate contact, for the carbon-PPS tape 
and laminate under consideration. The time required for interdiffusion is two orders of magnitude smaller than the intimate contact time. Nevertheless, the latter was still rather small and tape placement velocities in the order of $300 \mathrm{~mm} / \mathrm{s}$ should be possible. Higher placement velocities can be obtained by an increase in compaction pressure or interface temperature, or by using flatter tapes.

\section{Performance}

A mandrel peel test was developed to quantify the interfacial fracture toughness between the tape and the laminate as a measure for the weld quality. The test yielded repeatable results and, moreover, these test results were shown to be sensitive to the variation of the tape placement processing parameters.

Mandrel peel experiments demonstrated that the tape-placed specimens outperformed the (slowly cooled) press-molded specimens in terms of the interfacial fracture toughness, by almost a factor two. The toughness depends, however, not only on the degree of interlaminar bonding. Also the crystallinity and structural morphology at the interface play an important role. The former is related to the high cooling rates during tape placement, while the latter is related to the short processing time.

The high cooling rate prevents the PPS tape from crystallizing during the tape placement process. Consequently, the tape has a low degree of crystallinity which was found to increase the amount of plastic work during fracture and thereby improves the fracture toughness. Long process times, such as observed during press molding, allow the migration of the tape's fibers into the resin pockets between the bundles of the laminate. The resulting increase of fiber-fiber contact has a detrimental effect on the interfacial fracture toughness of press-molded specimens. The short processing time during tape placement prevents this fiber migration, which results in a further improvement of the interfacial fracture toughness.

\section{Optimum placement strategy}

The laser-assisted tape placement processing parameters (i.e. laser power, placement velocity and incident angle) were optimized for interfacial fracture toughness, using the developed mandrel peel test. For the specific cases investigated in this thesis, the highest energy efficiency and productivity were obtained when the laser power was predominantly supplied to the tape. An excellent fracture toughness was obtained when the interface temperature exceeds $240{ }^{\circ} \mathrm{C}$, irrespective of the individual tape or laminate temperature. The tape and laminate temperature, however, should not exceed $500{ }^{\circ} \mathrm{C}$, to prevent thermal degradation of the PPS matrix. 
The experimental work in this thesis demonstrated that the laser-assisted tape placement process shows a high energy efficiency compared to the values reported for conventional autoclave processing. Moreover, there is ample room for improvement to further increase both the energy efficiency and productivity of the process.

\subsection{Recommendations}

The present thesis focuses on the laser-assisted tape placement of a single UD reinforced tape and a woven fabric reinforced laminate. An in situ processing strategy was proposed, which results in a high weld strength in combination with a high energy efficiency and productivity. Although this is a fundamental step towards the application of the tape placement process to tailor press-formed components, additional research is still required. The present section discusses the important research topics for further research.

\section{Processing}

This thesis focused on the weld strength development under steady-state conditions (i.e. constant placement velocity). Due to its incremental nature, however, the tape placement process is inseparably connected to a repeated stopping and restarting of the process. As opposed to the production of flat laminates, where the edges can be trimmed off after production, the tailoring of pre-consolidated components requires a high weld strength at these start and stop positions. The application of the process, therefore, needs the development of an appropriate starting and stopping strategy.

Tailoring press-formed woven fabric reinforced components requires the deposition of tapes onto complex (doubly curved) geometries. In these cases, the application of the required compaction pressure (over the full width of the tape) can be quite challenging. Especially, sharp edges or highly double-curved surfaces might prove problematic. Future research should, therefore, definitely comprise a study into the pressure history between a compaction roller or shoe and a (highly) double-curved surface.

\section{Dimensional accuracy}

A practical application will require the placement of multiple tapes next to and on top of each other. Ideally, these tapes are deposited such that no gaps or overlaps are created. Nevertheless, the tapes will deform and spread under the application of heat and pressure. A thorough understanding of this spreading behavior is required in order to develop an appropriate placement strategy. 
The manufacturing of thermoplastic composites is inevitably accompanied by the development of residual stresses. These stresses usually cause shape distortions of the final structure. There is not much literature available on the development of residual stress during the tape placement process and the resulting shape distortions. Hence, this particular subject deserves attention in future research.

\section{Part quality}

The void content of the final structure is an important parameter. Any voids present in the initial tape should be compressed during tape placement and the growth of voids should be prevented. This might impose restrictions on the maximum attainable velocity. Successful application of the tape placement technology requires a good understanding of the phenomena involved. Moreover, the development of predictive models would ease the development of a placement strategy.

As discussed above, the tape placement process can be accompanied by the development of residual stresses. Besides shape distortions, these stresses might also reduce the load-carrying capacity of the final structure. Additional research should therefore include the effect of residual stresses on the mechanical properties of the final part. 


\section{Experimental optimization of the laser-assisted tape placement process using the mandrel peel test ${ }^{1}$}

The present appendix summarizes the important results of an optimization study for the automated laser-assisted tape placement process. An industrial tape placement machine was used in this work to manufacture the test specimens. The mandrel peel test method was applied to quantify the weld strength. First, the performed experiments are outlined after which the obtained results are presented.

\section{A.1 Experimental work}

\section{A.1.1 Specimen preparation}

The laser-assisted tape placement machine was used to manufacture the mandrel peel specimens. The basic lay-out of the equipment is described in Section 6.2.2. The equipment was fitted with a thermal imaging system, mounted on the tape placement head. A feedback control loop is subsequently used to ensure that the nip-point temperature is kept constant at a pre-set value.

The machine was used to weld UD carbon-PPS reinforced tapes onto carbon woven fabric (5 harness satin) reinforced PPS laminates. The placement velocity was varied between 25, 50, 100, 150, 200 and $250 \mathrm{~mm} / \mathrm{s}$, while the nip-point temperature was chosen between 250, 275, 300 and $325^{\circ} \mathrm{C}$. The maximum applied compaction pressure was kept constant during all experiments at a value of approximately $600 \mathrm{kPa}$, as measured using pressure-sensitive film. The distance between the tapes equaled $25 \mathrm{~mm}$, which ensured that the previously placed tapes were not

\footnotetext{
${ }^{1}$ Based on: W.J.B. Grouve, L.L. Warnet, R. Akkerman, S. Wijskamp, J.S.M. Kok. Weld strength assessment for tape placement. International Journal of Material Forming 3(1):707-710, 2010.
} 
influenced by the welding of the new tape. Finally, the specimens were cut from the laminate using a diamond-coated saw. Five specimens were manufactured for every combination of processing parameters.

\section{A.1.2 Testing procedure}

The mandrel peel test was used to quantify the interfacial fracture toughness as a measure for the degree of interlaminar bonding. The testing procedure was elaborated in Chapter 4 . The applied alignment force $F_{\mathrm{a}}$ and peel rate were kept constant for all tests at a value of $100 \mathrm{~N}$ and $15 \mathrm{~mm} / \mathrm{min}$, respectively.

\section{A.2 Experimental results}

Figure A.1 illustrates the influence of placement velocity on the normalized interfacial fracture toughness for various nip-point temperatures. The toughness was normalized with respect to the maximum value obtained $\left(\mathcal{G}_{\mathrm{c}}=2.2 \mathrm{~kJ} / \mathrm{m}^{2}\right)$. The fracture toughness improves with increasing nip-point temperature, which corresponds well with the expectations based on the phenomena governing weld strength development. The times required for intimate contact and intermolecular diffusion both reduce with increasing temperature.

The graph also shows that the weld strength improves with increasing velocity. As the time available for bonding is inversely proportional to the placement velocity, a decrease in bond quality was expected. The thermal imaging and feedback system complicate the analysis of the results, as it is not exactly clear where the temperature was measured. Nevertheless, the optimization study showed that high placement velocities (> $250 \mathrm{~mm} / \mathrm{s}$ ) can be achieved for the tested materials. Moreover, the applicability of the mandrel peel test for process optimization was demonstrated.

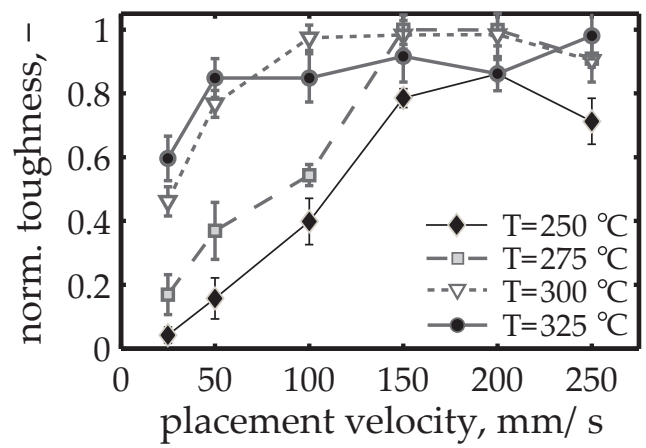

Figure A.1 Interfacial fracture toughness versus placement velocity for different nip-point temperatures. 


\section{Dankwoord}

Zo! Driemaal is scheepsrecht! Ik ben toegekomen aan het, naar men zegt, allerleukste deel van promoveren: het schrijven van een dankwoord. $\mathrm{Nu}$ zal ik meteen toegeven dat de lol niet zit in het schrijven als zodanig, daar ben ik na zeven maanden wel behoorlijk klaar mee. Het zijn de herinneringen aan de afgelopen jaren, waarin ik met veel plezier op de UT heb gewerkt, die dit hoofdstukje zo leuk maken. In die tijd heb ik veel verschillende en inspirerende mensen ontmoet. Van sommige heb ik iets mogen leren, met anderen heb ik slechts onbehoorlijk mogen lachen, maar met vrijwel de meeste van jullie heb ik beide. In dit stuk bedank ik de mensen die op enige wijze een bijdrage hebben geleverd aan dit proefschrift. Het is onvermijdelijk (en ja ook onvergeeflijk) maar ik ga ongetwijfeld mensen vergeten. Hiervoor bied ik bij voorbaat mijn excuses aan: sorry. Voor een fles whisky zorg ik dat je in een tweede druk komt...

Allereerst wil ik graag mijn promotor en dagelijks begeleider Remko Akkerman bedanken. Door jouw vrije en open manier van begeleiden heb ik het grootste gedeelte van dit onderzoek naar eigen inzicht kunnen inkleuren. Deze luxe heb ik als uitermate plezierig ervaren en het heeft mij gevormd als onderzoeker. Dank daarvoor! Daarnaast denk ik met veel plezier en bewondering terug aan de vele papier-en-potlood discussies die we hebben gevoerd, waarin je zonder enige zichtbare moeite ingewikkelde zaken tot de (schematische) essentie wist terug te brengen. Ook de begeleiding van Laurent Warnet wil ik niet onvermeld laten. Jouw kennis, handigheid, pragmatisme, enthousiasme, maar bovenal prettige persoonlijkheid maken dat ik enorm graag met je samenwerk! Ik ben dan ook erg blij dat onze samenwerking een vervolg krijgt binnen TPRC.

Mijn onderzoek is gefinancierd door het Europese onderzoeksproject CleanSky, onder andere mogelijk gemaakt door alle Europese lezers van dit proefschrift. Dank daarvoor! Van alle onderzoekers binnen het Eco-Design cluster in CleanSky wil met name Irene Fernandez Villegas bedanken voor alle herinneringen aan (verstreken) deadlines en voor je hulp bij het ontrafelen van het CleanSky werkpakketcoderingssysteem. Ik moet je eerlijk bekennen dat ik nog steeds niet weet wat nu het verschil is tussen blue, yellow en white level leaders. Naast de financiële bijdrage van de Europese burger was dit proefschrift niet tot stand gekomen zonder de hulp van AFPT en Ten Cate. Graag wil ik Coert Kok en Frank Rittenbruch van AFPT bedanken voor jullie enthousiasme, gastvrijheid en vooral flexibiliteit met betrekking tot het gebruik van jullie tape placement machine in het schöne Dörth. Ik hoop 
dat het voor jullie net zo zinvol en leerzaam is geweest als voor mij. Daarnaast wil ik Sebastiaan Wijskamp van Ten Cate bedanken voor het 'last-minute' leveren van talloze laminaten en voor de keren dat je mee was naar Dörth, zodat ik niet alleen in de lokale kroeg biertjes hoefde te drinken!

Naast de dagelijkse begeleiding van Remko en Laurent, heb ik ook erg veel baat gehad bij de talloze inhoudelijke discussies met collega's. Met name de discussies met Sebastiaan Haanappel, Bo Cornelissen, Bert Rietman, Ton Bor, Roy Visser en Durk van Dijk wil ik niet onvermeld laten. Ook wil ik graag de technici bedanken die een bijdrage hebben geleverd aan dit werk: Bert Vos, Gert-Jan Nevenzel, Laura Vargas Llona, Walter Lette, Erik de Vries, Bert Wolbert en Norbert Spikker. Zonder jullie hulp was ik nu nog steeds aan het prutsen in het lab. In al die jaren heb ik het geluk gehad een aantal afstudeerders te mogen begeleiden. Helaas is niet al jullie fantastische werk in dit boekje terecht gekomen (de onderwerpen liepen nogal uiteen), wel heb ik in alle gevallen veel van jullie geleerd. Rolf Wiering, Erik Schwarte, Mark Oude Voshaar, Tjalling Stelma en Eelco van Ruiten, bedankt voor de leuke en (vooral) gezellige discussies. Een speciaal woord van dank voor Debbie en Belinda. Zonder jullie hulp zou ik de helft van mijn tijd bezig zijn met zalen reserveren, afspraken vastleggen, vliegtickets boeken, hotels reserveren, koffie halen, blocnotes bestellen, auto's huren, huisvesting regelen enzovoorts... Jullie hulp is onbetaalbaar!

Ik wil ook graag de leescommissie bedanken voor het doorlezen van het gehele proefschrift. Een hele prestatie! Bo Cornelissen, Sebastiaan Haanappel en Ted Ooijevaar dank voor jullie tijd en vooral kritische blik. Roy Visser bedankt voor het beschikbaar stellen van jouw stylesheet voor dit proefschrift. Verder dank ik Sebastiaan Haanappel en Wouter Quak voor het meehelpen met het verdedigen van mijn proefschrift. Ik weet zeker dat ik met jullie aan mijn zijde ontspannen de dag door kom!

Naast het serieuze onderzoekswerk was er ook volop ruimte om flink te ouwehoeren. Ik denk met veel plezier terug aan de gezellige tijd op ons kantoor met, in wisselende samenstelling: Roy Visser, Sebastiaan Haanappel, Bo Cornelissen en Uli Sachs, zo nu en dan aangevuld met Wouter Quak, Arjan Schutte, Ashok Sridhar, Rob Bosman en Bert (plakbandhumor is ook humor) Rietman. Met name de talloze joeptjoepsessies waarin verschillende topartiesten de revue passeerden (ik denk bijvoorbeeld aan Rinus en Romana, kabouter Wesley en Manita) staan mij nog levendig bij. Ook aan de avondjes Bolwerk, bowling, barbecue en voetbal denk ik met veel plezier terug. Bedankt voor jullie gezelligheid, moeten we vaker doen!

Als allerlaatste wil ik Anne-Marie bedanken voor de leuke en soms spannende dingen die we samen hebben beleefd de laatste jaren. Dank ook voor je lieve woordjes en zachte aai over de bol op de momenten dat dit nodig was. Je bent een schatje. Lufjoe!

Het proefschrift is af. Einde. 


\section{Publications}

\section{Journal articles}

1. W.J.B. Grouve, L.L. Warnet and R. Akkerman. Critical assessment of the mandrel peel test for fiber reinforced thermoplastic laminates. Accepted for publication in: Engineering Fracture Mechanics, 2012. (Chapter 4 of this thesis).

2. W.J.B. Grouve, L.L. Warnet, B. Rietman and R. Akkerman. On the weld strength of in situ tape placed reinforcements on woven fabric reinforced structures. Composites Part $A, 43: 1530-1536,2012$. (Chapter 6 of this thesis).

3. W.J.B. Grouve and R. Akkerman. Consolidation process model for film stacking glass/PPS laminates. Plastics, Rubber and Composites, 39(3-5):208-215, 2010.

4. W.J.B. Grouve, L.L. Warnet, A. De Boer, R. Akkerman and J. Vlekken. Delamination detection with fibre Bragg gratings based on dynamic behavior. Composites Science and Technology, 68(12):2418-2424, 2008.

\section{Conference proceedings}

1. R. Loendersloot, W.J.B. Grouve, E.A.D. Lamers and S. Wijskamp. Textile impregnation with thermoplastic resin - Models and application. 11th International Conference on Flow Processes in Composite Materials (FPCM-11), Auckland, New Zealand, 2012.

2. W.J.B. Grouve, L.L. Warnet, R. Akkerman, S. Wijskamp and J.S.M. Kok. Weld Strength Assessment for Tape Placement. 13th ESAFORM Conference on Material Forming, Brescia, Italy. In: International Journal of Material Forming, 3(1):707-710, 2010.

3. W.J.B. Grouve, L.L. Warnet and R. Akkerman. Towards a process simulation tool for the laser assisted tape placement process. 14th European Conference on Composite Materials (ECCM-14), Budapest, Hungary, 2010.

4. R. Loendersloot, W.J.B. Grouve, R. Akkerman and A. De Boer. Development of a multigrid finite difference solver for benchmark permeability analysis. 10th International Conference on Flow Processes in Composite Materials (FPCM-10), Ascona, Switzerland, 2010.

5. W.J.B. Grouve and R. Akkerman. A consolidation process model for film stacking glass/PPS laminates. 17th International Conference on Composite Materials (ICCM-17), Edinburgh, United Kingdom, 2009. 
6. W.J.B. Grouve and R. Akkerman. Multi-scale effects in the consolidation of thermoplastic laminates. 13th ESAFORM Conference on Material Forming, Enschede, The Netherlands. In: International Journal of Material Forming, 2(1):157-160, 2009.

7. W.J.B. Grouve and R. Akkerman. An idealised BC for the meso scale analysis of textile impregnation. 9th International Conference on Flow Processes in Composite Materials, FPCM-9, Montreal, Canada, 2008.

8. R. Loendersloot, W.J.B. Grouve, R. Akkerman and S. Van den Berg. Permeability prediction using a multigrid method. 9th International Conference on Flow Processes in Composite Materials (FPCM-9), Montreal, Canada, 2008.

9. W.J.B. Grouve, R. Akkerman, R. Loendersloot and S. Van den Berg. Transverse permeability of woven fabrics. 11th ESAFORM Conference on Material Forming, Lyon, France. In: International Journal of Material Forming, 1(1):859-862, 2008. 